Biotechnological application of microbial sulfidogenesis at haloalkaline conditions

João A.B. Sousa 


\section{Thesis committee}

\section{Promotor}

Prof. Dr Alfons J.M. Stams

Personal chair at the Laboratory of Microbiology

Wageningen University \& Research

\section{Co-promotors}

Dr Caroline M. Plugge

Associate professor, Laboratory of Microbiology

Wageningen University \& Research

Dr Martijn F.M. Bijmans

Manager Europe

Wetsus, European Centre of Excellence for Sustainable Water Technology, Leeuwarden

\section{Other members}

Prof. Dr Cees J.N. Buisman, Wageningen University \& Research

Prof. Dr Piet N.L. Lens, UNESCO-IHE, Delft

Prof. Dr Gerard Muyzer, University of Amsterdam

Prof. Dr Aharon Oren, The Hebrew University of Jerusalem, Israel

This research was conducted under the auspices of the Graduate School for SocioEconomic and Natural Sciences of the Environment (SENSE) 


\title{
Biotechnological application of microbial sulfidogenesis at haloalkaline conditions
}

\author{
João A.B. Sousa
}

Thesis

submitted in fulfillment of the requirements for the degree of doctor at Wageningen University

by the authority of the Rector Magnificus,

Prof. Dr A.P.J. Mol,

in the presence of the

Thesis Committee appointed by the Academic Board

to be defended in public

on Friday 21 April 2017

at 4 p.m. in the Kanselarij, Leeuwarden. 
João A.B. Sousa

Biotechnological application of microbial sulfidogenesis at haloalkaline conditions, 247 pages.

PhD thesis, Wageningen University, Wageningen, the Netherlands (2017)

With references, with summary in English

ISBN 978-94-6343-149-1

DOI $10.18174 / 410685$ 


\section{Table of contents}

Chapter 1 - Introduction .............................................................................. 7

Chapter 2 - Ecology and application of haloalkaliphilic anaerobic microbial communities

Chapter 3 - Sulfate reduction in a hydrogen fed bioreactor operated at haloalkaline conditions

Chapter 4 - Thiosulfate conversion to sulfide by a haloalkaliphilic microbial community in a bioreactor fed with $\mathrm{H}_{2}$ gas

Chapter 5 - Immobilization of sulfate/thiosulfate-reducing biomass on sand under haloalkaline conditions

Chapter 6 - Syngas as electron donor for sulfate \& thiosulfate reducing haloalkaliphilic microorganisms in a gas-lift bioreactor.

Chapter 7 - Tindallia wetsonia strain JE1, sp. nov., isolated from a bioreactor reducing sulfate at haloalkaline conditions

Chapter 8 - Formate as key intermediate for sulfate-reducing bacteria in haloalkaline environments. 



\title{
Chapter 1
}

\section{Introduction}

\author{
João AB Sousa
}

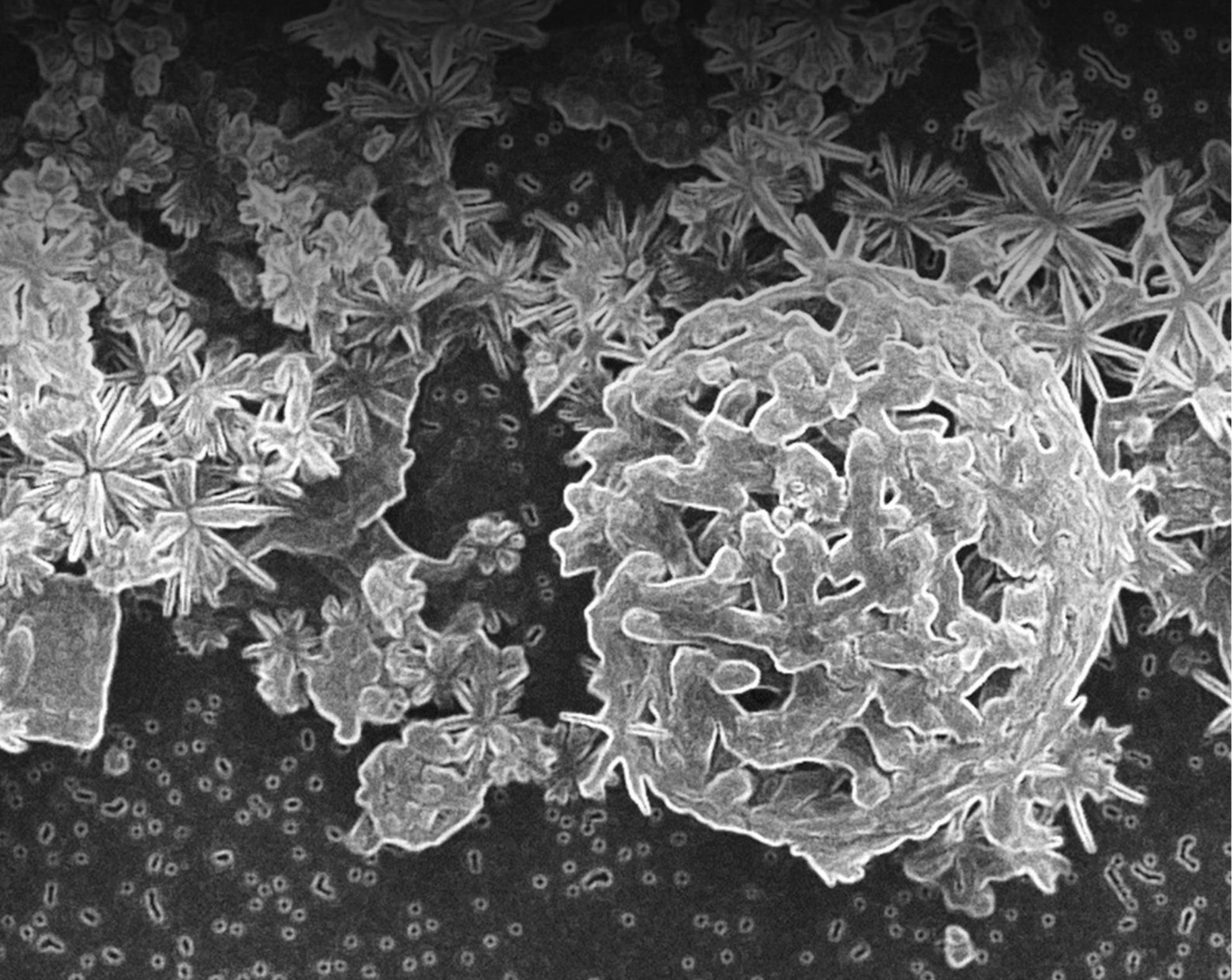




\section{Haloalkaline environments}

Haloalkaline environments are defined by high $\mathrm{pH}(\geq 8.5)$ and salinity from $0.5 \mathrm{M}$ salt up to saturation concentrations due to evaporation (Jones et al., 1977; Kolpakova et al., 2016). An important characteristic of these extreme environments is the dominance of soluble monovalent cations, such as sodium $\left(\mathrm{Na}^{+}\right)$and potassium $\left(\mathrm{K}^{+}\right)$, and the absence of soluble divalent cations, such as calcium $\left(\mathrm{Ca}^{2+}\right)$ and magnesium $\left(\mathrm{Mg}^{2+}\right)$. This is mainly due to the precipitation of $\mathrm{Ca}^{2+}$ and $\mathrm{Mg}^{2+}$ as calcium carbonate and magnesium carbonate salts at the stable high $\mathrm{pH}$ buffered by the high carbonate $\left(\mathrm{CO}_{3}{ }^{2-}\right.$ ) and bicarbonate $\left(\mathrm{HCO}_{3}{ }^{-}\right)$concentration (Figure 1).

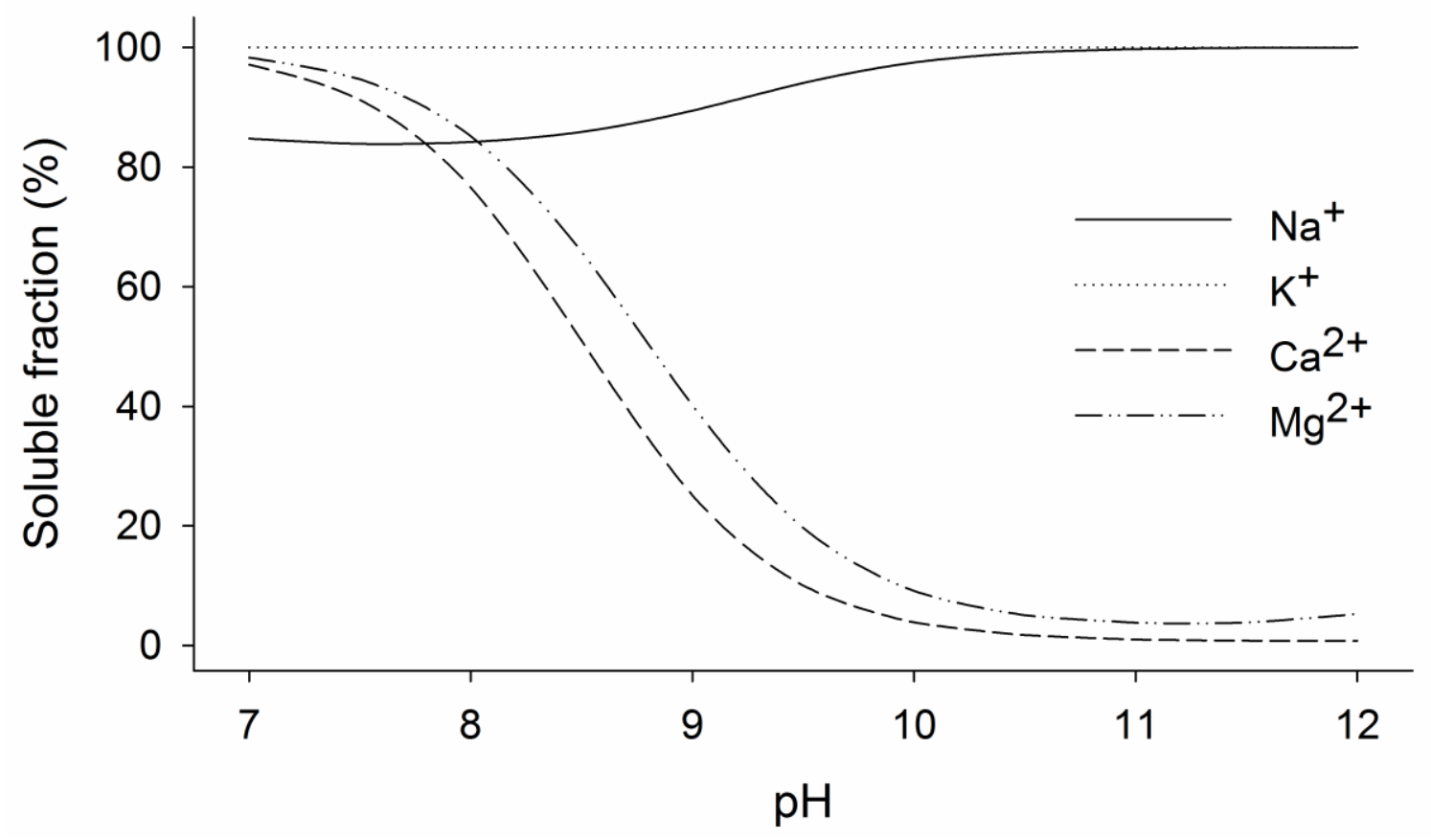

Figure 1 - Calculated soluble fractions of $\mathrm{Na}^{+}, \mathrm{K}^{+}, \mathrm{Ca}^{2+}$ and $\mathrm{Mg}^{2+}$ in a solution containing: 0.1 $\mathrm{M}$ of each cation, $1 \mathrm{M} \mathrm{CO}_{3}{ }^{2-}$ and a total ionic strength of $1.5 \mathrm{M}$. Calculations were performed at $25^{\circ} \mathrm{C}$ using Visual MINTEQ 3.1 (Software developed by KTH Royal Institute of Technology, Stockholm, Sweden).

\section{Natural haloalkaline environments}

Haloalkaline environments are wide spread on Earth, mainly soda lakes and soda soils (Figure 2). Soda lakes are usually formed by leaching of carbonates rich rocks with rainwater, and the accumulation of this carbonate rich water in the body of a lake. 
These lakes are usually subjected to volume fluctuations, and some of them go through wet and dry seasons during the year. This makes soda lakes very dynamic and extreme environments that are rich in life. In soda lakes life forms, such as microorganisms, plants and animals, are perfectly adapted to these extreme conditions (Jones et al., 1998; Sorokin et al., 2014b).

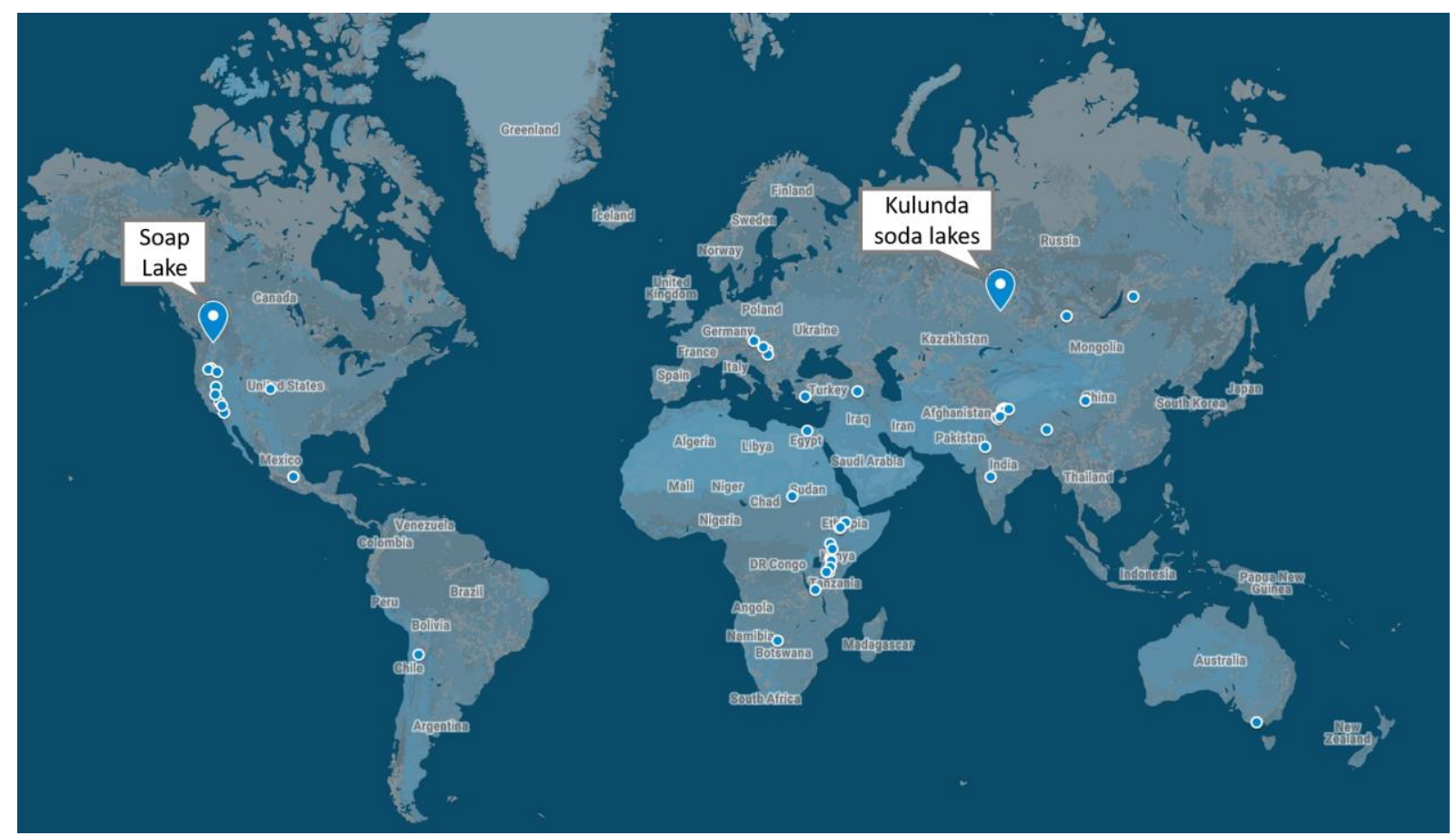

Figure 2 - Location of well-known soda lakes (indicated by the blue markers). The large blue markers indicate soda lakes from which sediments were used in this thesis as inoculum.

\section{Microbial adaptations to haloalkaline environments}

To endure the high $\mathrm{pH}$ and salt conditions of haloalkaline environments, life had to evolve special adaptations. In microorganisms, such adaptations range from membrane composition and ion transport to the production of specialized proteins and organic compounds (compatible solutes). These microorganisms are known as haloalkaliphiles. 


\section{Microbial life at high $\mathrm{pH}$}

Ecosystems with high $\mathrm{pH}(>9)$ create three challenges for microorganisms: i) low abundance of protons $\left(\mathrm{H}^{+}\right)$, which is important for proton motive force-driven processes, ii) stability of proteins and iii) precipitation of essential elements, such as calcium, magnesium and trace metals.

To cope with the low abundance of $\mathrm{H}^{+}$, alkaliphiles and haloalkaliphiles possess specific cell wall and membrane compositions. Alkaliphiles have acidic secondary cell wall polymers (SCWP), such as teichuronic acids or teichuronopeptide, which are associated with peptidoglycan (Ito and Aono 2002; Shirai et al. 2007; Janto et al. 2011). These SCWP not only have a structural function but also provide additional negative charge to the cell surface. To prevent excessive leaking of $\mathrm{H}^{+}$and $\mathrm{Na}^{+}$, alkaliphilic microbes have more compact cell membranes that are rich in non-polar lipids, unsaturated fatty acids and cyclopropane fatty acids (Banciu et al., 2008; Krulwich and Ito, 2013).

Inside the cells, alkaliphiles can function at high $\mathrm{pH}$ in their cytoplasm, but still lower than the external $\mathrm{pH}$. At extreme alkalinity, the internal $\mathrm{pH}$ can be up to $2.3 \mathrm{pH}$ units lower than the external $\mathrm{pH}$ (Krulwich and Ito, 2013). This difference means a higher $\mathrm{H}^{+}$ concentration inside the cell compared to the outside of the cell, which renders ATP production using proton motive force, via ATPases, not feasible. To tackle this challenge, alkaliphilic microorganisms developed another strategy that involves $\mathrm{Na}^{+}$ based energy conservation instead of $\mathrm{H}^{+}$based energy conservation. Alkaliphiles can achieve this by using $\mathrm{Na}^{+}$gradient-dependent mechanisms, such as $\mathrm{Na}^{+}$-dependent ATPases and movement by flagella (Ito et al., 2004; Mesbah and Wiegel, 2011). The use of $\mathrm{Na}^{+}$translocating mechanisms, such as the Rnf complex or the $\mathrm{Na}^{+}$ translocating ferredoxin, can increase the ion gradient, which increases the $\mathrm{Na}^{+}-$ mediated ATP production. These $\mathrm{Na}^{+}$translocating mechanisms can be activated by reactions with less negative Gibbs free energy, increasing the metabolic flexibility to produce ATP (Biegel et al., 2011; Biegel and Müller, 2010; Lim et al., 2014; Muyzer et al., 2011).

To keep the structure and function of their proteins at high $\mathrm{pH}$, microorganisms developed different strategies. A common feature of the proteins in alkaliphiles is the increase of negatively charged residues, which might contribute to the attraction of $\mathrm{H}^{+}$ 
or other cations essential for cell functions (Janto et al., 2011). The isoelectric point of proteins from alkaliphiles is lower than in neutrophiles (Krulwich and Ito, 2013). Comparison of homologous proteins in alkaliphiles and neutrophiles revealed that the increased negative charge increases the hydrophobic interactions between different monomer domains (Kapetaniou et al., 2006). This is essential to have a functional protein under alkaline conditions. Additionally, ions such as calcium or magnesium and trace metals are essential for the function of several enzymes. As explained above, at high $\mathrm{pH}$ most of the divalent cations precipitate. This also occurs to trace metals, lowering their availability for microorganisms. The mechanism used by alkaliphiles to cope with this is poorly researched and needs further research.

\section{Microbial life at high salt concentrations}

The high salt environment $\left(>0.5 \mathrm{M} \mathrm{Na}^{+}\right)$influences how microorganisms maintain the osmotic pressure. Halophilic microorganisms invest energy to maintain the osmotic pressure balance with the environment using two different strategies: the "salt-in" strategy and the "compatible solutes" strategy (Detkova and Boltianskaia, 2007).

In the "salt in" strategy, microorganisms balance the osmotic pressure by actively accumulating salts inside the cell to prevent dehydration. Some microorganisms, like Natroniella acetigena and Halobacteroides halobius, accumulate cations, typically $\mathrm{K}^{+}$, inside the cell to balance the osmotic pressure (Oren, 2013). However, the presence of high intracellular salt concentration increases hydrophobic interactions between cytoplasmic proteins, which leads to aggregation and a possible loss of functionality (Dennis and Shimmin, 1997). To cope with this, halophilic microorganisms have different amino acid composition of their proteins. This is achieved mainly by increasing the acid residues of aspartate and glutamate and decreasing the use of basic residues, such as lysine and arginine (Dennis and Shimmin, 1997).

In the "compatible solutes" strategy, halophilic microorganisms accumulate compatible solutes inside the cell, keeping the intracellular salt concentration lower than their outside environment. These compatible solutes are mostly organic molecules that do not disturb the cell processes, but protect proteins and lipids against the very high salt concentrations (Galinski, 1993). These compatible solutes can be sugars (e.g. trehalose), polyols (e.g. glycerol), amino acids (e.g. glutamic acid) and quaternary 
amines (e.g glycine and betaine). This helps microorganisms to cope with high salt concentrations together with the active pumping out of cations. The pumping out of cations is usually performed by $\mathrm{Na}^{+} / \mathrm{H}^{+}$antiporters under neutral $\mathrm{pH}$ (Hamaide et al., 1983), but at high $\mathrm{pH}$ this is probably performed by a $\mathrm{Na}^{+}$-translocating process (Lim et al., 2014). An energy generating reaction can be used to actively pump $\mathrm{H}^{+}$out, which drives then the $\mathrm{Na}^{+}$outside via $\mathrm{Na}^{+} / \mathrm{H}^{+}$antiporter. As this strategy does not involve structural changes of proteins, it allows microorganisms to survive over a wide range of salinities as long as there is enough energy available (Oren, 2011). In soda lakes, the salinity fluctuates considerably and there are energy sources available (e.g. good light penetration and high concentration of sulfur compounds), rendering the "compatible solutes" strategy the most common strategy in haloalkaliphiles in these environments.

\section{The sulfur cycle in haloalkaline environments}

The sulfur cycle is one of the major global element cycles. The sulfur cycle interacts with the carbon, nitrogen and oxygen biogeochemical cycles. Sulfur metabolism may have fuelled the earliest forms of life on Earth, around 3.47 billion years ago (Jørgensen and Bak, 1991; Shen and Buick, 2004). The sulfur cycle is a complex cycle due to the change of valence of the sulfur atom from -2 (sulfide) to +6 (sulfate) and interaction of biological and chemical reactions. Most of the reactions in the sulfur cycle do not occur chemically under ambient conditions, but they can occur when catalysed by microorganisms. The sulfur-dependent microbial processes active in nature are: the oxidation of reduced inorganic sulfur species using $\mathrm{O}_{2}$ or nitrate $\left(\mathrm{NO}_{3}{ }^{-}\right)$, or via phototrophs; reduction of oxidized inorganic sulfur species using organic compounds or $\mathrm{H}_{2}$ as electron donors; disproportionation of intermediate sulfur compounds, such as thiosulfate $\left(\mathrm{S}_{2} \mathrm{O}_{3}{ }^{2-}\right)$ or elemental sulfur $\left(\mathrm{S}^{0}\right)$, into sulfide and sulfate $\left(\mathrm{SO}_{4}{ }^{2-}\right)$ (Jørgensen, 1990).

Oxidation and reduction of sulfur compounds can occur in a wide variety of environments with an oxic-anoxic transition zone. These environments can be river basins and ocean floor and also more extreme environments, such as deep hydrothermal vents, geothermal springs, acidic rivers, salt lakes and soda lakes 
(Grégoire et al., 2012; Kjeldsen et al., 2007; Kleindienst et al., 2012; Pallud and van Cappellen, 2006; Sánchez-Andrea et al., 2012; Sorokin et al., 2010; Weber and Jørgensen, 2002).

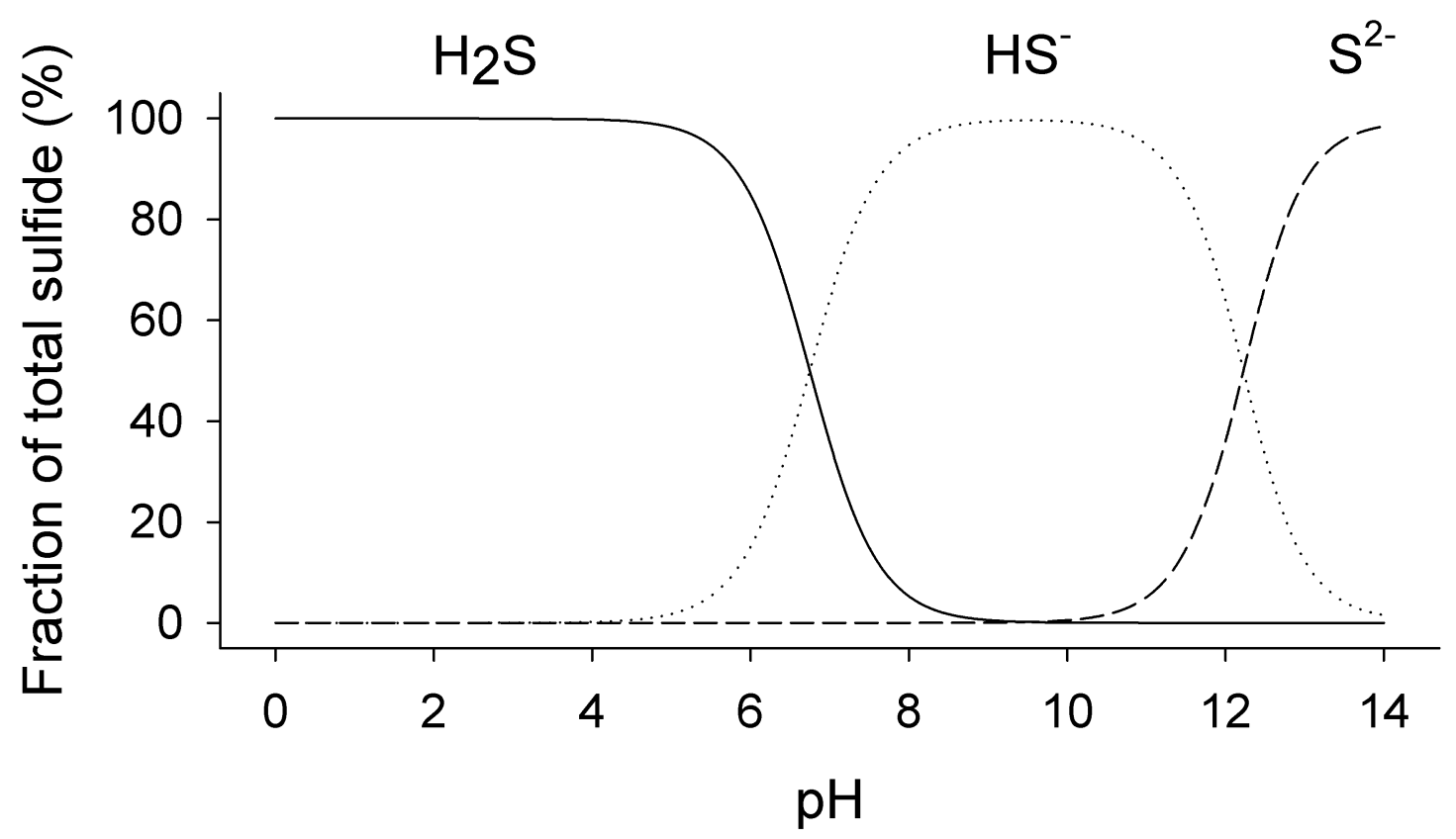

Figure 3 - Chemical speciation of sulfide in solution between $\mathrm{pH} 0$ and 14 .

In haloalkaline environments, the biological sulfur cycle has unique characteristics, especially because some chemical reactions occur spontaneously. Due to the high $\mathrm{pH}$ (8.5 - 10.5), sulfide is mostly present as HS which is soluble and not volatile such as $\mathrm{H}_{2} \mathrm{~S}$ (Figure 3). The dominance of $\mathrm{HS}^{-}$also allows microorganisms to thrive under higher sulfide concentrations. HS cannot easily cross the cell membranes in contrast to $\mathrm{H}_{2} \mathrm{~S}$, and this prevents toxicity effects (Sousa et al., 2015b). HS- also reacts chemically with $S^{0}$, producing polysulfides $\left(S_{x^{2}}{ }^{2-}\right)$ which are soluble opposed to $S^{0}$ (Figure 4). In general, the high concentrations of $\mathrm{HS}^{-}$and $\mathrm{S}^{2-}$ make the sulfur cycle important under haloalkaline conditions (Sorokin et al., 2007). 


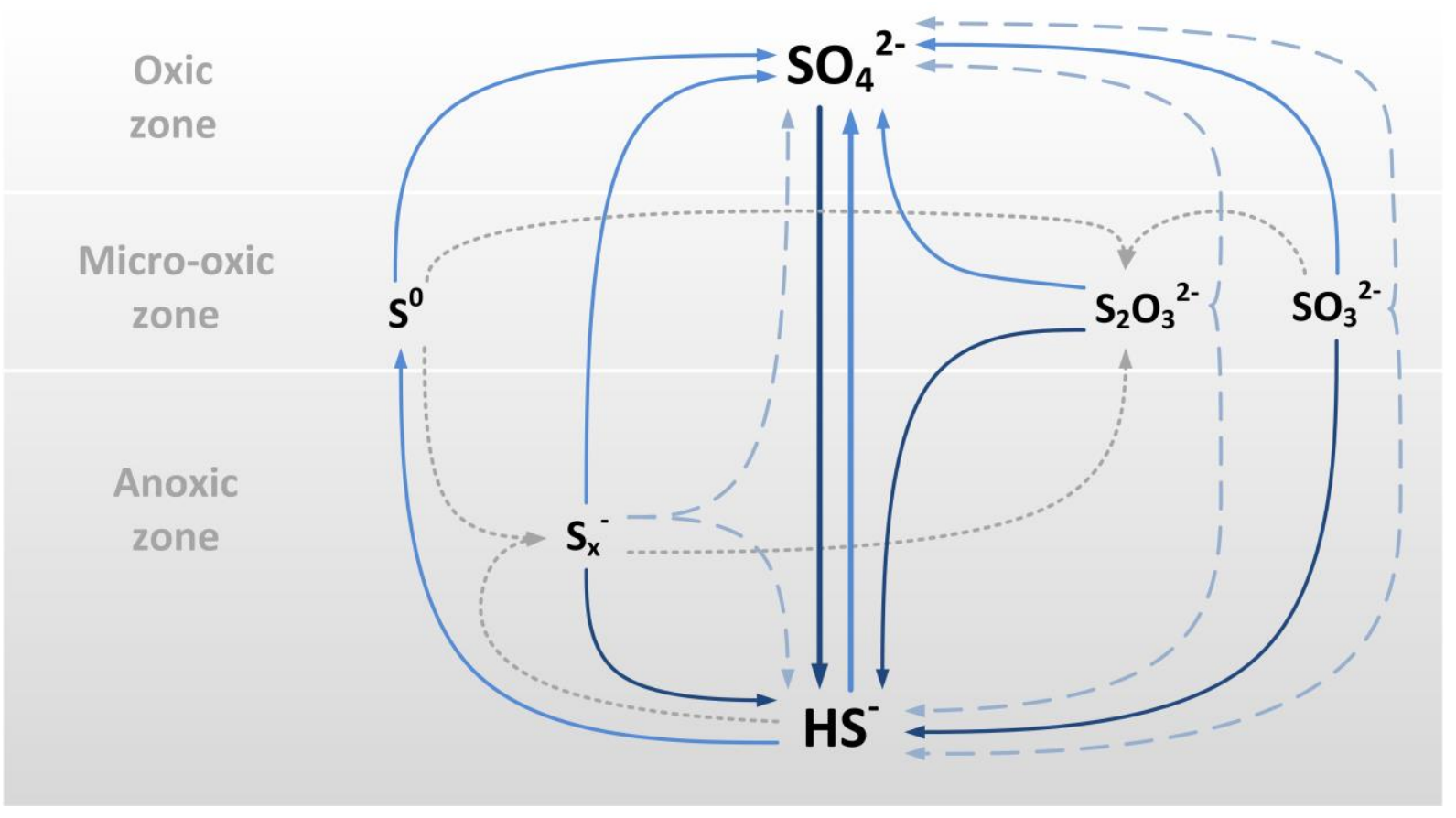

Figure 4 - Main reactions of the inorganic sulfur cycle. Solid lines represent biotic reduction (dark blue) or oxidation (light blue) reactions; dashed lines represent biotic disproportionation reactions; dotted lines represent abiotic reactions.

\section{Haloalkaliphilic sulfur-oxidizing bacteria}

Sulfur-oxidizing bacteria $(\mathrm{SOB})$ have their habitat niche in oxic/anoxic boundary layers of a wide variety of environments (Sorokin et al., 2013a). At these locations, they have access to the reduced sulfur species produced in anoxic environments and electron acceptors such as $\mathrm{O}_{2}$ or $\mathrm{NO}_{3}$ present in the oxic environments. The main sulfuroxidizing microorganisms known can be divided into two main physiological groups: photoautotrophic and chemolithotrophic SOB.

Photoautotrophic SOB, most commonly green and purple SOB, use light as source of energy. Reducing power that is needed to reduce $\mathrm{CO}_{2}$ to cell components comes from reduced sulfur compounds such as sulfides and/or $\mathrm{S}^{0}$ (Tang et al., 2009). The $\mathrm{CO}_{2}$ assimilation is mainly done via the Calvin cycle for purple $\mathrm{SOB}$ and via the reductive tricarboxylic acid cycle in green SOB (Overmann and Garcia-Pichel, 2013). In haloalkaline environments, most phototrophic SOB that we know today belong to the genera Thiorhodospira, Thioalkalicoccus, and Ectothiorhodosinus at moderate salinities (0.5-1.5 $\mathrm{M} \mathrm{Na}^{+}$) and to the genera Halorhodospira at high salinities (>1.5 M $\mathrm{Na}^{+}$) (Gorlenko, 2007). The haloalkaliphilic phototrophic SOB from the genera 
Ectothiorhodospira and Halorhodospira can be found in moderate and high salinities, and from Halorhodospira are the most common in high salinities ( Imhoff and Trüper, 1981; Bryantseva et al., 2010; Oren, 2014).

Chemolithoautotrophic SOB conserve energy directly from oxidizing reduced sulfur compounds using either $\mathrm{O}_{2}$ or $\mathrm{NO}_{3}{ }^{-}$as electron acceptors. All these bacteria are autotrophs, dependent on carbon fixation from $\mathrm{CO}_{2}$ via the Calvin cycle (Tourova et al., 2006, 2007). In soda lakes, chemolithoautotrophic SOB belong mostly to the genera Thioalkalimicrobium and Thioalkalispira at moderate salinities $\left(0.5-1.5 \mathrm{M} \mathrm{Na}^{+}\right)$ and mostly to the genera Thioalkalivibrio and Thioalkalibacter at high salinities ( $>1.5$ $\mathrm{M} \mathrm{Na}^{+}$) (Sorokin et al., 2013a). Thioalkalimicrobium and Thioalkalivibrio species both exhibit different growth and metabolic strategies (Sorokin et al., 2001, 2013a). Thioalkalimicrobium species have high growth yield and require high substrate concentrations while Thioalkalivibrio species have low growth yield but require lower substrate concentrations. Thioalkalimicrobium species can only produce $\mathrm{S}^{0}$ when oxidizing $\mathrm{S}_{2} \mathrm{O}_{3}{ }^{2-}$ in conditions of $\mathrm{O}_{2}$ limitation, and are unable to oxidize $\mathrm{S}^{0}$ and sulfite $\left(\mathrm{SO}_{3}{ }^{2-}\right)$. On the other hand, Thioalkalivibrio species can produce $\mathrm{S}^{0}$ when oxidizing $\mathrm{S}_{2} \mathrm{O}_{3}{ }^{2-}$ even when $\mathrm{O}_{2}$ is not limited and can oxidize $\mathrm{S}^{0}$ and $\mathrm{SO}_{3}{ }^{2-}$. Overall, Thioalkalivibrio species have a more flexible metabolism than Thioalkalimicrobium species which contributes to making them the dominant chemolithoautotrophic SOB in soda lakes from Kulunda steppe, Russia (Vavourakis et al., 2016).

\section{Haloalkaliphilic sulfate-reducing bacteria}

Sulfate-reducing bacteria (SRB) are present in aquatic and terrestrial anoxic environments where oxidized sulfur compounds, like $\mathrm{SO}_{4}{ }^{2-}, \mathrm{S}_{2} \mathrm{O}_{3}{ }^{2-}, \mathrm{SO}_{3}{ }^{2-}, \mathrm{S}^{0}$ and $\mathrm{S}_{2}{ }^{2-}$, are present. SRB can reduce these sulfur compounds by using various electron donors, like hydrogen, formate and volatile fatty acids, alcohols, sugars, amino-acids and hydrocarbons through anaerobic respiration (Liamleam and Annachhatre, 2007; Muyzer and Stams, 2008; Widdel and Rabus, 2001). SRB have a flexible physiology that allows them to thrive in different conditions (Plugge et al., 2011). They can tolerate the low $\mathrm{O}_{2}$ concentrations of microaerophilic environments (Cypionka, 2000), some are able to reduce other electron acceptors such as nitrate, arsenate or Fe(III) and grow 
in a syntrophic relation with acetogens, methanogens, other sulfate reducers or anaerobic methane oxidizers (Stams and Plugge, 2009).

In soda lakes, chemo-lithotrophic SRB have been found that are phylogenetically affiliated with the genera Desulfonatronum, Desulfonatronovibrio, Desulfonatronospira and Desulfohalophilus from the Deltaprotobacteria (Table 1). These SRB use mostly $\mathrm{H}_{2}$, formate and VFA as electron donors for dissimilatory reduction of $\mathrm{SO}_{4}{ }^{2-}, \mathrm{S}_{2} \mathrm{O}_{3}{ }^{2-}$ and $\mathrm{SO}_{3}{ }^{2-}$. They are also able to perform disproportionation of $\mathrm{S}_{2} \mathrm{O}_{3}{ }^{2-}$ and $\mathrm{SO}_{3}{ }^{2-}$ to $\mathrm{SO}_{4}{ }^{2-}$ and HS. Some of the isolated species from these 4 genera are autotrophic bacteria, dependent on $\mathrm{CO}_{2}$ as carbon source. Due to the presence of high $\mathrm{HCO}_{3}{ }^{-}$ concentrations in haloalkaline environments, haloalkaliphilic SRB use $\mathrm{HCO}_{3}{ }^{-}$as $\mathrm{CO}_{2}$ source, via the carbonic anhydrase, and fix $\mathrm{CO}_{2}$ using the Wood-Ljungdahl pathway (Melton et al., 2016; Pitryuk et al., 2006). However, at pH values above 10, $\mathrm{CO}_{2}$ is mostly present as carbonate and not bicarbonate, which might hinder the carbon fixation by bacteria above this $\mathrm{pH}$ (Sorokin et al., 2011b). On the other hand, there exist haloalkaliphilic chemo-organoheterotrophic SRB and these can be divided into two major groups: incomplete oxidizers and complete oxidizers. The incomplete oxidizers use organic acids, such as propionate and butyrate, as electron donor and carbon source and produce acetate as final product. From the haloalkaliphilic incomplete oxidizers, two species have been isolated and characterized so far: Desulfobulbus alkaliphilus and Desulfobotulus alkaliphilus (Sorokin et al., 2009, 2012b). Complete oxidizers also use VFA and produce $\mathrm{CO}_{2}$. Desulfonatronobacter acidivorans was for long the only complete oxidizer isolated from soda lakes (Sorokin et al., 2012b). Recently, Desulfonatronobacter acetoxydans, isolated from soda lake Bitter-1 (Altai, Russia), is only able to reduce $\mathrm{S}_{2} \mathrm{O}_{3}{ }^{2-}$ and $\mathrm{SO}_{3}{ }^{2-}$ but not $\mathrm{SO}_{4}{ }^{2-}$ (Sorokin et al., 2015b). Another mechanism for $\mathrm{SO}_{4}{ }^{2-}$ reduction with acetate is through syntrophic relations between lithotrophic SRB and acetate oxidizing bacteria (Sorokin et al., 2014a). 
Table 1 - Sulfate reducing bacteria and sulfur reducing bacteria isolated and characterized from haloalkaline environments.

\begin{tabular}{|c|c|c|c|c|c|}
\hline Species & $\begin{array}{l}\text { Optimum } \\
\text { pH/salinity a }\end{array}$ & $\begin{array}{l}\text { Electron } \\
\text { acceptors }\end{array}$ & $\begin{array}{l}\text { Dispropor- } \\
\text { tionation }\end{array}$ & $\begin{array}{l}\text { Autotrophic } \\
\text { growth }\end{array}$ & Source \\
\hline $\begin{array}{l}\text { Desulfonatronum } \\
\text { lacustre }{ }^{\mathrm{It}, 1}\end{array}$ & $9.4 / 1.7$ & $\begin{array}{l}\mathrm{SO}_{4}{ }^{2-}, \mathrm{SO}_{3}{ }^{2-} \\
\mathrm{S}_{2} \mathrm{O}_{3}{ }^{2-}\end{array}$ & $\mathrm{S}_{2} \mathrm{O}_{3}{ }^{2-}$ & - & $\begin{array}{l}\text { Lake Khadin, } \\
\text { Tuva, Russia }\end{array}$ \\
\hline $\begin{array}{l}\text { Desulfonatronum } \\
\text { thiodismutans }{ }^{\mathrm{It}, 2}\end{array}$ & $9.5 / 1.1$ & $\begin{array}{l}\mathrm{SO}_{4}^{2-}, \mathrm{SO}_{3}{ }^{2-} \\
\mathrm{S}_{2} \mathrm{O}_{3}{ }^{2-}\end{array}$ & $\begin{array}{l}\mathrm{SO}_{3}{ }^{2-} \\
\mathrm{S}_{2} \mathrm{O}_{3}{ }^{2-}\end{array}$ & + & $\begin{array}{l}\text { Mono lake, } \\
\text { California, US }\end{array}$ \\
\hline $\begin{array}{l}\text { Desulfonatronum } \\
\text { cooperativum } 1 \mathrm{tt}, 3\end{array}$ & $8-9 / 1.3$ & $\begin{array}{l}\mathrm{SO}_{4}{ }^{2-}, \mathrm{SO}_{3}{ }^{2-} \\
\mathrm{S}_{2} \mathrm{O}_{3}{ }^{2-}\end{array}$ & N.D. & - & $\begin{array}{l}\text { Lake Khadin, } \\
\text { Tuva, Russia }\end{array}$ \\
\hline $\begin{array}{l}\text { Desulfonatronum } \\
\text { thioautotrophicum } \mathrm{It}, 4\end{array}$ & $9.3 / 1.75$ & $\begin{array}{l}\mathrm{SO}_{4}^{2-}, \mathrm{SO}_{3}{ }^{2-} \\
\mathrm{S}_{2} \mathrm{O}_{3}{ }^{2-}\end{array}$ & $\begin{array}{l}\mathrm{SO}_{3}{ }^{2-} \\
\mathrm{S}_{2} \mathrm{O}_{3}{ }^{2-}\end{array}$ & + & $\begin{array}{l}\text { Lake Tanatar 1, } \\
\text { Kulunda, Russia }\end{array}$ \\
\hline $\begin{array}{l}\text { Desulfonatronum } \\
\text { thiosulfatophilum It, } 4\end{array}$ & $9.5 / 1.5$ & $\begin{array}{c}\mathrm{SO}_{4}^{2-}, \mathrm{SO}_{3}{ }^{2-} \\
\mathrm{S}_{2} \mathrm{O}_{3}{ }^{2-}\end{array}$ & $\begin{array}{l}\mathrm{SO}_{3}{ }^{2-} \\
\mathrm{S}_{2} \mathrm{O}_{3}{ }^{2-}\end{array}$ & - & $\begin{array}{c}\text { Lake } \\
\text { Picturesque, } \\
\text { Kulunda, Russia }\end{array}$ \\
\hline $\begin{array}{l}\text { Desulfonatronum } \\
\text { alkalitolerans }{ }^{\mathrm{tt}, 5}\end{array}$ & $8.5-9 / 0.3-0.6$ & $\begin{array}{c}\mathrm{SO}_{4}^{2-}, \mathrm{SO}_{3}{ }^{2-} \\
\mathrm{S}_{2} \mathrm{O}_{3}{ }^{2-}\end{array}$ & - & - & $\begin{array}{l}\text { Thiopaq® } \\
\text { bioreactor }\end{array}$ \\
\hline $\begin{array}{l}\text { Desulfonatronum } \\
\text { zhilinae }^{\mathrm{lt}, 6}\end{array}$ & $9 / 0.7$ & $\begin{array}{c}\mathrm{SO}_{4}^{2-}, \mathrm{SO}_{3}{ }^{2-} \\
\mathrm{S}_{2} \mathrm{O}_{3}{ }^{2-}\end{array}$ & N.D. & - & $\begin{array}{l}\text { Lake Alginskoe, } \\
\text { Buryatiya, Russia }\end{array}$ \\
\hline $\begin{array}{l}\text { Desulfonatronovibrio } \\
\text { hydrogenovorans }^{\mathrm{lt}, 7}\end{array}$ & $9.5-9.7 / 0.5$ & $\begin{array}{l}\mathrm{SO}_{4}{ }^{2-}, \mathrm{SO}_{3}{ }^{2-} \\
\mathrm{S}_{2} \mathrm{O}_{3}{ }^{2-}\end{array}$ & N.D. & - & $\begin{array}{l}\text { Lake Magadi, } \\
\text { Kenya }\end{array}$ \\
\hline $\begin{array}{l}\text { Desulfonatronovibrio } \\
\text { thiodismutans }{ }^{\text {It, } 4}\end{array}$ & $9.5-10 / 2-3$ & $\begin{array}{l}\mathrm{SO}_{4}^{2-}, \mathrm{SO}_{3}{ }^{2-} \\
\mathrm{S}_{2} \mathrm{O}_{3}{ }^{2-}\end{array}$ & $\begin{array}{l}\mathrm{SO}_{3}{ }^{2-} \\
\mathrm{S}_{2} \mathrm{O}_{3}{ }^{2-}\end{array}$ & + & $\begin{array}{l}\text { Lake Tanatar-5, } \\
\text { Kulunda, Russia }\end{array}$ \\
\hline $\begin{array}{l}\text { Desulfonatronovibrio } \\
\text { magnus }{ }^{\mathrm{t}, 4} 4\end{array}$ & $10 / 2$ & $\begin{array}{l}\mathrm{SO}_{4}{ }^{2--}, \mathrm{SO}_{3}{ }^{2-} \\
\mathrm{S}_{2} \mathrm{O}_{3}{ }^{2-}\end{array}$ & $\begin{array}{l}\mathrm{SO}_{3}{ }^{2-} \\
\mathrm{S}_{2} \mathrm{O}_{3}{ }^{2-}\end{array}$ & - & $\begin{array}{c}\text { Lake } \\
\text { Picturesque, } \\
\text { Kulunda, Russia }\end{array}$ \\
\hline $\begin{array}{l}\text { Desulfonatronovibrio } \\
\text { halophilus }^{\mathrm{It}, 8}\end{array}$ & $8 / 2$ & $\begin{array}{l}\mathrm{SO}_{4}{ }^{2-}, \mathrm{SO}_{3}{ }^{2-} \\
\mathrm{S}_{2} \mathrm{O}_{3}{ }^{2-}\end{array}$ & - & - & $\begin{array}{l}\text { Chloride-sulfate } \\
\text { lakes, Kulunda, } \\
\text { Russia }\end{array}$ \\
\hline $\begin{array}{l}\text { Desulfonatronospira } \\
\text { thiodismutans }{ }^{\text {It, }} 9\end{array}$ & $9.5-10 / 2-2.5$ & $\begin{array}{c}\mathrm{SO}_{4}^{2-}, \mathrm{SO}_{3}{ }^{2-} \\
\mathrm{S}_{2} \mathrm{O}_{3}{ }^{2-}\end{array}$ & $\begin{array}{l}\mathrm{SO}_{3}{ }^{2-} \\
\mathrm{S}_{2} \mathrm{O}_{3}{ }^{2-}\end{array}$ & + & $\begin{array}{c}\text { Soda lakes } \\
\text { Kulunda steppe, } \\
\text { Russia }\end{array}$ \\
\hline $\begin{array}{l}\text { Desulfonatronospira } \\
\text { delicata }^{\mathrm{lt}, 9}\end{array}$ & $10 / 1-1.5$ & $\begin{array}{l}\mathrm{SO}_{4}{ }^{2-}, \mathrm{SO}_{3}{ }^{2-} \\
\mathrm{S}_{2} \mathrm{O}_{3}{ }^{2-}\end{array}$ & $\begin{array}{l}\mathrm{SO}_{3}{ }^{2-} \\
\mathrm{S}_{2} \mathrm{O}_{3}{ }^{2-}\end{array}$ & + & $\begin{array}{l}\text { Soda lakes Wadi } \\
\text { al Natrun, Egypt }\end{array}$ \\
\hline
\end{tabular}


Table 1 - Continued.

\begin{tabular}{|c|c|c|c|c|c|}
\hline $\begin{array}{l}\text { Desulfohalophilus } \\
\text { alkaliarsenatis }^{\text {It, } 10}\end{array}$ & $9.25 / 2-3$ & $\begin{array}{l}\mathrm{SO}_{4}{ }^{2-}, \mathrm{SO}_{3}{ }^{2-} \\
\mathrm{S}_{2} \mathrm{O}_{3}{ }^{2-}\end{array}$ & - & + & $\begin{array}{l}\text { Lake Searles, } \\
\text { California, US }\end{array}$ \\
\hline $\begin{array}{l}\text { Sulfurospirillum } \\
\text { alkalitolerans }^{\text {It, } 5}\end{array}$ & $8.5 / 0.6$ & $\mathrm{~S}_{2} \mathrm{O}_{3}{ }^{2-}$ & - & - & $\begin{array}{l}\text { Thiopaq® } \\
\text { bioreactor }\end{array}$ \\
\hline $\begin{array}{l}\text { Natronolimnobius } \\
\text { baerhuensis }{ }^{\text {It, } 11}\end{array}$ & $9 / 3$ & $\mathrm{~S}_{2} \mathrm{O}_{3}{ }^{2-}$ & - & - & $\begin{array}{l}\text { Lake Baerhu, } \\
\text { Mongolia }\end{array}$ \\
\hline $\begin{array}{l}\text { Desulfobulbus } \\
\text { alkaliphilus og, } 12\end{array}$ & $9.4 / 0.2$ & $\mathrm{SO}_{4}^{2-}, \mathrm{SO}_{3}^{2-}$ & - & - & $\begin{array}{c}\text { Soda lakes } \\
\text { Kulunda steppe, } \\
\text { Russia }\end{array}$ \\
\hline $\begin{array}{l}\text { Desulfobotulus } \\
\text { alkaliphilus og, } 13^{\text {olk }}\end{array}$ & $9.9-10.1 / 1.75$ & $\begin{array}{l}\mathrm{SO}_{4}^{2-}, \mathrm{SO}_{3}{ }^{2-} \\
\quad \mathrm{S}_{2} \mathrm{O}_{3}{ }^{2-}\end{array}$ & - & - & $\begin{array}{c}\text { Lake Bitter-1, } \\
\text { Kulunda steppe, } \\
\text { Russia }\end{array}$ \\
\hline $\begin{array}{l}\text { Desulfonatronobacter } \\
\text { acidivorans og, } 12\end{array}$ & $10 / 0.6$ & $\mathrm{SO}_{4}^{2-}, \mathrm{S}_{2} \mathrm{O}_{3}^{2-}$ & - & - & $\begin{array}{c}\text { Soda lakes } \\
\text { Kulunda, Russia }\end{array}$ \\
\hline $\begin{array}{l}\text { Desulfonatronobacter } \\
\text { acetoxydans }^{\circ g}, 14\end{array}$ & $9.5 / 1$ & $\begin{array}{l}\mathrm{SO}_{4}{ }^{2-}, \mathrm{SO}_{3}{ }^{2-} \\
\mathrm{S}_{2} \mathrm{O}_{3}{ }^{2-}\end{array}$ & - & - & $\begin{array}{l}\text { Lake Bitter-1, } \\
\text { Kulunda, Russia }\end{array}$ \\
\hline $\begin{array}{l}\text { Desulfurispira } \\
\text { natronophila lt, } 15\end{array}$ & 10.2 / 0.4-0.6 & $\mathrm{S}^{0}, \mathrm{~S}^{2-}$ & - & - & $\begin{array}{l}\text { Soda lakes } \\
\text { Kulunda, Russia }\end{array}$ \\
\hline $\begin{array}{l}\text { Desulfuribacillus } \\
\text { alkaliarsenatis It, } 16^{\text {Iliarsen }}\end{array}$ & $10 / 0.6-0.8$ & $\mathrm{~S}^{0}, \mathrm{~S}_{2} \mathrm{O}_{3}{ }^{2-}$ & - & - & $\begin{array}{l}\text { Soda lakes } \\
\text { Kulunda, Russia }\end{array}$ \\
\hline $\begin{array}{l}\text { Natroniella } \\
\text { sulfidigena }^{\text {It, } 17}\end{array}$ & $10 / 3$ & $\mathrm{~S}^{0}, \mathrm{~S}_{\mathrm{x}^{2-}}$ & - & + & $\begin{array}{c}\text { Soda lakes } \\
\text { Kulunda, Russia }\end{array}$ \\
\hline $\begin{array}{l}\text { Natronolimnobius } \\
\text { innermongolicus }{ }^{\text {It, } 11}\end{array}$ & $9.5 / 2-3$ & $\mathrm{~S}^{0}$ & - & - & $\begin{array}{l}\text { Lake Baerhu, } \\
\text { Mongolia }\end{array}$ \\
\hline \multicolumn{6}{|c|}{ 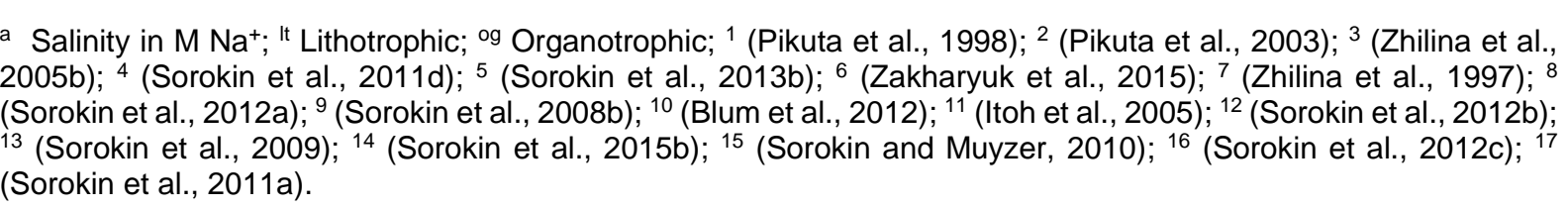 } \\
\hline
\end{tabular}

\section{Haloalkaliphilc sulfur-reducing bacteria}

Elemental $\mathrm{S}^{0}$ reduction has not been shown for isolated haloalkaliphilic SRB. However, fast sulfur reduction occurs in the anaerobic zones of haloalkaline environments, such as soda lakes sediments (Sorokin et al., 2010). This is probably due to the stability of $\mathrm{Sx}^{2-}$ at high $\mathrm{pH}$ conditions (Kleinjan et al., 2005). Due to their solubility in contrast to the non-soluble $\mathrm{S}^{0}, \mathrm{~S}_{\mathrm{x}}{ }^{2-}$ are better available as electron acceptor, which explains the high activity of sulfur reduction under high pH environments (Sorokin et al., 2010). 
The sulfur-reducing bacteria (SuRB) isolated and characterized so far belong to 4 different phylogenetic groups. Desulfurispira natronophila, belonging to the phylum Chrysiogenetes, is capable of reducing $\mathrm{S}^{0}, \mathrm{~S}^{2-}$ and arsenate using several VFAs as electron donor and carbon source (Sorokin and Muyzer, 2010). At moderate salt concentrations, Desulfuribacillus alkaliarsenatis was isolated which is able to reduce $\mathrm{S}^{0}, \mathrm{Sx}^{2-}$, arsenate and $\mathrm{S}_{2} \mathrm{O}_{3}{ }^{2-}$, using $\mathrm{H}_{2}$ and formate as electron donor (Sorokin et al., 2012c). At high salt concentrations $\left(>1.5 \mathrm{M} \mathrm{Na}^{+}\right.$) two isolates were obtained so far, Natroniella sulfidigena which can reduce $\mathrm{S}^{0}$ using $\mathrm{H}_{2}$, formate and acetate, and strain AHT5 which can reduce $\mathrm{S}^{0}$ with $\mathrm{H}_{2}$ and $\mathrm{S}_{2} \mathrm{O}_{3}{ }^{2-}$ with formate (Sorokin et al., 2011a). At high salt concentrations $\left(>1.5 \mathrm{M} \mathrm{Na}^{+}\right)$, also a $\mathrm{S}^{0}$ reducing haloarchaea was isolated, Natronolimnobius innermongolicus, which can use $\mathrm{H}_{2}$, formate and all VFA except acetate as electron donor (Itoh et al., 2005).

\section{Biotechnological application of the haloalkaliphilic sulfur cycle}

The biological sulfur cycle has been applied in industries to treat $\mathrm{SO}_{4}{ }^{2-}$-rich effluents originated mainly from the mining and paper pulp industries (Janssen et al., 2009; Sánchez-Andrea et al., 2014). In these industries, biological $\mathrm{SO}_{4}{ }^{2-}$ reduction is used to remove $\mathrm{SO}_{4}{ }^{2-}$ and metals, and to produce products that can be further used as resources, like $\mathrm{S}^{0}$ or metal sulfides such as copper or zinc sulfide (Buisman et al., 1989; van Houten et al., 2009). These processes are usually performed under acidic or neutral conditions. In another worldwide application, biogas, natural gas and flue gas biodesulfurization processes operate at high $\mathrm{pH}$ and salinity conditions due to the high $\mathrm{pH}$ conditions required to absorb $\mathrm{H}_{2} \mathrm{~S}$ into liquid. To treat this $\mathrm{HS}^{-}$-rich waste stream with high $\mathrm{pH}$ and salinity, bioreactors operated under haloalkaline conditions have been used where haloalkaliphilc microorganisms were able to oxidize HS- (van den Bosch, 2008).

There are two main biodesulfurization technologies: biotrickling filters and the so called Thiopaq ${ }^{\circledR}$ process (van den Bosch et al. 2007). In biotrickling filters, a reactor filled with packing material is used as carrier material for microorganisms. The microorganisms in these filters grow in a biofilm formed on the packing material while a solution is trickled through the packing material. Using $\mathrm{O}_{2}$ or $\mathrm{NO}_{3}{ }^{-}$as electron acceptors, these 
microorganisms oxidize the $\mathrm{HS}^{-}$absorbed in the liquid (neutral or alkaline $\mathrm{pH}$ ) to $\mathrm{SO}_{4}{ }^{2-}$ which is then discarded (Fernández et al., 2014; Fortuny et al., 2011). In this biodesulfurization process sulfide is absorbed using a caustic solution in a scrubber. The caustic solution rich in sulfide is then treated in a microaerophilic bioreactor where the reduction-oxidation potential (ORP) is controlled to low values (between - $220 \mathrm{mV}$ and $-450 \mathrm{mV}$ ) (Bosch et al., 2007; Klok et al., 2013). SOB present in this reactor have an $\mathrm{O}_{2}$ limitation and due to that reason, they produce $\mathrm{S}^{0}$ from $\mathrm{HS}^{-}$instead of $\mathrm{SO}_{4}{ }^{2-}$ which requires more $\mathrm{O}_{2}$ (Figure 5). The $\mathrm{S}^{0}$ produced is not soluble and can be separated from the caustic solution by settling. The caustic solution can then be recycled back to the scrubber for absorbing more $\mathrm{H}_{2} \mathrm{~S}$.

\section{The Thiopaq ${ }^{\circledR}$ process - a case of complete use of the haloalkaliphilic biological sulfur cycle}

The Thiopaq ${ }^{\circledR}$ process includes both biological oxidation and reduction of sulfur compounds in a single process (Figure 5). In the microaerophilic bioreactor, SOB, mainly Thioalkalivibrio, oxidize $\mathrm{HS}^{-}$to $\mathrm{S}^{0}$ under low ORP and consequently low $\mathrm{O}_{2}$ concentrations (Sorokin et al., 2008a). Different ORP values lead to different product selectivity in the bioreactor. If the ORP is too high $(>-350 \mathrm{mV})$, SOB produce more $\mathrm{SO}_{4}{ }^{2-}$ from $\mathrm{HS}^{-}$, leading to accumulation of $\mathrm{SO}_{4}{ }^{2-}$ in the liquid which cannot be easily separated (van den Bosch et al. 2007; Roman et al. 2015). Besides the production of $\mathrm{S}^{0}$ and $\mathrm{SO}_{4}{ }^{2-}$, also $\mathrm{S}_{2} \mathrm{O}_{3}{ }^{2-}$ can be produced when the $\mathrm{HS}^{-}$loading to the bioreactor exceeds the biological HS- oxidation capacity. In this case the HS- reacts with $\mathrm{S}^{0}$ producing $\mathrm{S}_{\mathrm{x}}{ }^{2-}$ (Roman et al., 2014). The $\mathrm{S}_{\mathrm{x}}{ }^{2-}$ will then chemically react with the available $\mathrm{O}_{2}$ and produce $\mathrm{S}_{2} \mathrm{O}_{3}{ }^{2-}$ which also cannot be easily separated. The effect of ORP in these bioreactors has been investigated in depth during the last two decades. The maximum selectivity for $\mathrm{S}^{0}$ production from $\mathrm{HS}^{-}$reported is close to $95 \%$ and modelling studies show that $98 \%$ can be achieved if a more accurate operation control is applied (Bosch et al., 2007; Klok et al., 2013; Roman et al., 2015). 


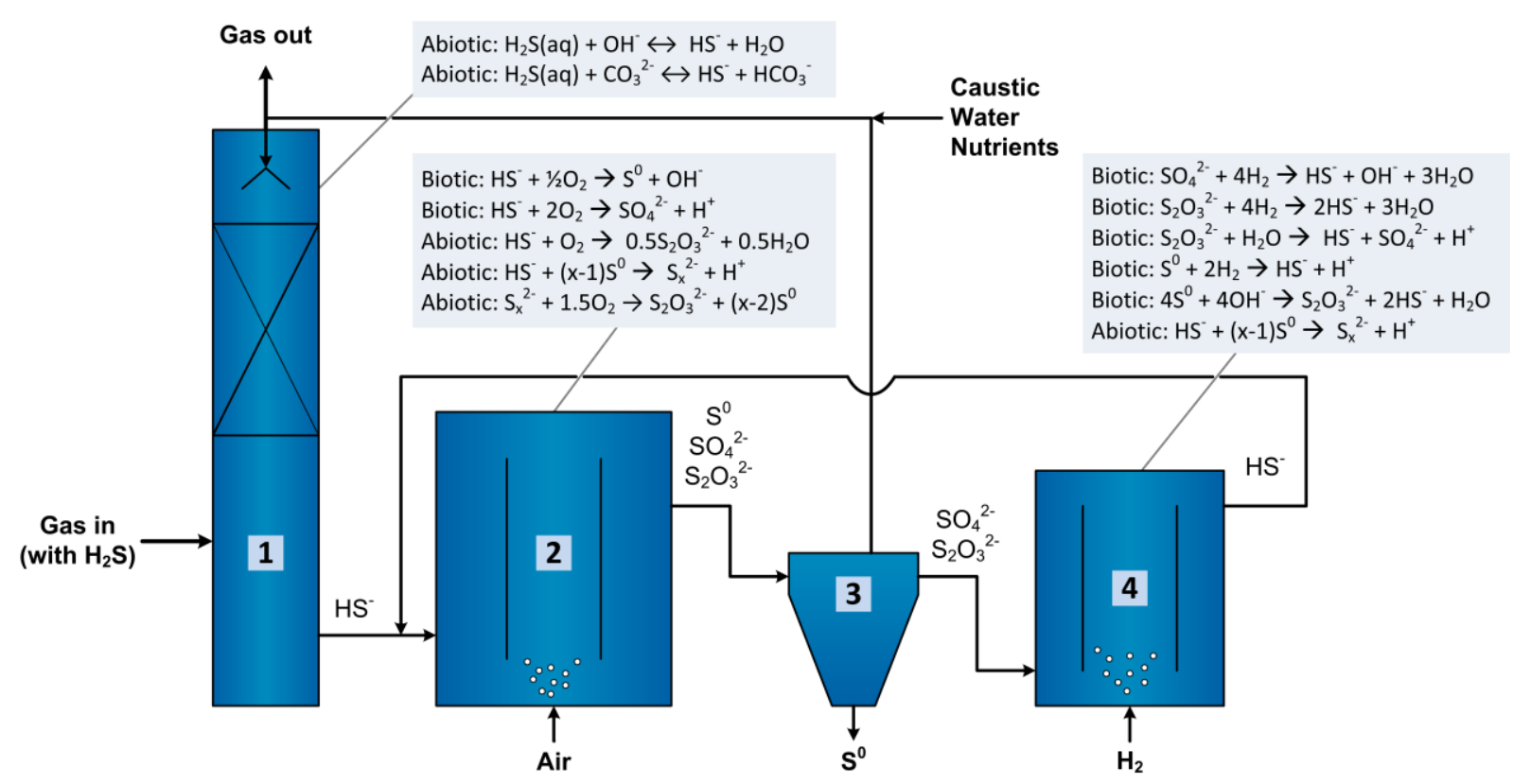

Figure 5 - Schematic overview of the Thiopaq ${ }^{\circledR}$ process including bleed stream treatment and recycling. 1 - Scrubber where absorption of $\mathrm{H}_{2} \mathrm{~S}$ into the liquid occurs. 2 - Microaerophilic reactor where sulfide is biologically oxidized to $\mathrm{S}^{0}$, and minor parts to $\mathrm{SO}_{4}{ }^{2-}$ and abiotically to $\mathrm{S}_{2} \mathrm{O}_{3}{ }^{2-} .3$ - Settler where $\mathrm{S}^{0}$ is separated by settling. 4 - Anaerobic bioreactor where $\mathrm{SO}_{4}{ }^{2-}$ and $\mathrm{S}_{2} \mathrm{O}_{3}{ }^{2-}$ are reduced to $\mathrm{HS}^{-}$and recycled in 2.

Even when a suitable ORP value for $\mathrm{S}^{0}$ production is used $\left(<-350 \mathrm{mV}\right.$ ), $\mathrm{O}_{2}$ concentrations are not equal in all areas of industrial scale bioreactors due to diffusion limitations. This leads to unwanted reactions of biological oxidation of $\mathrm{HS}^{-}$to $\mathrm{SO}_{4}{ }^{2-}$ and chemical oxidation of $\mathrm{HS}^{-}$to $\mathrm{S}_{2} \mathrm{O}_{3}{ }^{2-}$. The produced $\mathrm{SO}_{4}{ }^{2-}$ and $\mathrm{S}_{2} \mathrm{O}_{3}{ }^{2-}$ accumulate in the system, due to their high solubility, and reduce the $\mathrm{pH}$. This lowering of $\mathrm{pH}$ occurs because there is no regeneration of caustic when they are produced, $\mathrm{SO}_{4}{ }^{2-}$ production yields $\mathrm{H}^{+}$and $\mathrm{SO}_{4}{ }^{2-}$ complexes with $\mathrm{Na}^{+}$as $\mathrm{Na}_{2} \mathrm{SO}_{4}$ disturbing the buffer balance. To maintain the $\mathrm{pH}$ high enough to absorb HS- efficiently in the scrubber, part of the liquid in the microaerophilic bioreactor must be removed and replaced with new caustic solution. This liquid removed from the bioreactor is defined as the bleed stream.

The bleed stream is rich in $\mathrm{SO}_{4}{ }^{2-}$ and/or $\mathrm{S}_{2} \mathrm{O}_{3}{ }^{2-}$ and can be treated in a separate bioreactor. They both can be reduced to $\mathrm{HS}^{-}$by SRB when a suitable electron donor is provided. The HS produced can be recycled to the microaerophilic bioreactor for optimized biological oxidation to $S^{0}$ (van den Bosch, 2008). Additionally, the reduction of $\mathrm{SO}_{4}{ }^{2-}$ and $\mathrm{S}_{2} \mathrm{O}_{3}{ }^{2-}$ generates alkalinity $\left(\mathrm{OH}^{-}\right)$that reduces the need for new caustic 
addition. Thus, the bleed stream treatment allows savings in caustic addition to the process and avoids the disposal of a $\mathrm{SO}_{4}{ }^{2-}$ and/or $\mathrm{S}_{2} \mathrm{O}_{3}{ }^{2-}$-rich effluent. However, in contrast to the microaerophilic bioreactor studies, at the start of this research there were no reported studies on the possible application of biological $\mathrm{SO}_{4}{ }^{2-}$ and $\mathrm{S}_{2} \mathrm{O}_{3}{ }^{2-}$ reduction under haloalkaline conditions for this purpose. Recently, Zhou et al. (2014) investigated the use of anaerobic filter reactors for $\mathrm{SO}_{4}{ }^{2-}$ reduction at haloalkaline conditions using ethanol as electron donor, and the effect of different electron donors was studied (Zhou and Xing 2015a). In these studies, $\mathrm{SO}_{4}{ }^{2-}$ reduction occurred and up to about $100 \mathrm{mM} \mathrm{HS}^{-}$was produced when using ethanol as electron donor. The use of ethanol, lactate and glucose as electron donors led to the accumulation of acetate (between 100 and $200 \mathrm{mM}$ ), showing that microorganisms active in the process are mainly incomplete oxidizing SRB and fermentative microorganisms. The use of formate resulted in lower acetate concentration (up to $50 \mathrm{mM}$ ), indicating the presence of acetogenic microorganisms. The main SRB identified in all bioreactors were related to Desulfonatronovibrio which are known chemolithotrophic and chemoorganotrophic SRB (Sorokin et al. 2011c; Zhou et al. 2015b). The dominance of Desulfonatronovibrio spp. among sulfate reducers indicates they have a competitive advantage in these reactors, even with different electron donors.

The use of liquid electron donors in biodesulfurization processes might be complicated due to the need for transportation of the chemical to the biodesulfurization plants which are often located in remote locations. Here, production of syngas or $\mathrm{H}_{2}$ purified from syngas on site is possible via gas reforming processes (Pei et al., 2014). As discussed above, haloalkaliphilic SRB in nature use $\mathrm{H}_{2}$ as electron donor and thus this should be possible also in bioreactors. Thus, there is a need of knowledge on this subject. Such research is essential to evaluate the feasibility of to apply biological reduction of $\mathrm{SO}_{4}{ }^{2-}$ and $\mathrm{S}_{2} \mathrm{O}_{3}{ }^{2-}$ to the bleed stream treatment in the biodesulfurization processes.

\section{Goals and thesis outline}

The gap of knowledge mentioned marks the beginning of the work presented in this thesis. Different possibilities for application of biological reduction of $\mathrm{SO}_{4}{ }^{2-}$ and $\mathrm{S}_{2} \mathrm{O}_{3}{ }^{2-}$ at haloalkaline conditions using $\mathrm{H}_{2}$ or syngas as electron donor were investigated. The 
haloalkaline conditions represent a unique environment with new challenges for biotechnological applications. In chapter 2 , a review on the biotechnological potential of anaerobic haloalkaliphilic microorganisms is presented.

To better understand the biological reduction of $\mathrm{SO}_{4}{ }^{2-}$ and $\mathrm{S}_{2} \mathrm{O}_{3}{ }^{2-}$ under haloalkaline conditions using $\mathrm{H}_{2}$ as electron donor, two bioreactors were operated. In chapter $\mathbf{3}$, a bioreactor performing of $\mathrm{SO}_{4}{ }^{2-}$ reduction was investigated, where $\mathrm{SO}_{4}{ }^{2-}$ reduction occurred up to high concentrations of dissolved $\mathrm{HS}^{-}$. However, the volumetric $\mathrm{SO}_{4}{ }^{2-}$ reduction rates achieved were lower compared with previous studies at neutral conditions. These lower rates were a consequence of low biomass retention due to the lack of microbial aggregation and granulation at haloalkaline conditions. The lack of aggregation and granulation was also observed in another bioreactor that was investigated in chapter 4. Here, the bioreactor was operated in the same way as described in chapter 3 , but $\mathrm{S}_{2} \mathrm{O}_{3}{ }^{2-}$ was the only electron acceptor used instead of $\mathrm{SO}_{4}{ }^{2}$. The addition of $\mathrm{S}_{2} \mathrm{O}_{3}{ }^{2-}$ led to more biomass growth and consequently resulted in higher volumetric rates. $\mathrm{S}_{2} \mathrm{O}_{3}{ }^{2-}$ was converted via 2 pathways: direct reduction to $\mathrm{HS}^{-}$with hydrogen as electron donor and disproportionation to $\mathrm{SO}_{4}{ }^{2-}$ and $\mathrm{HS}^{-}$without the use of electron donor. The occurrence of $\mathrm{S}_{2} \mathrm{O}_{3}{ }^{2-}$ disproportionation led to the design of a new process where this process could be applied to remove S-COD from the biodesulfurization processes bleed stream without additional electron donor.

To tackle the absence of microbial aggregation observed in the first two experimental chapters, the addition of sand as a biomass carrier material was investigated in chapter 5. In this chapter, an increase in biomass concentration inside the bioreactor led to higher $\mathrm{SO}_{4}{ }^{2-}$ and $\mathrm{S}_{2} \mathrm{O}_{3}{ }^{2-}$ reduction volumetric rates. The biomass did not form biofilms attached to the sand particles, but was mostly suspended or as small aggregates that appeared after acetate started to accumulate in the bioreactor.

In all the chapters described above $\mathrm{H}_{2}$ was used as electron donor. However, syngas that contains mainly $\mathrm{H}_{2}, \mathrm{CO}$ and $\mathrm{CO}_{2}$ is a cheaper alternative as electron donor source compared to purified $\mathrm{H}_{2}$. In chapter 6 the use of syngas was investigated by adding $\mathrm{CO}$ together with $\mathrm{H}_{2}$. $\mathrm{CO}$ is an inhibitor of hydrogenase activity and, even though it inhibited most $\mathrm{H}_{2}$ consuming reactions in the bioreactor, the biomass adapted and performed $\mathrm{SO}_{4}{ }^{2-}$ and $\mathrm{S}_{2} \mathrm{O}_{3}{ }^{2-}$ reduction in the presence of up to $15 \%$ of $\mathrm{CO}$ in the gas phase. This showed that with further development, syngas could be used as electron donor source for $\mathrm{SO}_{4}{ }^{2-}$ and $\mathrm{S}_{2} \mathrm{O}_{3}{ }^{2-}$ reduction at haloalkaline conditions. 
From the chapters 3-6, two observations led to perform additional research: the dominance of a bacterium closely related to Tindallia spp. and the production and accumulation of formate up to high concentrations $(90 \mathrm{mM})$. The microbial community analysis was performed in the studies described in chapters 3 to 6 . This revealed that bacteria closely related to Tindallia spp. were most dominant. The role of these bacteria in the bioreactors was unclear and, in chapter $\mathbf{7}$ the dominant strain (strain JE1) was isolated. Strain JE1 could ferment glucose to mainly acetate, succinate and formate. Strain JE1 could reduce $\mathrm{S}_{2} \mathrm{O}_{3}{ }^{2-}$ but not $\mathrm{SO}_{4}{ }^{2-}$ with hydrogen and formate as electron donors, suggesting that this strain might be involved in the reduction of $\mathrm{S}_{2} \mathrm{O}_{3}{ }^{2-}$ in the bioreactors, but not in the reduction of $\mathrm{SO}_{4}{ }^{2-}$. In the presence of only $\mathrm{H}_{2}$ and $\mathrm{HCO}_{3}$, strain JE1 produced formate to high concentrations $(90 \mathrm{mM})$ which could explain the formate production in the bioreactors. However, after all research was done, it was still not clear why formate production, which is a low energy yielding reaction, was such a main process in all bioreactors investigated in this thesis. In chapter $\mathbf{8}$ the production of formate at haloalkaline conditions was investigated in detail by testing the hypothesis that SRB could be dependent on formate produced by strain JE1 as electron donor, using mixed pure cultures representing conditions in the bioreactors. Our research led to the hypothesis that, when using $\mathrm{H}_{2}$ as electron donor, SRB are dependent on the formate produced by formate producing microorganisms, such as strain JE1. However, acetate production as carbon source or another essential compound might also be produced by the SRB that allows growth of the formate producing microorganism.

The general discussion of this thesis is separated in two parts:

1. The data obtained were used to assess the feasibility of $\mathrm{SO}_{4}{ }^{2-}$ and $\mathrm{S}_{2} \mathrm{O}_{3}{ }^{2-}$ reduction using $\mathrm{H}_{2}$ or syngas to treat the bleed stream of the Thiopaq ${ }^{\circledR}$ process. The economic feasibility for different scenarios of application are discussed and the main challenges for future research are described.

2. The role of Tindallia sp. strain JE1 and the importance of formate production at haloalkaline conditions are discussed. Also, here the knowns and unknowns are put together and suggestions for future research and possible application of this new strain are discussed. 


\section{References}

Banciu HL, Sorokin DY, Tourova TP, Galinski EA, Muntyan MS, Kuenen JG, Muyzer G (2008) Influence of salts and $\mathrm{pH}$ on growth and activity of a novel facultatively alkaliphilic, extremely salt-tolerant, obligately chemolithoautotrophic sufur-oxidizing Gammaproteobacterium Thioalkalibacter halophilus gen. nov., sp. nov. from SouthWestern Siberian soda lakes. Extremophiles 12:391-404.

Biegel E, Müller V (2010) Bacterial $\mathrm{Na}^{+}$-translocating ferredoxin:NAD+ oxidoreductase. Proc Natl Acad Sci 107:18138-18142.

Biegel E, Schmidt S, González JM, Müller V (2011) Biochemistry, evolution and physiological function of the Rnf complex, a novel ion-motive electron transport complex in prokaryotes. Cell Mol Life Sci 68:613-634.

Blum JS, Kulp TR, Han S, Lanoil B, Saltikov CW, Stolz JF, Miller LG, Oremland RS (2012) Desulfohalophilus alkaliarsenatis gen. nov., sp. nov., an extremely halophilic sulfate- and arsenate-respiring bacterium from Searles Lake, California. Extremophiles 16:727-742.

Bryantseva IA, Tourova TP, Kovaleva OL, Kostrikina NA, Gorlenko VM (2010) Ectothiorhodospira magna sp. nov., a new large alkaliphilic purple sulfur bacterium. Microbiology 79:780-790.

Buisman C, Post R, IJspeert P, Geraats G, Lettinga G (1989) Biotechnological process for sulphide removal with sulphur reclamation. Acta Biotechnol 9:255-267.

Cypionka H (2000) Oxygen respiration by Desulfovibrio species. Annu Rev Microbiol 54:82748.

Dennis PP, Shimmin LC (1997) Evolutionary divergence and salinity-mediated selection in halophilic archaea. Microbiol Mol Biol Rev 61:90-104.

Detkova EN, Boltianskaia IV (2007) Osmoadaptation of haloalkaliphilic bacteria: role of osmoregulators and their possible practical application. Mikrobiologiia 76:581-593.

Fernández M, Ramírez M, Gómez JM, Cantero D (2014) Biogas biodesulfurization in an anoxic biotrickling filter packed with open-pore polyurethane foam. J Hazard Mater 264:529_ 535.

Fortuny M, Gamisans X, Deshusses MA, Lafuente J, Casas C, Gabriel D (2011) Operational aspects of the desulfurization process of energy gases mimics in biotrickling filters. Water Res 45:5665-5674. 
Galinski EA (1993) Compatible solutes of halophilic eubacteria: molecular principles, watersolute interaction, stress protection. Experientia 49:487-496.

Gorlenko VM (2007) Anoxygenic phototrophic bacteria from soda lakes. Trans Winogradsky Inst Microbiol 14:159-183.

Grégoire P, Fardeau ML, Guasco S, Lagière J, Cambar J, Michotey V, Bonin P, Ollivier B (2012) Desulfosoma profundi sp. nov., a thermophilic sulfate-reducing bacterium isolated from a deep terrestrial geothermal spring in France. Antonie van Leeuwenhoek 101:595-602.

Hamaide F, Kushner DJ, Sprott GD (1983) Proton motive force and $\mathrm{Na}^{+} / \mathrm{H}^{+}$antiport in a moderate halophile. J Bacteriol 156:537-544.

Imhoff JF, Trüper HG (1981) Ectothiorhodospira abdelmalekii sp. nov., a new halophilic and alkaliphilic phototrophic bacterium. Zentralblatt für Bakteriol Mikrobiol und Hyg I Abt Orig C Allg Angew und Ökologische Mikrobiol 2:228-234.

Ito $\mathrm{M}$, Aono $\mathrm{R}$ (2002) Decrease in cytoplasmic pH-homeostastatic activity of the alkaliphile Bacillus lentus C-125 by a cell wall defect. Biosci Biotechnol Biochem 66:218-220.

Ito M, Hicks DB, Henkin TM, Guffanti AA, Powers BD, Zvi L, Uematsu K, Krulwich TA (2004) MotPS is the stator-force generator for motility of alkaliphilic Bacillus, and its homologue is a second functional Mot in Bacillus subtilis. Mol Microbiol 53:1035-1049.

Itoh T, Yamaguchi T, Zhou P, Takashina T (2005) Natronolimnobius baerhuensis gen. nov., sp. nov. and Natronolimnobius innermongolicus sp. nov., novel haloalkaliphilic archaea isolated from soda lakes in Inner Mongolia, China. Extremophiles 9:111-116.

Janssen AJH, Lens PNL, Stams AJM, Plugge CM, Sorokin DY, Muyzer G, Dijkman H, van Zessen E, Luimes P, Buisman CJN (2009) Application of bacteria involved in the biological sulfur cycle for paper mill effluent purification. Sci Total Environ 407:13331343.

Janto B, Ahmed A, Ito M, Liu J, Hicks DB, Pagni S, Fackelmayer OJ, Smith TA, Earl J, Elbourne LDH, Hassan K, Paulsen IT, Kolstø AB, Tourasse NJ, Ehrlich GD, Boissy R, Ivey DM, Li G, Xue Y, Ma Y, Hu FZ, Krulwich TA (2011) Genome of alkaliphilic Bacillus pseudofirmus OF4 reveals adaptations that support the ability to grow in an external $\mathrm{pH}$ range from 7.5 to 11.4. Environ Microbiol 13:3289-3309.

Jones BE, Grant WD, Duckworth AW, Owenson GG (1998) Microbial diversity of soda lakes. Extremophiles 2:191-200. 
Jones BF, Eugster HP, Rettig SL (1977) Hydrochemistry of the Lake Magadi basin, Kenya. Geochim Cosmochim Acta 41:53-72.

Jørgensen BB (1990) A thiosulfate shunt in the sulfur cycle of marine sediments. Science 249:152-154.

Jørgensen BB, Bak F (1991) Pathways and microbiology of thiosulfate transformations and sulfate reduction in a marine sediment (Kattegat, Denmark). Appl Environ Microbiol 57:847-56.

Kapetaniou E, Thanassoulas A, Dubnovitsky A, Nounesis G, Papageorgiou A (2006) Effect of $\mathrm{pH}$ on the structure and stability of Bacillus circulans ssp. alkalophilus phosphoserine aminotransferase: thermodynamic and crystallographic studies. Proteins 63:742-753.

Kjeldsen KU, Loy A, Jakobsen TF, Thomsen TR, Wagner M, Ingvorsen K (2007) Diversity of sulfate-reducing bacteria from an extreme hypersaline sediment, Great Salt Lake (Utah). FEMS Microbiol Ecol 60:287-298.

Kleindienst S, Ramette A, Amann R, Knittel K (2012) Distribution and in situ abundance of sulfate-reducing bacteria in diverse marine hydrocarbon seep sediments. Environ Microbiol 14:2689-2710.

Kleinjan WE, De Keizer A, Janssen AJH (2005) Equilibrium of the reaction between dissolved sodium sulfide and biologically produced sulfur. Colloids Surfaces B Biointerfaces 43:228-237.

Klok JBM, de Graaff M, van den Bosch PLF, Boelee NC, Keesman KJ, Janssen AJH (2013) A physiologically based kinetic model for bacterial sulfide oxidation. Water Res 47:483492.

Kolpakova MN, Shvartsev SL, Borzenko SV, Isupov VP, Shatskaya SS (2016) Geochemical features of Kulunda plain lakes (Altay region, Russia). Earth Environ Sci 33:1-6.

Krulwich TA, Ito M (2013) Alkaliphilic prokaryotes. In: Rosenberg E, DeLong EF, Lory S, Stackebrandt E, Thomson F (ed) Prokaryotes-Prokaryotic Physiology and Biochemisty., 4th edn. Springer, Berlin, Heidelberg, pp 441-469.

Liamleam W, Annachhatre AP (2007) Electron donors for biological sulfate reduction. Biotechnol Adv 25:452-463.

Lim JK, Mayer F, Kang SG, Müller V (2014) Energy conservation by oxidation of formate to carbon dioxide and hydrogen via a sodium ion current in a hyperthermophilic archaeon. Proc Natl Acad Sci U S A 111:11497-11502. 
Mesbah NM, Wiegel $\mathrm{J}$ (2011) The $\mathrm{Na}^{+}$-translocating $\mathrm{F}_{1} \mathrm{~F}_{\mathrm{O}^{-}}$-ATPase from the halophilic, alkalithermophile Natranaerobius thermophilus. Biochim Biophys Acta - Bioenerg 1807:1133-1142.

Melton ED, Sorokin DY, Overmars L, Chertkov O, Clum A, Pillay M, Ivanova N, Shapiro N, Kyrpides NC, Woyke T, Lapidus AL, Muyzer G (2016) Complete genome sequence of Desulfurivibrio alkaliphilus strain $\mathrm{AHT}^{\top}$, a haloalkaliphilic sulfidogen from Egyptian hypersaline alkaline lakes. Stand Genomic Sci 11:1-9.

Muyzer G, Sorokin DY, Mavromatis K, Lapidus A, Clum A, Ivanova N, Pati A, D'Haeseleer P, Woyke T, Kyrpides NC (2011) Complete genome sequence of "Thioalkalivibrio sulfidophilus" HL-EbGr7. Stand Genomic Sci 4:23-35.

Muyzer G, Stams AJM (2008) The ecology and biotechnology of sulphate-reducing bacteria. Nat Rev Microbiol 6:441-454.

Oren A (2011) Thermodynamic limits to microbial life at high salt concentrations. Environ Microbiol 13:1908-1923.

Oren A (2013) Life at High Salt Concentrations. In: Rosenberg E, DeLong EF, Lory S, Stackebrandt E, Thomson F (ed) Prokaryotes-Prokaryotic Physiology and Biochemisty., 4th edn. Springer, Berlin, Heidelberg, pp 421-440.

Oren A (2014) The Family Ectothiorhodospiraceae. In: Rosenberg E, DeLong EF, Lory S, Stackebrandt E, Thomson F (ed) The Prokaryotes, 4th edn. Springer, Berlin, Heidelberg, pp 201-223.

Overmann J, Garcia-Pichel F (2013) The Phototrophic Way of Life. In: Rosenberg E, DeLong EF, Lory S, Stackebrandt E, Thomson F (ed) Prokaryotes-Prokaryotic Physiology and Biochemisty., 4th edn. Springer, Berlin, Heidelberg, pp 203-257.

Pallud C, van Cappellen P (2006) Kinetics of microbial sulfate reduction in estuarine sediments. Geochim Cosmochim Acta 70:1148-1162.

Pei P, Korom SF, Ling K, Nasah J (2014) Cost comparison of syngas production from natural gas conversion and underground coal gasification. Mitig Adapt Strateg Glob Chang 115.

Pikuta EV, Zhilina TN, Zavarzin GA, Kostrikina NA, Osipov GA, Rainey FA (1998) Desulfonatronum lacustre gen. nov., sp. nov.: A new alkaliphilic sulfate-reducing bacterium utilizing ethanol. Mikrobiologiia 67:123-131. 
Pikuta EV, Hoover RB, Bej AK, Marsic D, Whitman WB, Cleland D, Krader P (2003) Desulfonatronum thiodismutans sp. nov., a novel alkaliphilic, sulfate-reducing bacterium capable of lithoautotrophic growth. Int J Syst Evol Microbiol 53:1327-1332.

Pitryuk AV, Pusheva MA, Kupriyanova EV (2006) Carbonic anhydrase activity in halophilic anaerobes from soda lakes. Microbiology 75:12-14.

Plugge CM, Zhang W, Scholten JCM, Stams AJM (2011) Metabolic flexibility of sulfatereducing bacteria. Front Microbiol 2:1-8.

Roman P, Bijmans MFM, Janssen AJH (2014) Quantification of individual polysulfides in labscale and full-scale desulfurisation bioreactors. Environ Chem 11:702-708.

Roman P, Veltman R, Bijmans MFM, Keesman KJ, Janssen AJH (2015) Effect of methanethiol concentration on sulfur production in biological desulfurization systems under haloalkaline conditions. Environ Sci Technol 49:9212-9221.

Sánchez-Andrea I, Knittel K, Amann R, Amils R, Sanz JL (2012) Quantification of Tinto river sediment microbial communities: Importance of sulfate-reducing bacteria and their role in attenuating acid mine drainage. Appl Environ Microbiol 78:4638-4645.

Sánchez-Andrea I, Sanz JL, Bijmans MFM, Stams AJM (2014) Sulfate reduction at low pH to remediate acid mine drainage. J Hazard Mater 269:98-109.

Shen Y, Buick R (2004) The antiquity of microbial sulfate reduction. Earth-Science Rev 64:243-272.

Sorokin DY, Lysenko AM, Mityushina LL, Tourova TP, Jones BE, Rainey FA, Robertson LA, Kuenen GJ (2001) Thioalkalimicrobium aerophilum gen. nov., sp. nov. and Thioalkalimicrobium sibericum sp. nov., and Thioalkalivibrio versutus gen. nov., sp. nov., Thioalkalivibrio nitratis sp. nov. and Thioalkalivibrio denitrificans sp. nov., novel obligately alkaliphilic and obligately chemolithotrophic sulfur-oxidizing bacteria from soda lakes. Int J Syst Evol Microbiol 51:565-580.

Shirai T, Igarashi K, Ozawa T, Hagihara H, Kobayashi T, Ozaki K, Ito S (2007) Ancestral sequence evolutionary trace and crystal structure analyses of alkaline $\alpha$-amylase from Bacillus sp. KSM-1378 to clarify the alkaline adaptation process of proteins. Proteins Struct Funct Bioinforma 66:600-610.

Sorokin DY, Foti M, Pinkart HC, Muyzer G (2007) Sulfur-oxidizing bacteria in Soap Lake (Washington State), a meromictic, haloalkaline lake with an unprecedented high sulfide content. Appl Environ Microbiololy 73:451-455. 
Sorokin DY, Tourova TP, Henstra AM, Stams AJM, Galinski EA, Muyzer G (2008a) Sulfidogenesis under extremely haloalkaline conditions by Desulfonatronospira thiodismutans gen. nov., sp. nov., and Desulfonatronospira delicata sp. nov. - a novel lineage of Deltaproteobacteria from hypersaline soda lakes. Microbiology 154:14441453.

Sorokin DY, van Den Bosch PLF, Abbas B, Janssen AJH, Muyzer G (2008b) Microbiological analysis of the population of extremely haloalkaliphilic sulfur-oxidizing bacteria dominating in lab-scale sulfide-removing bioreactors. Appl Microbiol Biotechnol 80:965975.

Sorokin DY, Detkova EN, Muyzer G (2009) Propionate and butyrate dependent bacterial sulfate reduction at extremely haloalkaline conditions and description of Desulfobotulus alkaliphilus sp. nov. Extremophiles 14:71-77.

Sorokin DY, Muyzer G (2010) Desulfurispira natronophila gen. nov. sp. nov.: an obligately anaerobic dissimilatory sulfur-reducing bacterium from soda lakes. Extremophiles 14:349-355.

Sorokin DY, Rusanov II, Pimenov N V, Tourova TP, Abbas B, Muyzer G (2010) Sulfidogenesis under extremely haloalkaline conditions in soda lakes of Kulunda Steppe (Altai, Russia). FEMS Microbiol Ecol 73:278-290.

Sorokin DY, Detkova EN, Muyzer G (2011a) Sulfur-dependent respiration under extremely haloalkaline conditions in soda lake "acetogens" and the description of Natroniella sulfidigena sp. nov. FEMS Microbiol Lett 319:88-95.

Sorokin DY, Kuenen JG, Muyzer G (2011b) The microbial sulfur cycle at extremely haloalkaline conditions of soda lakes. Front Microbiol 2:1-44.

Sorokin DY, Tourova TP, Kolganova T V, Detkova EN, Galinski EA, Muyzer G (2011c) Culturable diversity of lithotrophic haloalkaliphilic sulfate-reducing bacteria in soda lakes and the description of Desulfonatronum thioautotrophicum sp. nov., Desulfonatronum thiosulfatophilum sp. nov., Desulfonatronovibrio thiodismutans sp. nov., and Desulfonatronovibrio magnus sp. nov. Extremophiles 15:391-401.

Sorokin DY, Tourova TP, Abbas B, Suhacheva M V, Muyzer G (2012a) Desulfonatronovibrio halophilus sp. nov., a novel moderately halophilic sulfate-reducing bacterium from hypersaline chloride-sulfate lakes in Central Asia. Extremophiles 16:411-417.

Sorokin DY, Tourova TP, Panteleeva AN, Muyzer G (2012b) Desulfonatronobacter acidivorans gen. nov., sp. nov. and Desulfobulbus alkaliphilus sp. nov., haloalkaliphilic heterotrophic sulfate-reducing bacteria from soda lakes. Int J Syst Evol Microbiol 62:2107-2113. 
Sorokin DY, Tourova TP, Sukhacheva MV., Muyzer G (2012c) Desulfuribacillus alkaliarsenatis gen. nov. sp. nov., a deep-lineage, obligately anaerobic, dissimilatory sulfur and arsenate-reducing, haloalkaliphilic representative of the order Bacillales from soda lakes. Extremophiles 16:597-605.

Sorokin DY, Banciu H, Robertson LA, Kuenen JG, Muntyan MS, Muyzer G (2013a) Halophilic and haloalkaliphilic sulfur-oxidizing bacteria. In: Rosenberg E, DeLong EF, Lory S, Stackebrandt E, Thomson F (ed) Prokaryotes-Prokaryotic Physiology and Biochemisty., 4th edn. Springer, Berlin, Heidelberg, pp 530-551.

Sorokin DY, Tourova TP, Muyzer G (2013b) Isolation and characterization of two novel alkalitolerant sulfidogens from a Thiopaq bioreactor, Desulfonatronum alkalitolerans sp. nov., and Sulfurospirillum alkalitolerans sp. nov. Extremophiles 17:535-543.

Sorokin DY, Abbas B, Tourova TP, Bumazhkin BK, Kolganova TV, Muyzer G (2014a) Sulfatedependent acetate oxidation under extremely natron-alkaline conditions by syntrophic associations from hypersaline soda lakes. Microbiololy (United Kingdom) 160:723-732.

Sorokin DY, Berben T, Melton ED, Overmars L, Vavourakis CD, Muyzer G (2014b) Microbial diversity and biogeochemical cycling in soda lakes. Extremophiles 18:791-809.

Sorokin DY, Chernyh NA, Poroshina MN (2015) Desulfonatronobacter acetoxydans sp. nov.,: a first acetate-oxidizing, extremely salt-tolerant alkaliphilic SRB from a hypersaline soda lake. Extremophiles 19:899-907.

Sousa JAB, Sorokin DY, Bijmans MFM, Plugge CM, Stams AJM (2015) Ecology and application of haloalkaliphilic anaerobic microbial communities. Appl Microbiol Biotechnol 99:9331-9336.

Stams AJM, Plugge CM (2009) Electron transfer in syntrophic communities of anaerobic bacteria and archaea. Nat Rev Microbiol 7:568-577.

Tang K, Baskaran V, Nemati M (2009) Bacteria of the sulphur cycle: An overview of microbiology, biokinetics and their role in petroleum and mining industries. Biochem Eng J 44:73-94.

Tourova TP, Spiridonova EM, Berg IA, Kuznetsov BB, Sorokin DY (2006) Occurrence, phylogeny and evolution of ribulose-1,5-bisphosphate carboxylase/oxygenase genes in obligately chemolithoautotrophic sulfur-oxidizing bacteria of the genera Thiomicrospira and Thioalkalimicrobium. Microbiology 152:2159-2169. 
Tourova TP, Spiridonova EM, Berg IA, Slobodova NV., Boulygina ES, Sorokin DY (2007) Phylogeny and evolution of the family Ectothiorhodospiraceae based on comparison of 16S rRNA, cbbL and nifH gene sequences. Int J Syst Evol Microbiol 57:2387-2398.

van Den Bosch PLF, Beusekom OC, Buisman CJN, Janssen AJH (2007) Sulfide oxidation at halo-alkaline conditions in a fed-batch bioreactor. Biotechnol Bioeng 97:1053-1063.

van Den Bosch PLF (2008) Biological sulfide oxidation by natron-alkaliphilic bacteria Application in gas desulfurization. PhD Thesis. Wageningen University

van Houten BHGW, van Doesburg W, Dijkman H, Copini C, Smidt H, Stams AJM (2009) Longterm performance and microbial community analysis of a full-scale synthesis gas fed reactor treating sulfate- and zinc-rich wastewater. Appl Microbiol Biotechnol 84:555-563.

Vavourakis CD, Ghai R, Rodriguez-Valera F, Sorokin DY, Tringe SG, Hugenholtz P, Muyzer $G$ (2016) Metagenomic insights into the uncultured diversity and physiology of microbes in four hypersaline soda lake brines. Front Microbiol 7:1-18.

Weber A, Jørgensen BB (2002) Bacterial sulfate reduction in hydrothermal sediments of the Guaymas Basin, Gulf of California, Mexico. Deep Sea Res Part I Oceanogr Res Pap 49:827-841.

Widdel F, Rabus R (2001) Anaerobic biodegradation of saturated and aromatic hydrocarbons. Curr Opin Biotechnol 12:259-276.

Zakharyuk AG, Kozyreva LP, Khijniak TV., Namsaraev BB, Shcherbakova VA (2015) Desulfonatronum zhilinae sp. nov., a novel haloalkaliphilic sulfate-reducing bacterium from soda Lake Alginskoe, Trans-Baikal Region, Russia. Extremophiles 19:673-680.

Zhilina TN, Zavarzin GA, Rainey FA, Pikuta EN, Osipov GA, Kostrikina NA (1997) Desulfonatronovibrio hydrogenovorans gen. nov., sp. nov., an alkaliphilic, sulfatereducing bacterium. Int J Syst Bacteriol 47:144-149.

Zhilina TN, Zavarzina DG, Kuever J, Lysenko AM, Zavarzin GA (2005) Desulfonatronum cooperativum sp. nov., a novel hydrogenotrophic, alkaliphilic, sulfate-reducing bacterium, from a syntrophic culture growing on acetate. Int $\mathrm{J}$ Syst Evol Microbiol 55:1001-1006.

Zhou JM, Song ZY, Yan DJ, Liu YL, Yang MH, Cao HB, Xing JM (2014) Performance of a haloalkaliphilic bioreactor and bacterial community shifts under different $\mathrm{COD} / \mathrm{SO}_{4}{ }^{2-}$ ratios and hydraulic retention times. J Hazard Mater 274:53-62. 
Zhou J, Xing J (2015a) Effect of electron donors on the performance of haloalkaliphilic sulfatereducing bioreactors for flue gas treatment and microbial degradation patterns related to sulfate reduction of different electron donors. Biochem Eng J 96:14-22.

Zhou J, Zhou X, Li Y, Xing J (2015b) Bacterial communities in haloalkaliphilic sulfate-reducing bioreactors under different electron donors revealed by $16 \mathrm{~S}$ rRNA MiSeq sequencing. $J$ Hazard Mater 295:176-184. 


\title{
Chapter 2
}

\section{Ecology and application of haloalkaliphilic anaerobic microbial communities}

\author{
João AB Sousa, Dimitry Y Sorokin, Martijn FM Bijmans, \\ Caroline M Plugge, Alfons JM Stams
}

Published as:

Sousa JAB, Sorokin DY, Bijmans MFM, Plugge CM, Stams AJM (2015) Ecology and application of haloalkaliphilic anaerobic microbial communities. Appl Microbiol Biotechnol

99:9331-9336

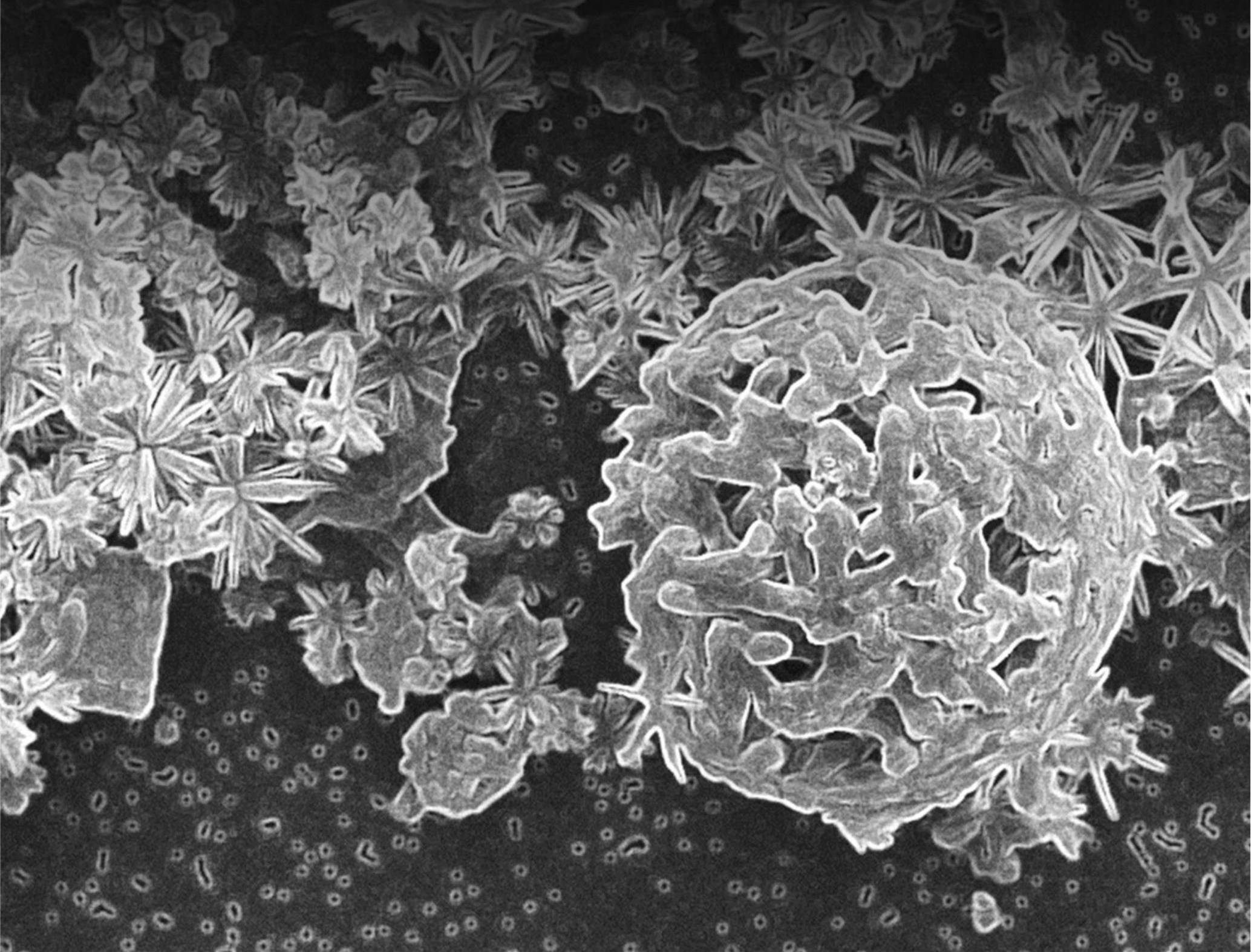




\section{Abstract}

Haloalkaliphilic microorganisms that grow optimally at high $\mathrm{pH}$ and high salinity conditions can be found in natural environments such as soda lakes. These globally spread lakes harbour interesting anaerobic microorganisms that have the potential of being applied in existing technologies or create new opportunities. In this review, we discuss the potential application of haloalkaliphilic anaerobic microbial communities in the fermentation of lignocellulosic feedstocks material subjected to an alkaline pretreatment, methane production and sulfur removal technology. Also, the general advantages of operation at haloalkaline conditions, such as low volatile fatty acid and sulfide toxicity, are addressed. Finally, an outlook into the main challenges like ammonia toxicity and lack of aggregation is provided. 


\section{Introduction}

The metabolic potential of anaerobic microorganisms has been exploited in a wide range of applications, like volatile fatty acids (VFAs), alcohols, $\mathrm{H}_{2}$ and methane production. However, information about the application of haloalkaliphilic anaerobes that thrive in high $\mathrm{pH}(>8.5)$ and high salt conditions $\left(>35 \mathrm{~g} \mathrm{l}^{-1}\right)$ is very limited.

In these extreme environments, microorganisms adapted physiological mechanisms to cope with high $\mathrm{pH}$ and salinity. The high salinity of the environment must be compensated to prevent osmotic stress and water leakage from the cell. To cope with high salinity, microorganisms accumulate inorganic or organic compounds that work as osmoregulators, preventing the loss of water inside the cell (Dektova et al. 2007). The high $\mathrm{pH}$, on the other hand, affects the proton balance and transport by the ATPases that are responsible for ATP production. Even though the $\mathrm{pH}$ of the environment is alkaline, the cell inside usually operates close to neutral $\mathrm{pH}$. Cells cope with this by having more negatively charged cell walls that generate a layer of more concentrated protons, lower $\mathrm{pH}$, near the cell while repelling anions. These adaptations to alkaline conditions have already been recently reviewed in more detail (Banciu et al. 2015; Preiss et al. 2015).

Various haloalkaline environments, like soda lakes, soda solonchak soil, mining industry waste and leaves of salt secreting trees have been described (Qvit-Raz et al. 2008; Sorokin et al. 2008; Sorokin et al. 2014; 2015a; Santini et al. 2015). However, only soda lakes and soda solonchak soils have the buffer capacity to maintain a high $\mathrm{pH}(>8.5)$ and high salinity $\left(>35 \mathrm{~g} \mathrm{l}^{-1}\right)$. Soda solonchak soils have a higher aeration when compared to soda lakes and favour aerotolerant microorganisms (Sorokin et al. 2008). Thus, soda lakes are the most suitable habitats to find anaerobic haloalkaliphilic microorganisms. In these lakes, a high pH and salinity is caused by the evaporative concentration of soluble sodium carbonates because of low concentrations of divalent cations such as calcium or magnesium in the ground waters and surrounding minerals. The extremely high $\mathrm{pH}$ (between 9 and 11) is stable due to a high alkaline buffering capacity of soluble carbonates and salinity can go from $35 \mathrm{~g} \mathrm{l}^{-1}$ up to saturation. Soda lakes harbour highly active and diverse microbial communities involved in the carbon, sulfur and nitrogen cycles. Microbiological studies on soda lakes have been reviewed by Sorokin et al. $(2014 ; 2015 a)$ Also reviews on application of haloalkaliphilic 
microorganisms on nitrogen cycle, sulfide oxidation, heavy metals removal, biofuel production and enzymes production are available (Horikoshi 1999; Zhao et al 2014)

In this mini-review, research focused on potential application of anaerobic haloalkaliphilic microorganisms in fermentation of lignocellulosic feedstocks, methane production and sulfur removal technology will be reviewed. The advantages of low VFAs and sulfide toxicity and high methane content will be discussed. We will also focus on the main technological challenges, such as ammonia toxicity and lack of microbial aggregation.

\section{Anaerobic digestion of lignocellulosic feedstocks}

The rate of hydrolysis of sugar polymers is crucial in the fermentation of lignocellulosic feedstocks by anaerobic fermentative bacteria. These feedstocks include waste from agriculture, forest and paper industry where the hydrolytic step is a bottleneck. This is mainly due to the highly packed crystal structure of the fibres composed of lignin, cellulose and hemicellulose (Mathews et al., 2015). To improve hydrolysis, an alkaline pre-treatment can be performed to reduce the fibres crystallinity, making them more accessible to attack of microbial hydrolases (Hendriks and Zeeman, 2009).

\section{Fermentation}

After alkaline pre-treatment, the current approach is biofermentation at neutral $\mathrm{pH}$ after neutralizing the alkaline broth. However, the use of haloalkaliphilic microorganisms eliminates the need for $\mathrm{pH}$ adjustments, thus reducing costs (Porsch et al., 2015). The information on haloalkaliphilic cellulolytic anaerobes is, so far, limited to a few soda lake alkaliphiles. Clostridium alkalicellulosi (Table 1) (Zhilina et al., 2005a; Zvereva et al., 2006) is able to produce acetate, ethanol, lactate, hydrogen and traces of formate as products during fermentation of cellulose and cellobiose. Pikuta et al (2006) reported that Anaerovirgula multivorans can weakly grow on cellulose in alkaline medium supplemented with yeast extract. However, no growth kinetics and activity data have been provided. The sugars released from the lignocellulosic feedstocks 
during alkaline pre-treatment can be used by many cultured haloalkaliphilic saccharolytic fermenters. Such bacteria, belonging to the genera Spirochaeta, Amphibacillus, Alkaliflexus and Alkalitalea were isolated from different soda lakes and are capable of fermenting cellobiose and glucose, the main product of cellulose hydrolysis (Table 1) (Zhilina et al. 2001; Zhilina et al. 2004; Pikuta et al. 2009; Zhao and Chen 2012). The fermentation products varied between species, but are mainly acetate, ethanol, lactate and hydrogen. However, Halanaerobium hydrogeniformans produced acetate, formate and hydrogen as main products in a haloalkaline fed-batch bioreactor fed with hydrolysed switchgrass (Table 1) (Begemann et al. 2012). Ethanol, lactate and hydrogen can be used by haloalkaliphilic acetogens, such as Natroniella and Fuchsiella, converting them to acetate (Table 1) (Zhilina et al., 2012).

\section{Methane production}

Methanogenic fermentation of wastes at haloalkaline conditions can be an interesting option for renewable biogas production. At high pH, VFA toxicity is reduced because VFA are mostly present in the dissociated form which cannot easily cross cell membranes and disrupt the proton balance (Figure 1). This would allow the operation of such bioreactors at higher organic loadings. At high $\mathrm{pH}$ the $\mathrm{CO}_{2}$ is more retained as carbonates which could lead to a lower $\mathrm{CO}_{2}$ content in the biogas. Also, sulfide at high $\mathrm{pH}$ is mainly in the ionized form (HS-) which is less volatile and toxic, resulting in a gas with very low concentrations of sulfide. A recent study on the digestion of the microalga Spirulina at haloalkaline conditions resulted in a biogas with a methane content of $96 \%$ and without traces of sulfide (Nolla-Ardèvol et al 2015). This might reduce the need for biogas post treatment to remove $\mathrm{CO}_{2}$ and $\mathrm{H}_{2} \mathrm{~S}$, allowing the use of the biogas directly in natural gas supply grid. 
Table 1 - Relevant haloalkaliphilic microorganisms for fermentation of lignocellulosic feedstocks at haloalkaline conditions and their role, optimum $\mathrm{pH}$ and optimum salinity.

\begin{tabular}{|c|c|c|c|c|}
\hline Microorganism & Metabolic type & $\begin{array}{c}\text { Optimum } \\
\text { pH }\end{array}$ & $\begin{array}{c}\text { Optimum } \\
\text { salinity } \\
\left(\mathrm{M} \mathrm{Na}^{+}\right)\end{array}$ & Reference \\
\hline Clostridium alkalicellum & $\begin{array}{l}\text { Cellulolytic / } \\
\text { fermenter }\end{array}$ & 9 & $0.15-0.3$ & Zhilina et al. 2005 \\
\hline Anaerovirgula multivorans & $\begin{array}{l}\text { Cellulolytic*/ } \\
\text { fermenter }\end{array}$ & 8.5 & $0.17-0.34$ & Pikuta et al. 2006 \\
\hline Spirochaeta alkalica & Fermenter & $8.7-9.6$ & $0.5-1.7$ & Pikuta al. 2009 \\
\hline Spirochaeta africana & Fermenter & $8.8-9.75$ & $0.85-1.2$ & Pikuta al. 2009 \\
\hline Spirochaeta asiatica & Fermenter & $8.4-9.4$ & $0.5-1$ & Pikuta al. 2009 \\
\hline Amphibacillus tropicus & Fermenter & $9.5-9.7$ & $0.17-3.6$ & Zhilina et al. 2001 \\
\hline Amphibacillus fermentum & Fermenter & 8-9.5 & 1.87 & Zhilina et al. 2001 \\
\hline Alkaliflexus imshenetskii & Fermenter & 8.5 & 0.35 & Zhilina et al. 2004 \\
\hline Alkalitalea saponilacus & Fermenter & 9.7 & $0.44-0.69$ & Zhao et al. 2012 \\
\hline $\begin{array}{l}\text { Halanaerobium } \\
\text { hydrogeniformans }\end{array}$ & Fermenter & 11 & 1.3 & Begemann et al. 2012 \\
\hline $\begin{array}{l}\text { Natroniella } \\
\text { acetigena }\end{array}$ & Acetogen & $9.7-10$ & $2.1-2.7$ & Zhilina et al. 2012 \\
\hline Fuchsiella alkaliacetigena & Acetogen & $8.8-9.3$ & 2.8-3.3 & Zhilina et al. 2012 \\
\hline
\end{tabular}

* More information is required to clearly prove that Anaerovirgula multivorans is capable of growing on cellulose.

In soda lakes, the methanogenic activity in the sediments is similar to freshwater lakes and marine sediments (Kuivila et al. 1989;1990; Sorokin et al. 2015b). Just a few methanogenic archaea have been isolated from soda lakes (Sorokin et al., 2015a; Zhilina et al., 2013). The isolated hydrogenotrophic methanogens belong to the genus 
Methanocalculus that use $\mathrm{H}_{2}$ and formate. The isolated methylotrophic methanogens belong to the genera Methanolobus and Methanosalsum that use various methylated compounds. Acetate conversion to methane is also possible, albeit at very low rates, either directly at moderate salinity by alkaliphilic Methanosaeta or by syntrophic associations of reversed acetogens and lithotrophic Methanocalculus at moderate to high salinity (Sorokin et al., 2015b).

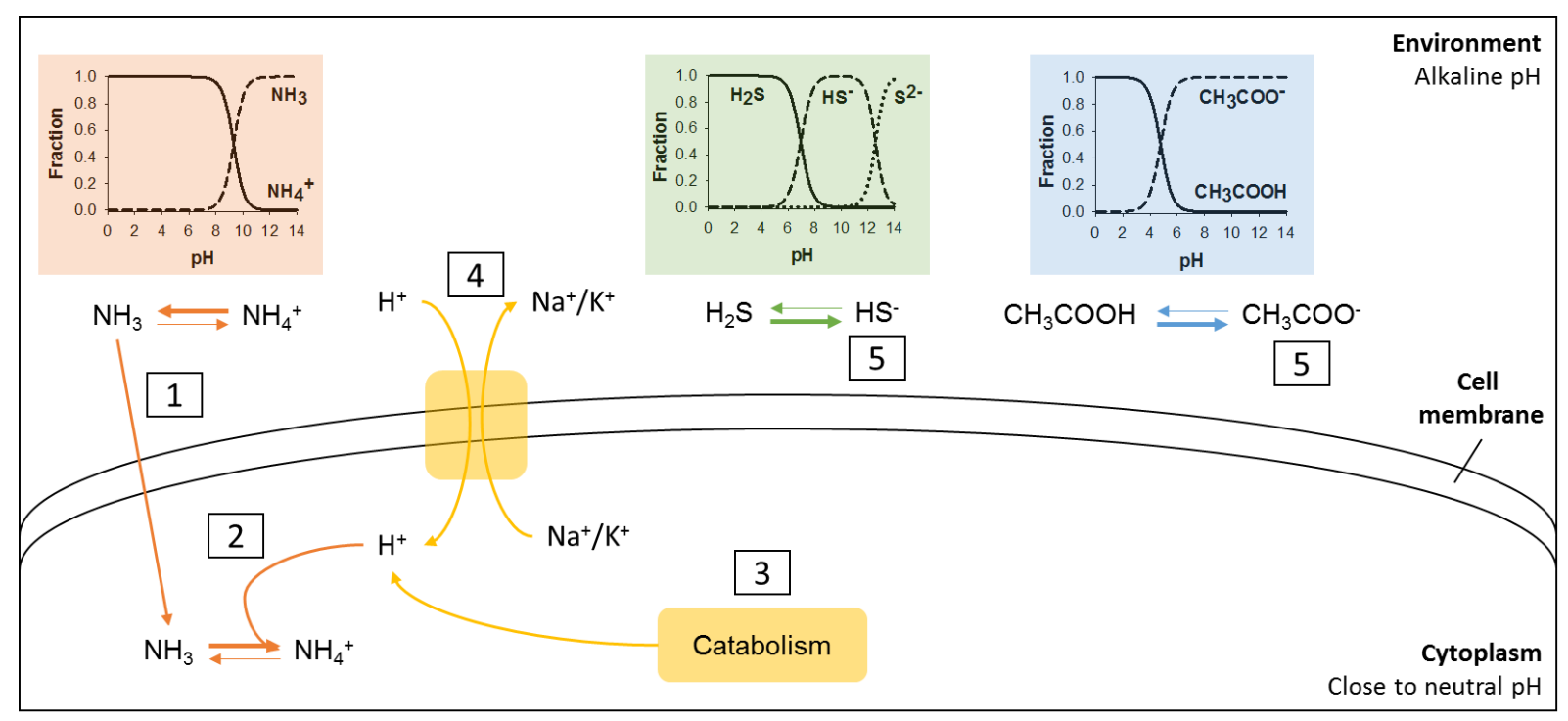

Figure 1 - Effect of ammonia, sulfide and acetate (representing VFAs in general) on microorganisms living at alkaline $\mathrm{pH}$, and chemical equilibrium of ammonia sulfide and acetate at different $\mathrm{pH}$ values. 1 - At alkaline $\mathrm{pH}$, ammonia tends to the un-ionized species $\left(\mathrm{NH}_{3}\right)$ which can cross cell membranes in contrast with the ionized species $\left(\mathrm{NH}_{4}^{+}\right) ; 2$ - Due to the close to neutral $\mathrm{pH}$ inside the cell, the chemical equilibrium shifts towards the $\mathrm{NH}_{4}{ }^{+}$species, consuming one proton $\left(\mathrm{H}^{+}\right)$and disrupting the proton balance; 3 - To compensate the lost $\mathrm{H}^{+}$, the primary source of $\mathrm{H}^{+}$is from the catabolic reactions; 4 - Also, antiporters in the cell membrane may pump $\mathrm{H}^{+}$in and simultaneously pump sodium $\left(\mathrm{Na}^{+}\right)$or potassium $\left(\mathrm{K}^{+}\right)$out, generating an osmotic difference that needs to be compensated; 5 - At alkaline $\mathrm{pH}$ sulfide and acetate exist in the ionized form, $\mathrm{HS}^{-}$and $\mathrm{CH}_{3} \mathrm{COO}$, which cannot easily pass the cell membrane.

\section{Sulfidogenesis}

Bioreduction of inorganic sulfur compounds can be applied to treat sulfur-rich waste streams with high $\mathrm{pH}$ and salinity originated from the oil, natural gas and mining 
industries. When such streams are exposed to oxygen, mainly oxidized compounds exist like sulfate, thiosulfate, sulfite or sulfur. However, in the environment such compounds might be reduced, producing sulfide which is toxic and characterized by the rotten egg smell. To prevent this, the sulfur compounds can be removed from such streams by microbial processes. Oxidized sulfur compounds can be reduced to sulfide in a controlled environment, like a bioreactor. The sulfide produced can be biologically oxidized at oxygen-limited conditions to elemental sulfur, which has economic value (Janssen et al. 2009). Sulfur cycle related haloalkaliphilic bacteria can be found in soda lakes where the microbial sulfur cycle is very active (Sorokin et al., 2011c). Haloalkaliphilic sulfate-reducing bacteria (SRB) that use besides sulfate also thiosulfate and sulfite as electron acceptor and often can disproportionate thiosulfate and sulfite have also been isolated from soda lakes. Both lithotrophic and organotrophic SRB have been described and reviewed by Sorokin et al $(2011 ; 2014$; 2015a). Elemental sulfur was never shown to be reduced by haloalkaliphilic SRB. However, the specialized sulfur-reducing bacteria, which can reduce or disproportionate elemental sulfur, are also present in these environments (Sorokin et al. 2014; 2015a).

Sulfate reduction at haloalkaline conditions was tested in anaerobic filters and gas-lift bioreactors using various electron donors (Sousa et al., 2015a; Zhou and Xing, 2015). These results revealed that the most reliable electron donors are formate, hydrogen and ethanol (Table 2). The dominant SRB found in these bioreactors belonged to the lithotrophic genera Desulfonatronospira and Desulfonatronovibrio. As produced sulfide at high $\mathrm{pH}$ is present in the dissociated form (HS-), this has a much lower toxicity to the biomass compared to neutral pH (Figure 1). Sousa et al (2015) showed that sulfate reduction occurred up to $260 \mathrm{mM}$ of sulfide at $\mathrm{pH} 9$, while at $\mathrm{pH} 7$ the sulfide toxicity was already severe at $30 \mathrm{mM}$ (van Houten et al., 1994). Therefore, bioreactors operated at haloalkaline conditions can handle more concentrated sulfur streams than at neutral $\mathrm{pH}$. 
Table 2 - Comparison of different studies on sulfate reduction in bioreactors operated at haloalkaline conditions.

\begin{tabular}{|c|c|c|c|}
\hline Reference & Sousa et al. 2015 & Zhou et al. 2015 & $\begin{array}{c}\text { Zhou et al. } 2015 \\
\text { (Zhou et al., 2014b) }\end{array}$ \\
\hline Reactor type & $\begin{array}{c}\text { Gas lift with } 3 \text { phase } \\
\text { separator }\end{array}$ & Anaerobic filter & Anaerobic filter \\
\hline $\mathrm{e}^{-}$acceptor & Sulfate & Sulfate & Sulfate \\
\hline$e^{-}$donor & $\mathrm{H}_{2}$ & Formate & Ethanol \\
\hline $\mathrm{pH}$ & 9 & 9.5 & 9.5 \\
\hline $\mathrm{Na}^{+}$conc. $(\mathrm{M})$ & 1.5 & 1 & 1 \\
\hline Temperature $\left({ }^{\circ} \mathrm{C}\right)$ & 35 & 37 & 37 \\
\hline $\mathrm{HRT}(\mathrm{d})$ & 3.3 & 1 & 1 \\
\hline $\begin{array}{l}\text { Conversion rates } \\
\left(\mathrm{mmols}^{-1} \mathrm{~d}^{-1}\right)\end{array}$ & 18 & 85 & 89.5 \\
\hline $\begin{array}{l}\text { Max. sulfide conc. } \\
\left(\mathrm{mmol} \mathrm{l}^{-1}\right)\end{array}$ & 260 & 76 & 82 \\
\hline Side products & Formate & Acetate & $\begin{array}{l}\text { Acetate/formate/ } \\
\text { lactate }\end{array}$ \\
\hline $\begin{array}{l}\text { Biomass conc. } \\
\left(\mathrm{mg} \mathrm{l}^{-1}\right)\end{array}$ & $7.2( \pm 3)$ & N.D. & N.D. \\
\hline $\begin{array}{l}\text { Biomass } \\
\text { aggregation }\end{array}$ & No aggregation & N.D. & N.D. \\
\hline
\end{tabular}

N.D. - Not described

\section{Future challenges for haloalkaline bioreactor research}

The application of anaerobic haloalkaline microbial communities has numerous advantages. But even though these microorganisms are highly adapted to these extreme conditions, there are challenges to overcome before applying such technologies at full scale.

\section{Ammonia toxicity}

One challenge is the ammonia toxicity at high pH (Figure 1). At haloalkaline conditions un-ionized ammonia $\left(\mathrm{NH}_{3}\right)$ rather than ammonium $\left(\mathrm{NH}_{4}{ }^{+}\right)$is the dominant chemical 
species, as the pKa is 9.25. $\mathrm{NH}_{3}$ can freely diffuse through the cell membrane and disrupt the proton balance inside the cells, making it toxic while $\mathrm{NH}_{4}{ }^{+}$cannot cross the membrane and, therefore, is not toxic (Kayhanian, 1999). After crossing the membrane, $\mathrm{NH}_{3}$ is protonized into $\mathrm{NH}_{4}{ }^{+}$due to the near neutral $\mathrm{pH}$ in the cytoplasm maintained by alkaliphiles which, in turn, may weaken its neutral buffering. To compensate this, haloalkaliphiles primarily use protons from the catabolic reactions or can also use antiporters to transport protons into the cell while transporting potassium or sodium out of the cells (Kayhanian, 1999). This use of antiporters, however, would generate additional osmotic stress that needs to be compensated.

\section{Lack of aggregation}

The high $\mathrm{pH}$ and salinity in bioreactors can prevent a stable aggregation of microorganisms which is usually essential for biomass retention of slowly growing organisms. Previous studies showed that aggregation in bioreactors at high $\mathrm{pH}$ and salt concentrations did not occur at all or that stable granules disintegrated in high salinity bioreactors (Ismail et al., 2008; Sousa et al., 2015a). The causes for this are still in discussion and different mechanisms are proposed. At high $\mathrm{pH}$ the hydrophobicity of cell surfaces and extracellular polymeric substance (EPS) might change and hydrophobicity has been reported to affect the microbial attachment (van Loosdrecht et al. 1987; Otto et al. 1999). Another possibility was proposed by Ismail et al (2008) who suggested that at high $\mathrm{Na}^{+}$concentrations, $\mathrm{Na}^{+}$replaces divalent cations, such as $\mathrm{Ca}^{2+}$, in the EPS matrix of aggregates, making the aggregates less stable. Another possible effect could be down regulation of carbon metabolism at high salinities as reported by $\mathrm{He}$ et al (2010). This subsequently lowers the EPS production in favour of osmolites production to balance the high salinity. Yet, halophilic isolates from the Halomonas genus were shown to produce EPS, and this could point to a significant role of high $\mathrm{pH}$ in the lack of aggregation at haloalkaline conditions (Martínez-Cánovas et al., 2004). To overcome the challenge of no aggregation at haloalkaline conditions, technologies like use of a biofilm support material in the reactor or a membrane biological reactor (MBR) should be considered. 


\section{Operational challenges}

Additional factors related to the engineering of haloalkaline bioreactors need to be addressed. By operating bioreactors at high salt and high $\mathrm{pH}$, there is an increased risk of scaling if divalent cations are added. This problem requires special attention when designing and optimizing the processes. Also, the high $\mathrm{pH}$ and salinity effluent might require additional treatment to neutralize $\mathrm{pH}$ and salinity prior to its discharge.

\section{Conclusions and future prospects}

Application of haloalkaliphilic anaerobic microbial communities in the above-mentioned processes is an interesting route to consider in specific cases and/or to increase their efficiency. Operation at haloalkaline conditions has several advantages, like low VFA and sulfide toxicity, production of low $\mathrm{CO}_{2}$-containing and $\mathrm{H}_{2} \mathrm{~S}$-containing biogas and reduced need for $\mathrm{pH}$ control. On the other hand, the challenges of ammonia toxicity and lack of biomass aggregation need to be overcome for application in industry. In general, more laboratory scale bioreactor studies focusing on these microorganisms are required. Information on reaction rates, biomass growth and microbial communities during long-term experiments in bioreactors is essential to scale up these technologies. 


\section{References}

Banciu HL, Muntyan MS (2015) Adaptive strategies in the double-extremophilic prokaryotes inhabiting soda lakes. Curr Opin Microbiol 25:73-79.

Begemann MB, Mormile MR, Sitton OC, Wall JD, Elias DA (2012) A streamlined strategy for biohydrogen production with Halanaerobium hydrogeniformans, an alkaliphilic bacterium. Front Microbiol 3, doi=10.3389/fmicb.2012.00093.

Dektova EN, Boltyanskaya YV (2007) Osmoadaptation of haloalkaliphilic bacteria: role of osmoregulators and their possible practical application. Microbiology 76:511-522.

He Z, Zhou A, Baidoo E, He Q, Joachimiak MP, Benke P, Phan R, Mukhopadhyay A, Hemme CL, Huang K, Alm EJ, Fields MW, Wall J, Stahl D, Hazen TC, Keasling JD, Arkin AP, Zhou J (2010) Global transcriptional, physiological, and metabolite analyses of the response of Desulfovibrio vulgaris Hildenborough to salt adaptation. Appl Environ Microbiol 76:1574-1586.

Hendriks ATWM, Zeeman G (2009) Pretreatments to enhance the digestibility of lignocellulosic biomass. Bioresour Technol 100:10-18.

Horikoshi K (1999) Alkaliphiles: some applications of their products for biotechnology. Microbiol Mol Biol 63:735-750.

Janssen AJH, Lens P, Stams AJM, Plugge CM, Sorokin DY, Muyzer G, Dijkman H, van Zessen $E$, Luimes P, Buisman CJN (2009) Application of bacteria involved in the biological sulfur cycle for paper mill effluent purification. Sci Total Environ 407:1333-1343.

Ismail SB, Gonzalez P, Jeison D, van Lier JB (2008) Effects of high salinity wastewater on methanogenic sludge bed systems. Water Sci Technol 58:1963-1970.

Kayhanian M (1999) Ammonia inhibition in high-solids biogasification: an overview and practical solutions. Environ Technol 20:355-365.

Kuivila KM, Murray JW, Devol AH, Novelli PC (1989) Methane production, sulfate reduction and competition for substrates in the sediments of Lake Washington. Geochim Cosmochim Acta 53:409-416.

Kuivila KM, Murray JW, Devol AH (1990) Methane production in the sulfate-depleted sediments of two marine basins. Geochim Cosmochim Acta 54:403-411. 
Martínez-Cánovas MJ, Quesada E, Martínez-Checa F, Béjar V (2004) A taxonomic study to establish the relationship between exopolysaccharide-producing bacterial strains living in diverse hypersaline habitats. Curr Microbiol 48:348-353.

Mathews SL, Pawlak J, Grunden AM (2015) Bacterial biodegradation and bioconversion of industrial lignocellulosic streams. Appl Microbiol Biotechnol 99:2939-2954.

Nolla-Ardèvol V, Strous M, Tegetmeyer HE (2015) Anaerobic digestion of the microalga Spirulina at extreme alkaline conditions: biogas production, metagenome, and metatranscriptome. Front Microbiol 6:1-21.

Otto K, Elwing H, Hermansson M (1999) Effect of ionic strength on initial interactions of Escherichia coli with surfaces, studied on-line by a novel quartz crystal microbalance technique. J Bacteriol 181:5210-5218.

Pikuta EV, Takashi I, Krader P, Tang J, Whitman WB, Hoover RB (2006) Anaerovirgula multivorans gen. nov., sp. nov., a novel spore-forming, alkaliphilic anaerobe isolated from Owens Lake, California, USA. Int J Syst Evol Microbiol 56:2623-2629.

Pikuta EV, Hoover RB, Bej AK, Marsic D, Whitman WB, Krader P (2009) Spirochaeta dissipatitropha sp. nov., an alkaliphilic, obligately anaerobic bacterium, and emended description of the genus Spirochaeta Ehrenberg 1835. Int J Syst Evol Microbiol 59:1798-1804.

Porsch K, Wirth B, Tóth EM, Schattenberg F, Nikolausz M (2015) Characterization of wheat straw-degrading anaerobic alkali-tolerant mixed cultures from soda lake sediments by molecular and cultivation techniques. Microb Biotechnol 8:801-814.

Preiss L, Hicks DB, Suzuki S, Meier T, Krulwich TA (2015) Alkaliphilic bacteria with impact on industrial applications, concepts of early life forms, and bioenergetics of ATP synthesis. Front Bioeng Biotechnol 3:1-16.

Qvit-Raz N, Jurkevitch E, Belkin S (2008) Drop-size soda lakes: transient microbial habitats on a salt-secreting desert tree. Genetics 178:1615-1622.

Santini TC, Warren LA, Kendra KE (2015) Microbial diversity in engineered haloalkaline evironments shaped by shared geochemical drivers observed in natural analogues. Appl Environ Microbiol 81:5026-5036. 
Sorokin ID, Kravchenko IK, Doroshenko EV, Boulygina ES, Zadorina EV, Tourova TP, Sorokin DY (2008) Haloalkaliphilic diazotrophs in soda solonchak soils. FEMS Microbiol Ecol 65:452-433.

Sorokin DY, Kuenen JG, Muyzer G (2011) The microbial sulfur cycle at extremely haloalkaline conditions of soda lakes. Front Microbiol 2:1-16.

Sorokin DY, Berben T, Melton ED, Overmars L, Vavourakis CD, Muyzer G (2014) Microbial diversity and biogeochemical cycling in soda lakes. Extremophiles 18:791-809.

Sorokin DY, Banciu HL, Muyzer G (2015a) Functional microbiology of soda lakes. Curr Opinions Microbiol 25:88-96.

Sorokin DY, Abbas B, Geleijnse M, Pimenov NV, Sukhacheva MV, van Loosdrecht MCM (2015b) Methanogenesis at extremely haloalkaline conditions in the soda lakes of Kulunda Steppe (Altai, Russia). FEMS Microbiol Ecol 91:1-12.

Sousa JAB, Plugge CM, Stams AJM, Bijmans MFM (2015) Sulfate reduction in a hydrogen fed bioreactor operated at haloalkaline conditions. Water Res 68:67-76.

van Houten RT, Hulshoff Pol LW, Lettinga G (1994) Biological sulphate reduction using gaslift reactors fed with hydrogen and carbon dioxide as energy and carbon source. Biotechnol Bioeng 44:586-594.

van Loosdrecht MCM, Lyklema J, Norde W, Schraa G, Zehnder AJB (1987) The role of bacterial cell wall hydrophobicity in adhesion. Appl Environ Microbiol 53:1893-1897.

Zhao B, Chen S (2012) Alkalitalea saponilacus gen. nov., sp. nov., an obligately anaerobic, alkaliphilic, xylanolytic bacterium from a meromictic soda lake. Int J Syst Evol Microbiol 62:2618-2623.

Zhao B, Yan Y, Chen S (2014) How could haloalkaliphilic microorganisms contribute to biotechnology? Can J Microbiol 60:717-727.

Zhilina TN, Garnova ES, Turova TP, Kostrikina NA, Zavarzin GA (2001) Amphibacillus fermentum sp. nov., Amphibacillus tropicus sp. nov.--new alkaliphilic, facultatively anaerobic, saccharolytic Bacilli from Lake Magadi. Microbiology 70:825-837.

Zhilina TN, Appel R, Probian C, Brossa EL, Harder J, Widdel F, Zavarzin GA (2004) Alkaliflexus imshenetskii gen. nov. sp. nov., a new alkaliphilic gliding carbohydrate- 
fermenting bacterium with propionate formation from a soda lake. Arch Microbiol 182:244-253.

Zhilina TN, Kevbrin VV, Tourova TP, Lysenko AM, Kostrikina NA, Zavarzin GA (2005) Clostridium alkalicellum sp. nov., an obligately alkaliphilic cellulolytic bacterium from a soda lake in the Baikal region. Microbiology 74:557-566.

Zhilina TN, Zavarzina DG, Panteleeva AN, Osipov GA, Kostrikina NA, Tourova TP, Zavarzin GA (2012) Fuchsiella alkaliacetigena gen. nov., sp. nov., an alkaliphilic, lithoautotrophic homoacetogen from a soda lake. Int J Syst Evol Microbiol 62:1666-1673.

Zhilina TN, Zavarzina DG, Kevbrin VV, Kolganova TV (2013) Methanocalculus natronophilus sp. nov., a new alkaliphilic hydrogenotrophic methanogenic archaeon from a soda lake, and proposal of the new family Methanocalculaceae. Microbiology 82:698-706.

Zhou J, Xing J (2015) Effect of electron donors on the performance of haloalkaliphilic sulfatereducing bioreactors for flue gas treatment and microbial degradation patterns related to sulfate reduction of different electron donors. Biochem Eng J 96:14-22.

Zvereva EA, Fedorova TV, Kevbrin VV, Zhilina TN, Rabinovich ML (2006) Cellulase activity of a haloalkaliphilic anaerobic bacterium, strain Z-7026. Extremophiles 10:53-60. 


\title{
Chapter 3
}

\section{Sulfate reduction in a hydrogen fed bioreactor operated at haloalkaline conditions}

\author{
João AB Sousa, Caroline M Plugge, \\ Alfons JM Stams, Martijn FM Bijmans
}

Published as:

Sousa JAB, Plugge CM, Stams AJM, Bijmans MFM (2015) Sulfate reduction in a hydrogen fed bioreactor operated at haloalkaline conditions. Water Res 68:67-76 


\section{Abstract}

Biological sulfate reduction is used as a biotechnological process to treat sulfate rich streams. However, application of biological sulfate reduction at high $\mathrm{pH}$ and high salinity using $\mathrm{H}_{2}$ was not thoroughly investigated before. In this work the sulfate reduction activity, biomass growth, microbial community and biomass aggregation were investigated in a $\mathrm{H}_{2}$-fed gas lift bioreactor at haloalkaline conditions. The process was characterized by low sulfate reduction volumetric rates due to slow growth and lack of biomass aggregation. Apparently, the extreme conditions and absence of organic compounds prevented the formation of stable aggregates. The microbial community analysis revealed a low abundance of known haloalkaliphilic sulfate reducers and presence of a Tindallia sp.. The identified archaea were related to Methanobacterium alcaliphilum and Methanocalculus sp. The biomass did not attach to metal sulfides, calcite and magnesite crystals. However, biofilm formation on the glass bioreactor walls showed that attachment to glass occurs. 


\section{Introduction}

Dissimilatory reduction of sulfate to sulfide is an important process in the biogeochemical cycling of sulfur and carbon (Jørgensen, 1982). Sulfate reducing bacteria (SRB) can oxidize hydrogen gas and various organic compounds using sulfate as electron acceptor (Muyzer and Stams, 2008; Rabus et al., 2013). Biological sulfate reduction is also used as a biotechnological process for treatment of sulfate- and heavy metal-rich effluents, wastes and waste streams (Muyzer and Stams, 2008). At pH neutral conditions high specific sulfate reduction rates have been achieved (van Houten et al., 1995; van Houten et al. 2006). Also application of biological sulfate reduction at extreme conditions like treatment of acidic mining effluents or high salinity waste streams have been previously investigated (Vallero et al., 2005; Bijmans et al., 2008).

The application of biological sulfate reduction to treat waste streams with both high $\mathrm{pH}$ (>8.5) and high salinity $\left(>1 \mathrm{M} \mathrm{Na}^{+}\right.$) was shown previously in a combined denitrification and sulfate reduction bioreactor (Zhou et al., 2014). Application of solely biological sulfate reduction at haloalkaline conditions, however, was never thoroughly investigated before. These conditions are present in biodesulfurization systems where sulfate reduction may be applied to treat sulfate-rich bleed streams. These extreme conditions are present in nature, only in soda lakes which are characterized by high $\mathrm{Na}$ carbonate/bicarbonate alkalinity resulting in stable high $\mathrm{pH}$ of the brines around 10 (Sorokin et al., 2011a). In these lakes, where pH can reach up to 11 and salinity up to $4 \mathrm{M} \mathrm{Na}^{+}$, sulfate reduction was shown to occur (Sorokin et al., 2010). The haloalkaliphilic SRB isolated from these lakes are represented by the three genera of lithotrophs (Desulfonatronovibrio, Desulfonatronum and Desulfonatronospira) and several VFA-utilizing SRB (Sorokin et al., 2012a, 2012b).

Information on in situ sulfate reduction activities in these extreme environments and optimal growth conditions for haloalkaliphilic SRB in pure culture already exists. Yet, there are no available studies on continuously operated bioreactors where haloalkaliphilic biomass is active. Information about volumetric and specific sulfate reduction activities, aggregation of biomass and adaptation are essential to successfully apply biological sulfate reduction under extreme haloalkaline conditions in biotechnological systems. 
We investigated the performance of a lab scale $\mathrm{H}_{2}$-fed gas lift bioreactor at haloalkaline conditions that could be applied to treat sulfate-rich bleed streams. The sulfate reduction activity rate, growth rate, structure of the microbial community and biomass aggregation were investigated during the bioreactor operation. The influence of the wall biofilm formation on the sulfate reduction activity and sulfide toxicity was also investigated. As there is no dedicated biomass available, inocula from combined natural and man-made high $\mathrm{pH}$ and high salinity sources were used to enrich for haloalkaliphilic hydrogenotrophic SRB.

\section{Methods}

\section{Bioreactor set-up}

A 4.4 I glass gas lift reactor with an internal 3 phase separator was used (Figure. 1). A water jacket connected to a thermostat bath (DC10-P5/U, Haake, Germany) was used to maintain the bioreactor temperature at $35^{\circ} \mathrm{C}$. The liquid feeding was performed by a membrane pump (Stepdos $08 \mathrm{RC}, \mathrm{KNF}-$ Verder, the Netherlands). The gas supply was controlled using $\mathrm{H}_{2}$ and $\mathrm{CO}_{2}$ digital mass flow controllers (F-201CV-020-AGD-22-V and F-201CV-020-AGD-22-Z, Bronkhorst, the Netherlands). For the gas recirculation a vacuum pump (Laboport $\AA$, KNF, Trenton, $\mathrm{NJ}$ ) was used and the gas flow measured using a flow meter (URM, Kobold, the Netherlands). A pH and an oxidation-reduction potential sensor (CPS11D and CPS12D, Endress+Hauser, the Netherlands) connected to a controller (Liquiline CM44x, Endress+Hauser, the Netherlands) were used to monitor the conditions inside the reactor. The $\mathrm{pH}$ was controlled at $\mathrm{pH} 9$ by supplying $\mathrm{CO}_{2}$ through the mass flow controller.

\section{Inoculum}

The bioreactor was inoculated with $50 \mathrm{ml}$ of biomass that was collected from a sulfate and thiosulfate (1/1 mol ratio) reducing gas-lift bioreactor with 3 phase separator fed with $\mathrm{H}_{2}$ and $\mathrm{CO}_{2}$, with the same set-up as described in Figure 1. This bioreactor was operated for 3 months with $150 \mathrm{mM}$ (total $\mathrm{S}$ loading) and the biomass was collected 
and washed with anoxic carbonate/bicarbonate buffer $\left(\mathrm{pH} 9,1.5 \mathrm{M} \mathrm{Na}^{+}\right)$. The original inoculum used for this bioreactor is a mix of sediments and sludge listed in Table A.1 in supplementary data. From each sediment $20 \mathrm{~g}$ (wet weight) and from each sludge type $10 \mathrm{ml}$ were added to start the reactor.

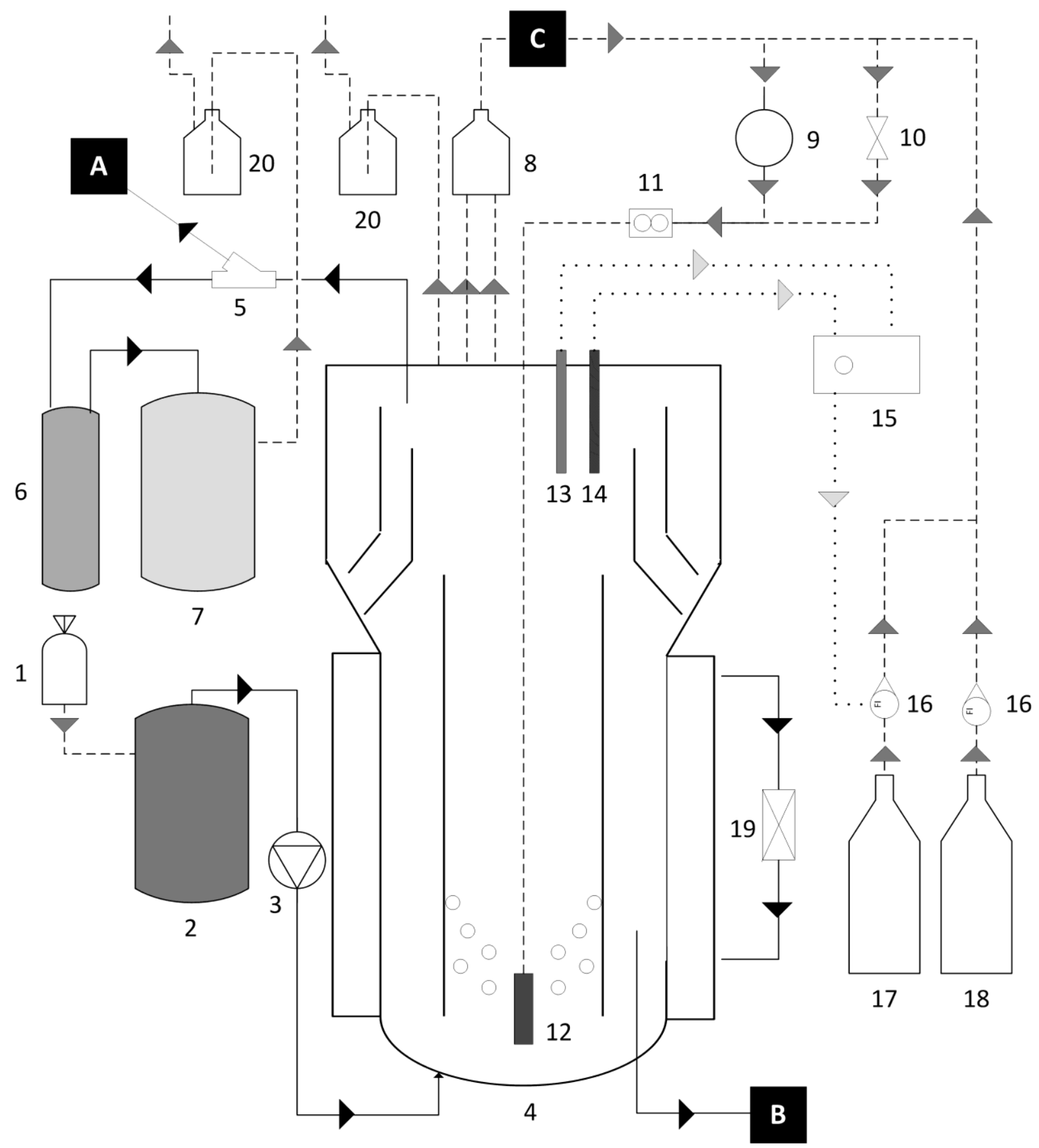

Figure 1 - Scheme of the gas-lift bioreactor set-up. A - outlet sampling point; B - biomass sampling point; $\mathrm{C}$ - gas sampling point; 1 - $\mathrm{N}_{2}$ gas bag; 2 - medium bottle; 3 - membrane pump; 4 - gas-lift bioreactor with 3 phase separator; 5 - sampling valve; 6 - long water lock; 7 - effluent 
bottle; 8 - condenser; 9 - vacuum pump; 10 - gas flow adjusting valve; 11 - gas flow meter; 12 - diffuser; 13 - ORP sensor; 14 - pH sensor; 15 - controller; 16 - mass flow controller; 17 - $\mathrm{CO}_{2}$ gas bottle; 18 - $\mathrm{H}_{2}$ gas bottle; 19 - thermostat bath; 20 - water lock.

\section{Medium}

A mineral medium that was buffered at $\mathrm{pH} 9( \pm 0.05)$ with sodium carbonate and sodium bicarbonate and with a total of $1.5 \mathrm{M} \mathrm{Na}^{+}$was used. The medium composition was as follows: $\mathrm{Na}_{2} \mathrm{CO}_{3}\left(33.6 \mathrm{~g} \mathrm{l}^{-1}\right), \mathrm{NaHCO}_{3}\left(69.3 \mathrm{~g} \mathrm{l}^{-1}\right), \mathrm{KHCO}_{3}\left(1 \mathrm{~g} \mathrm{l}^{-1}\right), \mathrm{K}_{2} \mathrm{HPO}_{4}(1 \mathrm{~g}$ $\left.\mathrm{l}^{-1}\right), \mathrm{NH}_{4} \mathrm{Cl}\left(0.27 \mathrm{~g} \mathrm{l}^{-1}\right), \mathrm{MgCl}_{2} .6 \mathrm{H}_{2} \mathrm{O}\left(0.1 \mathrm{~g} \mathrm{l}^{-1}\right), \mathrm{CaCl}_{2} .2 \mathrm{H}_{2} \mathrm{O}\left(0.01 \mathrm{~g} \mathrm{l}^{-1}\right)$ and $10 \mathrm{ml} \mathrm{l}^{-1}$ of vitamin solution (Wolin et al., 1963). Two trace (TE) element solutions with the following composition were mixed together and $1 \mathrm{ml}$ added: TE1 - sodium EDTA $\left(1000 \mathrm{mg} \mathrm{l}^{-1}\right)$, $\mathrm{FeCl}_{2} .4 \mathrm{H}_{2} \mathrm{O}\left(370 \mathrm{mg} \mathrm{l}^{-1}\right), \mathrm{H}_{3} \mathrm{BO}_{3}\left(60 \mathrm{mg} \mathrm{l}^{-1}\right), \mathrm{MnCl}_{2} .2 \mathrm{H}_{2} \mathrm{O}\left(26 \mathrm{mg} \mathrm{l}^{-1}\right), \mathrm{CoCl}_{2} .6 \mathrm{H}_{2} \mathrm{O}(40$ $\left.\mathrm{mg} \mathrm{l}^{-1}\right), \mathrm{ZnCl}_{2}\left(10 \mathrm{mg} \mathrm{l}^{-1}\right), \mathrm{CuCl}_{2}\left(3 \mathrm{mg} \mathrm{l}^{-1}\right), \mathrm{KAl}\left(\mathrm{SO}_{4}\right)_{2} .12 \mathrm{H}_{2} \mathrm{O}\left(32 \mathrm{mg} \mathrm{l}^{-1}\right), \mathrm{NiCl}_{2} .6 \mathrm{H}_{2} \mathrm{O}(31$ $\left.\mathrm{mg} \mathrm{l}^{-1}\right)$; TE2 - NaOH (40 mg l-1), $\mathrm{Na}_{2} \mathrm{SiO}_{3} .5 \mathrm{H}_{2} \mathrm{O}\left(10 \mathrm{mg} \mathrm{l}^{-1}\right), \mathrm{Na}_{2} \mathrm{MoO}_{4} .2 \mathrm{H}_{2} \mathrm{O}\left(10 \mathrm{mg} \mathrm{l}^{-}\right.$ $\left.{ }^{1}\right), \mathrm{Na}_{2} \mathrm{SeO}_{3} .5 \mathrm{H}_{2} \mathrm{O}\left(10 \mathrm{mg} \mathrm{l}^{-1}\right), \mathrm{Na}_{2} \mathrm{WO}_{4} .2 \mathrm{H}_{2} \mathrm{O}\left(10 \mathrm{mg} \mathrm{l}^{-1}\right)$. As electron acceptor, $7.1 \mathrm{~g}$ $(50 \mathrm{mM})$ of sodium sulfate $\left(\mathrm{NaSO}_{4}\right)$ was added.

\section{Experimental design}

The bioreactor was filled with medium and flushed with hydrogen gas over night with gas recirculation to lower the redox potential. The hydrogen gas supply was set to 5 $\mathrm{ml} \mathrm{min}{ }^{-1}$, the gas recirculation to $2.5 \mathrm{I} \mathrm{min}^{-1}$ and the $\mathrm{pH}$ control set at $\mathrm{pH}$ 9. Inoculation of the reactor was defined as time 0 . A batch run was performed to start-up the bioreactor and verify the biomass sulfate reduction activity (Start-up, Table 1). Three continuous experiments (Run 1, 23) with different hydraulic retention times (HRT) were performed as described in Table 1. Two batch experiments, biofilm run and sulfide toxicity run, were performed to investigate the contribution of the bioreactor wall biofilm to the sulfate reduction activity and the toxicity of high sulfide concentrations (Table 1). In the biofilm run, the suspended biomass was removed leaving only the biofilm in the bioreactor and fresh medium was added. In the sulfide toxicity run, the biofilm was removed and only suspended biomass was used in the same concentration as measured during the continuous runs, approximately $5 \mathrm{mg} \mathrm{l}^{-1}$. 
Table 1 - Operational differences between the bioreactor runs performed

\begin{tabular}{|c|c|c|c|c|c|}
\hline Run & Period (d) & Mode & HRT (d) & $\begin{array}{l}\mathrm{SO}_{4}{ }^{2-} \text { loading } \\
\text { rate }\left(\mathrm{mmol} \mathrm{d}^{-1}\right)\end{array}$ & $\begin{array}{c}\mathrm{SO}_{4}^{2-} \\
\text { concentration } \\
(\mathrm{mM})\end{array}$ \\
\hline Start-up & $0-13$ & Batch & N.A. ${ }^{a}$ & N.A. ${ }^{a}$ & 50 \\
\hline Run 1 & $15-123$ & Continuous & 5 & 10 & N.A. ${ }^{a}$ \\
\hline Run 2 & $124-147$ & Continuous & 2.5 & 20 & N.A. ${ }^{a}$ \\
\hline Run 3 & $148-155$ & Continuous & 3.3 & 15 & N.A. ${ }^{a}$ \\
\hline Biofilm run & $6^{b}$ & Batch & N.A. ${ }^{a}$ & N.A. ${ }^{a}$ & 50 \\
\hline $\begin{array}{l}\text { Sulfide toxicity } \\
\text { run }\end{array}$ & $70^{\mathrm{b}}$ & Batch & N.A. ${ }^{a}$ & N.A. ${ }^{a}$ & 500 \\
\hline
\end{tabular}

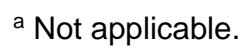

${ }^{\mathrm{b}}$ Duration of the batch test.

\section{Analytical procedures}

Samples for organic acids analysis were filtered through $0.4 \mu \mathrm{m}$ pore size filters and quantified using ultra-high performance liquid chromatography (Dionex ultimate 3000RS, Thermo scientific, USA) equipped with a Phenomenex Rezex Organic Acid $\mathrm{H}^{+}$column ( $300 \times 7.8 \mathrm{~mm}$ ). $2.5 \mathrm{mM}$ sulfuric acid was used as mobile phase with a flow rate of $0.5 \mathrm{ml} \mathrm{min}^{-1}$ at $80^{\circ} \mathrm{C}$. The UV detector was set at $210 \mathrm{~nm}$.

Samples for sulfide and sulfate analysis were stabilized with zinc acetate $(0.2 \mathrm{M})$ in a 1:1 ratio immediately after sampling. Sulfide was analyzed using a cuvette test (LCK653, Hach Lange, Germany). For sulfate analysis the sample was filtered through $0.4 \mu \mathrm{m}$ pore size filters and analyzed by ion chromatography (761 compact IC with a 762 IC interface, Metrohm, Switzerland). The IC was equipped with a conductivity detector. A pre-column (Metrosep A sup 4/5 guard) and column (Metrosep A sup 5) were used. A chemical suppressor (Metrohm, Switzerland), $\mathrm{CO}_{2}$ suppressor (type 853, Metrohm, Switzerland) and conductivity detector were used. The mobile phase composed of $3.2 \mathrm{mM}$ sodium carbonate and $1 \mathrm{mM}$ sodium bicarbonate $+1 \%$ acetone $+5 \mu \mathrm{M} \mathrm{IO}_{3}$ was used with a $0.7 \mathrm{ml} \mathrm{min}^{-1}$ flow rate. The liquid suppressor consisted of 
$50 \mathrm{mM}$ sulfuric acid $+1 \%$ acetone Milli-Q water $+1 \%$ acetone and was with a $0.4 \mathrm{ml}$ $\min ^{-1}$ flow rate.

Gaseous compounds $\left(\mathrm{H}_{2}, \mathrm{CO}_{2}, \mathrm{~N}_{2}\right.$ and $\left.\mathrm{CH}_{4}\right)$ were analyzed by gas chromatography using a microGC (CP-4900, Varian, CA) equipped with a TCD detector. Argon was applied as carrier gas at a flow rate of $1.47 \mathrm{ml} \mathrm{min}^{-1}$. The injector, and detector temperature were $105^{\circ} \mathrm{C}$ and $100^{\circ} \mathrm{C}$, respectively. The microGC cabinet was set at $40^{\circ} \mathrm{C}$ and $100.4 \mathrm{kPa}$. $\mathrm{H}_{2}$ and $\mathrm{N}_{2}$ were analyzed with a Mol Sieve 5A PLOT column at at $80^{\circ} \mathrm{C}$ and $150 \mathrm{kPa}$ and $\mathrm{CO}_{2}$ and $\mathrm{CH}_{4}$ were analyzed with a PoraPlot $\mathrm{U}$ column at $65^{\circ} \mathrm{C}$ and $150 \mathrm{kPa}$.

The biomass content was analyzed using the total nitrogen (total N). Samples (10 ml) for biomass measurement were centrifuged (10 min, 7500g) and washed 3 times with carbonate/bicarbonate buffer $\left(\mathrm{pH} 9,1.5 \mathrm{M} \mathrm{Na}^{+}\right)$to remove dissolved nitrogen compounds. The total $\mathrm{N}$ concentration was determined using a cuvette test (LCK238, Hach Lange, Germany).

Particle size was measured using laser measurement in a particle size and shape analyzer (Eyetech, Doner technologies, Israel) with the Dipa 2000 software (Doner technologies, Israel). Measurements were done in triplicate for $120 \mathrm{~s}$ with stirring. Microscopy pictures were taken using a light microscope (DMI6000B, Leica, Germany).

\section{Scanning electron microscopy (SEM)}

Biomass samples were fixed in $2.5 \%(\mathrm{w} / \mathrm{v})$ glutaraldehyde overnight at $4{ }^{\circ} \mathrm{C}$. The fixed samples were washed twice with carbonate/bicarbonate buffer $\left(\mathrm{pH} 9,1.5 \mathrm{M} \mathrm{Na}^{+}\right)$and then dehydrated in a series of ethanol solutions $(10 \%, 25 \%, 50 \%, 75 \%, 90 \%$ and twice $100 \%)$ with 20 minutes in each step. The samples were dried in a desiccator. The samples were coated with gold and analyzed in a JEOL JSM-6480LV Scanning Electron Microscope. Energy-dispersive X-ray spectroscopy (EDX) analysis was performed using a NORAN Systems SIX (Thermo Scientific, USA). 


\section{DNA extraction and amplification}

Samples $(50 \mathrm{ml})$ for DNA analysis were centrifuged $(10 \mathrm{~min}, 7500 \mathrm{~g}$ ), the biomass

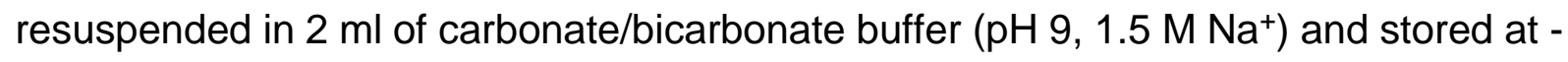
$80^{\circ} \mathrm{C}$. Total genomic DNA was extracted using the PowerBiofilm ${ }^{\mathrm{TM}}$ DNA Isolation Kit (MoBio, USA) following the manufacturer's instructions. Bacterial 16S rRNA genes were amplified by PCR using a Taq DNA polymerase kit (Invitrogen, Carlsbad, USA) and Primer sets U968f/L1401r and Bact27f/Uni1492r were used for 16S rRNA gene amplification for denaturing gradient gel electrophoresis (DGGE) and sequencing purposes, respectively (Lane, 1991; Nübel et al., 1996). A 40 bp GC-clamp was added at the 5' end sequence of the primer U968-f. For archaeal 16S rRNA genes the A109(T)f/GC515r and A109f/Uni1492r primers sets were used for DGGE and sequencing purposes, respectively (Großkopf et al., 1998; Lane, 1991). The PCR program used for DGGE was: initial denaturation for $2 \mathrm{~min}$; 35 cycles of $30 \mathrm{~s}$ denaturation at $95^{\circ} \mathrm{C}, 40 \mathrm{~s}$ at $56^{\circ} \mathrm{C}$ for annealing and $1.5 \mathrm{~min}$ elongation step at $72^{\circ} \mathrm{C}$; $7 \mathrm{~min}$ at $72^{\circ} \mathrm{C}$ of post-elongation step. PCR settings for cloning were as described above except that a total number of 25 cycles and an annealing temperature of $52^{\circ} \mathrm{C}$ were used.

\section{DGGE analysis}

Biodiversity of the sulfate plus thiosulfate run and the different operational periods of the sulfate reducing bioreactor described in this study (Table 1) was visualized on DGGE. DGGE analysis of the PCR products was performed by using the DCode system (Bio-Rad, Hercules, CA, USA). Gels containing $8 \%(\mathrm{w} / \mathrm{v})$ polyacrylamide (37.5:1 acrylamide/bis-acrylamide) were used with a linear denaturing gradient of 30$60 \%$, with $100 \%$ of denaturant corresponding to $7 \mathrm{M}$ urea and $40 \%(\mathrm{v} / \mathrm{v})$ formamide. Electrophoresis was performed for $16 \mathrm{~h}$ at $85 \mathrm{~V}$ and $60^{\circ} \mathrm{C}$ in a $0.5 \mathrm{x}$ Tris-Acetate-EDTA buffer. DGGE gels were stained with silver nitrate (Sanguinetti et al., 1994), scanned and the band profiles were analyzed using Bionumerics ${ }^{\circledR}$ software (Applied Maths, USA). 


\section{Cloning, sequencing and phylogenetic analysis}

The 16S rRNA of the final biomass (day 155) from the bioreactor operation was amplified for cloning. The amplicons purified using the ssDNA/RNA Clean \& Concentrator (Zymo Research, USA) and ligated into the pGEM-T Easy Vector System I (Promega, Madison, MI, USA) and cloned in XL-1 blue competent Escherichia coli cells (Stratagene, USA) and grown on LB-agar with $100 \mathrm{mg} \mathrm{l}^{-1}$ ampicillin, $0.1 \mathrm{mM}$ isopropyl-1-thio- $\beta$-D-galactopyranoside (X-gal). 96 Positive transformants were selected (by blue/white screening) and were transferred to solid LB medium with 100 $\mathrm{mg} \mathrm{l}^{-1}$ ampicilin and incubated overnight at $37^{\circ} \mathrm{C}$. 96 bacterial clones and 96 archaeal clones were sent for sequencing of the 16S rRNA gene insert (Baseclear BV, the Netherlands) using the primers sets Bact27f/Univ1492r and A109f/Uni1492r (Großkopf et al., 1998; Lane, 1991). The DNA sequences were analyzed using Chromas (ver. 2.32, Technelysium). From the 96 clones, 67 good sequences were obtained and were used. Similarity searches for 16S rRNA gene sequences derived from the clones were performed using the NCBI BLAST search program within the GenBank database (http://www.ncbi.nlm.nih.gov/blast/).

\section{Calculations}

Assumptions:

The bioreactor liquid volume is constant during the operation which means that the liquid flow that goes into the bioreactor is equal to the liquid flow getting out of the bioreactor $\left(\varnothing_{\text {in }}=\varnothing_{\text {out }}\right)$.

Sulfur compounds accumulation in the bioreactor, by incorporation in biomass and formation of sulfide precipitates, is assumed to play a minor role due to the high sulfate concentration in the influent and is not taken into account.

The $\mathrm{N}$ fraction value of 0.2 was used to calculate biomass concentration based on total $\mathrm{N}$, following the biomass molecular formula: $\mathrm{C}_{1} \mathrm{H}_{1.8} \mathrm{O}_{0.5} \mathrm{~N}_{0.2}$

For suspended biomass doubling time, biomass retention in the bioreactor was not taken into account since aggregation did not occur. The bioreactor ran as a continuous stirred tank reactor for which the suspended biomass doubling time equals the HRT. 


$$
\begin{aligned}
& C_{x}=\frac{C_{\text {TotalN }}}{0.2} \cdot M_{x} \\
& \mu=H R T \\
& r_{v}=\frac{\emptyset \cdot C_{s, \text { in }}-\emptyset \cdot C_{s, \text { out }}}{V_{r}}
\end{aligned}
$$

Nomenclature:

$\begin{array}{ll}C_{x} & \text { Biomass concentration }\left(\mathrm{g} \mathrm{l}^{-1}\right) \\ C_{t n} & \text { Total Nitrogen concentration }\left(\mathrm{mol} \mathrm{l}^{-1}\right) \\ \mathrm{M}_{\mathrm{x}} & \text { Biomass molecular weight }\left(\mathrm{g} \mathrm{mol}^{-1}\right) \\ \mathrm{r}_{v} & \text { Volumetric activity }\left(\mathrm{mmol} \mathrm{Ir}^{-1} \mathrm{~d}^{-1}\right) \\ \varnothing & \text { Flow rate }\left(\mathrm{I} \mathrm{d}^{-1}\right) \\ C_{s} & \text { Sulfate concentration }\left(\mathrm{mmol} \mathrm{l}^{-1}\right) \\ \mathrm{V}_{\mathrm{r}} & \text { Bioreactor volume }(\mathrm{l}) \\ \mu & \text { Suspended biomass growth rate }(\mathrm{d})\end{array}$

Subscript:

$\begin{array}{cc}x & \text { Biomass } \\ r & \text { Reactor } \\ \text { in } & \text { Influent } \\ \text { out } & \text { Effluent }\end{array}$

TotalN Total nitrogen 


\section{Results \& Discussion}

\section{Reactor operation}

The continuous cultivation of hydrogenotrophic sulfate-reducing biomass in a bioreactor at haloalkaline conditions was shown. This process was characterized by the absence of biomass aggregation which prevented biomass retention in the bioreactor. As consequence, the biomass growth rate $(\mu)$ was the main parameter affecting the biomass concentration $\left(C_{x}\right)$ which was low (Figure $\left.2 c\right)$. Because of this, the maximum sulfate volumetric reduction rate $\left(r_{v}\right)$ of $18 \mathrm{mmol} \mathrm{l}^{-1} \mathrm{~d}^{-1}$ (Figure. 2b) was lower than previously reported for a full-scale sulfate reducing bioreactor operating at neutral conditions, $200 \mathrm{mmol} \mathrm{l}^{-1} \mathrm{~d}^{-1}$ (van Houten et al., 2006). The biomass could tolerate up to $266 \mathrm{mM}$ of sulfide (Figure. 3), which is higher than the maximum naturally occurring sulfide concentrations measured in the Soap Lake where an active biological sulfur cycle takes place with sulfide concentration up to $200 \mathrm{mM}$ ( Sorokin et al., 2007; Sorokin et al., 2011a). Because $\mathrm{H}_{2} \mathrm{~S}$ is the main toxic sulfide species and its pKa value is 7 , at $\mathrm{pH} 9$ it represents only $0.4 \%$ of the total sulfide. This might explain the high sulfide tolerance of the biomass compared to lower pH conditions (Bijmans et al., 2008; van Houten et al., 1995). The HS species was also suggested to be toxic by precipitating essential metals to microorganisms. In this study, even though metal precipitation did occur, no toxic effect was observed. 

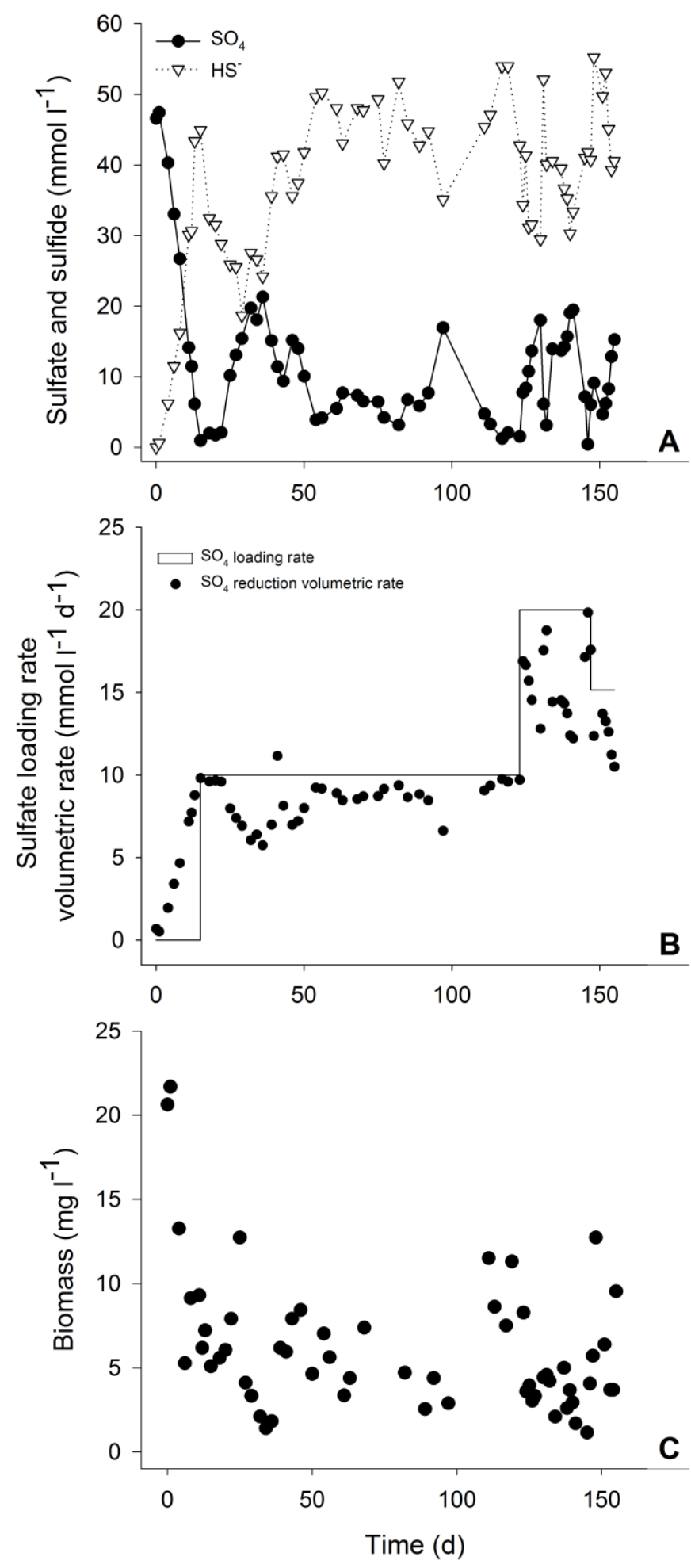

Figure 2 - Sulfate, sulfide and biomass concentration, sulfate loading rate and sulfate volumetric reduction rate during start-up and continuous run of the $\mathrm{H}_{2}$ fed sulfate reducing gaslift bioreactor operated at haloalkaline conditions (Start-up, Run 1, Run 2 and Run 3). A Sulfate and sulfide concentrations in the bioreactor effluent. B - Sulfate loading rate and sulfate reduction volumetric rate. $\mathrm{C}$ - Biomass concentration $\left(\mathrm{C}_{\mathrm{x}}\right)$ in the bioreactor. 


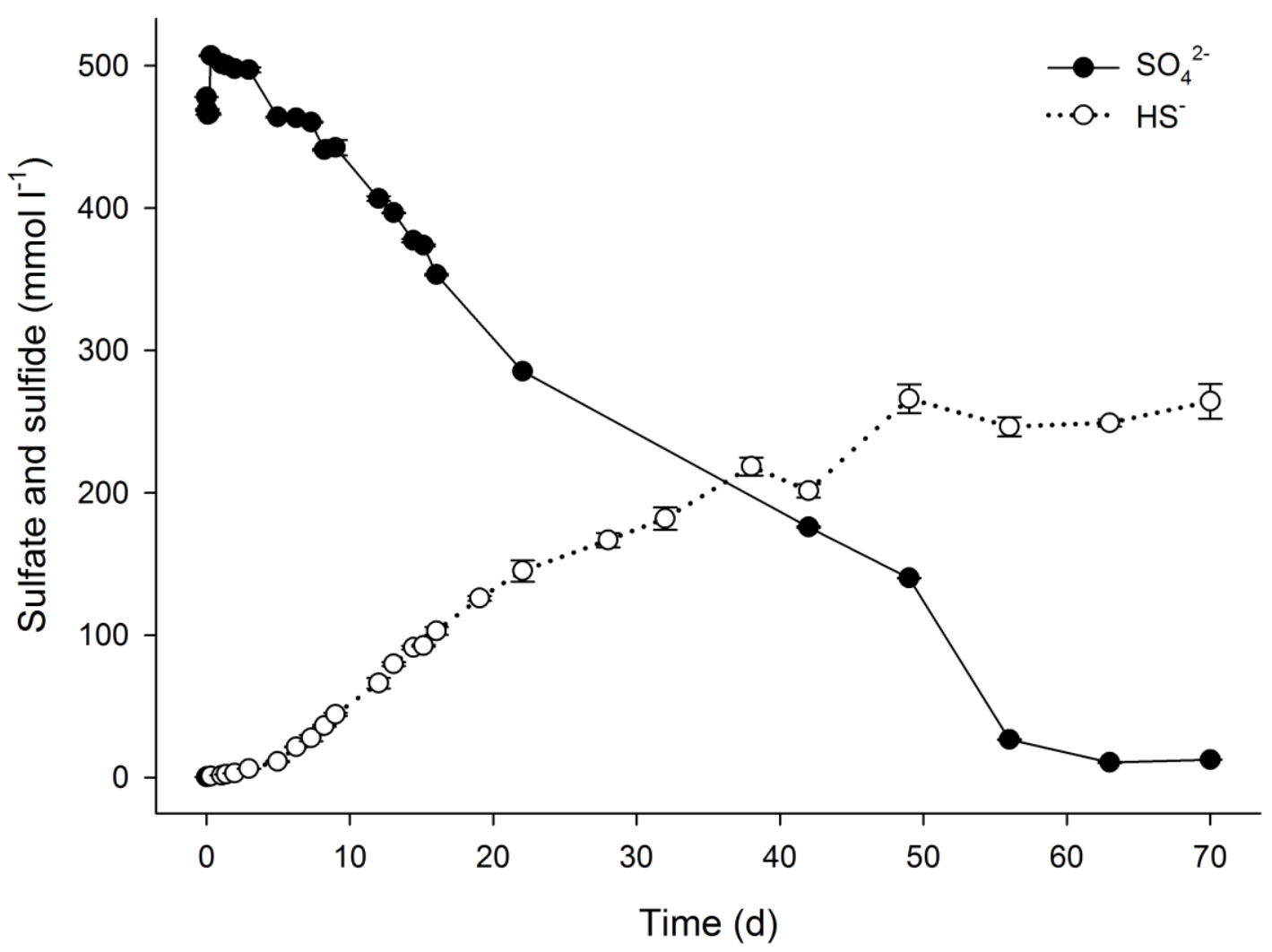

Figure 3 - Sulfate and sulfide concentration during the sulfide run.

\section{Microbial community}

The microbial community was constant during the continuous runs (Run 1, 2 and 3) and only one DGGE band decreased in intensity when the $2.5 \mathrm{~d}$ HRT was used in Run 2 (Figure 4). This indicates that at $2.5 \mathrm{~d} \mathrm{HRT} \mathrm{a} \mathrm{major} \mathrm{player} \mathrm{in} \mathrm{sulfate} \mathrm{reduction} \mathrm{activity}$ was flushed out of the bioreactor, which is shown by the decrease in sulfate reduction activity (Figure $2 \mathrm{a}$ and $2 \mathrm{~b}$ ). The main clones of sulfate reducing bacteria detected in the biomass from the bioreactor, closely related to the haloalkaliphilic SRB Desulfonatronospira delicata, Desulfonatronospira thiodismutans and Desulfonatronovibrio sp. (Table 2), were previously isolated from Siberian soda lakes (Sorokin et al., 2008a; Sorokin et al., 2011b). 


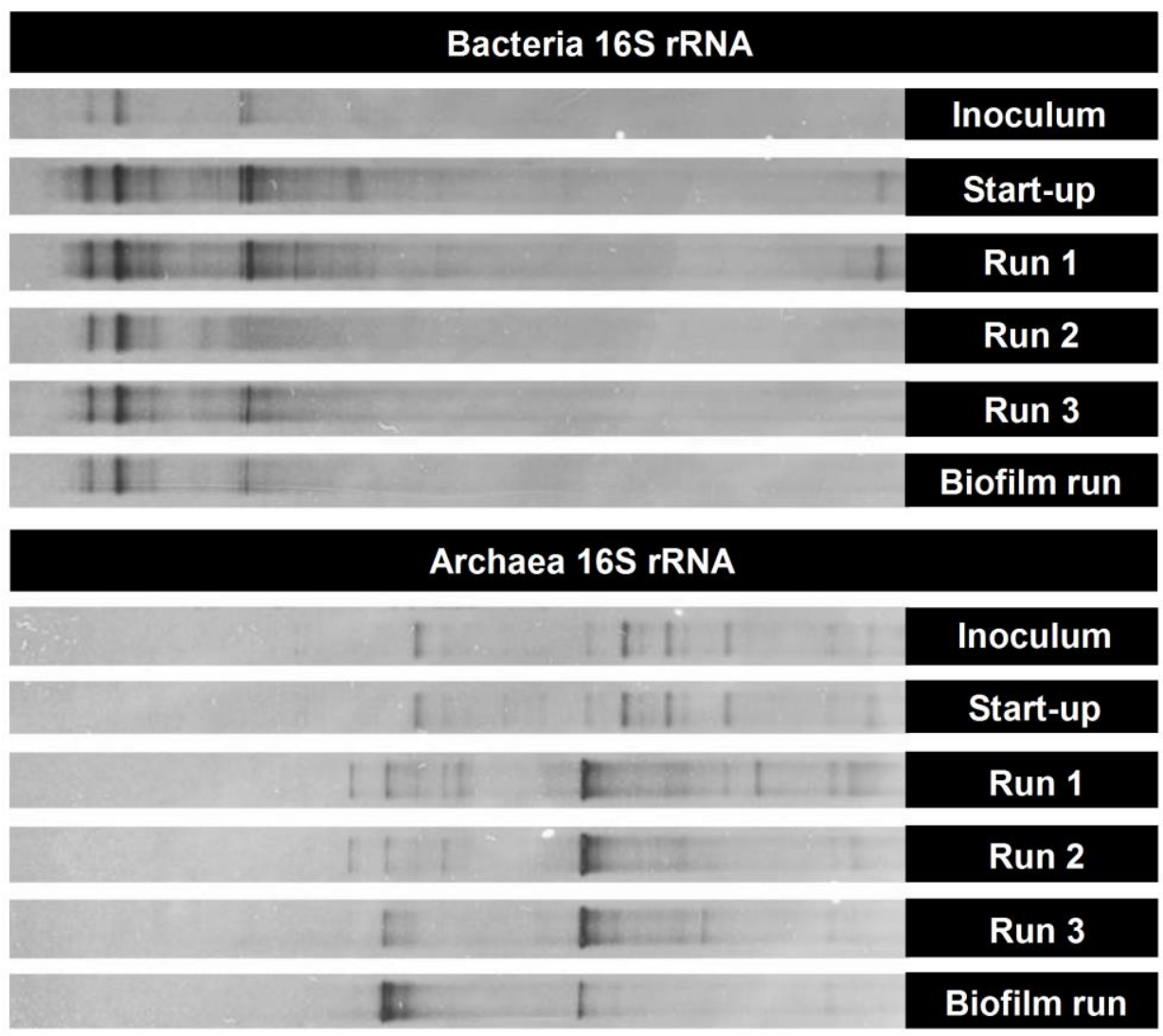

Figure 4 - Bacteria and Archaea 16S rRNA DGGE profiles from inoculum enriched with sulfate and thiosulfate, biomass at the end of start-up, run 1,2 and 3 , and biofilm run.

Bacterial clone library analysis also revealed the presence of a clostridium belonging to the genus Tindallia (54 out of 67 clones, max. 97\% identity with T. texcoconensis). This suggests that this clostridium has the ability to grow lithoautotrophically though Tindallia texcoconensis was described as a fermentative bacterium (Alazard et al., 2007). However, hydrogenase and CO-dehydrogenase activity in Tindallia magadiensis and Tindallia californiensis suggest an active homoacetic pathway (Pikuta et al. 2003). Sorokin et al. (2011c) also showed that a Tindallia isolate from soda lakes produced formate from $\mathrm{H}_{2}$ and $\mathrm{CO}_{2}$. The Tindallia sp. found in this study might also be involved in the observed formate production or production of acetate that even though was not measured, might be present in low concentrations. 
Table 2 - Bacteria clones sequenced and their similarity with their closest relative.

\begin{tabular}{|c|c|c|c|c|}
\hline Closest relative & $\begin{array}{c}\text { Max. } \\
\text { Identity } \\
(\%)\end{array}$ & $\begin{array}{c}\text { № of } \\
\text { clones } \\
\text { (total 67) }\end{array}$ & Metabolism & $\begin{array}{c}\text { Accession } \\
\text { number }\end{array}$ \\
\hline $\begin{array}{l}\text { Tindallia texcoconensis } \\
\text { strain IMP-300 }\end{array}$ & 97 & 54 & Fermentation & NR 043664 \\
\hline $\begin{array}{l}\text { Desulfonatronospira } \\
\text { delicata strain AHT } 6\end{array}$ & 99 & 4 & $\begin{array}{l}\text { Sulfate reduction \& } \\
\text { thiosulfate and sulfite } \\
\text { disproportionation }\end{array}$ & NR 044460 \\
\hline $\begin{array}{l}\text { Desulfonatronovibrio sp. } \\
\text { AHT } 10\end{array}$ & 99 & 2 & Thiosulfate reducer & FJ469580 \\
\hline $\begin{array}{l}\text { Desulfonatronospira } \\
\text { thiodismutans ASO3-1 }\end{array}$ & 98 & 2 & $\begin{array}{l}\text { Sulfate reduction \& } \\
\text { thiosulfate and sulfite } \\
\text { disproportionation }\end{array}$ & NR 044459 \\
\hline $\begin{array}{l}\text { Desulfonatronovibrio sp. } \\
\text { AHT22 }\end{array}$ & 96 & 1 & $\begin{array}{c}\text { Sulfate reduction \& } \\
\text { thiosulfate } \\
\text { disproportionation }\end{array}$ & GU196831 \\
\hline $\begin{array}{l}\text { Uncultured low } \mathrm{G}+\mathrm{C} \\
\text { Gram-positive bacterium } \\
\text { clone ML635J-4 }\end{array}$ & 97 & 1 & N.D. ${ }^{a}$ & AF507887 \\
\hline $\begin{array}{l}\text { Uncultured } \\
\text { Clostridiisalibacter sp. } \\
\text { Clone } 328\end{array}$ & 94 & 1 & N.D. ${ }^{a}$ & GU202952 \\
\hline $\begin{array}{l}\text { Uncultured CFB group } \\
\text { bacterium clone } \\
\text { ML1228J-16 }\end{array}$ & 97 & 1 & N.D. ${ }^{a}$ & AF449766 \\
\hline $\begin{array}{l}\text { Uncultured organism } \\
\text { clone SBXZ_5781 }\end{array}$ & 85 & 1 & N.D. ${ }^{a}$ & JN436861 \\
\hline
\end{tabular}

${ }^{a}$ No data available. 
Table 3 - Archaea clones sequenced and their similarity with their closest relative.

\begin{tabular}{lcccc}
\hline Closest relative & $\begin{array}{c}\text { Max. } \\
\text { Identity } \\
(\%)\end{array}$ & $\begin{array}{c}\text { Number of } \\
\text { clones } \\
\text { (total 61) }\end{array}$ & Metabolism & $\begin{array}{c}\text { Accession } \\
\text { number }\end{array}$ \\
\hline $\begin{array}{l}\text { Methanobacterium } \\
\text { alcaliphilum }\end{array}$ & 99 & 53 & Methanogenesis & AB496639 \\
$\begin{array}{l}\text { Methanocalculus sp. } \\
\text { LA5 }\end{array}$ & 99 & 2 & Methanogenesis & DQ987523 \\
$\begin{array}{l}\text { Uncultured archaeon } \\
\text { clone MOB4-4 }\end{array}$ & 99 & 2 & N.D, a & DQ841230 \\
$\begin{array}{l}\text { Methanocalculus sp. } \\
\text { LA7 }\end{array}$ & 99 & 1 & Methanogenesis & DQ987524 \\
$\begin{array}{l}\text { Uncultured } \\
\begin{array}{l}\text { Methanolobus sp. clone } \\
\text { IV-A3 }\end{array}\end{array}$ & 99 & 1 & N.D. ${ }^{\text {a }}$ & EU546840 \\
\hline
\end{tabular}

${ }^{\text {a }}$ No data available.

The Desulfonatronovibrio sp. closely related to the clones identified in this study are heterotrophic, requiring acetate for growth (Sorokin et al. 2011b). This indicates that acetate production and consumption in the bioreactor may occur. The presence of unknown biodiversity other than sulfate reducers and Tindallia sp. also indicates that fermenters might be active in the biomass (Table 2). Archaeal clone library analysis revealed the presence clones closely related to Methanobacterium alcaliphilum (99\% identity), a moderately alkaliphilic hydrogenotrophic methanogen (Worakit et al., 1986), and Methanocalculus sp., a haloalkaliphilic hydrogenotrophic methanogen. Since no methane was detected during the continuous runs (Run 1, 2 and 3) but only in the biofilm run, these archaea likely only play a minor role in the bioreactor $\mathrm{H}_{2}$ consumption and performance.

\section{Biomass aggregation}

The biomass concentration $\left(C_{x}\right)$ obtained in this research (Figure 1c) was lower than reported in previous studies where $10^{3}$ fold higher concentrations of volatile suspended solids were obtained (Bijmans et al., 2008; van Houten et al., 1995). Actually, a big fraction of the sulfate reduction activity was performed by the biofilm on the bioreactor 
glass wall and not by the suspended biomass (Figure 5). This low suspended biomass concentration is explained by the slow suspended biomass growth rate, 3.3 days, and the absence of aggregation. The particle size distribution obtained matches the size of single microbes revealing that the biomass was suspended and not aggregated (Figure 6). Aggregated biomass is usually obtained by applying the liquid up-flow velocity as a selection force (Alphenaar et al., 1993). In the current study no aggregation was observed even though a 3 phase separator was used to apply a controlled liquid upflow velocity ( $1 \mathrm{~m} \mathrm{hr}^{-1}$ in run $1,2 \mathrm{~m} \mathrm{hr}^{-1}$ in run 2, $1.7 \mathrm{~m} \mathrm{hr}^{-1}$ in run 3 ) and biomass separation to select for aggregated biomass. Aggreagated biomass has previously been used in sulfate reducing bioreactors at neutral conditions (van Houten et al. 1995; van Houten et al. 2006; Sipma et al. 2006). Also, in studies at more extreme conditions, like low $\mathrm{pH}$ and high $\mathrm{NaCl}$ concentrations, aggregation was observed (van Houten et al. 1995; Vallero et al. 2004; Bijmans 2008). This indicates that the haloalkaline conditions used may prevent a stable microbial aggregation.

The first stage of bacterial aggregation has been explained by the thermodynamic approach using the extended DLVO theory (van Oss, 1989,1993). According to this theory, at high salt concentrations the formation of a condensed electrical double layer by the high amount of cations may minimize repulsion forces that are usually an obstacle for aggregation. It was shown, however, that Escherichia coli aggregation starts to decrease at higher salt concentrations (> $0.185 \mathrm{M}$ ionic strength) (Otto et al., 1999). The pH may also affect the hydrophobicity which has been shown to affect attachment of Escherichia coli (Otto et al., 1999). Such effects in haloalkaline conditions might prevent initial nucleation between microorganisms, which is essential for aggregates formation. Biofilm formation, however, was observed on the bioreactor glass walls. The shear forces near the bioreactor wall and the properties of glass may have provided conditions to overcome the challenges of haloalkaline conditions and promote biofilm formation. 


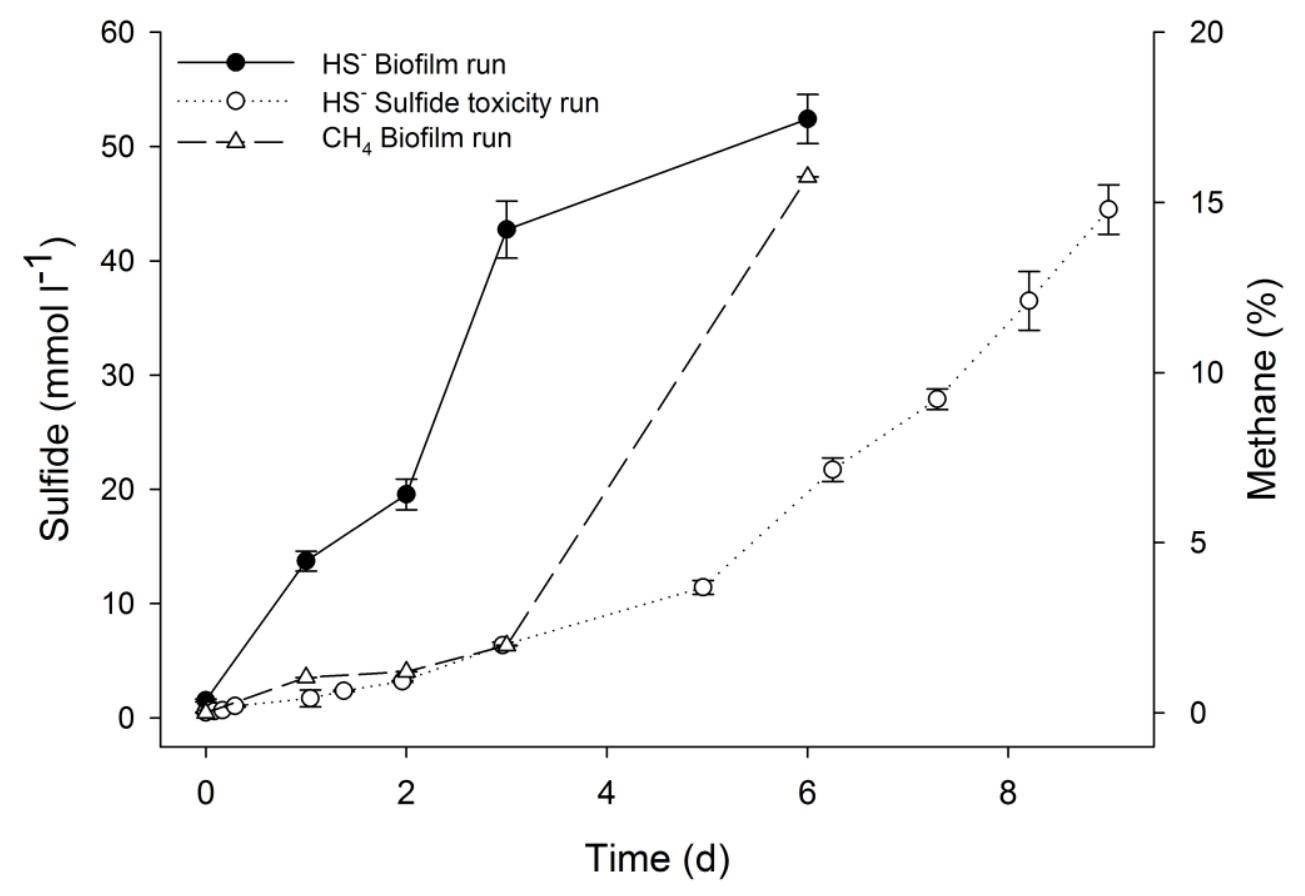

Figure 5 - Sulfide concentration during the batch runs (Biofilm run and Sulfide run) and methane fraction in the gas phase during Biofilm run.

These phenomena only explain the moment when bacteria encounter each other or a support material. Thus, this also does not explain why aggregates present in the inoculum used in this study could not resist the shear forces in the bioreactor. This can be seen by the bigger particle size of the inoculum compared to the biomass growing in the bioreactor (Figure 6). A similar decrease in size and strength of aggregates was reported in anaerobic digestion at high salinity (Ismail et al., 2008). After first attraction, molecules at the outside of the cell membranes, such as polysaccharides and protein complexes, and other exopolymeric substances (EPS) form a stable connection between cells or between the cell and other surfaces. It was shown before that at 0.87 $\mathrm{M} \mathrm{Na}^{+}$the polysaccharide concentration in EPS decreases in granules from an upflow anaerobic sludge blanket reactor (Ismail et al., 2010). In another study it was proposed that at high salinities $\left(0.65 \mathrm{M} \mathrm{Na}^{+}\right), \mathrm{Ca}^{2+}$ is substituted by $\mathrm{Na}^{+}$in the aggregates EPS matrix, thus resulting in the loss of granules strength reported (Ismail et al., 2008). There are also indications that the carbon metabolism is down-regulated at high salt conditions which could lead to a reduced EPS production (He et al., 2010). 


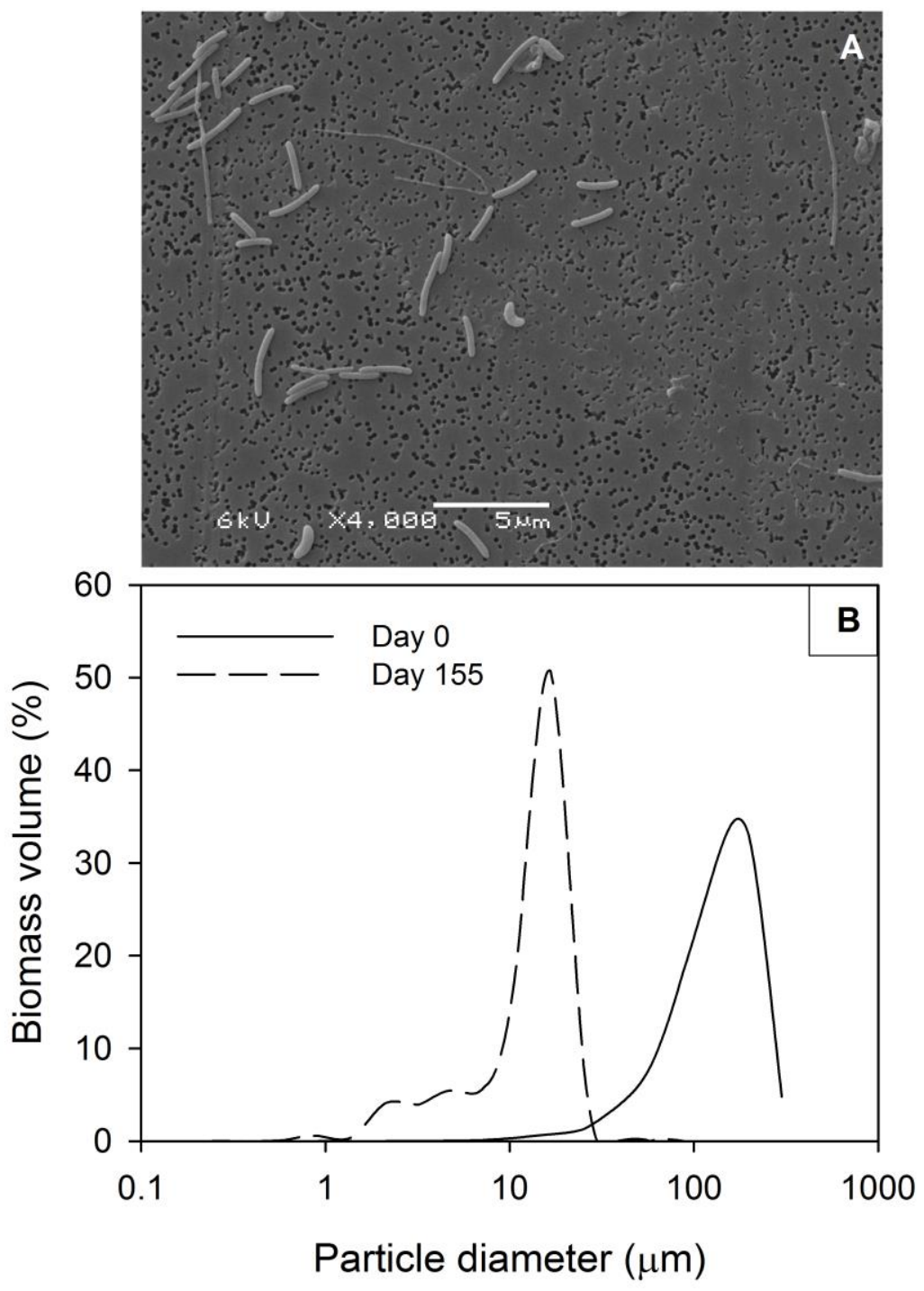

Figure 6 - Biomass SEM picture and particle size distribution. A - SEM picture (5000x) with the different microbial morphotypes. B - Particle size distribution by biomass volume using laser measurement ( 3 measurements of 120 s with mixing) of biomass from day 0 and 155 of continuous runs (begin of Start-up and end of Run 3).

Another factor that strongly influences aggregation is the metabolic relations between different microorganisms (Hulshoff Pol et al., 2004). To make these relations more efficient, microorganism need to be physically close to each other and aggregate. This was shown in sulfate reducing bioreactors where besides sulfate reducers also other metabolic groups such as methanogens and homoacetogens were present (van Houten et al, 1995; van Houten et al., 2006). In the present study, acetate was not detected and homoacetogens were not found in the biomass at the end of Run 3 (Table 2). Howeve, formate was detected which could also be used as carbon source and 
electron donor as was shown in other studies (Sorokin et al. 2011a). The diversity visualized by the DGGE profiles and unknown biodiversity from the clone library (Figure 4 and Table 2 and 3 ), shows the possible presence of other microbial metabolic groups in the bioreactor, like fermentative bacteria. The biomass concentration was low, and not enough to sustain an abundant population of fermentative bacteria feeding on dead biomass. This indicates that the food chain was short and mostly consisted of autotrophic microorganisms. Still some metabolic interactions may have occurred in the bioreactor wall biofilm but not in the suspended biomass. Methane was not detected in the run with suspended biomass while it was detected in the run with only biofilm (Figure 5). Also archaea closely related to isolated methanogens were identified (Table 3). The higher biomass retention time in the biofilm allowed the development of slow growing microorganisms which might have played a role. Such results indicate that the metabolic relations may have contributed to biofilm formation but did not constitute a driving force for aggregation of the suspended biomass at haloalkaline conditions.

In previous studies, inorganic particles, like pumice or sand, were used to promote aggregation (van Houten et al., 1995; Jong and Parry, 2006). It was also shown that bacteria may attach to crystallized metal sulfides (Noël et al., 2010). At sulfate reducing conditions, metal sulfides precipitate and thus could be used as support for attachment. Zinc sulfide crystals were identified through SEM-EDX in the current study but no microbial attachment was observed. Also, at high $\mathrm{pH}$ and salt concentration, precipitation of salts occurs. Such crystals like calcium or magnesium carbonates are known to affect granulation and increase the stability of EPS in aggregates (Braissant et al., 2007; Liu et al., 2010). Calcite (crystallized calcium carbonate) and magnesite (crystalized magnesium carbonate) were identified using SEM-EDX analysis. Still, there was no indication of microbial attachment to these crystals, showing that these are not used as support material for aggregation probably due to their instability. On the other hand, sand and pumice, being silica based, may have similar characteristics as glass. Their use as initial attachment support for aggregation could lead to formation of stable aggregates since biofilm growth on glass was observed.

The maximum sulfate reduction volumetric rate $\left(\mathrm{V}_{\mathrm{r}}\right)$ achieved, $18 \mathrm{mmol} \mathrm{l}^{-1} \mathrm{~d}^{-1}$ (Figure 2 ), was approximately 10 fold lower than reported for a full-scale $\mathrm{H}_{2}$ fed sulfatereducing bioreactor at neutral conditions (van Houten et al., 2006). Using silica based 
particles with biofilm would allow an increase of biomass concentration inside the bioreactor thus generating a potential increase of the sulfate reduction volumetric rate.

\section{Conclusions}

This study shows the possibility of performing sulfate reduction at haloalkaline conditions in a continuous bioreactor. The process is characterized by low growth rate and lack of microbial aggregation. The haloalkaline conditions seem to prevent biomass aggregation but the mechanism behind this effect is still unclear. The low microbial diversity might have contributed to the poor aggregation ability of the biomass. However, biofilm formation on the bioreactor glass wall shows that attachment to silica support materials is possible. Further research on how haloalkaline conditions affect the aggregation process could provide clues to improve granulation. 


\section{References}

Alazard D, Badillo C, Fardeau ML, Cayol JL, Thomas P, Roldan T, Tholozan JL, Ollivier B (2007) Tindallia texcoconensis sp. nov., a new haloalkaliphilic bacterium isolated from lake Texcoco, Mexico. Extremophiles 11:33-39.

Alphenaar AP, Visser A, Lettinga G (1993) The effect of liquid upward velocity and hydraulic retention time on granulation in UASB reactors treating wastewater with a high sulphate content. Biores Technol 43:249-258.

Bijmans MFM, Dopson M, Ennin F, Lens PNL, Buisman CJN (2008) Effect of sulfide removal on sulfate reduction at $\mathrm{pH} 5$ in a hydrogen fed gas-lift bioreactor. J Microbiol Biotechnol 18:1809-1818.

Braissant O, Decho AW, Dupraz C, Glunk C, Przekop KM, Visscher PT (2007) Exopolymeric substances of sulfate-reducing bacteria: Interactions with calcium at alkaline $\mathrm{pH}$ and implication for formation of carbonate minerals. Geobiology 5:401-411.

Großkopf R, Janssen PH, Liesack W (1998) Diversity and structure of the methanogenic community in anoxic rice paddy soil microcosms as examined by cultivation and direct 16S rRNA gene sequence retrieval. Appl Environ Microbiol 64:960-969.

He Z, Zhou A, Baidoo E, He Q, Joachimiak MP, Benke P, Phan R, Mukhopadhyay A, Hemme CL, Huang K, Alm EJ, Fields MW, Wall J, Stahl D, Hazen TC, Keasling JD, Arkin AP, Zhou J (2010) Global transcriptional, physiological, and metabolite analyses of the responses of Desulfovibrio vulgaris Hildenborough to salt adaptation. Appl Environ Microbiol 76:1574-1586.

Hulshoff Pol LW, de Castro Lopes SI, Lettinga G, Lens PNL (2004) Anaerobic sludge granulation. Water Res 38:1376-1389.

Ismail SB, Gonzalez P, Jeison D, van Lier JB (2008) Effects of high salinity wastewater on methanogenic sludge bed systems. Water Sci Technol 58:1963-1970.

Ismail SB, de La Parra CJ, Temmink H, van Lier JB (2010) Extracellular polymeric substances (EPS) in upflow anaerobic sludge blanket (UASB) reactors operated under high salinity conditions. Water Res 44:1909-1917.

Janssen AJH, Lens PNL, Stams AJM, Plugge CM, Sorokin DY, Muyzer G, Dijkman H, van Zessen E, Luimes P, Buisman CJN (2009) Application of bacteria involved in the biological sulfur cycle for paper mill effluent purification. Sci Total Environ 407:13331343. 
Jong T, Parry DL (2006) Microbial sulfate reduction under sequentially acidic conditions in an upflow anaerobic packed bed bioreactor. Water Res 40:2561-2571.

Jørgensen BB (1982) Mineralization of organic matter in the sea bed - The role of sulphate reduction. Nature 296:643-645.

Lane DL (1991) 16S/23S rRNA sequencing. In: Stackebrandt E, Goodfellow M (ed) Nucleic Acid Techniques in Bacterial Systematics, John Wiley \& Sons Ltd, Chichester, United Kingdom, pp 115-148.

Liu L, Gao DW, Zhang M, Fu Y (2010) Comparison of $\mathrm{Ca}^{2+}$ and $\mathrm{Mg}^{2+}$ enhancing aerobic granulation in SBR. J Hazard Mater 181:382-387.

Muyzer G, Stams AJM (2008) The ecology and biotechnology of sulphate-reducing bacteria. Nat Rev Microbiol 6:441-454.

Noël N, Florian B, Sand W (2010) AFM \& EFM study on attachment of acidophilic leaching organisms. Hydrometallurgy 104:370-375.

Otto K, Elwing H, Hermansson M (1999) Effect of ionic strength on initial interactions of Escherichia coli with surfaces, studied on-line by a novel quartz crystal microbalance technique. J Bacteriol 181:5210-5218.

Oude Elferink SJWH, Vorstman WJC, Sopjes A, Stams AJM (1998) Characterization of the sulfate-reducing and syntrophic population in granular sludge from a full-scale anaerobic reactor treating papermill wastewater. FEMS Microbiol Ecol 27:185-194.

Pikuta EV, Zhilina TN, Zavarzin GA, Kostrikina NA, Osipov GA, Rainey FA (1998) Desulfonatronum lacustre gen. nov., sp. nov.: a new alkaliphilic sulfate-reducing bacterium utilizing ethanol. Microbiology (Moscow, English translation) 67:105-113.

Pikuta EV, Hoover RB, Bej AK, Marsic D, Detkova EN, Whitman WB, Krader P (2003) Tindallia californiensis sp. nov., a new anaerobic, haloalkaliphilic, spore-forming acetogen isolated from Mono Lake in California. Extremophiles 7:327-334.

Rabus R, Hansen TA, Widdel F (2013) Dissimilatory sulfate- and sulfur-reducing prokaryotes. In: Rosenberg E, DeLong EF, Lory S, Stackebrandt E, Thomson F (ed) ProkaryotesProkaryotic Physiology and Biochemisty., 4th edn. Springer, Berlin, Heidelberg, pp 310-379.

Sipma J, Lettinga G, Stams AJM, Lens PNL (2006) Hydrogenogenic CO conversion in a moderately thermophilic $\left(55^{\circ} \mathrm{C}\right)$ sulfate-fed gas lift reactor: competition for $\mathrm{CO}$-derived $\mathrm{H}_{2}$. Biotechnol Prog 22:1327-1334. 
Sorokin DY, Foti M, Pinkart HC, Muyzer G (2007) Sulfur-oxidizing bacteria in Soap Lake (Washington State), a meromictic, haloalkaline lake with an unprecedented high sulfide content. Appl Environ Microbiol 73:451-455.

Sorokin DY, Tourova TP, Henstra AM, Stams AJM, Galinski EA, Muyzer G (2008a) Sulfidogenesis under extremely haloalkaline conditions by Desulfonatronospira thiodismutans gen. nov., sp. nov., and Desulfonatronospira delicata sp. nov. - a novel lineage of Deltaproteobacteria from hypersaline soda lakes. Microbiology 154:14441453.

Sorokin DY, Tourova TP, Mussmann M, Muyzer G (2008b) Dethiobacter alkaliphilus gen. nov. sp. nov., and Desulfurivibrio alkaliphilus gen. nov. sp. nov.: two novel representatives of reductive sulfur cycle from soda lakes. Extremophiles 12:431-439.

Sorokin DY, Rusanov II, Pimenov NV, Tourova TP, Abbas B, Muyzer G (2010) Sulfidogenesis under extremely haloalkaline conditions in soda lakes of Kulunda Steppe (Altai, Russia). FEMS Microbiol Ecol 73:278-290.

Sorokin DY, Kuenen JG, Muyzer G (2011a) The microbial sulfur cycle at extremely haloalkaline conditions of soda lakes. Front Microbiol 2, doi:10.3389/fmicb.2011.00044.

Sorokin DY, Tourova TP, Kolganova TV, Detkova EN, Galinski EA, Muyzer G (2011b) Culturable diversity of lithotrophic haloalkaliphilic sulfate-reducing bacteria in soda lakes and the description of Desulfonatronum thioautotrophicum sp. nov., Desulfonatronum thiosulfatophilum sp. nov., Desulfonatronovibrio thiodismutans sp. nov., and Desulfonatronovibrio magnus sp. nov.. Extremophiles 15:391-401.

Sorokin DY, Detkova EN, Muyzer G (2011c) Sulfur-dependent respiration under extremely haloalkaline conditions in soda lake 'acetogens' and the description of Natroniella sulfidigena sp. nov. FEMS Microbiol Lett 319:88-95.

Vallero MVG, Sipma J, Lettinga G, Lens PNL (2004) High-rate sulfate reduction at high salinity (up to $90 \mathrm{mS} . \mathrm{cm}^{-1}$ ) in mesophilic UASB reactors. Biotechnol Bioeng 86:226-235.

Vallero MVG, Lettinga G, Lens PNL (2005) High rate sulfate reduction in a submerged anaerobic membrane bioreactor (SAMBaR) at high salinity. J Memb Sci 253:217-232.

van Houten BHGW, Roest K, Tzeneva VA, Dijkman H, Smidt H, Stams AJM (2006) Occurrence of methanogenesis during start-up of a full-scale synthesis gas-fed reactor treating sulfate and metal-rich wastewater. Water Res 40:553-560. 
van Houten RT, Oude Elferink SJWH, van Hamel SE, Hulshoff Pol LW, Lettinga G (1995) Sulphate reduction by aggregates of sulphate-reducing bacteria and homo-acetogenic bacteria in a lab-scale gas-lift reactor. Biores Technol 54:73-79.

van Oss CJ (1989) Energetics of cell-cell and cell-biopolymer interactions. Cell Biophys 14:116.

van Oss CJ (1993) Acid—base interfacial interactions in aqueous media. Colloids Surfaces A Physicochem Eng Asp 78:1-49.

Wolin EA, Wolin MJ, Wolfe RS (1963) Formation of methane by bacterial extract. J Biol Chem 238:2882-2886.

Worakit S, Boone DR, Mah RA, Abdel-Samie M, El-Halwagi MM (1986) Methanobacterium alcaliphilum sp. nov. an $\mathrm{H}_{2}$-utilizing methanogen that grows at high $\mathrm{pH}$ values. Int $\mathrm{J}$ Syst Bacteriol 36:380-382.

Zhou JM, Song ZY, Yan DJ, Liu YL, Yang MH, Cao HB, Xing JM (2014) Performance of a haloalkaliphilic bioreactor under different $\mathrm{NO}_{3} / \mathrm{SO}_{4}{ }^{2-}$ ratios. Biores Technol 153:216222. 


\section{Supplementary information}

Table A1 - Origin, type, $\mathrm{pH}$ and salinity of the inocula used in this study

\begin{tabular}{|c|c|c|c|c|c|}
\hline Source & Location & Type & $\mathrm{pH}$ & $\begin{array}{l}\text { Salts } \\
\left(\mathrm{g} \mathrm{l}^{-1}\right)\end{array}$ & Reference \\
\hline Soap lake & $\begin{array}{c}\text { Washington, } \\
\text { USA }\end{array}$ & Sediment & 9.9 & $20-140$ & $\begin{array}{l}\text { Sorokin et } \\
\text { al., } 2011 a\end{array}$ \\
\hline $\begin{array}{l}\text { Kulunda steppe soda } \\
\text { lakes }\end{array}$ & Altai, Russia & Sediment & $9.3-10.6$ & $20-380$ & $\begin{array}{l}\text { Sorokin et } \\
\text { al., 2011a }\end{array}$ \\
\hline $\begin{array}{l}\text { Traditional salt } \\
\text { production ponds }\end{array}$ & $\begin{array}{l}\text { Tavira, } \\
\text { Portugal }\end{array}$ & Sediment & 7.5 & N.D. & This study \\
\hline $\begin{array}{l}\text { Thiopaq® sulfide } \\
\text { oxidizing bioreactor }\end{array}$ & $\begin{array}{l}\text { Eerbeek, the } \\
\text { Netherlands }\end{array}$ & Sludge & $8.5-9$ & 18.4 & $\begin{array}{l}\text { Janssen et } \\
\text { al., } 2009\end{array}$ \\
\hline $\begin{array}{l}\text { Thiopaq® sulfide } \\
\text { oxidizing bioreactor }\end{array}$ & Illinois, USA & Sludge & $8.5-9$ & N.D. & This study \\
\hline $\begin{array}{l}\text { UASB methanogenic } \\
\text { bioreactor }\end{array}$ & $\begin{array}{l}\text { Eerbeek, the } \\
\text { Netherlands }\end{array}$ & Sludge & 6.9 & N.D. & $\begin{array}{c}\text { Oude } \\
\text { Elferink et } \\
\text { al., } 1998\end{array}$ \\
\hline
\end{tabular}

N.D. - No data available 


\section{Chapter 4}

\section{Thiosulfate conversion to sulfide by a haloalkaliphilic microbial community in a bioreactor fed with $\mathrm{H}_{2}$ gas}

João AB Sousa, Martijn FM Bijmans, Alfons JM Stams, Caroline M Plugge

Published as:

Sousa JAB, Bijmans MFM, Stams AJM, Plugge CM (2016) Thiosulfate conversion to sulfide by a haloalkaliphilic microbial community in a bioreactor fed with $\mathrm{H}_{2}$ gas. Environ Sci

Technol.

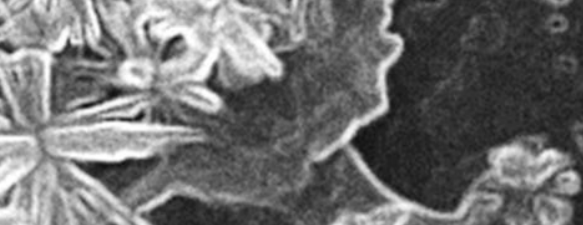
, is siscos 


\section{Abstract}

In industrial gas biodesulfurization systems, where haloalkaline conditions prevail, a thiosulfate containing bleed stream is produced. This bleed stream can be treated in a separate bioreactor by reducing thiosulfate to sulfide and recycling it. By performing treatment and recycling of the bleed stream, its disposal decreases and less caustics is required to maintain the high $\mathrm{pH}$. In this study, anaerobic microbial thiosulfate conversion to sulfide in a $\mathrm{H}_{2} / \mathrm{CO}_{2}$ fed bioreactor operated at haloalkaline conditions was investigated. Thiosulfate was converted by reduction to sulfide as well as disproportionation to sulfide and sulfate. Formate production from $\mathrm{H}_{2} / \mathrm{CO}_{2}$ was observed as an important reaction in the bioreactor. Formate, rather than $\mathrm{H}_{2}$, might have been used as the main electron donor by thiosulfate/sulfate-reducing bacteria. The microbial community was dominated by bacteria belonging to the family Clostridiaceae most closely related to Tindallia texcoconensis. Bacteria phylogenetically related to known haloalkaline sulfate and thiosulfate reducers, thiosulfate-disproportionating bacteria and remarkably sulfur-oxidizing bacteria were also detected. Based on the results, two approaches to treat the biodesulfurization waste stream are proposed: i) addition of electron donor to reduce thiosulfate to sulfide and ii) thiosulfate disproportionation without the need for an electron donor. The concept of application of solely thiosulfate disproportionation is discussed. 


\section{Introduction}

Thiosulfate $\left(\mathrm{S}_{2} \mathrm{O}_{3}{ }^{2-}\right)$ is one of the major reactive intermediate in the biogeochemical sulfur cycle (Jørgensen 1990). Thiosulfate can be formed abiotically through oxidation of sulfide $\left(\mathrm{HS}^{-}\right)$, polysulfide $\left(\mathrm{S}_{\mathrm{x}^{2-}}\right)$ or pyrite with $\mathrm{O}_{2}$. Most sulfate-reducing bacteria (SRB) are able to reduce thiosulfate to sulfide with $\mathrm{H}_{2}$ or an organic electron donor (Eq. 1) (Widdel 1988). However, thiosulfate can also be disproportionated to sulfate and sulfide in the absence of an electron donor (Eq. 2) (Bak \& Cypionka 1987). Disproportionation of thiosulfate can also be performed by several SRB (Finster 2008; Sorokin et al 2011a).

$$
\begin{aligned}
& \mathrm{S}_{2} \mathrm{O}_{3}^{2-}+4 \mathrm{H}_{2} \rightarrow 2 \mathrm{HS}^{-}+3 \mathrm{H}_{2} \mathrm{O} \\
& \mathrm{S}_{2} \mathrm{O}_{3}^{2-}+\mathrm{H}_{2} \mathrm{O} \rightarrow \mathrm{SO}_{4}^{2-}+\mathrm{HS}^{-}+\mathrm{H}^{+}
\end{aligned}
$$

Thiosulfate is particularly relevant in the sulfur cycle of haloalkaline environments, such as soda lakes where sodium carbonate and bicarbonate are the dominant salts. In these environments, thiosulfate is abiotically formed by the oxidation of polysulfides that are chemically stable at high $\mathrm{pH}$ and anoxic conditions (van den Bosch et al 2008). In soda lakes thiosulfate reduction is even more prominent than sulfate reduction (Sorokin et al 2010; Sorokin et al 2011b). Several anaerobic thiosulfate-converting microorganisms have been isolated from soda lakes (Sorokin et al 2011b). These isolated microbes, mainly belonging to genus Desulfonatronum, Desulfonatronovibrio and Desulfonatronospira, are able to perform both thiosulfate disproportionation and thiosulfate reduction.

Thiosulfate is also an important intermediate in biodesulfurization processes that operate at haloalkaline conditions (Janssen et al 2009). In these processes thiosulfate is an unwanted soluble product along with sulfate and needs to be removed via a bleed stream. This bleed stream is rich in thiosulfate which contributes to the chemical oxygen demand (COD) of the disposed water. Additionally, the production of a bleed stream increases the demand in water and caustic to maintain the $\mathrm{pH}$ high enough to absorb hydrogen sulfide from the gas. The increased demand of water and caustics is 
critical when biodesulfurization plants are built in locations without easy access to water and caustics, requiring transport of both.

Thiosulfate in the bleed stream can be removed by biological conversion to sulfide in a separate anaerobic bioreactor. The sulfide produced in this anaerobic bioreactor can then be recycled back to the sulfide oxidation bioreactor. In this bioreactor, the oxygen supply is controlled to maximize production of elemental sulfur and minimize sulfate and thiosulfate formation. The elemental biosulfur is recovered and used in agriculture or in chemical and biotechnological industries (Buisman et al 1989).

At present, there are no studies available on long-term cultivation of thiosulfatereducing biomass in reactor systems at haloalkaline conditions, which is needed for full-scale application of the proposed concept. Detailed information on the microbial activity and composition, metabolic interactions of microorganisms and biomass characteristics is lacking. This information is crucial to understand and improve thiosulfate conversion in bioreactors.

In this work, microbial thiosulfate conversion at haloalkaline conditions in a continuous reactor system was investigated. A gas-lift bioreactor fed with $\mathrm{H}_{2}$ as electron donor and thiosulfate as electron acceptor was used. The bioreactor was operated at $\mathrm{pH} 9$ and $1.5 \mathrm{M} \mathrm{Na}^{+}$and no organic compounds were present in the feed. Thiosulfate conversion was monitored and biomass growth and biomass characteristics were determined. The dominant microbes were identified using molecular biological techniques.

\section{Methods}

\section{Bioreactor set-up}

A 4.4 I glass gas lift reactor with an internal 3 phase-separator was used (Figure 1 Chapter 3). Temperature was maintained at $35^{\circ} \mathrm{C}$ using a water jacket connected to a thermostat bath (DC10-P5/U, Haake, Dreieich, Germany). The influent feeding was performed by a membrane pump (Stepdos 08 RC, KNF-Verder, Utrecht, the Netherlands). The $\mathrm{H}_{2}$ and $\mathrm{CO}_{2}$ gas supply was controlled using digital mass flow controllers (F-201CV-020-AGD-22-V and F-201CV-020-AGD-22-Z, Bronkhorst, 
Ruurlo, the Netherlands). The gas was recycled using a vacuum pump (Laboport $\circledast$, $\mathrm{KNF}$, Trenton, $\mathrm{NJ}$ ) and the gas flow was measured with a calibrated flow meter (URM, Kobold, Arnhem, the Netherlands). A pH and a redox potential sensor (CPS11D and CPS12D, Endress+Hauser, Naarden, the Netherlands) connected to a controller (Liquiline CM44x, Endress+Hauser, Naarden, the Netherlands) were used to monitor the conditions inside the reactor. The $\mathrm{pH}$ was controlled at $\mathrm{pH} 9$ by supplying $\mathrm{CO}_{2}$ using the mass flow controller with a supply rate range between $0.05-5 \mathrm{ml} \mathrm{min}^{-1}$.

The bioreactor was inoculated with $50 \mathrm{ml}$ of biomass collected from a gas lift bioreactor earlier operated with sulfate and thiosulfate $\left(1 / 1\right.$ mol ratio) and fed with $\mathrm{H}_{2}$ and $\mathrm{CO}_{2}$ (Sousa et al 2015).

\section{Medium}

The mineral medium used was buffered at pH $9( \pm 0.05)$ with sodium carbonate and sodium bicarbonate, adding to a total of $1.5 \mathrm{M} \mathrm{Na}^{+}$. The medium composition was as follows: $\mathrm{Na}_{2} \mathrm{CO}_{3}\left(33.6 \mathrm{~g} \mathrm{l}^{-1}\right), \mathrm{NaHCO}_{3}\left(69.3 \mathrm{~g} \mathrm{l}^{-1}\right), \mathrm{KHCO}_{3}\left(1 \mathrm{~g} \mathrm{l}^{-1}\right), \mathrm{K}_{2} \mathrm{HPO}_{4}\left(1 \mathrm{~g} \mathrm{l}^{-1}\right)$, $\mathrm{NH}_{4} \mathrm{Cl}\left(0.27 \mathrm{gl}^{-1}\right), \mathrm{MgCl}_{2} .6 \mathrm{H}_{2} \mathrm{O}\left(0.1 \mathrm{gl}^{-1}\right), \mathrm{CaCl}_{2} .2 \mathrm{H}_{2} \mathrm{O}\left(0.01 \mathrm{gl}^{-1}\right)$ and $10 \mathrm{mll}^{-1}$ of vitamin solution (Wolin et al 1963). Two trace element solutions with the following composition were mixed together: TE1 - Na-EDTA (1000 mg l-1), FeCl $2.4 \mathrm{H}_{2} \mathrm{O}\left(370 \mathrm{mg} \mathrm{l}^{-1}\right), \mathrm{H}_{3} \mathrm{BO}_{3}$ (60 mg l-1), $\mathrm{MnCl}_{2} 2 \mathrm{H}_{2} \mathrm{O}\left(26 \mathrm{mg} \mathrm{l}^{-1}\right), \mathrm{CoCl}_{2} .6 \mathrm{H}_{2} \mathrm{O}\left(40 \mathrm{mg} \mathrm{l}^{-1}\right), \mathrm{ZnCl}_{2}\left(10 \mathrm{mg} \mathrm{l}^{-1}\right), \mathrm{CuCl}_{2}$ (3 $\left.\mathrm{mg} \mathrm{l}^{-1}\right), \mathrm{KAl}\left(\mathrm{SO}_{4}\right)_{2} .12 \mathrm{H}_{2} \mathrm{O}\left(32 \mathrm{mg} \mathrm{l}^{-1}\right), \mathrm{NiCl}_{2} .6 \mathrm{H}_{2} \mathrm{O}\left(31 \mathrm{mg} \mathrm{l}^{-1}\right)$; TE2 - $\mathrm{NaOH}\left(40 \mathrm{mg} \mathrm{l}^{-1}\right)$, $\mathrm{Na}_{2} \mathrm{SiO}_{3} .5 \mathrm{H}_{2} \mathrm{O}\left(10 \mathrm{mg} \mathrm{l}^{-1}\right), \mathrm{Na}_{2} \mathrm{MoO}_{4} .2 \mathrm{H}_{2} \mathrm{O}\left(10 \mathrm{mg} \mathrm{l}^{-1}\right), \mathrm{Na}_{2} \mathrm{SeO}_{3} .5 \mathrm{H}_{2} \mathrm{O}\left(10 \mathrm{mg} \mathrm{l}^{-1}\right)$, $\mathrm{Na}_{2} \mathrm{WO}_{4} .2 \mathrm{H}_{2} \mathrm{O}\left(10 \mathrm{mg} \mathrm{l}^{-1}\right)$. From this mixed solution, $10 \mathrm{ml} \mathrm{l}^{-1}$ was added to the medium. As electron acceptor, $3.95 \mathrm{~g} \mathrm{l}^{-1}(25 \mathrm{mM})$ of sodium thiosulfate $\left(\mathrm{Na}_{2} \mathrm{~S}_{2} \mathrm{O}_{3}\right)$ was added.

\section{Experimental design}

The bioreactor was filled with medium and flushed with hydrogen overnight with gas recirculation to lower the redox potential. Afterwards, hydrogen was supplied at $5 \mathrm{ml}$ $\mathrm{min}^{-1}$, the gas recirculation was set to approximately $2.5 \mathrm{I} \mathrm{min}^{-1}$ and the $\mathrm{pH}$ was controlled at pH $9( \pm 0.05)$. Inoculation of the reactor was defined as time 0 . A batch run was performed to start-up the bioreactor and to verify thiosulfate conversion (Startup, Table 1). Four continuous experiments (Run 1, 2, 3 and 4) with different hydraulic 
retention times (HRT) were performed as described in Table 1. Another batch experiment (Biofilm run) was performed to investigate the contribution of the reactor wall biofilm to the thiosulfate conversion (Table 1). In the biofilm run, all suspended biomass was removed leaving only the biofilm in the bioreactor and fresh medium was added.

Table 1 - Operational differences between the different bioreactor runs performed

\begin{tabular}{lcccc}
\hline & $\begin{array}{c}\text { Period } \\
(\mathbf{d})\end{array}$ & Mode & $\begin{array}{c}\text { HRT } \\
(\mathbf{d})\end{array}$ & $\begin{array}{c}\mathbf{S}_{2} \mathrm{O}_{3}{ }^{2-} \text { loading rate } \\
\left(\mathbf{m m o l ~ d}^{-1}\right)\end{array}$ \\
\hline Start-up & $0-12$ & Batch & N.A. ${ }^{\mathrm{a}}$ & N.A. ${ }^{\mathrm{a}}$ \\
Run 1 & $12-42$ & Continuous & 5 & 10 \\
Run 2 & $42-91$ & Continuous & 2.5 & 20 \\
Run 3 & $91-117$ & Continuous & 1.7 & 29.4 \\
Run 4 & $117-140$ & Continuous & 1 & 50 \\
Biofilm run & $13^{b}$ & Batch & N.A. ${ }^{\mathrm{a}}$ & N.A. \\
\hline
\end{tabular}

a Not applicable.

${ }^{b}$ Duration of the batch test.

\section{Batch bottle experiments}

To gain further insight into biomass growth and use of $\mathrm{H}_{2}$, batch experiments were performed. The bottles had a total volume of $250 \mathrm{ml}$. At the beginning of the experiments the bottles contained $100 \mathrm{ml}$ liquid and a headspace of $150 \mathrm{ml}$. For gas measurements $1 \mathrm{ml}$ headspace was sampled and for liquid composition analysis, $5 \mathrm{ml}$ was collected. To start the experiment, $5 \mathrm{ml}$ of biomass obtained at the end of run 4 was inoculated into the serum bottles with sterile medium, $\mathrm{pH} 9$ and $1.5 \mathrm{M} \mathrm{Na}^{+}$, containing $25 \mathrm{mM}$ thiosulfate. Three bottles were incubated with a $\mathrm{H}_{2} / \mathrm{CO}_{2}(80 \% / 20 \%)$ gas phase and three bottles were incubated with a $\mathrm{N}_{2} / \mathrm{CO}_{2}(80 \% / 20 \%)$ gas phase. All bottles were incubated at $35^{\circ} \mathrm{C}$ while shaking at $120 \mathrm{rpm}$. Chemical controls without biomass were included. 


\section{Analytical procedures}

Samples for organic acids were filtered through $0.4 \mu \mathrm{m}$ pore size filters and analyzed using ultra-high performance liquid chromatography (Dionex ultimate 3000RS, Thermo scientific, Wilmington, MA) as described previously (Sousa et al 2015). Samples for sulfide, thiosulfate and sulfate analysis were stabilized with zinc acetate $(0.2 \mathrm{M})$ in a 1:1 ratio immediately after sampling. Sulfide was analyzed using a colorimetric test (LCK653, Hach Lange, Düsseldorf, Germany). For sulfate and thiosulfate analysis the samples were filtered through $0.4 \mu \mathrm{m}$ pore size filters and analyzed by ion chromatography (761 compact IC with a 762 IC interface, Metrohm, Herisau, Switzerland) as described previously (Sousa et al 2015).

Gaseous compounds $\left(\mathrm{H}_{2}, \mathrm{CO}_{2}, \mathrm{~N}_{2}\right.$ and $\left.\mathrm{CH}_{4}\right)$ were analyzed by gas chromatography using a microGC (CP-4900, Varian, Palo Alto, CA) as described previously (Sousa et al 2015).

The biomass development in the bioreactor was determined by analyzing the total nitrogen (total $\mathrm{N}$ ) content of biomass. Samples $(10 \mathrm{ml})$ were centrifuged $(10 \mathrm{~min}$, $7500 \mathrm{~g})$ and washed 3 times with carbonate/bicarbonate buffer $\left(\mathrm{pH} 9,1.5 \mathrm{M} \mathrm{Na}^{+}\right)$to remove dissolved nitrogen compounds. The total $\mathrm{N}$ content was determined using a colorimetric test (LCK238, Hach Lange, Düsseldorf, Germany).

Biomass particle size was quantified using laser measurement in a particle size and shape analyzer (Eyetech, Doner technologies, Or Akiva, Israel) with the Dipa 2000 software (Doner technologies, Or Akiva, Israel). Measurements were done in triplicate for 120s while stirring. Microscopy pictures were taken using a light microscope (DMI6000B, Leica, Biberach, Germany).

\section{DNA extraction}

Samples $(50 \mathrm{ml})$ for DNA analysis were centrifuged $(10 \mathrm{~min}, 7500 \mathrm{~g})$. The biomass

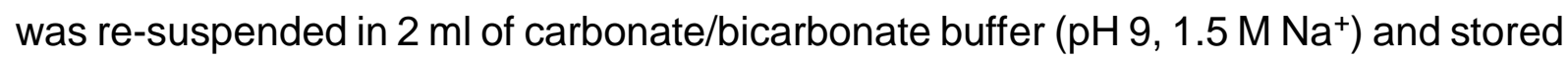
at $-80^{\circ} \mathrm{C}$. Genomic DNA was extracted from the pellet after centrifugation of stored samples using the PowerBiofilm ${ }^{\mathrm{TM}}$ DNA Isolation Kit (MoBio, Carlsbad, CA) following the manufacturer's instructions. After extraction, the DNA quantity and quality was 
analyzed using NanoDrop 1000 (ThermoScientific, Wilmington, MA). Only samples with more than $5 \mathrm{ng} \mathrm{ul}^{-1}$ DNA and ratio 260/280 nm between 1.7 and 2 were used. When required, the extraction process was repeated to achieve the quantity and quality mentioned. Amplified DNA samples were used for DGGE for a routine check of the microbial community, for a clone library to identify the species in the bioreactor, and for Illumina sequencing for investigating the relative abundance of different OTUs.

\section{PCR for DGGE and clone library}

Bacterial 16S rRNA genes were amplified by PCR using a Taq DNA polymerase kit (Invitrogen, Carlsbad, CA). The primer sets used were U968f/L1401r for denaturing gradient gel electrophoresis (DGGE) and Bact27f/Uni1492r for 16S rRNA cloning and sequencing (Lane 1991). A 40 bp GC-clamp was added at the 5' end sequence of the primer U968-f. For archaeal 16S rRNA genes the A109(T)f/GC515r primers set were used for DGGE (Lane 1991; Großkopf et al 1998).

For both bacteria and archaea $16 \mathrm{~S}$ rRNA gene DGGE, the PCR program was: initial denaturation for $2 \mathrm{~min} ; 35$ cycles of $30 \mathrm{~s}$ denaturation at $95^{\circ} \mathrm{C}, 40 \mathrm{~s}$ at $56^{\circ} \mathrm{C}$ for annealing and $1.5 \mathrm{~min}$ elongation step at $72^{\circ} \mathrm{C} ; 7 \mathrm{~min}$ at $72^{\circ} \mathrm{C}$ of post-elongation step. PCR settings for bacteria 16S rRNA gene cloning were as described above except that a total number of 25 cycles and an annealing temperature of $52^{\circ} \mathrm{C}$ were used.

\section{Clone library}

The bacterial 16S rRNA amplicons obtained from the final biomass (day 140) were purified using the ssDNA/RNA Clean \& Concentrator (Zymo Research, Irvine, CA) and ligated into the pGEM-T Easy Vector System I (Promega, Madison, MI) and cloned in XL-1 blue competent Escherichia coli cells (Stratagene, la Jolla, CA) and grown on LBagar with $100 \mathrm{mg} \mathrm{l}^{-1}$ ampicillin, $0.1 \mathrm{mM}$ isopropyl-1-thio- $\beta$-D-galactopyranoside (X-gal). 96 Positive transformants were selected (by blue/white screening) and transferred to solid LB medium with $100 \mathrm{mg} \mathrm{l}^{-1}$ ampicilin and incubated overnight at $37^{\circ} \mathrm{C} .96$ bacterial clones were sent for sequencing of the 16S rRNA gene insert (Baseclear BV, the Netherlands) using the primers sets Bact27f/Univ1492r (Lane, 1991). The DNA sequences were analyzed using Chromas (ver. 2.32, Technelysium). From the 96 
clones, 64 good sequences (without chimeras) were obtained and analyzed further. The sequences were in average 1400 base pairs length. Similarity searches for $16 \mathrm{~S}$ rRNA gene sequences derived from the clones were performed using the EMBL-EBI ENA sequence search program within the ENA database. (http://www.ebi.ac.uk/ena).

\section{Bacteria community profiling}

From the biomass sample on day 140, a fragment of the 16S rRNA gene of bacteria was amplified with primers $341 \mathrm{~F}$ and $805 \mathrm{R}$ (Herlemann et al 2011). The PCR protocol was performed according as previously described (Hugerth et al 2014) and sequenced using the Illumina Miseq platform (Lindh et al 2015) at the Science for Life Laboratory, Sweden (www.scilifelab.se). The sequence data were processed with the UPARSE pipeline (Edgar, 2013a) and annotated against the SINA/SILVA database SILVA 119 (Quast et al., 2013a). Finally, the data were analyzed using Explicet 2.10.5 (Robertson et al., 2013). Sequences were submitted to the ENA database (http://www.ebi.ac.uk/ena) under the accession number PRJEB11708.

\section{Archaea community profiling}

For Archaea community profiling, an adapted method was used to analyze the biomass sample from day 140 (Jaeggi et al., 2014). A fragment of the 16S rRNA gene of archaea was amplified with primers 340F and 1000R (Gantner et al.2011). The PCR protocol was followed using a $50 \mu \mathrm{l}$ solution with $1 \mu \mathrm{l}$ DNA, $200 \mathrm{nM}$ of the forward and reverse primer, $1 \mathrm{U}$ KOD Hot Start DNA Polymerase (Novagen, Madison, WI), $5 \mu \mathrm{l}$ KOD-buffer (10x), $3 \mu \mathrm{l} \mathrm{MgSO} 4$ ( $25 \mathrm{mM}$ ), $5 \mu \mathrm{dNTP}$ mix (2 mM each), and $33 \mu \mathrm{l}$ sterile water. The PCR program used was: 2 minutes at $95^{\circ} \mathrm{C}$ and 35 cycles of $20 \mathrm{~s}$ at $95^{\circ} \mathrm{C}$, $10 \mathrm{~s}$ at $5^{\circ} \mathrm{C}$ and $15 \mathrm{~s}$ at $70^{\circ} \mathrm{C}$. The amplicons were purified with a MSB spin PCRapace kit (Invitek, Dublin, OH) and the concentration measured with a Nanodrop 1000 spectrophotometer (Thermo scientific, Wilmington, DE). Equimolar amounts of amplicons from each sample were mixed to a total of $200 \mathrm{ng}$. This mixed sample was purified with a Purelink PCR Purification kit (Invitrogen, Carlsbad, CA), using a high cutoff binding buffer B3. The amplicons were sequenced on the 454 Life Sciences GSFLX platform using Titanium sequencing chemistry (GATC-Biotech, Konstanz, Germany). The sequencing data was analysed using QIIME v1.2 (Caporaso et al 2010) 
and the chimeric sequences were filtered using Chimera Slayer (Haas et al 2011). The OTU clustering was performed as described in QIIME newsletter of December 17th 2010 (http://qiime.wordpress.com/2010/12/17/new-default-parameters-for-uclust-otupickers/) and with $97 \%$ identity threshold. The diversity metrics were calculated in QIIME 1.2. Hierarchical clustering was done with UPGMA with weighted UniFrac as distance measure in QIIME 1.2 (Caporaso et al 2010). For the taxonomic classification the Ribosomal Database Project (RDP) classifier 2.2 was used (Cole et al 2009).

\section{Calculations}

Calculations are described in supplementary material. The following assumptions were made:

1. Thermodynamic calculations were made based on Eq. 1 for thiosulfate reduction, Eq. 2 for thiosulfate disproportionation and for sulfate reduction based on Eq. 3 .

$$
4 \mathrm{H}_{2}+\mathrm{SO}_{4}^{2-}+\mathrm{H}^{+} \rightarrow \mathrm{HS}^{-}+4 \mathrm{H}_{2} \mathrm{O}
$$

2. Evaporation does not cause a major loss of liquid from the bioreactor because it is a closed system. The bioreactor liquid volume is assumed constant during the operation which means that the liquid flow that goes into the bioreactor is equal to the liquid flow getting out of the bioreactor $\left(Q_{\text {in }}=\right.$ Qout $)$.

3. Accumulation of sulfur compounds by incorporation in biomass and formation of sulfide precipitates is assumed to play a negligible role due to the high thiosulfate concentration in the influent.

4. Hydrogen used for biomass synthesis is assumed to play a negligible role in the bioreactor.

5. The $\mathrm{N}$ fraction value of 0.2 was used to calculate biomass concentration based on total $\mathrm{N}$, following the biomass molecular formula: $\mathrm{C}_{1} \mathrm{H}_{1.8} \mathrm{O}_{0.5} \mathrm{~N}_{0.2}$

6. For suspended biomass doubling time, the bioreactor was assumed as continuous stirred tank reactor for biomass growth rate calculations. It was assumed that there is hardly any retention of suspended biomass in the bioreactor. The role of the biomass growing in a biofilm that developed on the glass wall of the bioreactor, in the biomass retention is thus considered negligible for this specific parameter. 


$$
\begin{gathered}
C_{x}=\frac{C_{\text {TotalN }}}{0,2} \cdot M_{x} \\
D=\frac{1}{H R T} \\
\mu=D \\
r_{v}=\frac{Q \cdot C_{t s, \text { in }}-Q \cdot C_{t s, \text { out }}}{V_{r}} \\
\Delta G=\Delta G 0^{\prime}+R T \ln \left(\frac{(\text { Product } 1)^{n p 1} \cdot(\text { Product } 2)^{n p 2}}{(\text { Substrate } 1)^{n s 1} \cdot(\text { Substrate } 2)^{n s 2}}\right)
\end{gathered}
$$

Nomenclature used in calculations:

Cx Biomass concentration $\left(\mathrm{g} \mathrm{l}^{-1}\right)$

$\mathrm{M}_{\mathrm{x}} \quad$ Biomass molecular weight $\left(\mathrm{g} \mathrm{mol}^{-1}\right)$

$\mathrm{V}_{\mathrm{r}} \quad$ Bioreactor volume (I)

D Dilution rate $\left(d^{-1}\right)$

Q Flow rate $\left(\mathrm{d} \mathrm{d}^{-1}\right)$

$\mu \quad$ Specific biomass growth rate $\left(d^{-1}\right)$

$\mathrm{C}_{\mathrm{ts}} \quad$ Thiosulfate concentration $\left(\mathrm{mmol} \mathrm{I}^{-1}\right)$

CTotalN Total Nitrogen concentration $\left(\mathrm{mol} \mathrm{l}^{-1}\right)$

$r_{v} \quad$ Volumetric activity $\left(\mathrm{mmol} \mathrm{Ir}^{-1} \mathrm{~d}^{-1}\right)$

Subscript:

$\begin{array}{ll}x & \text { Biomass } \\ \text { out } & \text { Effluent } \\ \text { in } & \text { Influent } \\ r & \text { Reactor }\end{array}$


S

ts

TotalN
Sulfur

Thiosulfate

Total nitrogen

\section{Results \& Discussion}

\section{Bioreactor performance}

The biomass in the bioreactor efficiently converted thiosulfate from the beginning of the operation. A stable maximum volumetric thiosulfate conversion rate of $28.7( \pm 0.8)$ mmols $\mathrm{lr}^{-1} \mathrm{~d}^{-1}$ was achieved in run 3 with a hydraulic retention time (HRT) of 1.7 days (Figure $1 \mathrm{~A}$ and $\mathrm{B}$ ). This rate is almost two times higher than the sulfate reduction rate in a similar system (Table 2) (Sousa et al., 2015a). The higher volumetric rate can be explained by the 2 times higher biomass concentration obtained compared to that in the previous study (Table 2, Figure 1C). Such difference shows that thiosulfate is easier to convert than sulfate which might be related to the energy required for sulfate activation prior to its conversion while thiosulfate does not require activation (Sydow et al., 2002). In addition, there is an intrinsic higher energy gain from thiosulfate reduction to sulfide ( $\Delta G^{\prime}=-121 \mathrm{~kJ}$ per reaction) compared to sulfate reduction ( $\Delta \mathrm{G}^{\prime}=-99 \mathrm{~kJ}$ per reaction) at $35^{\circ} \mathrm{C}$ and $\mathrm{pH} 9$. With a HRT of 1 day (run 4) initially even higher volumetric rates were measured (Figure 1B). Yet, the gradual decrease in biomass concentration and the decrease of volumetric thiosulfate conversion rate showed that the system was not stable at an HRT of 1 day. Apparently, bacteria actively involved in thiosulfate conversion were washed out. This can also be seen in the 16S rRNA gene DGGE bacteria profile where a dominant band disappeared during run 4 (Figure S1). The cause might be that the growth rate of these bacteria was lower than the dilution rate used in run 4 , and thus they were washed out of the bioreactor. 

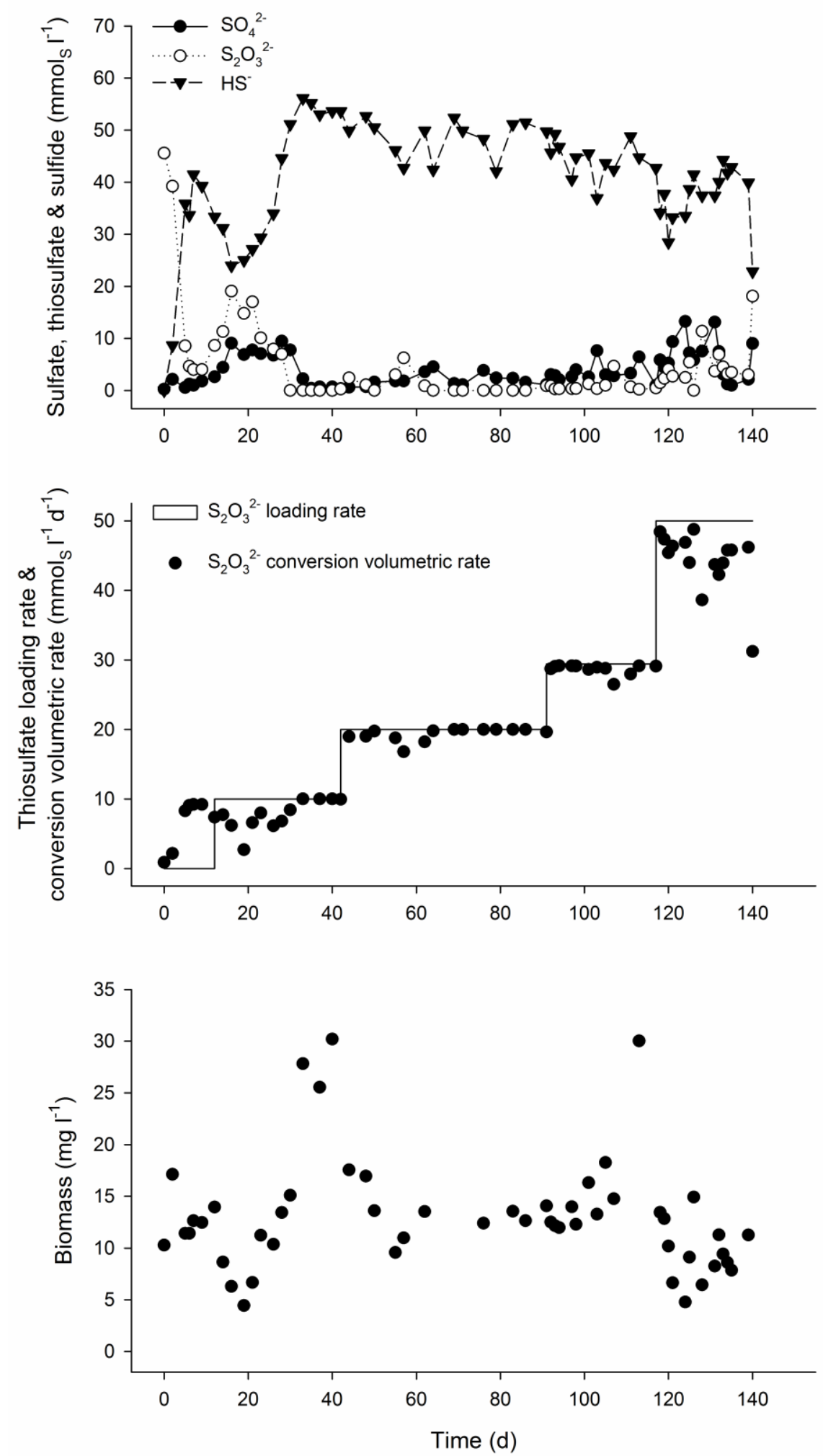

Figure 1 - Performance during start-up and continuous run of the $\mathrm{H}_{2}$ fed thiosulfate converting gas-lift bioreactor operated at haloalkaline conditions. A - Thiosulfate, sulfate and sulfide concentrations in the bioreactor effluent. B - Thiosulfate loading rate and thiosulfate conversion volumetric rate. $\mathrm{C}$ - Biomass concentration $\left(\mathrm{C}_{\mathrm{x}}\right)$ in the bioreactor. 
Table 2 - Conditions and performance of sulfate and thiosulfate reducing bioreactors operated at haloalkaline conditions.

\begin{tabular}{|c|c|c|c|c|}
\hline & This study & $\begin{array}{l}\text { Sousa et al } \\
(2015)\end{array}$ & $\begin{array}{l}\text { Zhou et al } \\
\text { (2015b) }\end{array}$ & $\begin{array}{l}\text { Zhou et al } \\
\text { (2015b) }\end{array}$ \\
\hline Reactor type & $\begin{array}{c}\text { Gas lift with } 3 \\
\text { phase separator }\end{array}$ & $\begin{array}{c}\text { Gas lift with } 3 \\
\text { phase separator }\end{array}$ & Anaerobic filter & Anaerobic filter \\
\hline $\mathrm{e}^{-}$acceptor & Thiosulfate & Sulfate & Sulfate & Sulfate \\
\hline e- donor & $\mathrm{H}_{2}$ & $\mathrm{H}_{2}$ & Formate & Ethanol \\
\hline Carbon source & $\mathrm{CO}_{2}$ & $\mathrm{CO}_{2}$ & Formate & Ethanol \\
\hline $\mathrm{pH}$ & 9 & 9 & 9.5 & 9.5 \\
\hline $\mathrm{Na}^{+}$conc. (M) & 1.5 & 1.5 & 1 & 1 \\
\hline Temperature $\left({ }^{\circ} \mathrm{C}\right)$ & 35 & 35 & 37 & 37 \\
\hline $\mathrm{HRT}(\mathrm{d})$ & 1.7 & 3.3 & 1 & 1 \\
\hline 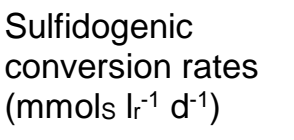 & $28.7( \pm 0.8)$ & 18 & 85 & 89.5 \\
\hline Side products & Formate & Formate & Acetate & $\begin{array}{c}\text { Acetate/Formate/ } \\
\text { Lactate }\end{array}$ \\
\hline $\begin{array}{l}\text { Biomass conc. } \\
\left(\mathrm{mg} \mathrm{l}^{-1}\right)\end{array}$ & $14.0( \pm 2.2)$ & $7.2( \pm 3)$ & N.D. ${ }^{b}$ & N.D. ${ }^{b}$ \\
\hline $\begin{array}{l}\text { Biomass } \\
\text { aggregation }\end{array}$ & No aggregation & No aggregation & N.D. ${ }^{b}$ & N.D. ${ }^{b}$ \\
\hline
\end{tabular}

a Data from reference.

b No data available.

The loss of bacteria could be prevented by the formation of microbial aggregates which would allow biomass to be retained in the bioreactor. However, microbial aggregation was not observed in the bioreactor even though a 3 phase separator was used to retain microbial aggregates inside the bioreactor. The biomass particle size distribution matches the size of the microorganisms found in the biomass, thick vibrio and thin rods shaped microorganisms, indicative of suspended biomass rather than aggregated biomass (Figure 2). No aggregates were observed by microscopy even though the 92 
initial inoculum had small biomass aggregates of around $100 \mu \mathrm{m}$ in diameter (Figure 2). Absence of biomass aggregation at haloalkaline conditions was also previously observed (Sousa et al., 2015a). However, a biofilm developed on the bioreactor glass wall over time. This biofilm was tested in a batch test (Biofilm run) to determine its contribution to the bioreactor performance. In this run, not only thiosulfate conversion and formate production, but also acetate and methane production was observed (Figure 3). Acetate and methane were not detected during continuous operation. Acetate, if intermediately produced during continuous operation, might also have been used as carbon source by heterotrophic sulfidogenic microorganisms. In the biomass, bacteria were detected that are phylogenetically closely related to sulfate/thiosulfate converting bacteria that use acetate as carbon source (Table 3). Some Desulfonatronovibrio $\mathrm{sp}$. are unable to grow autotrophically with $\mathrm{H}_{2}$ and formate, but are able to grow with acetate carbon source and hydrogen or formate as electron donor (Sorokin et al., 2008b, 2011d). 

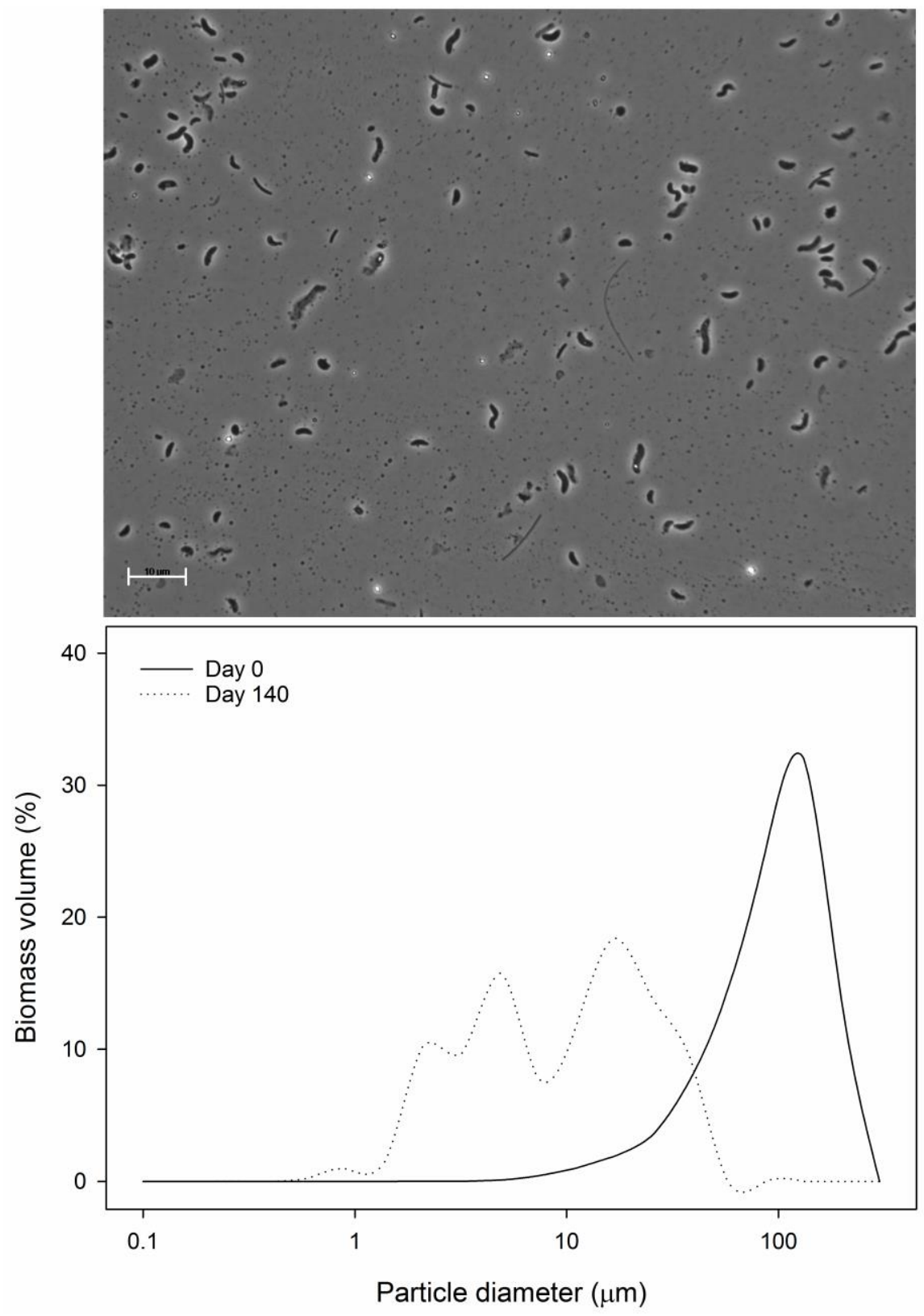

Figure 2 - Biomass micrograph and particle size distribution. A - Micrograph with the different microbial morphotypes found. White bar represents $10 \mu \mathrm{m}$. B - Particle size distribution by biomass volume using laser measurement (3 measurements of 120 s with mixing) of biomass from day 0 and 140 of continuous runs (begin of Start-up and end of Run 4). 

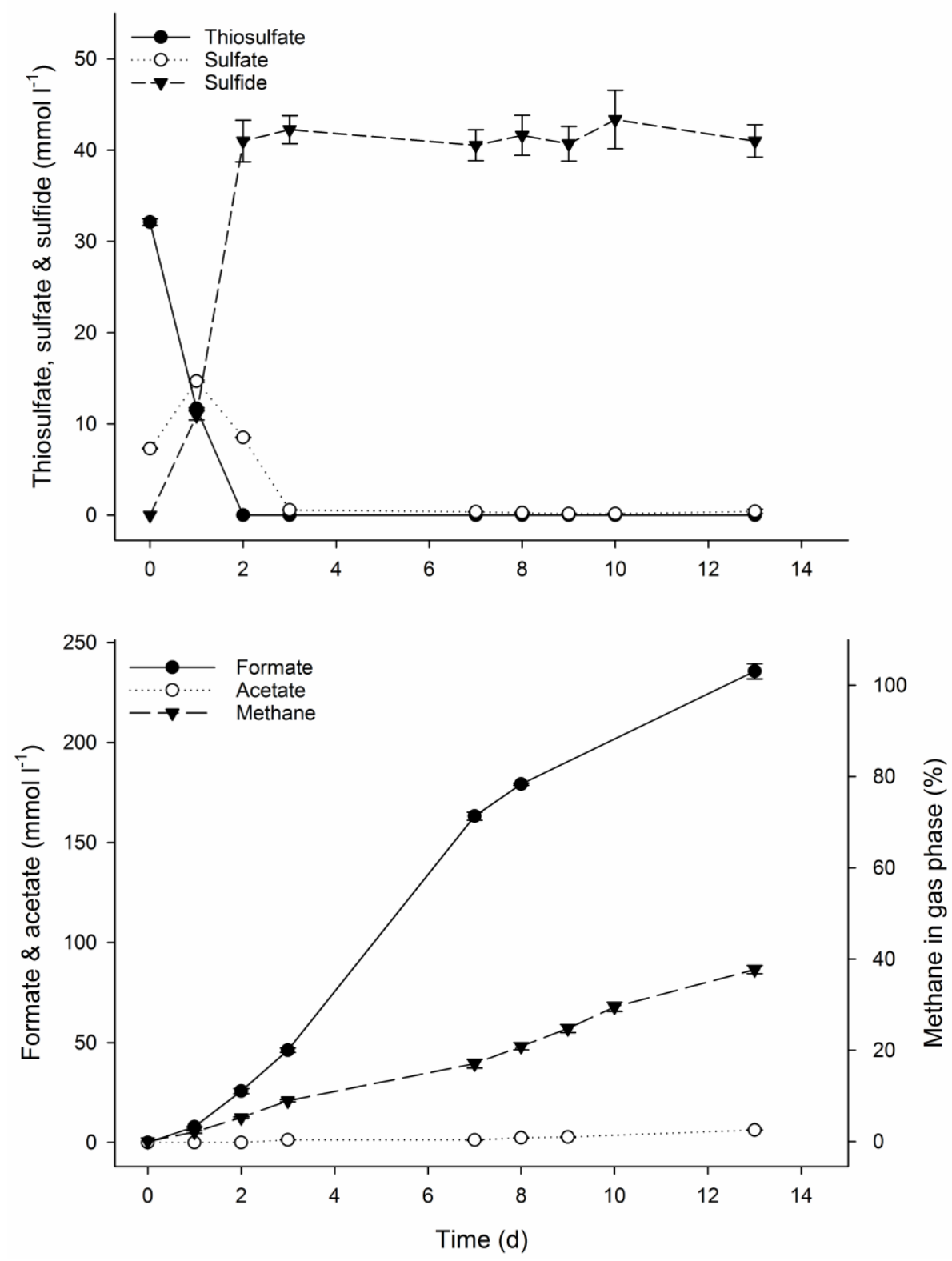

Figure 3 - Thiosulfate, sulfate, sulfide, formate and acetate concentration in the liquid phase and methane fraction in the gas phase during the Biofilm run. 
Table 3 - Phylogenetic affiliations and frequency of cloned bacterial 16S rRNA gene amplicons retrieved from the bioreactor at day 140 .

\begin{tabular}{|c|c|c|c|c|}
\hline Closest cultured relative & $\begin{array}{c}\text { Similarity } \\
(\%)\end{array}$ & $\begin{array}{l}\text { Number of } \\
\text { clones } \\
\text { (64 clones) }\end{array}$ & $\begin{array}{c}\text { Metabolism described in } \\
\text { literature }\end{array}$ & $\begin{array}{l}\text { Accession } \\
\text { number }\end{array}$ \\
\hline $\begin{array}{l}\text { Thioalkalibacter halophilus } \\
\text { strain ALCO1 }\end{array}$ & 99 & 14 & Sulfur oxidation & NR 044406 \\
\hline Thiomicrospira sp. V2501 & 99 & 14 & Sulfur oxidation & AB634592 \\
\hline $\begin{array}{l}\text { Tindallia texcoconensis } \\
\text { strain IMP- } 300\end{array}$ & 97 & 11 & Fermentation & NR 043664 \\
\hline $\begin{array}{l}\text { Thiomicrospira thyasirae } \\
\text { strain DSM } 5322\end{array}$ & 99 & 4 & Sulfur oxidation & NR 024854 \\
\hline $\begin{array}{l}\text { Desulfonatronovibrio sp. } \\
\text { AHT22 }\end{array}$ & 99 & 4 & $\begin{array}{c}\text { Sulfate reduction \& } \\
\text { thiosulfate } \\
\text { disproportionation }\end{array}$ & GU196831 \\
\hline $\begin{array}{l}\text { Candidate division SR1 } \\
\text { bacterium RAAC1_SR1_1 }\end{array}$ & 85 & 4 & Fermentation & СР006913 \\
\hline Halomonas sp. IB-559 & 99 & 2 & $\begin{array}{l}\text { Heterotrophic sulfide } \\
\text { oxidation }\end{array}$ & AJ309560 \\
\hline Desulfurivibrio sp. AMeS2 & 96 & 2 & Sulfur disproportionation & KF148062 \\
\hline Bacteroidetes VNs52 & 77 & 2 & N.D.* & FJ168485 \\
\hline $\begin{array}{l}\text { Desulfonatronospira } \\
\text { thiodismutans ASO3-1 }\end{array}$ & 98 & 1 & $\begin{array}{c}\text { Sulfate reduction \& } \\
\text { thiosulfate } \\
\text { disproportionation }\end{array}$ & NR 044459 \\
\hline $\begin{array}{l}\text { Desulfonatronovibrio sp. } \\
\text { AHT } 10\end{array}$ & 97 & 1 & Thiosulfate reduction & FJ469580 \\
\hline Thiomicrospira sp. JB-A1F & 99 & 1 & Sulfur oxidation & AF013976 \\
\hline $\begin{array}{l}\text { Dethiobacter alkaliphilus } \\
\text { AHT } 1\end{array}$ & 89 & 1 & $\begin{array}{l}\text { Thiosulfate reduction \& } \\
\text { Sulfur disproportionation }\end{array}$ & NR 044205 \\
\hline Bacillus sp. IST-38 & 86 & 1 & $\begin{array}{l}\text { Fermentation \& iron } \\
\text { reduction }\end{array}$ & FM877978 \\
\hline $\begin{array}{l}\text { Low } \mathrm{G}+\mathrm{C} \text { Gram-positive } \\
\text { bacterium IRB } 1\end{array}$ & 94 & 1 & Iron reduction & DQ631799 \\
\hline $\begin{array}{l}\text { Gracilimonas tropica } \\
\text { strain CL-CB462 }\end{array}$ & 92 & 1 & Fermentation & NR 044361 \\
\hline
\end{tabular}

*No data available. 


\section{Thiosulfate conversion}

Thiosulfate conversion occurred either through disproportionation and subsequent reduction of sulfate or through direct reduction (Figure $1 \mathrm{~A}$ ). In previous studies with marine sediments thiosulfate conversion was shown to occur partly by disproportionation and partly by reduction (Jørgensen, 1990). Disproportionation occurred as sulfate was produced in the bioreactor. The production of sulfate from thiosulfate using $\mathrm{O}_{2}$ or nitrate as electron acceptor can be discarded since these were not present in our system (Sorokin et al., 2011c). Phototrophic microorganisms can also produce sulfate from thiosulfate but such microorganisms were not found in microbial community analysis (Table 3 ), and therefore cannot explain sulfate production (Sorokin et al., 2011c). Thus, thiosulfate disproportionation is the most probable metabolism for sulfate production. Thiosulfate disproportionation can occur biologically and chemically (Bak and Cypionka, 1987; Kamyshny et al., 2014). However, chemical disproportionation did not occur at the conditions used as can be seen in the batch bottles experiments (Figure 4C). Clones with similarity to known thiosulfate-disproportionating bacteria (Desulfonatronovibrio and Desulfonatronospira) were identified (Table 3). Desulfonatronovibrio and Desulfonatronospira are also capable of sulfate reduction, which was also observed. For the two isolated and characterized species it was found that disproportionation can occur without electron donor (Sorokin et al., 2011d). In the current study, thiosulfate disproportionation also took place when electron donors were available $\left(\mathrm{H}_{2}\right.$ supplied and formate produced) (Figure S2). Assuming a complete mixing of the bioreactor, it is unlikely that there were regions where biomass did not have access to at least one of these electron donors. 

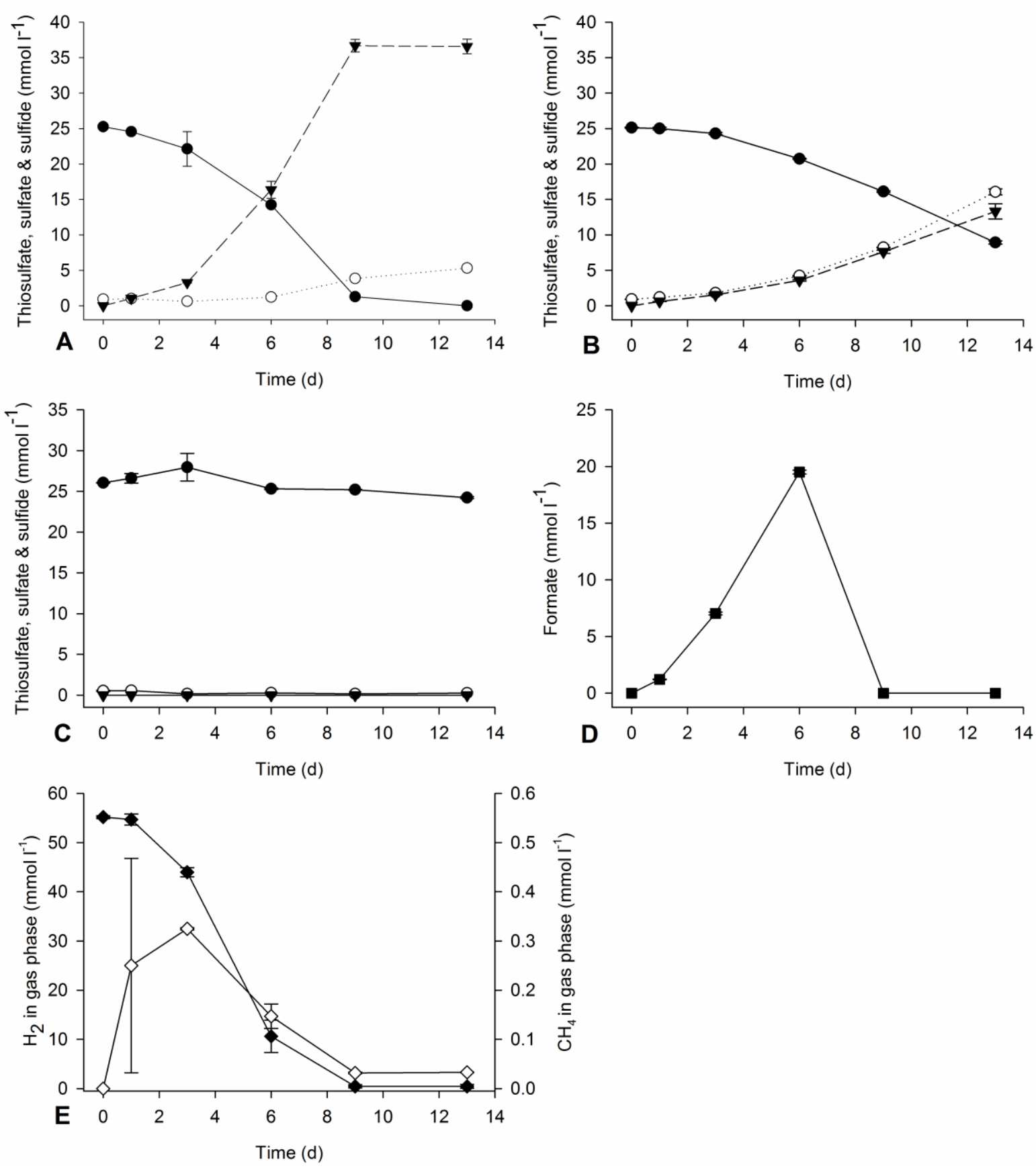

Figure 4 - Thiosulfate conversion and $\mathrm{H}_{2}$ use in batch tests. A - Average thiosulfate (•), sulfate ( $\circ$ ) and sulfide $(\boldsymbol{\nabla})$ concentration with $\mathrm{H}_{2}$. $\mathrm{B}$ - Average thiosulfate $(\bullet)$, sulfate $(\circ)$, sulfide $(\boldsymbol{\nabla})$ concentration with $\mathrm{N}_{2}$. C - Average thiosulfate $(\bullet)$, sulfate $(\circ)$, sulfide $(\boldsymbol{\nabla})$ concentration in the chemical controls with $\mathrm{N}_{2}$. D - Average formate $(\mathbf{a})$ concentration with $\mathrm{H}_{2}$. E - Average $\mathrm{H}_{2}(\diamond)$ and $\mathrm{CH}_{4}(\diamond)$ concentration in the gas phase with $\mathrm{H}_{2}$. 
To better understand the effect of $\mathrm{H}_{2}$ and formate on the overall thiosulfate conversion, batch experiments were performed. When no electron donor was available, only thiosulfate disproportionation occurred (Figure 4B). When $\mathrm{H}_{2}$ and/or formate were available, thiosulfate was mainly converted to sulfide and some sulfate, confirming that disproportionation occurred in the presence of an electron donor (Figure 4A). When all electron donors were depleted, after day 9, sulfate accumulated due to disproportionation (Figure $4 \mathrm{~A}, 4 \mathrm{D}$ and $4 \mathrm{E}$ ). These results reinforce the idea that thiosulfate disproportionation occurs even in the presence of an electron donor. More detailed studies are required to understand the mechanism of thiosulfate disproportionation.
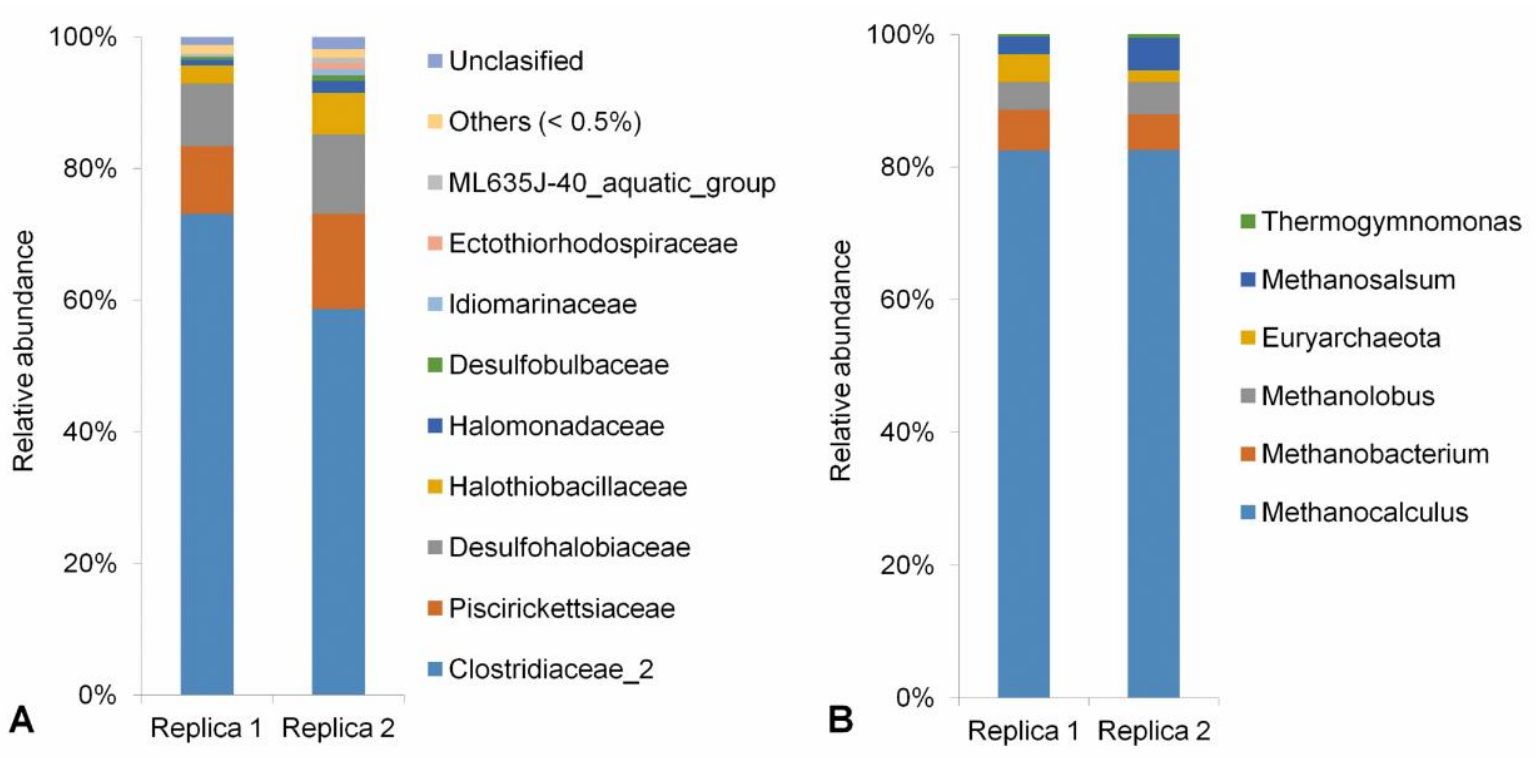

Figure 5 - Bacteria and Archaea 16S rRNA relative abundance at the end of Run 4 on family level. OTUs with less than $0.5 \%$ relative abundance were grouped in "others".

\section{Microbial community}

The microbial community in the bioreactor changed when the HRT was lowered during the bioreactor operation and was different between suspended biomass and biomass attached to the bioreactor walls (Figure S1).

For bacteria, there is a clear decrease in diversity with the decrease of HRT. The bacteria with higher growth rates are kept in the bioreactor while the ones that have 
growth rates lower than dilution rate get washed out, unless they grow attached to the bioreactor walls. This also suggests that adding support material to the bioreactor might improve the thiosulfate conversion efficiencies by keeping more biomass and microbial diversity inside the bioreactor.

A decrease in archaeal diversity with lower HRT was not observed (Figure S1). The archaeal community of suspended and attached biomass was similar, which indicates that the archaea in the bioreactor were not affected by the dilution rate applied.

The microbial community obtained at the end of run 4 (day 140) was studied further. A $16 \mathrm{~S}$ rRNA gene clone library for bacteria was made and used to identify phylogenetic affiliation of the dominant bacteria while a 16S rRNA gene MiSeq approach for both bacteria and archaea was used to study the relative abundance of different microorganisms (Table 3; Figure 5). Bacteria belonging to the family Clostridiaceae were dominant in the bioreactor (Figure 5). In the clone library, 16S rRNA genes that have $97 \%$ similarity to Tindallia texcoconensis were identified (Table 3 ). These clones were also dominant in a hydrogen fed sulfate-reducing bioreactor (Sousa et al., 2015a). Tindallia texcoconensis is a fermentative bacterium that uses peptone and a few amino acids for growth (Alazard et al., 2007). In our study, however, no organic compounds were fed to the bioreactor. Due to the low concentration of biomass in the bioreactor, it is very unlikely that such microorganisms can become dominant by feeding on dead biomass alone. Another isolate that is closely related to Tindallia magadiensis was able to produce formate from $\mathrm{H}_{2}$ and $\mathrm{CO}_{2}$ and use it to reduce thiosulfate (Sorokin et al., 2011a). In our bioreactor, high concentrations of formate (up to $100 \mathrm{mM}$ ) were found that could have been produced by the microorganisms closely related to Tindallia sp. (Figure S2). At the actual conditions in the bioreactor: $\mathrm{pH} \mathrm{9,1}$

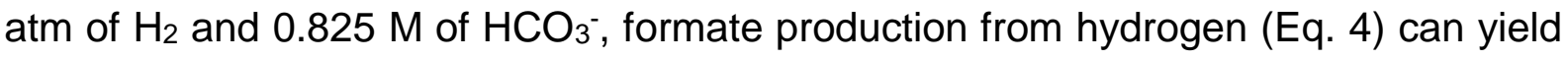
energy. The Gibbs free energy is $-24.3 \mathrm{~kJ}$ when formate concentration is low, $0.01 \mathrm{mM}$, and is close to the thermodynamic equilibrium $(6.88 \mathrm{~kJ})$ when formate reaches $90 \mathrm{mM}$.

$$
\mathrm{H}_{2}+\mathrm{HCO}_{3}^{-} \rightarrow \mathrm{HCO}_{2}^{-}+\mathrm{H}_{2} \mathrm{O}
$$

Thiosulfate-reducing and thiosulfate-disproportionating bacteria, belonging to the family Desulfohalobiaceae, only represent a small fraction of the total population, 
approximately 10\% (Figure 5). From this family Desulfonatronovibrio sp. and Desulfonatronospira thiodismutans related clones were identified (Table 3). These two genera can reduce sulfate. Sequences related to other known thiosulfate-reducing bacteria were identified, such as Desulfurivibrio sp. and Dethiobacter sp. (Table 3). The species previously studied that belong to these genera cannot use sulfate as electron acceptor. Likely, their role in the bioreactor was restricted to thiosulfate disproportionation or thiosulfate reduction.

Surprisingly, microorganisms related to the family Piscirickettsiaceae and Halothiobacillaceae represented approximately $10-14 \%$ and $3-6 \%$ of the total microbial community, respectively (Figure 5). In the clone library 28 out of 64 clones were closely related to Thiomicrospira sp. from the family Piscirickettsiaceae, and Thioalkalibacter $\mathrm{sp}$. from the family Halothiobacillaceae. These bacteria are mainly known as sulfuroxidizing bacteria that thrive in oxic and micro-oxic conditions (Sorokin et al., 2006). As $\mathrm{O}_{2}$ and nitrate were not added to the bioreactor the physiological role of these microorganisms remains unknown. Sulfide oxidizers were previously also identified in sulfate-reducing bioreactors operated at haloalkaline conditions, where their role was not established (Zhou et al., 2015a). It seems plausible to assume that sulfide-oxidizing microorganisms might be capable of disproportionation of sulfur compounds such as thiosulfate (Warren et al., 2008). However, this was never showed for haloalkaliphilc sulfide oxidizing microorganisms.

As methane production occurred in the biofilm run, the archaeal community was also investigated in the biomass at the end of the reactor run. Archaea belonging to the genus Methanocalculus were most dominant, approximately $82 \%$ of the total archaea. Methanocalculus sp. are known as haloalkaliphilic methanogens that can use $\mathrm{H}_{2} / \mathrm{CO}_{2}$ or formate as growth substrates (Sorokin et al., 2015).

\section{Application outlook}

The results clearly show that it is possible to efficiently convert thiosulfate to sulfide using a bioreactor fed with hydrogen as electron donor and without any addition of organic compounds. The conversion of thiosulfate to sulfide can thus be used in biodesulfurization processes to treat the bleed stream and reduced the water and caustic requirements. Two different approaches for a practical application of thiosulfate 
conversion can be considered (Table 4). One approach is using $\mathrm{H}_{2}$ or formate as electron donor to fully reduced thiosulfate to sulfide and eliminate the need for bleed stream disposal. Another new approach is without addition of electron donor by making use of thiosulfate disproportionation to sulfate and sulfide. The option without electron donor could be applied to selectively remove thiosulfate from biodesulfurization bleed streams without the additional cost of an electron donor (Figure 6). By disproportionating thiosulfate to sulfate and sulfide and recycling the bleed stream back, sulfate would become the main component of the bleed stream. Thiosulfate adds to the total COD of the bleed stream while sulfate does not. Due to COD disposal restrictions, removing thiosulfate without use of electron donor might be an attractive option to decrease the bleed stream COD content.

Table 4 - Relative comparison of three biodesulfurization processes.

\begin{tabular}{lcccc}
\hline Process & $\begin{array}{c}\text { Caustic } \\
\text { consumption }\end{array}$ & $\begin{array}{c}\text { Volume of } \\
\text { Waste bleed } \\
\text { stream disposal }\end{array}$ & $\begin{array}{c}\text { Bleed stream } \\
\text { neutralization }\end{array}$ & $\begin{array}{c}\text { Additional } \\
\text { chemical } \\
\text { consumption }\end{array}$ \\
\hline $\begin{array}{l}\text { Standard } \\
\text { biodesulfurization }\end{array}$ & High & High & $\begin{array}{c}\text { COD and Sulfate } \\
\text { removal required }\end{array}$ & None \\
$\begin{array}{l}\text { With thiosulfate } \\
\text { completely reduced } \\
\text { to sulfide }\end{array}$ & Low & Low & Not required & $\begin{array}{c}\text { Electron donor } \\
\left.\text { (e.g. } \mathrm{H}_{2}\right)\end{array}$ \\
$\begin{array}{l}\text { With thiosulfate } \\
\text { disproportionation }\end{array}$ & Medium & Medium & $\begin{array}{c}\text { Sulfate removal } \\
\text { required }\end{array}$ & $\begin{array}{c}\text { None or very } \\
\text { low }\end{array}$ \\
\hline
\end{tabular}

a Described in this work.

b Proposed in this work.

${ }^{c}$ COD (mainly from thiosulfate) removal is usually performed by aerobic biologic treatment.

d Sulfate removal is usually performed by precipitation with lime.

e An organic carbon source may be beneficial to support biomass growth.

Thiosulfate disproportionation results in a low amount of energy per reaction. It yields $-22 \mathrm{~kJ}$ at standard conditions $\left(\mathrm{pH} 7\right.$ and $\left.25^{\circ} \mathrm{C}\right)$ and $-62 \mathrm{~kJ}$ when taking into account the in situ concentrations, $\mathrm{pH} 9$ and $25 \mathrm{mM}$ thiosulfate. This limits biomass growth in a bioreactor without electron donor. But, at the conditions used in the bioreactor, $\mathrm{pH} 9$ and about $1.5 \mathrm{M}$ sodium carbonate/bicarbonate, thiosulfate disproportionation yields more energy, $-89 \mathrm{~kJ}$ per reaction. Because the disproportionation produces protons, it 
actually becomes thermodynamically more favourable at high $\mathrm{pH}$. Biomass growth was determined in small batch tests. It became clear that microorganisms grow by thiosulfate disproportionation, even though the growth yield is less than with electron donor (Figure S3). Thiosulfate disproportionation should be further explored in bioreactor systems to get insight into its feasibility for future large scale application.

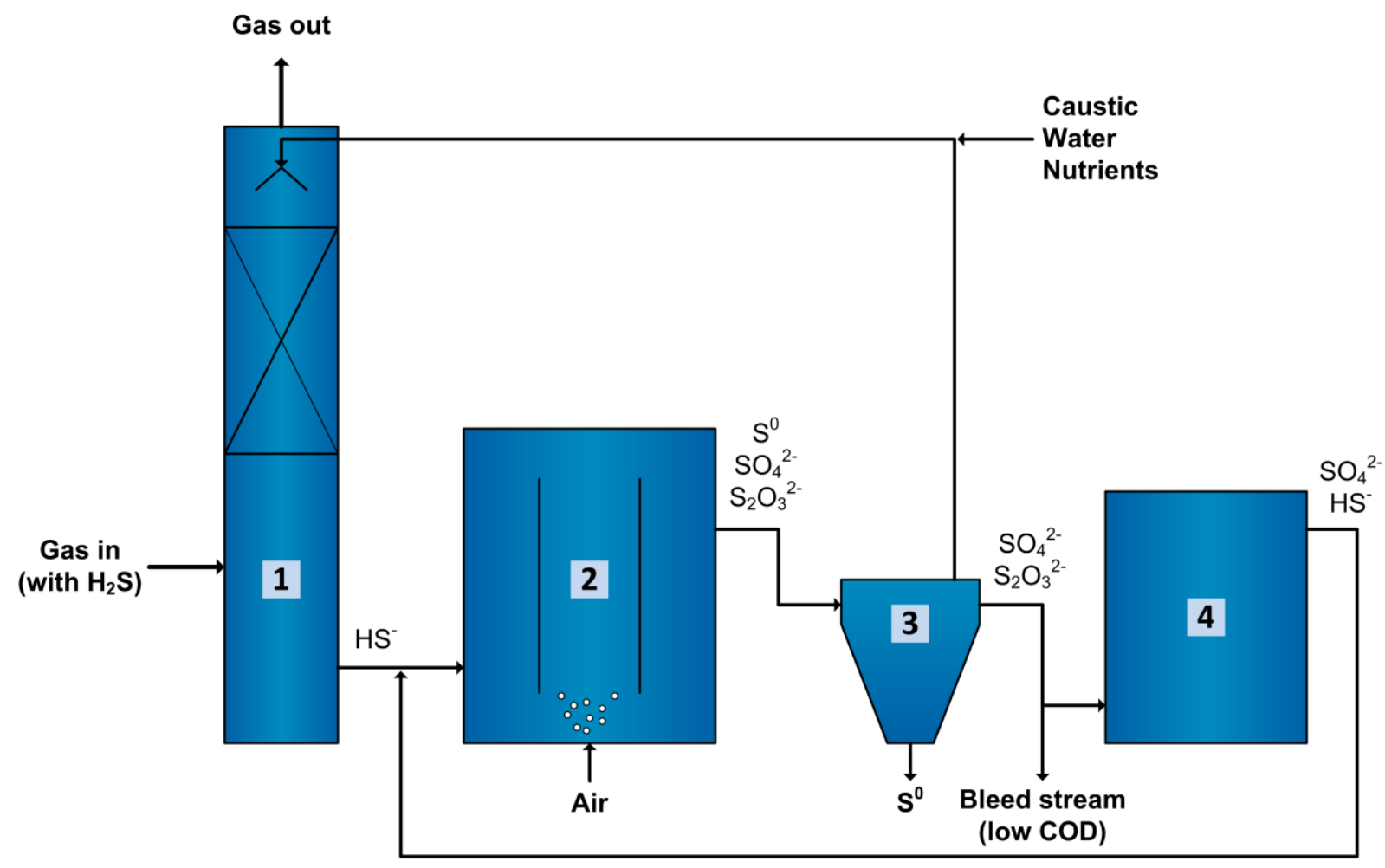

Figure 6 - Biological process for gas desulfurization using an anaerobic thiosulfate $\left(\mathrm{S}_{2} \mathrm{O}_{3}{ }^{2-}\right)$ disproportionating bioreactor to reduce the bleed stream COD content. The sulfide $\left(\mathrm{H}_{2} \mathrm{~S}\right)$ present in the gas is solubilized in an alkaline solution as HS- using a scrubber (1). This HSrich solution goes to an aerobic bioreactor (2) where is biologically oxidized, under controlled microaerophilic conditions, to mostly elemental sulfur $\left(\mathrm{S}^{0}\right)$ and in small part to sulfate $\left(\mathrm{SO}_{4}{ }^{2-}\right)$ and also chemically oxidized, via polysulfides, to thiosulfate $\left(\mathrm{S}_{2} \mathrm{O}_{3}{ }^{2-}\right)$. The $\mathrm{S}^{0}$ is separated in a settler (3) and most of the liquid is recycled to the scrubber (1) to solubilize more $\mathrm{H}_{2} \mathrm{~S}$. Other part of the liquid goes through an anaerobic bioreactor (4) where $\mathrm{S}_{2} \mathrm{O}_{3}{ }^{2-}$, without addition of edonor, is disproportionated to $\mathrm{SO}_{4}{ }^{2-}$ and $\mathrm{HS}^{-}$which are recycled back to the aerobic bioreactor (2). With time this prevents accumulation of $\mathrm{S}_{2} \mathrm{O}_{3}{ }^{2-}$ in the whole system. When a bleed stream is discarded to add new caustic to the system, this bleed stream will have low chemical oxygen demand (COD) because only $\mathrm{S}_{2} \mathrm{O}_{3}{ }^{2-}$ and $\mathrm{HS}^{-}$contribute to the $\mathrm{COD}$ and not $\mathrm{SO}_{4}{ }^{2-}$. 


\section{$\underline{\text { References }}$}

Alazard D, Badillo C, Fardeau ML, Cayol JL, Thomas P, Roldan T, Tholozan JL, Ollivier B (2006) Tindallia texcoconensis sp. nov., a new haloalkaliphilic bacterium isolated from lake Texcoco, Mexico. Extremophiles 11:33-39.

Bak F, Cypionka H (1987) A novel type of energy metabolism involving fermentation of inorganic sulphur compounds. Nature 326:891-892.

Buisman CJN, Post R, IJspeert P, Geraats G, Lettinga G (1989) Biotechnological process for sulphide removal with sulphur reclamation. Acta Biotechnol 9:255-267.

Caporaso JG, Kuczynski J, Stombaugh J, Bittinger K, Bushman FD, Costello EK, Fierer N, Pena AG, Goodrich JK, Gordon JI, Huttley GA, Kelley ST, Knights D, Koenig JE, Ley RE, Lozupone CA, McDonald D, Muegge BD, Pirrung M, Reeder J, Sevinsky JR, Turnbaugh PJ, Walters WA, Widmann J, Yatsunenko T, Zaneveld J, Knight R (2010) QIIME allows analysis of high-throughput community sequencing data. Nature Methods 7:335-336.

Cole JR, Wang Q, Cardenas E, Fish J, Chai B, Farris RJ, Kulam-Syed-Mohideen AS, McGarrell DM, Marsh T, Garrity GM, Tiedje JM (2009) The Ribosomal Database Project: improved alignments and new tools for rRNA analysis. Nucl Acids Res 37:141145.

Edgar RC (2013) UPARSE: highly accurate OTU sequences from microbial amplicon reads. Nature Methods 10:996-998.

Finster K (2008) Microbiological disproportionation of inorganic sulfur compounds. J Sulfur Chem 29:37-41.

Gantner SA, Andersson F, Alonso-Saez L, Bertilsson S (2011) Novel primers for 16S rRNAbased archaeal community analyses in environmental samples. J Microbiol Methods 84:12-18.

Großkopf R, Janssen PH, Liesack W (1998) Diversity and structure of the methanogenic community in anoxic rice paddy soil microcosms as examined by cultivation and direct 16S rRNA gene sequence retrieval. Appl Environ Microbiol 64:960-969.

Haas BJ, Gevers D, Earl AM, Feldgarden M, Ward DV, Giannoukos G, Ciulla D, Tabbaa D, Highlander SK, Sodergren E, Methe B, DeSantis TZ, Human Microbiome C, Petrosino JF, Knight R, Birren BW (2011) Chimeric 16S rRNA sequence formation and detection in Sanger and 454-pyrosequenced PCR amplicons. Genome Res 21:494-504. 
Herlemann DP, Labrenz M, Jurgens K, Bertilsson S, Waniek JJ, Andersson AF (2011) Transitions in bacterial communities along the $2000 \mathrm{~km}$ salinity gradient of the Baltic Sea. ISME J 5:1571-1579.

Hugerth LW, Wefer HA, Lundin S, Jakobsson HE, Lindberg M, Rodin S, Engstrand L, Andersson AF (2014) DegePrime, a program for degenerate primer design for broadtaxonomic-range PCR in microbial ecology studies. Appl Environ Microbiol 80:51165123.

Jaeggi T, Kortman GA, Moretti D, Chassard C, Holding P, Dostal A, Boekhorst J, Timmerman HM, Swinkels DW, Tjalsma H, Njenga J, Mwangi A, Kvalsvig J, Lacroix C, Zimmermann MB (2014) Iron fortification adversely affects the gut microbiome, increases pathogen abundance and induces intestinal inflammation in Kenyan infants. Gut 64:731-742.

Janssen AJH, Lens PNL, Stams AJM, Plugge CM, Sorokin DY, Muyzer G, Dijkman H, van Zessen E, Luimes P, Buisman CJN (2009) Application of bacteria involved in the biological sulfur cycle for paper mill effluent purification. Sci Total Environ 407:13331343.

Jørgensen BB (1990) A thiosulfate shunt in the sulfur cycle of marine sediments. Science 249:152-154.

Kamyshny A, Druschel G, Mansaray ZF, Farquhar J (2014) Multiple sulfur isotopes fractionations associated with abiotic sulfur transformations in Yellowstone National Park geothermal springs. Geochem Transactions 15:1-22.

Lane DL (1991) 16S/23S rRNA sequencing. In: Stackebrandt E, Goodfellow M (ed) Nucleic Acid Techniques in Bacterial Systematics, John Wiley \& Sons Ltd, Chichester, United Kingdom, pp 115-148.

Lindh MV, Figueroa D, Sjöstedt J, Baltar F, Lundin D, Andersson A, Legrand C, Pinhassi J (2015) Transplant experiments uncover Baltic Sea basin-specific responses in bacterioplankton community composition and metabolic activities. Front Microbiol $6: 223$.

Quast C, Pruesse E, Yilmaz P, Gerken J, Schweer T, Yarza P, Peplies J, Glöckner FO (2013) The SILVA ribosomal RNA gene database project: improved data processing and webbased tools. Nucl Acids Res 41:590-596.

Robertson CE, Harris JK, Wagner BD, Granger D, Browne K, Tatem B, Feazel LM, Park K, Pace NR, Frank DN (2013) Explicet: graphical user interface software for metadatadriven management, analysis and visualization of microbiome data. Bioinformatics 29:3100-3101. 
Sorokin DY, Tourova TP, Lysenko AM, Muyzer G (2006) Diversity of culturable halophilic sulfur-oxidizing bacteria in hypersaline habitats. Microbiololy 152:3013-3023.

Sorokin DY, Tourova TP, Henstra AM, Stams AJM, Galinski EA, Muyzer G (2008) Sulfidogenesis under extremely haloalkaline conditions by Desulfonatronospira thiodismutans gen. nov., sp. nov., and Desulfonatronospira delicata sp. nov. - a novel lineage of Deltaproteobacteria from hypersaline soda lakes. Microbiology 154:14441453.

Sorokin DY, Rusanov II, Pimenov NV, Tourova TP, Abbas B, Muyzer G (2010) Sulfidogenesis under extremely haloalkaline conditions in soda lakes of Kulunda Steppe (Altai, Russia). FEMS Microbiol Ecol 73:278-290.

Sorokin DY, Detkova EN, Muyzer G (2011a) Sulfur-dependent respiration under extremely haloalkaline conditions in soda lake 'acetogens' and the description of Natroniella sulfidigena sp. nov. FEMS Microbiol Lett 319:88-95.

Sorokin DY, Kuenen JG, Muyzer G (2011b) The microbial sulfur cycle at extremely haloalkaline conditions of soda lakes. Front Microbiol 2:1-16.

Sorokin DY, Tourova TP, Kolganova TV, Detkova EN, Galinski EA, Muyzer G (2011c) Culturable diversity of lithotrophic haloalkaliphilic sulfate-reducing bacteria in soda lakes and the description of Desulfonatronum thioautotrophicum sp. nov., Desulfonatronum thiosulfatophilum sp. nov., Desulfonatronovibrio thiodismutans sp. nov., and Desulfonatronovibrio magnus sp. nov.. Extremophiles 15:391-401.

Sorokin DY, Abbas B, Geleijnse M, Pimenov NV, Sukhacheva MV, van Loosdrecht MCM (2015) Methanogenesis at extremely haloalkaline conditions in the soda lakes of Kulunda Steppe (Altai, Russia). FEMS Microbiol Ecol 91 :fiv016.

Sousa JAB, Plugge CM, Stams AJM, Bijmans MFM (2015) Sulfate reduction in a hydrogen fed bioreactor operated at haloalkaline conditions. Water Res 68:67-76.

Sydow U, Wohland P, Wolke I, Cypionka H (2002) Bioenergetics of the alkaliphilic sulfatereducing bacterium Desulfonatronovibrio hydrogenovorans. Microbiol 148:853-860.

van den Bosch PLF, Sorokin DY, Buisman CJN, Janssen AJH (2008) The effect of pH on thiosulfate formation in a biotechnological process for the removal of hydrogen sulfide from gas streams. Environ Sci Technol 42:2637-2642.

Warren LA, Norlund LI, Bernier L (2008) Microbial thiosulphate reaction arrays: the interactive roles of $\mathrm{Fe}(\mathrm{III}), \mathrm{O}_{2}$ and microbial strain on disproportionation and oxidation pathways. Geobiol 6:461-470. 
Widdel F (1988) Microbiology and ecology of sulfate- and sulfur-reducing bacteria. In: Zehnder AJB (ed) The Biology of Anaerobic Microorganisms, Wiley, New York, 1988, pp 469586.

Wolin EA, Wolin MJ, Wolfe RS (1963) Formation of methane by bacterial extract. J Biol Chem 238:2882-2886.

Zhou J, Zhou X, Li Y, Xing J (2015a) Bacterial communities in haloalkaliphilic sulfate-reducing bioreactors under different electron donors revealed by 16S rRNA MiSeq sequencing. J Hazard Mater 295:176-184.

Zhou J, Xing J (2015b) Effect of electron donors on the performance of haloalkaliphilic sulfatereducing bioreactors for flue gas treatment and microbial degradation patterns related to sulfate reduction of different electron donors. Biochem Eng J 96:14-22. 


\section{Suplementary information}

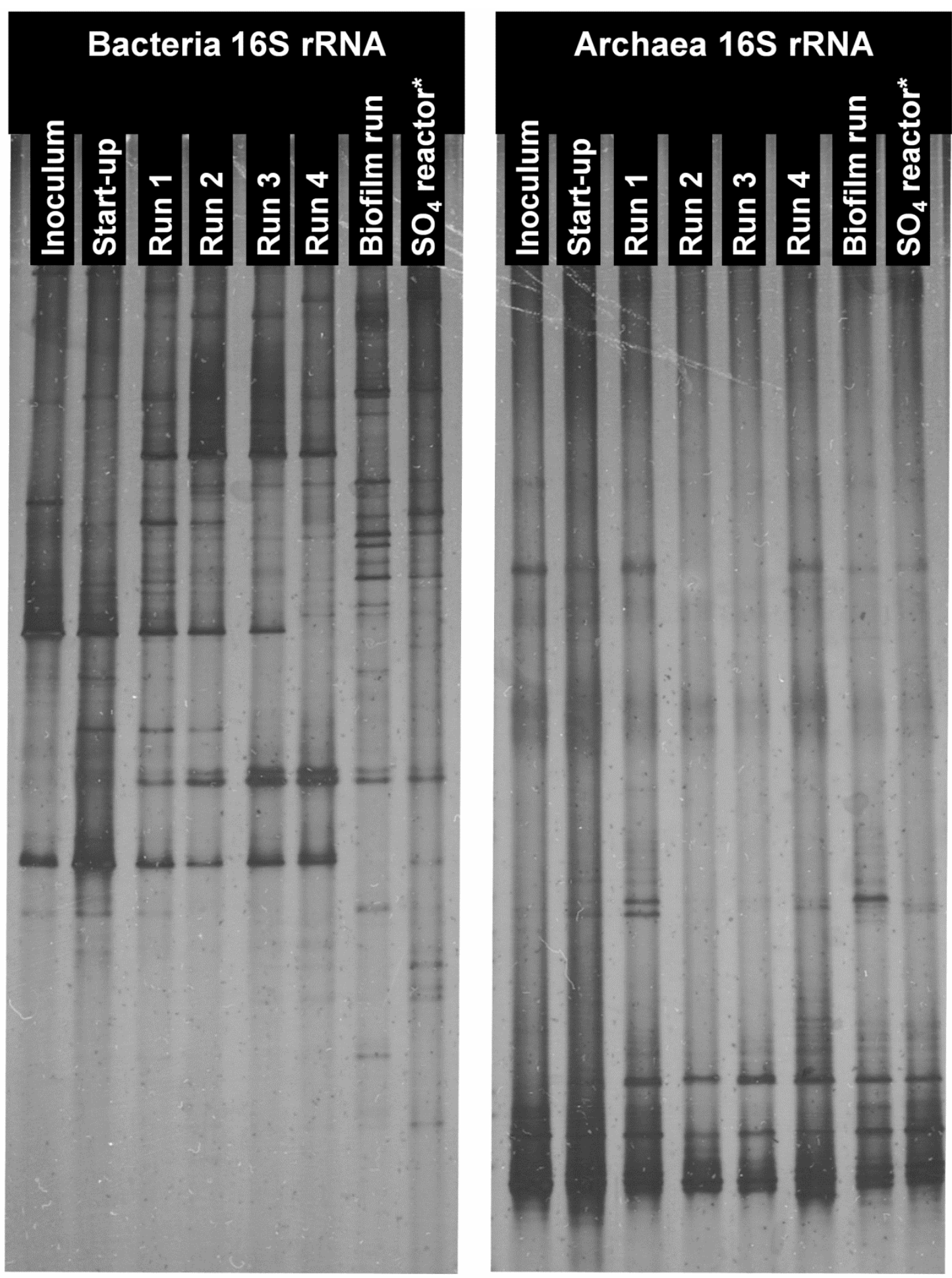

Figure S1 - 16S rRNA gene DGGE profiles of bacterial and archaeal community from inoculum, the end of start-up phase, run 1, run 2, run 3, run 4, biofilm run and biomass from a sulfate-reducing bioreactor previously reported (Sousa et al., 2015a). 


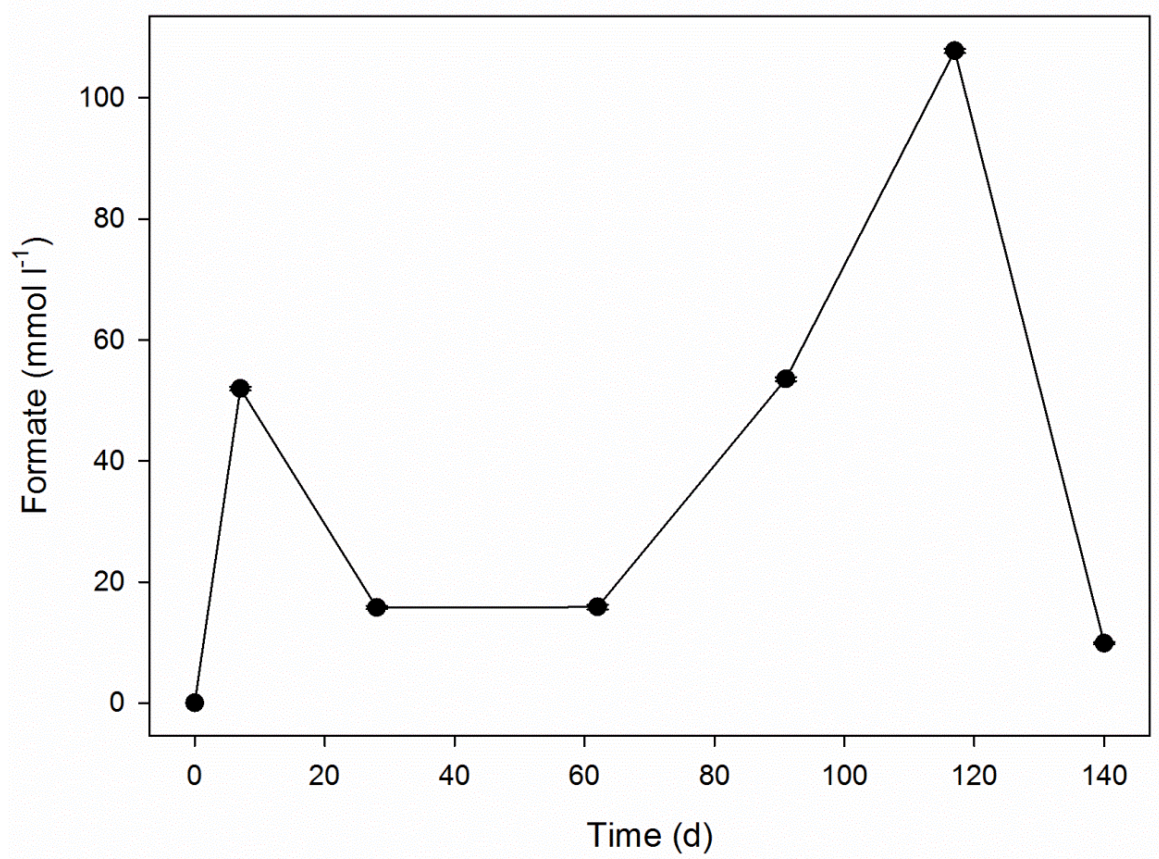

Figure S2 - Formate accumulation in the bioreactor over time.

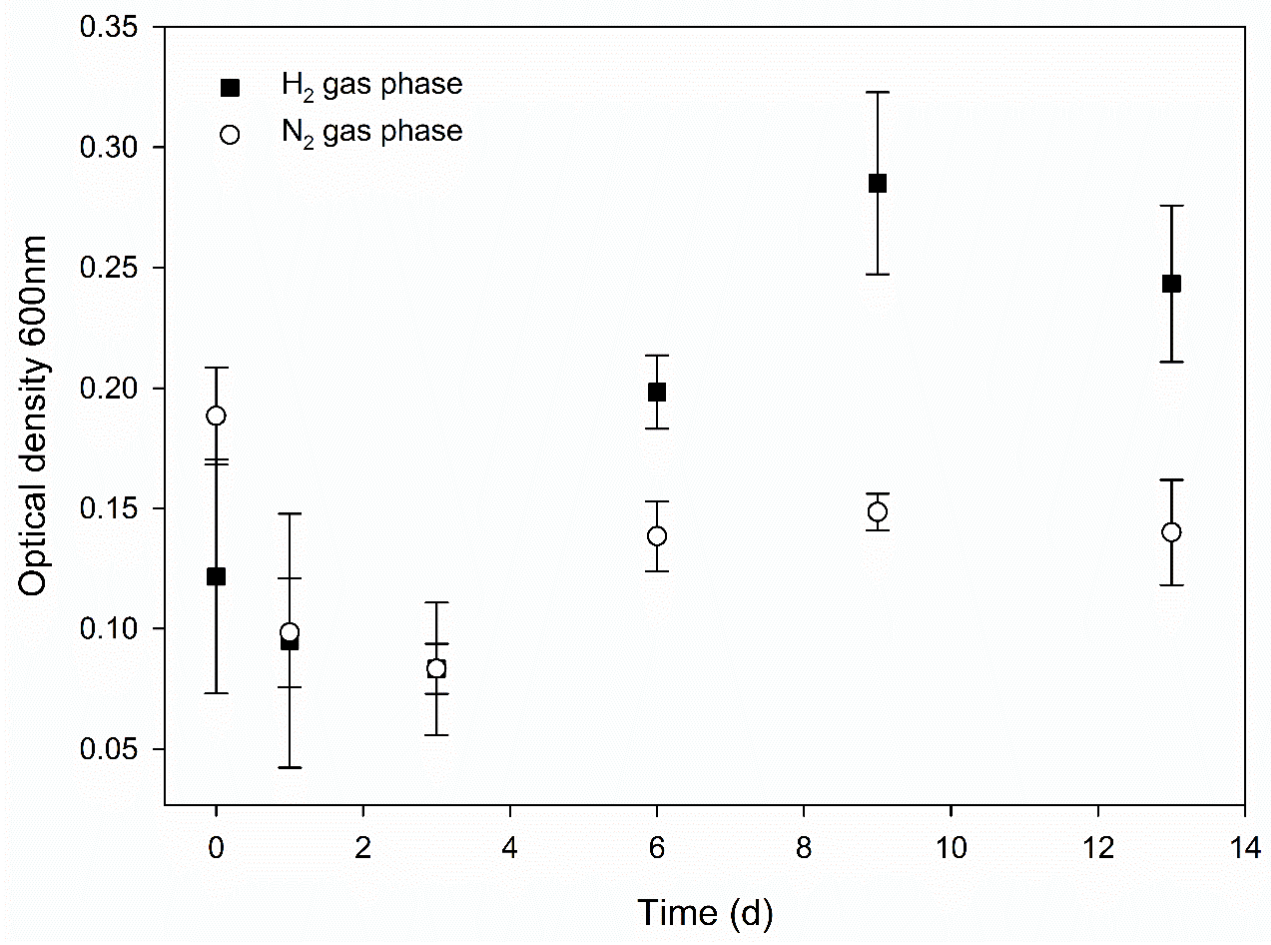

Figure S3 - Average optical density at $600 \mathrm{~nm}$ in batch tests with $\mathrm{N}_{2}$ and $\mathrm{H}_{2}$ over time. 


\section{Chapter 5}

\section{Immobilization of sulfate/thiosulfate-reducing biomass on sand under haloalkaline conditions}

João AB Sousa, Andrea Bolgár, Stephan Christel, Mark Dopson, Martijn FM Bijmans, Alfons JM Stams, Caroline M Plugge 


\section{Abstract}

Biological sulfate and thiosulfate reduction under haloalkaline conditions can be applied to treat waste streams from biodesulfurization systems. However, the lack of microbial aggregation under haloalkaline conditions limits the volumetric rates of sulfate and thiosulfate reducing bioreactors. In this study, sand was used as a biomass carrier material to increase biomass retention and consequently raise the volumetric rates. The results showed that higher biomass concentrations could be achieved with sand and that sulfate/thiosulfate reduction rates increased. However, the biomass attachment was weak and restricted to cavities within the sand particles. Acetate produced by acetogenic bacteria from $\mathrm{H}_{2}$ and $\mathrm{CO}_{2}$ enhanced biomass growth, while formate that was also produced from $\mathrm{H}_{2}$ and $\mathrm{CO}_{2}$ enhanced sulfate reduction. The results indicate that even though the biomass attachment to sand is weak, it can still increase the biomass concentration and consequently the sulfate and thiosulfate reduction volumetric rates. 


\section{Introduction}

Biological sulfate and thiosulfate reduction are widespread microbiological processes that occur under anoxic conditions. These processes can be applied to treat sulfate and thiosulfate-rich waste streams (van Houten et al., 2006; Muyzer and Stams, 2008). In gas biodesulfurization systems, for example, sulfate and thiosulfate rich waste streams with a high $\mathrm{pH}$ and salinity (haloalkaline conditions) are produced (Janssen et al., 2009). In this case, haloalkaliphilic sulfate- and thiosulfate-reducing microorganisms that thrive under these conditions are required. Such microorganisms can be found in natural environments such as soda lakes, where $\mathrm{pH}$ values up to 11 are commonly found and the salinity can reach saturation (Sorokin et al., 2011a). Sediments from soda lakes have been successfully used to inoculate a bioreactor to treat sulfate and thiosulfate-rich streams at haloalkaline conditions (Sousa et al., 2015a).

Even though sulfate and thiosulfate conversion to sulfide has been shown in a bioreactor operated at haloalkaline conditions, the reported lack of biomass aggregation poses a challenge (Sousa et al., 2015a). Without biomass aggregation, the hydraulic retention time (HRT) is the only parameter that allows the biomass concentration in these bioreactors to be controlled. When applying an HRT of 2.5 days in a sulfate-reducing bioreactor, the sulfate reduction capacity was significantly decreased compared to higher HRTs. Similarly, in a thiosulfate reducing bioreactor operated with a HRT of 1.7 days, the thiosulfate reduction capacity also decreased (Sousa et al., 2015a). This indicated that the system was limited by biomass growth. Therefore, retaining biomass in the bioreactor is a key factor to improve the sulfate and thiosulfate conversion capacity.

When biomass self-aggregation as flocks or granules does not occur, the use of carrier materials or membranes can improve the biomass retention. Sand and pumice were previously used for sulfate-reducing bioreactors operated at neutral and acidic conditions and the biomass successfully attached to these silica based carrier materials (Christensen et al., 1996; van Houten et al., 1995). In a prior study, biofilm growth was observed on the glass wall of a sulfate-reducing bioreactor operated at haloalkaline conditions (Sousa et al., 2015a). This suggests that silica based carrier material might also work under haloalkaline conditions to retain biomass. 
Studies on sulfate or thiosulfate converting gas-lift bioreactors at haloalkaline conditions using carrier material are not reported, while detailed information on microbial aggregation and attachment at haloalkaline conditions in natural environments is scarce (Sousa et al., 2015b). Haloalkaline environments have unique physical-chemical characteristics that may affect aggregation, such as reduced effect of electrostatic charges, difference in hydrophobicity of cell surfaces and low divalent ions concentration (Grant et al., 1990; van Loosdrecht et al., 1987; Otto et al., 1999).

In the current study, sand was used as a carrier material for biomass retention in a $\mathrm{H}_{2}$ fed, sulfate- and thiosulfate-converting gas-lift bioreactor operated at haloalkaline conditions. The bioreactor performance and biomass retention were investigated, and the attached and suspended microbial communities were characterized.

\section{Methods}

\section{Bioreactor}

A 4.4 liter glass gas lift reactor with an internal 3 phase separator was used as described previously (Sousa et al., 2015a). The temperature was kept at $35^{\circ} \mathrm{C}$ and the $\mathrm{pH}$ controlled at $\mathrm{pH} 9$ by supplying $\mathrm{CO}_{2}$ via a mass flow controller. As carrier material for biomass, $0.5 \mathrm{I}$ of acid washed sea sand with a particle size of $0.1-0.3 \mathrm{~mm}$ (VWR, Amsterdam, the Netherlands) was added.

\section{Inoculum}

The bioreactor was inoculated with $50 \mathrm{ml}$ of biomass collected from a sulfate-reducing bioreactor (operated for 155 days) and $50 \mathrm{ml}$ of biomass collected from a thiosulfateconverting bioreactor (operated for 140 days), both fed with $\mathrm{H}_{2}$ and $\mathrm{CO}_{2}$ and operated at $\mathrm{pH} 9$ and $1.5 \mathrm{M} \mathrm{Na}^{+}$(Sousa et al., 2015a). 


\section{Medium}

The mineral medium used was buffered at $\mathrm{pH} 9.00 \pm 0.05$ with sodium carbonate and sodium bicarbonate, adding to a total of $1.5 \mathrm{M} \mathrm{Na}^{+}$. The medium composition was as follows: $\mathrm{Na}_{2} \mathrm{CO}_{3}\left(33.6 \mathrm{~g} \mathrm{l}^{-1}\right), \mathrm{NaHCO}_{3}\left(69.3 \mathrm{~g} \mathrm{l}^{-1}\right), \mathrm{KHCO}_{3}\left(1 \mathrm{~g} \mathrm{l}^{-1}\right), \mathrm{K}_{2} \mathrm{HPO}_{4}\left(1 \mathrm{~g} \mathrm{l}^{-1}\right)$, $\mathrm{NH}_{4} \mathrm{Cl}\left(0.27 \mathrm{~g} \mathrm{l}^{-1}\right), \mathrm{MgCl}_{2} .6 \mathrm{H}_{2} \mathrm{O}\left(0.1 \mathrm{gl}^{-1}\right), \mathrm{CaCl}_{2} .2 \mathrm{H}_{2} \mathrm{O}\left(0.01 \mathrm{gl}^{-1}\right)$ and $10 \mathrm{ml}^{-1}$ of vitamin solution (Wolin et al., 1963). Two trace element solutions were added as described previously (Sousa et al., 2015a). As electron acceptor, $7.1 \mathrm{~g} \mathrm{l}^{-1}$ or $14.2 \mathrm{~g} \mathrm{l}^{-1}$ (25 or 50 $\mathrm{mM}$ ) of sodium sulfate $\left(\mathrm{Na}_{2} \mathrm{SO}_{4}\right)$ and $3.95 \mathrm{~g} \mathrm{l}^{-1}$ or $7.9 \mathrm{~g} \mathrm{l}^{-1}(12.5 \mathrm{mM}$ or $25 \mathrm{mM})$ of sodium thiosulfate $\left(\mathrm{Na}_{2} \mathrm{~S}_{2} \mathrm{O}_{3}\right)$ were added.

\section{Experimental design}

The bioreactor was filled with medium and flushed overnight with $10 \mathrm{ml} \mathrm{min}^{-1} \mathrm{H}_{2}$ and a gas recirculation at $5 \mathrm{I} \mathrm{min}^{-1}$ to lower the redox potential. Afterwards, $\mathrm{H}_{2}$ was supplied at $5 \mathrm{ml} \mathrm{min}{ }^{-1}$, but was increased during the experiment to maintain an overpressure in the bioreactor (Figure 1c). Different influent and gas recirculation flows were tested and adjusted to prevent washout of sand particles with the effluent. Finally, the gas recirculation was set to approximately 7 I $\mathrm{min}^{-1}$.

The operation was performed under non-sterile conditions. Inoculation of the reactor was defined as time 0 . A batch run was performed to start-up the bioreactor and to confirm that the biomass was still capable of performing sulfate and thiosulfate conversion to sulfide (Start-up, Table 1). The start-up run was performed until the sulfate and thiosulfate concentrations were each below $10 \mathrm{mM}$. After the start-up phase, five continuous experiments were performed (Table 1 ; runs 1 to 5 ) as well as two experiments, where formate and acetate were spiked. Sodium formate (100 mM increase) and sodium acetate (100 mM increase) were directly injected into the bioreactor at the beginning of each test. The tests were performed in duplicate for formate and a single test for acetate. 
Table 1 - Operational characteristics of bioreactor runs

\begin{tabular}{|c|c|c|c|c|}
\hline & $\begin{array}{l}\text { Period } \\
\text { (d) }\end{array}$ & Mode & $\begin{array}{l}\text { HRT } \\
\text { (d) }\end{array}$ & $\begin{array}{l}\text { Total S loading rate } \\
\quad\left(\mathrm{mmol}_{\mathrm{S}} \mathrm{l}^{-1} \mathrm{~d}^{-1}\right)\end{array}$ \\
\hline Start-up & $0-6$ & Batch & N.A. ${ }^{a}$ & N.A. ${ }^{a}$ \\
\hline Run 1 & $7-42$ & Continuous & 1.7 & 29.4 \\
\hline Run 2 & $53-96$ & Continuous & 1 & 50 \\
\hline Run 3 & $97-113$ & Continuous & 0.5 & 100 \\
\hline Run 4 & 114-152 & Continuous & 1 & 50 \\
\hline Run 5 & $153-181$ & Continuous & 1 & 100 \\
\hline Formate spike & $182-188$ & Continuous & 1 & 100 \\
\hline Acetate spike & $195-197$ & Continuous & 1 & 100 \\
\hline
\end{tabular}

\section{Analytical procedures}

Liquid samples for volatile fatty acids, sulfate, thiosulfate and sulfide analysis, and gas samples were prepared and analyzed as described previously (Sousa et al., 2015a).

For biomass measurements, the sand-attached biomass was separated from the suspended biomass by settling for $30 \mathrm{~s}$ and both fractions were transferred to a new tube. One $\mathrm{ml}$ of sand was collected and the samples were washed 3 times with a carbonate/bicarbonate buffer with lower salinity (LS buffer; $\mathrm{pH} 9,0.5 \mathrm{M} \mathrm{Na}^{+}$instead of $1.5 \mathrm{M} \mathrm{Na}^{+}$). In the washing steps, sand was separated from the buffer by settling for $30 \mathrm{~s}$. Two $\mathrm{ml}$ of the suspended biomass was centrifuged (10 min, 10000g) and was washed 3 times with LS buffer. Finally, the total nitrogen content was determined using a cuvette test (LCK238, Hach Lange, Düsseldorf, Germany).

Biomass particle size for the suspended fraction was measured using laser measurement in a particle size and shape analyzer (Eyetech, Doner technologies, Or Akiva, Israel) with the Dipa 2000 software (Doner technologies, Or Akiva, Israel). Measurements were performed in triplicate for $120 \mathrm{~s}$ while stirring continuously. The morphology of the microorganisms was routinely examined using light microscopy 
(DMI6000B, Leica, Biberach, Germany) equipped with a camera (DFC300FX, Leica, Biberach, Germany).

\section{Scanning electron microscopy}

Biomass samples were fixed in $2.5 \%(\mathrm{w} / \mathrm{v})$ glutaraldehyde overnight at $4^{\circ} \mathrm{C}$. The fixed samples were separated and washed following the same procedure for the attached and suspended fractions described above for biomass measurement. The samples were then dehydrated for $20 \mathrm{~min}$ in a series of ethanol solutions (10\%, 25\%, 50\%, $75 \%, 90 \%$, and twice 100\%) and dried in a desiccator overnight. The samples were coated with gold and analyzed in a JEOL JSM-6480LV Scanning Electron Microscope (JEOL Benelux, Nieuw-Vennep, The Netherlands).

\section{DNA extraction}

Suspended and sand attached biomass fractions $(10 \mathrm{ml})$ were separated by settling for $30 \mathrm{~s}$. The suspended fraction was centrifuged (10 min, $7500 \mathrm{~g}$ ) before both fractions were washed three times with buffer LS and finally re-suspended in $2 \mathrm{ml}$ of buffer LS and stored at $-80^{\circ} \mathrm{C}$. Total genomic DNA was extracted using the PowerBiofilm ${ }^{\mathrm{TM}}$ DNA Isolation Kit (MoBio, Carlsbad, CA) following the manufacturer's instructions.

\section{DGGE analysis}

Bacterial 16S rRNA genes were amplified by PCR using a Taq DNA polymerase kit (Invitrogen, Carlsbad, CA) and primer set U968f/L1401r (Lane, 1991; Nübel et al., 1996). A 40 bp GC-clamp was added at the 5' end sequence of the primer U968-f. For archaeal 16S rRNA genes the A109(T)f/GC515r primer sets were used (Großkopf et al., 1998; Lane, 1991). The PCR program included initial denaturation for 2 min; 35 cycles of $30 \mathrm{~s}$ denaturation at $95^{\circ} \mathrm{C}, 40 \mathrm{~s}$ at $56^{\circ} \mathrm{C}$ for annealing and 1.5 min elongation step at $72^{\circ} \mathrm{C}$; and $7 \min$ at $72^{\circ} \mathrm{C}$ as a post-elongation step.

Denaturing gradient gel electrophoresis (DGGE) analysis of the PCR products was performed by using the DCode system (Bio-Rad, Hercules, CA). Gels containing $8 \%$ (wt/vol) polyacrylamide (37.5:1 acrylamide/bis-acrylamide) were used with a linear 
denaturing gradient of $30-60 \%$, with $100 \%$ of denaturant corresponding to $7 \mathrm{M}$ urea and $40 \%(\mathrm{vol} / \mathrm{vol})$ formamide. Electrophoresis was performed for $16 \mathrm{~h}$ at $85 \mathrm{~V}$ and $60^{\circ} \mathrm{C}$ in a $0.5 \times$ Tris-Acetate-EDTA buffer. DGGE gels were stained with silver nitrate (Sanguinetti et al., 1994), scanned, and the band profiles were analyzed using Bionumerics ${ }^{\circledR}$ software (Applied Maths, Austin, TX).

\section{Sequencing and phylogenetic analysis}

For sequencing, suspended biomass samples from day 0 (inoculum), 53, 97, 113, 179, and 197 as well as biomass attached to sand samples from day 179 and 197 were used. A fragment of the V3-V5 region of 16S rRNA gene of bacteria was amplified using primers $341 \mathrm{~F}$ and $805 \mathrm{R}$ (Herlemann et al., 2011). The PCR protocol was performed according to Hugerth et al. (2014) and amplicons were sequenced on the Illumina platform according to Lindh et al. (2015) at the Science for Life Laboratory, Sweden (www.scilifelab.se). The sequence data was processed with the UPARSE pipeline (Edgar, 2013b) and annotated against the SINA/SILVA database (SILVA 119; Quast et al., 2013). Afterwards, the data was analyzed using Explicet 2.10.5 (Harris et al., 2013).

\section{Calculations}

Calculations were performed as describe in the supplementary material (Calculations) and followed the following assumptions:

1. Thermodynamic calculations were performed using eQuilibrator online tool (Flamholz et al., 2012) and the actual conditions in the bioreactor (pH 9, $1.5 \mathrm{M}$ ionic strength, $0.825 \mathrm{M} \mathrm{HCO}_{3}{ }^{-}$, and 1 bar $\mathrm{H}_{2}$. For formate production from $\mathrm{H}_{2}$ and $\mathrm{HCO}_{3}{ }^{-}$, calculations were made based on Eq. 1. For sulfate reduction using $\mathrm{H}_{2}$ or formate as electron donors, calculations were made based on Eq. 2 and Eq. 3.

$$
\begin{aligned}
& \mathrm{H}_{2}+\mathrm{HCO}_{3}^{-} \rightarrow \mathrm{HCO}_{2}^{-}+\mathrm{H}_{2} \mathrm{O} \\
& 4 \mathrm{H}_{2}+\mathrm{SO}_{4}^{2-}+\mathrm{H}^{+} \rightarrow \mathrm{HS}^{-}+4 \mathrm{H}_{2} \mathrm{O}
\end{aligned}
$$




$$
4 \mathrm{HCO}_{2}^{-}+\mathrm{SO}_{4}^{2-}+\mathrm{H}^{+} \rightarrow \mathrm{HS}^{-}+4 \mathrm{HCO}_{3}^{-}
$$

2. The bioreactor liquid volume was constant during the operation which means that the liquid flow that goes into the bioreactor is equal to the liquid flow exiting the bioreactor.

3. Accumulation of sulfur compounds in the bioreactor, by incorporation in biomass and formation of sulfide precipitates, was not taken into account in the calculations as it plays a minor role due to the high sulfate and thiosulfate concentration in the influent.

4. S volumetric conversion rate was calculated by the sum of the volumetric conversion rates of sulfate and thiosulfate based on mol of $S$ atoms.

5. The $\mathrm{N}$ molar fraction value of 0.2 was used to calculate biomass concentration based on total $\mathrm{N}$, following the biomass molecular formula: $\mathrm{C}_{1} \mathrm{H}_{1.8} \mathrm{O}_{0.5} \mathrm{~N}_{0.2}$.

\section{Results \& Discussion}

\section{Bioreactor performance}

In this study, we tested if sand as a biomass carrier material in a $\mathrm{H}_{2}$ fed sulfate and thiosulfate-converting bioreactor operated at haloalkaline conditions can improve reactor performance.

The use of sand allowed the operation of the gas-lift bioreactor at an HRT of one day, which is similar to studies using anaerobic filters filled with sediments (Zhou and Xing, 2015). Previously described sulfate and thiosulfate-reducing bioreactors fed with $\mathrm{H}_{2}$ at haloalkaline conditions did not contain aggregated biomass (Sousa et al., 2015a). Consequently, the minimum HRT achieved without a decrease of biomass concentration and reduction activity was 3.3 days for the sulfate-reducing bioreactor and $1.7 \mathrm{~d}$ for the thiosulfate-converting bioreactor. Operation of the bioreactor with 
sand as carrier material at lower HRT led to higher $\mathrm{S}$ volumetric conversion rates, 85 $\pm 3 \mathrm{mmols}^{-1}$ day $^{-1}$ during Run 5, compared with previous published results (Table 2).
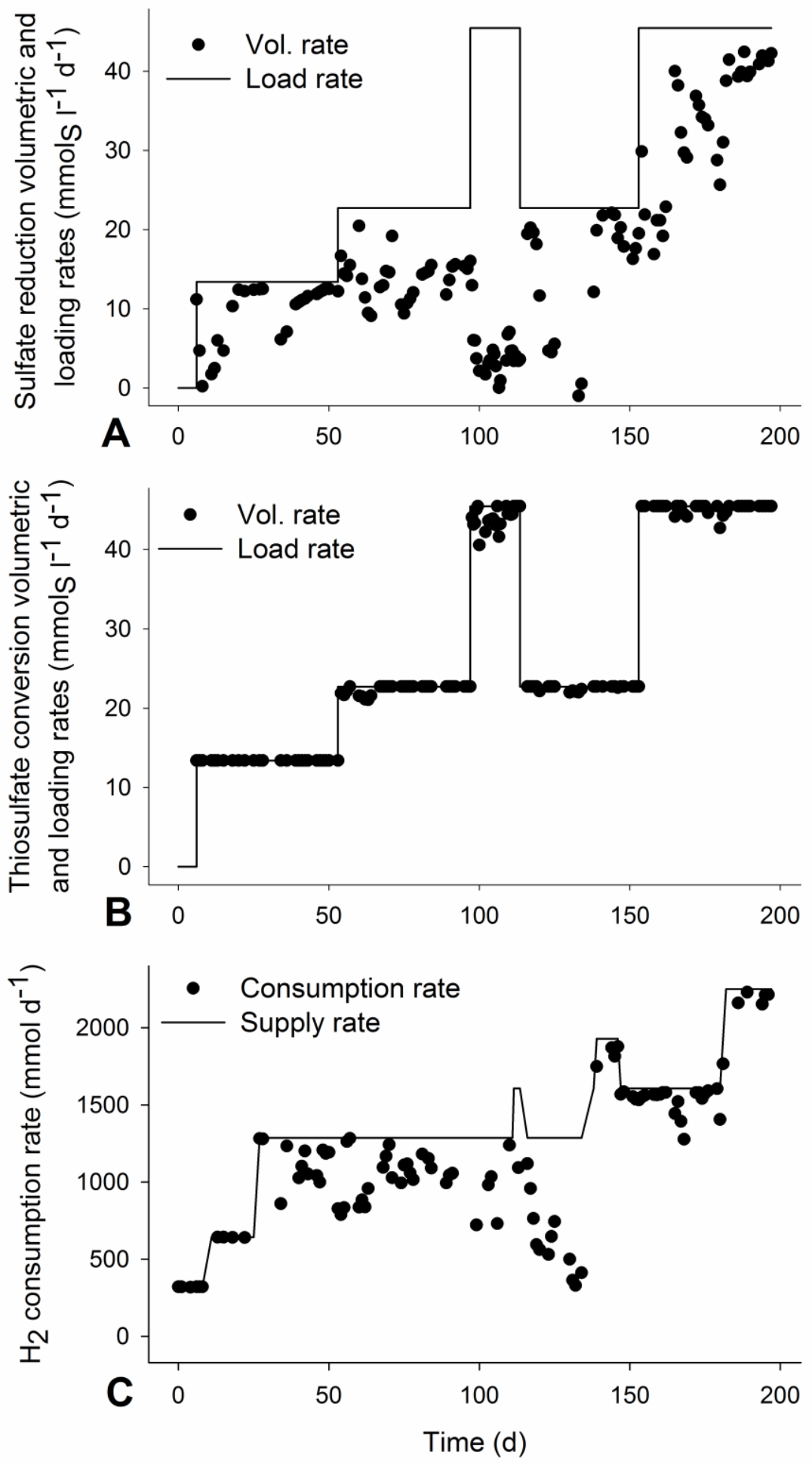

Figure 1 - Activities in the bioreactor during all operation periods. A - sulfate loading and volumetric reduction rates. $\mathrm{B}-$ Thiosulfate loading and volumetric reduction rates. $\mathrm{C}-\mathrm{H}_{2}$ supply and consumption rates. 

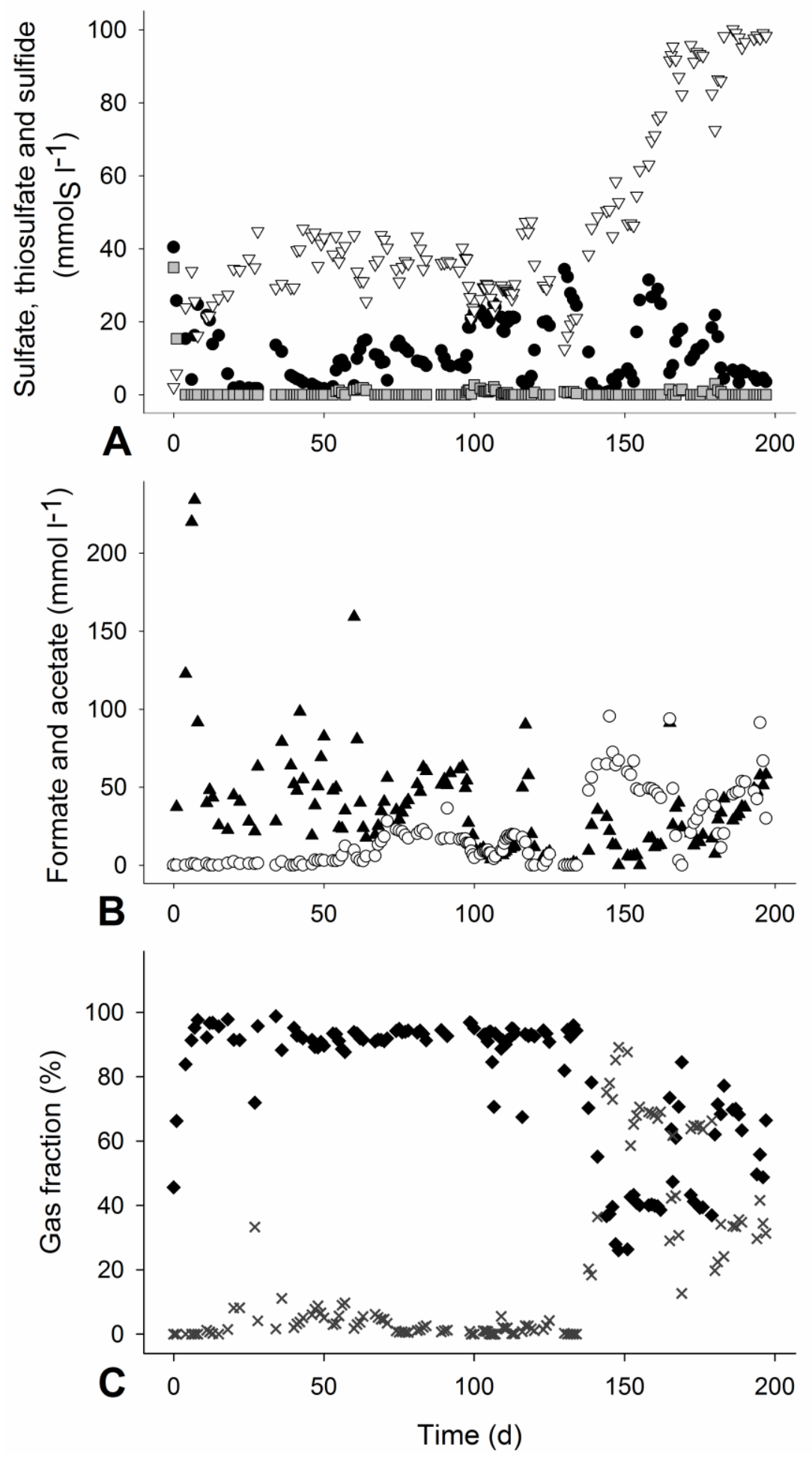

Figure 2 - Composition of the bioreactor effluent and gas phase during all operation periods. A - sulfate $(\bullet)$, thiosulfate $(\square)$, and sulfide $(\nabla)$ concentration in the effluent. $B-$ formate $(\boldsymbol{A})$ and acetate $(\circ)$ concentration in the effluent; $C$ - Hydrogen $(\bullet)$ and methane $(x)$ in the gas phase. 
Thiosulfate was completely converted to sulfide throughout the whole reactor operation, while $93 \pm 2 \%$ of the sulfate was converted in the stable phase of Run 5 (Figures 1 and 2). Such sulfate conversion efficiencies were similar to other systems using different bioreactors and electron donors (Table 2). To exclude the sulfide toxicity effect as cause for incomplete sulfate reduction, in run 5 the loading of sulfate and thiosulfate was doubled. This resulted in higher concentrations of sulfide and higher sulfate and thiosulfate reduction rates, and the conversion efficiencies of sulfate and thiosulfate remained in the same range as in previous runs. This shows that there is no sulfide toxicity up to $100 \mathrm{mM}$, but does not explain why sulfate is not completely reduced. An explanation for this limitation in sulfate reduction might be the sulfate uptake system of microorganisms. Tarpgaard et al. (2011) showed that some sulfate reducers possess two different sulfate uptake systems, one low affinity and another high affinity for low sulfate concentrations $(<0.2 \mathrm{mM})$. If the high affinity system is not switched on, or not present in the microorganisms, this might explain why the conversion of sulfate is not complete. 
Table 2 - Conditions and performance of sulfate and thiosulfate reducing bioreactors operated at haloalkaline conditions

\begin{tabular}{|c|c|c|c|c|}
\hline & This study & Sousa et al. 2015 & (Zhou et al 2015) & Sousa et al \\
\hline Reactor type & $\begin{array}{l}\text { Gas lift with } 3 \\
\text { phase separator }\end{array}$ & $\begin{array}{c}\text { Gas lift with } 3 \\
\text { phase separator }\end{array}$ & Anaerobic filter & $\begin{array}{l}\text { Gas lift with } 3 \\
\text { phase separator }\end{array}$ \\
\hline Carrier material & Sand & None & Sediments & None \\
\hline $\mathrm{e}^{-}$acceptor & $\begin{array}{l}\text { Sulfate } \\
\text { /thiosulfate }\end{array}$ & Sulfate & Sulfate & Thiosulfate \\
\hline $\mathrm{e}^{-}$donor & $\mathrm{H}_{2}$ & $\mathrm{H}_{2}$ & Formate & $\mathrm{H}_{2}$ \\
\hline Carbon source & $\mathrm{CO}_{2}$ & $\mathrm{CO}_{2}$ & Formate/ $\mathrm{CO}_{2}$ & $\mathrm{CO}_{2}$ \\
\hline $\mathrm{pH}$ & 9 & 9 & 9.5 & 9 \\
\hline $\mathrm{Na}^{+}$conc. (M) & 1.5 & 1.5 & 1 & 1.5 \\
\hline Temperature $\left({ }^{\circ} \mathrm{C}\right)$ & 35 & 35 & 37 & 35 \\
\hline HRT (d) & 1 & 3.3 & 1 & 1.7 \\
\hline $\begin{array}{l}\text { S volumetric } \\
\text { conversion rates } \\
\left(\mathrm{mmols}^{-1} \mathrm{~d}^{-1}\right)\end{array}$ & $85( \pm 3)$ & 18 & $85( \pm 0.2)$ & $57( \pm 0.8)$ \\
\hline Side products & Formate/Acetate & Formate & Acetate & Formate \\
\hline $\begin{array}{l}\text { Biomass conc. } \\
\left(\mathrm{mg} \mathrm{l}^{-1}\right)\end{array}$ & $127( \pm 41)$ & $7( \pm 3)$ & N.D. & $14( \pm 2)$ \\
\hline
\end{tabular}

N.D. - No data available

\section{Biomass attachment}

The swift and efficient sulfate and thiosulfate conversion points to a positive effect of adding sand as a carrier material for biomass when compared with results without using sand (Table 2). This is caused by an overall increase of biomass, which is $\sim 10$ times higher than without using carrier material. However, most biomass was suspended and not attached to the sand particles (Figure 3). Microorganisms were only detected in sand particle cavities, where they were protected from shear forces 
suggesting weak biomass attachment (Figure 4). At neutral $\mathrm{pH}$ and non-saline conditions using a similar bioreactor, no microbial attachment to basalt (non-porous) was observed, while attachment to pumice (porous) occurred (van Houten et al., 1994). However, in that study the biomass growing on the pumice pores, colonized and covered the whole particle, which was not observed in the current study. The main difference between that earlier work and the current study is the haloalkaline conditions. As discussed previously, aggregation and attachment at haloalkaline conditions is more difficult for microorganisms (Ismail et al., 2008; Sousa et al., 2015a). The aggregation is weak and vulnerable to shear forces which strongly indicates that the combination of high $\mathrm{pH}$ and high salinity, characteristic for soda lakes, affects the biofilm formation process. In the biofilm formation process at neutral $\mathrm{pH}$, soluble divalent cations such as $\mathrm{Ca}^{2+}$ have a crucial role in EPS stabilization (Sobeck and Higgins, 2002). However, at high pH the concentration of soluble divalent cations is low because of precipitation as carbonates. In salt lakes biofilms when the alkalinity inside the EPS becomes higher, the EPS binding capacity to divalent cations is reduced and subsequently precipitation of carbonates occurs (Dupraz et al., 2004). This illustrates the impact of the high $\mathrm{pH}$ on the stability of EPS, and consequently, on the stability of aggregates. 

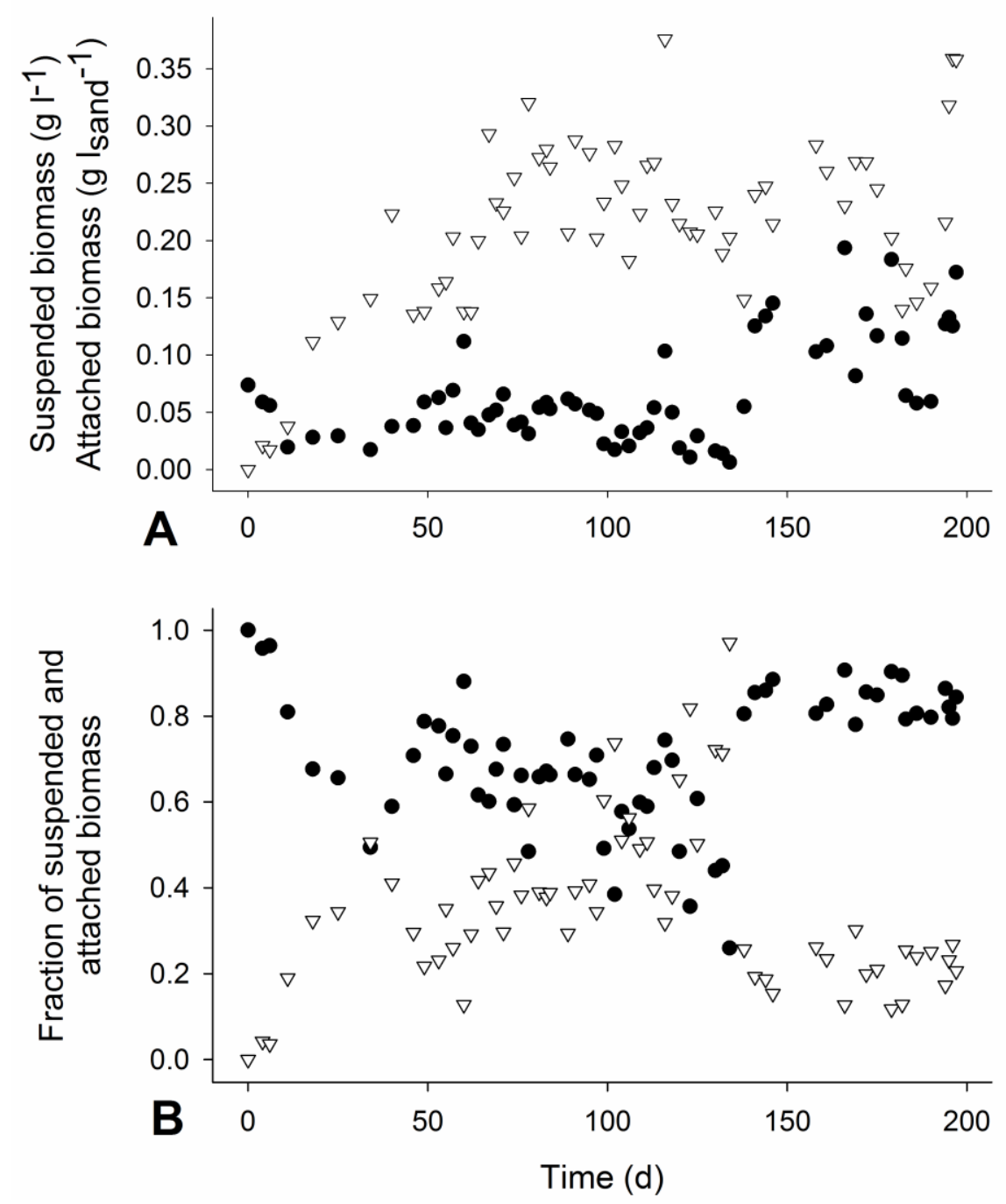

Figure 3 - Suspended $(\bullet)$ and attached $(\nabla)$ biomass concentration $(A)$ and fraction $(B)$ in the bioreactor during all operational periods.

To investigate if there is a dedicated microbial community attached to the sand particles, the composition of the suspended and attached biomass to sand was studied at the end of run 5 . Figure 5 shows the relative abundance of different $16 \mathrm{~S}$ rRNA gene sequences on the sand, which reveals that microorganisms most closely related to members of the Desulfohalobiaceae had a higher relative abundance than in suspended biomass. The Desulfohalobiaceae family consists of sulfate and thiosulfate-reducing bacteria. They were present in the inoculum (Sousa et al., 2015a). The microbial community data show that the relative abundance of bacteria categorized as "others" (abundance $>0.5 \%$ ) was higher in the attached fraction. Some 
of these rare microorganisms that are more abundant in the attached fraction might produce compounds, like vitamins, that are beneficial to other microorganisms in the bioreactor. This was previously shown for other different microbial communities (Seth and Taga, 2014).

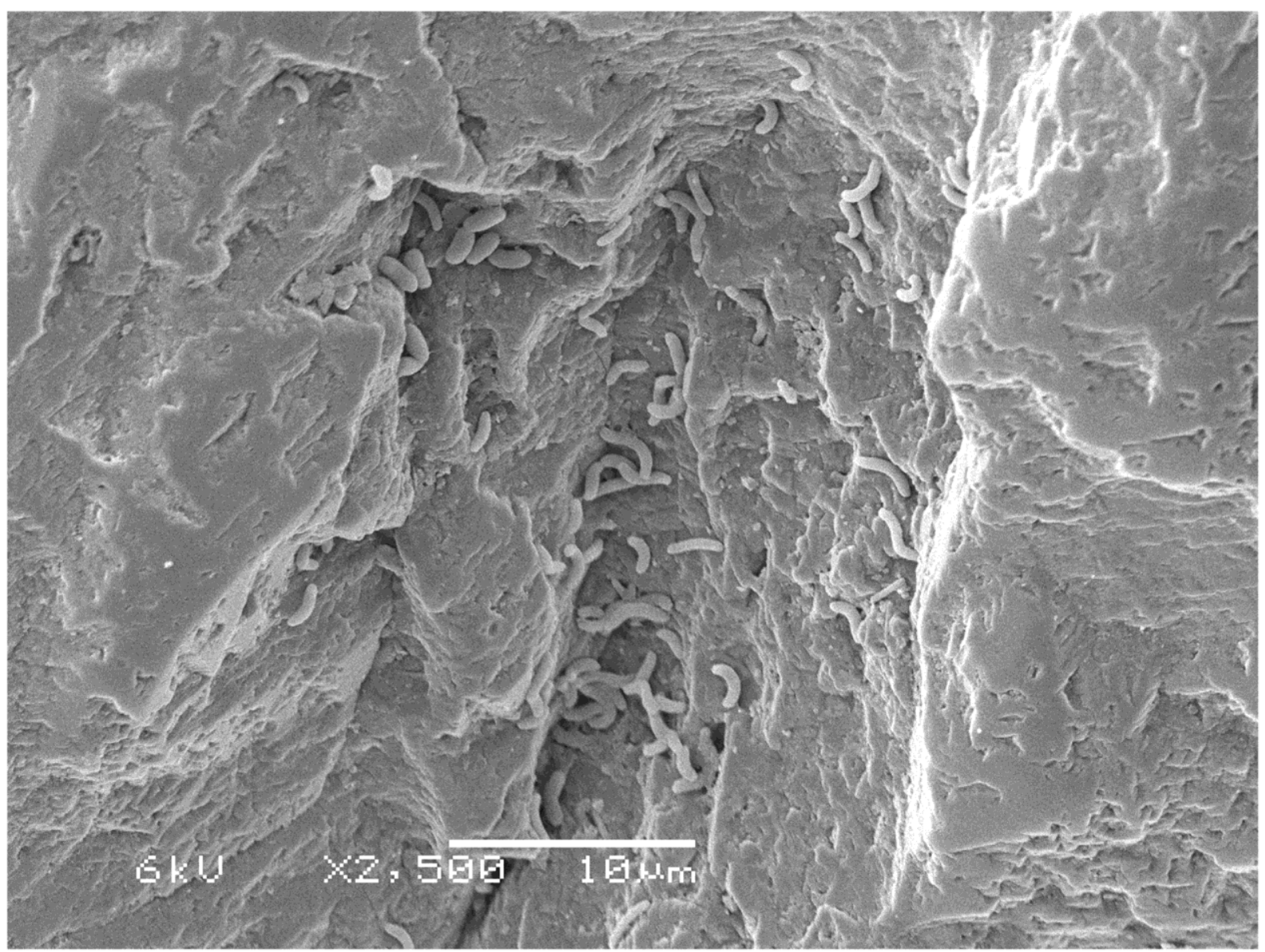

Figure 4 - Scanning electron micrograph of a sand particle with microorganisms attached to the sand surface inside cracks. Sample from day 75 (run 2). 


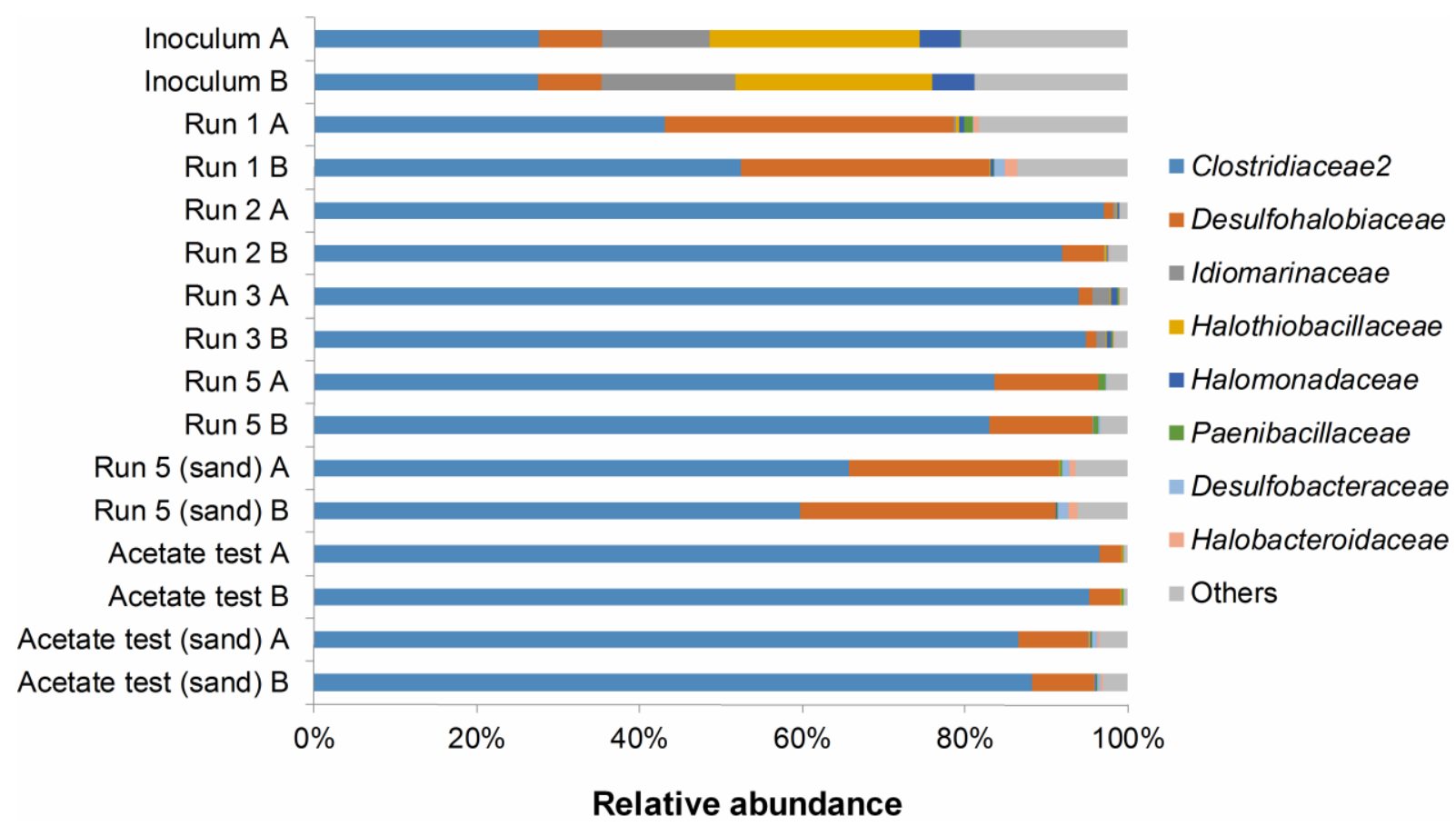

Figure 5 - Bacterial 16S rRNA gene relative abundance from a defined day from each run of the bioreactor operation. All samples were collected and sequenced in duplicate (represented by "A" and "B"). OTUs with less than $0.5 \%$ relative abundance were grouped in "others".

\section{Effect of acetate on biomass growth and attachment}

Acetate production in the bioreactor had an effect on biomass concentration, sulfate reduction and methane production. This is demonstrated by the increase of these parameters following an increase in acetate from the end of run 4 until the end of run 5 (Figure 2). Additionally, the acetate spiking test confirmed that indeed acetate enhances growth of the biomass, specifically of the attached fraction of biomass (Figure 6).

Heterotrophic growth (e.g. using acetate as carbon source) is energetically more efficient as it requires less energy input, compared to autotrophic growth (Oren, 1999). Stimulating effects of acetate on biomass growth were reported for neutral conditions where sulfate reducers were dependent on acetate produced from $\mathrm{H}_{2}$ and $\mathrm{CO}_{2}$ by acetogens (Weijma et al., 2002). Such an interaction might also have occurred in the current study. Most of the sulfate reducers present in the biomass had 16S rRNA gene sequences most similar to the Desulfohalobiaceae family (Figure 5). Within this family, most of the sequences were closely related to bacteria belonging to the 
Desulfonatronovibrio genus that indeed require acetate as carbon source (Sorokin et al., 2011b).

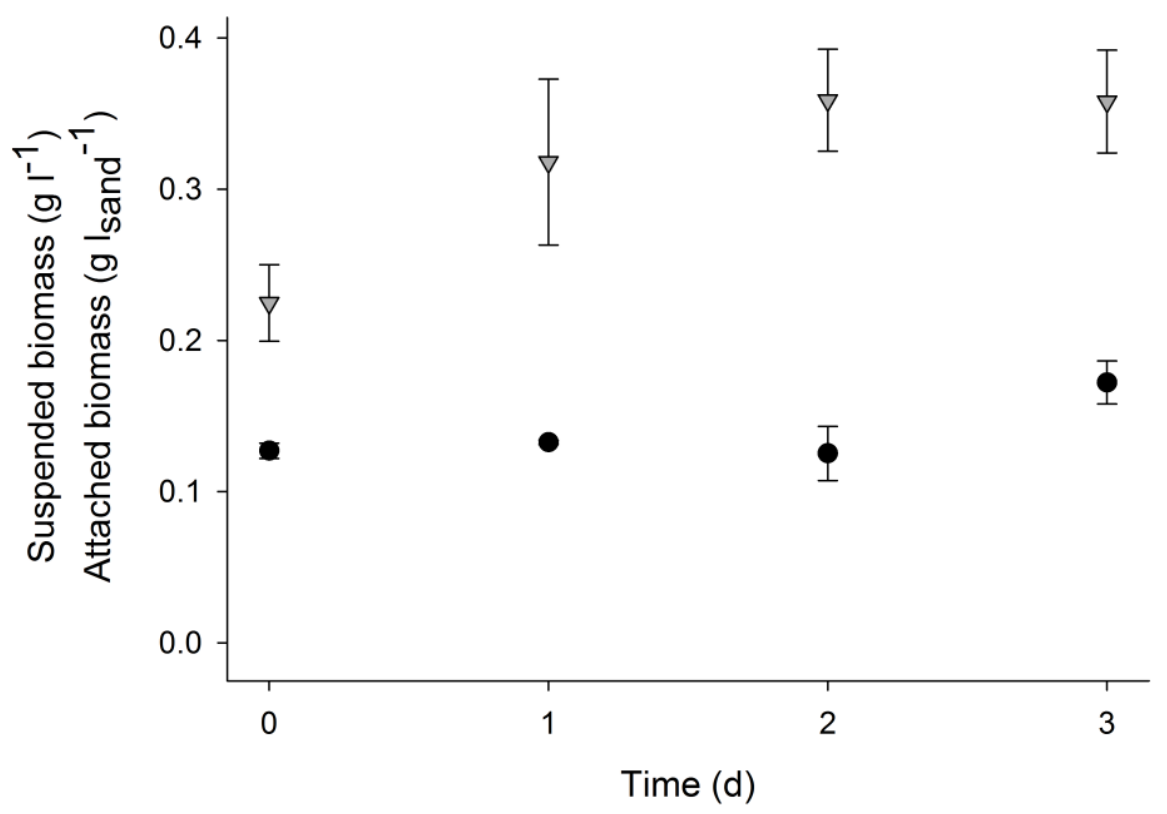

Figure 6 - Suspended $(\bullet)$ and attached $(\nabla)$ biomass concentration during the acetate spiking test (AT).

The formation of small microbial aggregates (not attached to sand) was observed after the acetate increase and these aggregates became more abundant during run 5 (Figure S1 and S2). This indicates that acetate cross feeding might play a crucial role in microbial aggregation in the bioreactor. The microbial aggregates size stabilized at approximately $10 \mu \mathrm{m}$ in diameter and the maximum size observed was approximately $30 \mu \mathrm{m}$ in diameter. The shear forces and the haloalkaline conditions in the bioreactor might have prevented further increase in aggregate size.

\section{Formate as an electron donor}

Formate production from $\mathrm{H}_{2}$ and $\mathrm{HCO}_{3}{ }^{-}$was one of the main reactions taking place in the bioreactor (Figure 2). From a thermodynamic point of view, although the Gibbs free energy change is low (Figure 7), this reaction is favorable at the conditions used in this study. Production of formate was shown previously, where it was proposed to be linked to the dominance of Tindallia related bacteria (Sousa et al., 2015a). In the current 
study, the dominant bacteria in the bioreactor were closely related to the Clostridiaceae family, and about $99 \%$ of these sequences were closely related to the Tindallia genus. The 16S rRNA gene sequences were 98\% similar to the 16S rRNA gene sequences related to Tindallia identified previously (Sousa et al., 2015a). In contrast, Tindallia related bacteria were not dominant in haloalkaline sulfate-reducing bioreactors fed with formate, ethanol, glucose, and lactate as electrons donors and no formate production was observed in any reactor where formate was absent (Zhou et al., 2015). These differences support the hypothesis that Tindallia related bacteria in the bioreactor use $\mathrm{H}_{2}$ and are possibly responsible for the formate production.

Formate production from $\mathrm{H}_{2}$ and $\mathrm{HCO}_{3}$ - occurred even though the Gibbs free energy $(\Delta G)$ per reaction is lower than sulfate reduction and methane or acetate production. In soda lakes of the Kulunda Steppe (Altai, Russia), formate is the preferred electron donor for sulfate and thiosulfate reduction when compared to $\mathrm{H}_{2}$ (Sorokin et al., 2010). The results from formate spike injections showed enhanced sulfate reduction with higher formate concentrations (Figure 8). The calculated $\Delta G$ for sulfate reduction with formate is less favorable than with $\mathrm{H}_{2}$ (Figure 7). However, the poor solubility of $\mathrm{H}_{2}$ might lead to low in situ concentrations of dissolved $\mathrm{H}_{2}$. A lower dissolved $\mathrm{H}_{2}$ concentration results in a less negative $\Delta \mathrm{G}$ of sulfate reduction using $\mathrm{H}_{2}$ making this less favorable than formate driven sulfate reduction. 

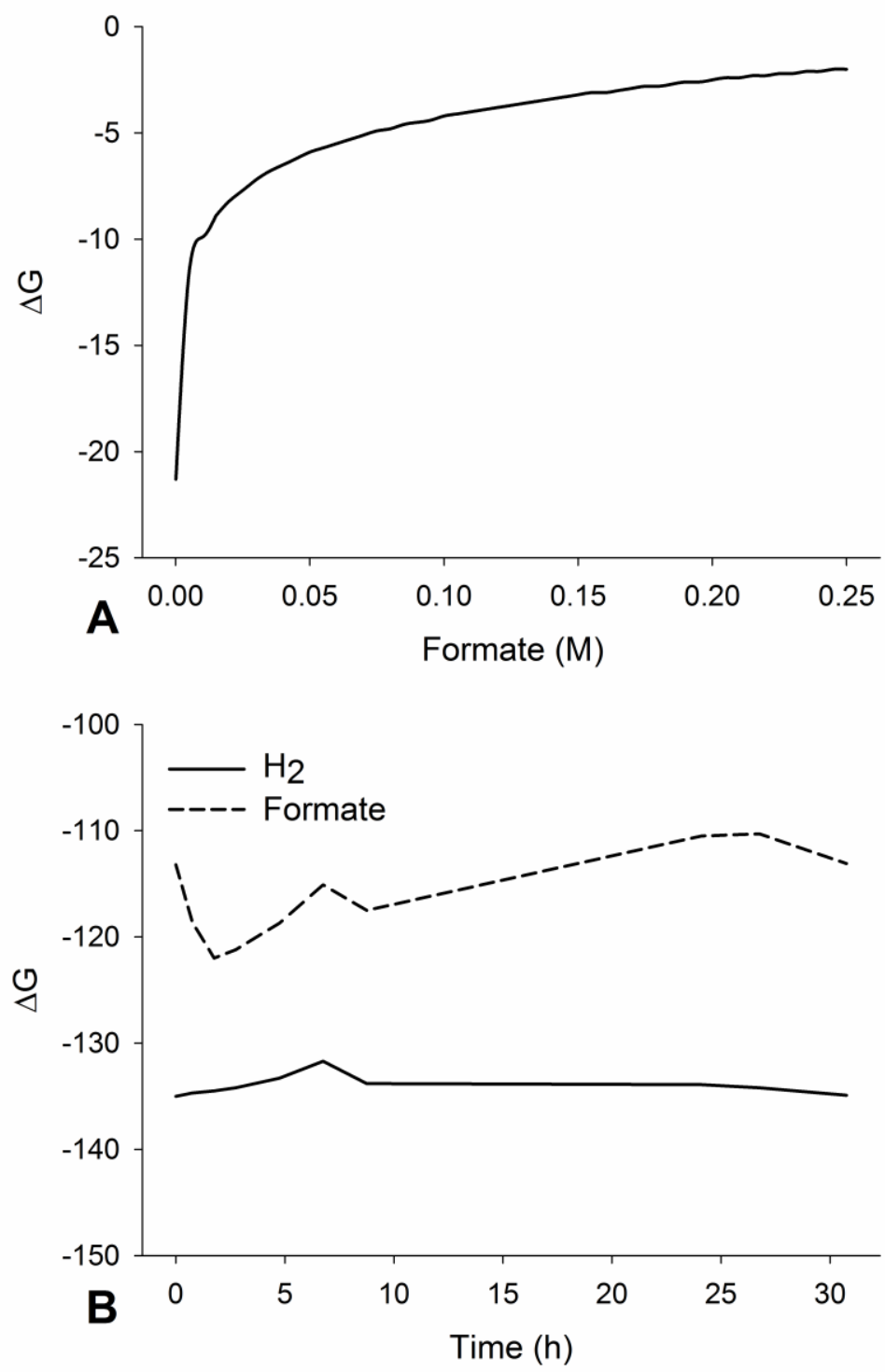

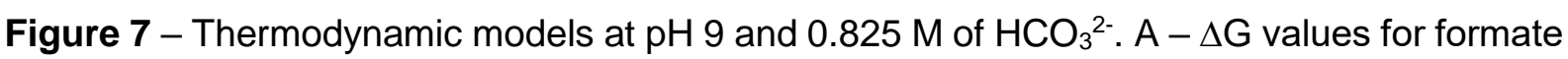
production following Eq. 1, at different formate concentrations. $\mathrm{H}_{2}$ was assumed to be constant at 1 atm. $B-\Delta G$ for sulfate reduction using $\mathrm{H}_{2}$ and formate during the first formate spike experiment. Measured concentrations of sulfate, sulfide, formate, $\mathrm{H}_{2}$, and $\mathrm{CO}_{2}$ were used for the calculations. 

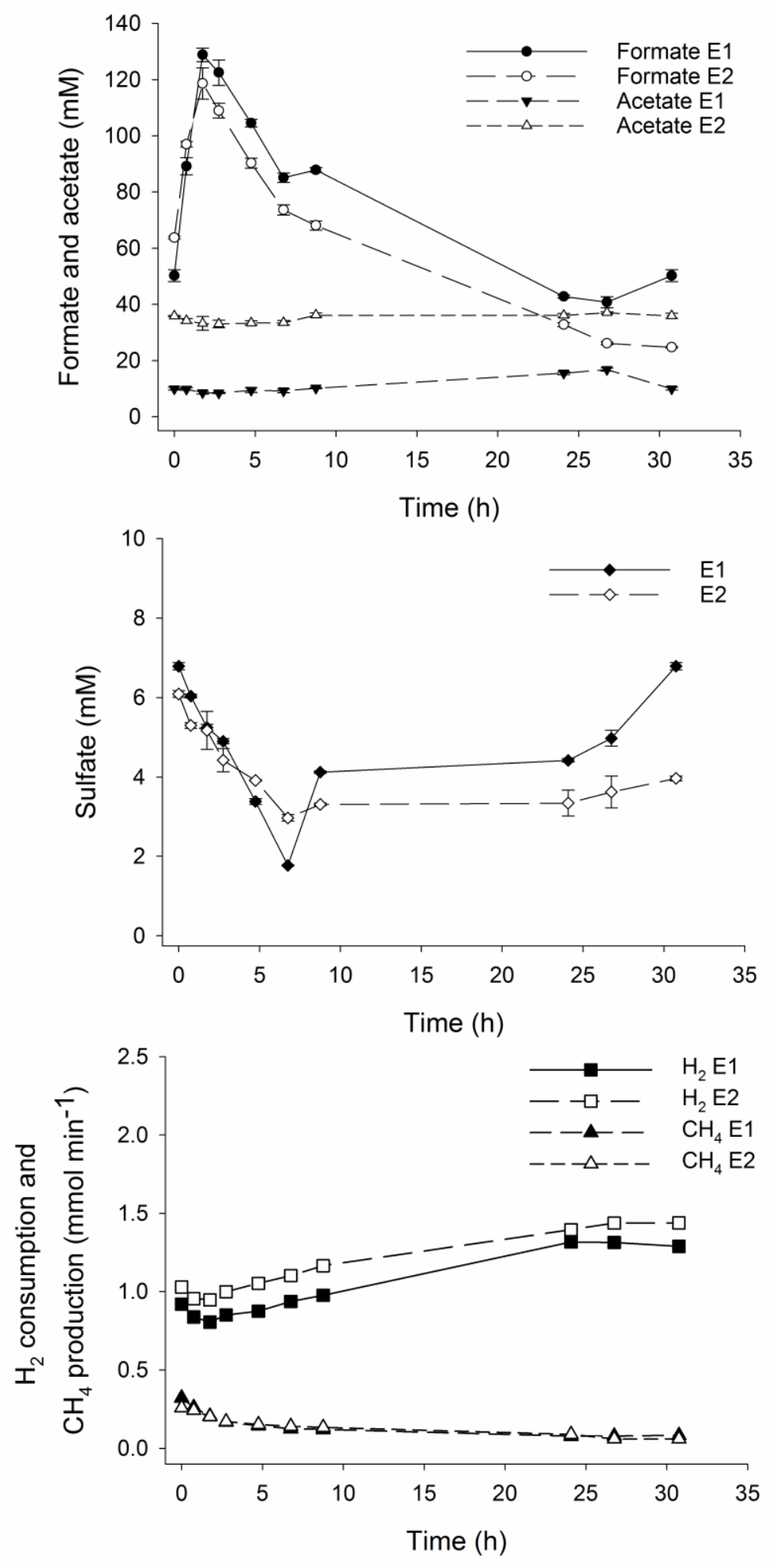

Figure 8 - Formate, acetate, and sulfate concentration as well as hydrogen consumption and methane production during the two formate spiking experiments. $100 \mathrm{mM}$ formate was injected at time 0 into the continuously operated bioreactor. 


\section{Conclusions}

- Sand as carrier material in $\mathrm{H}_{2}$ fed sulfate- and thiosulfate-reducing bioreactors at haloalkaline conditions increases biomass retention and $S$ volumetric conversion rates.

- Attachment of biomass to sand is weak and mostly confined to cavities in the sand particles where microorganisms are protected from shear forces.

- Acetate increases biomass growth, especially growth of the attached biomass. Addition of acetate could be used as a strategy to increase overall biomass growth and biomass retention.

- Formate has a central role in the bioreactor as electron donor for sulfate reduction. 


\section{References}

Amjres H, Béjar V, Quesada E, Carranza, D, Abrini J, Sinquin C, Ratiskol J, Colliec-Jouault S, Llamas I (2014) Characterization of haloglycan, an exopolysaccharide produced by Halomonas stenophila HK30. Int J Biol Macromol 72C:117-124.

Christensen B, Laake M, Lien T (1996) Treatment of acid mine water by sulfate-reducing bacteria; results from a bench scale experiment. Water Res 1354:1617-1624.

Dupraz C, Visscher PT, Baumgartner LK, Reid RP (2004) Microbe-mineral interactions: early carbonate precipitation in a hypersaline lake (Eleuthera Island, Bahamas). Sedimentology 51:745-765.

Edgar RC (2013) UPARSE: highly accurate OTU sequences from microbial amplicon reads. Nature Methods 10:996-998.

Flamholz A, Noor E, Bar-Even A, Milo R (2012) eQuilibrator--the biochemical thermodynamics calculator. Nucleic Acids Res 40:770-775.

Grant WD, Mwatha WE, Jones BE (1990) Alkaliphiles: Ecology, diversity and applications. FEMS Microbiol Rev 75:255-269.

Großkopf R, Janssen PH, Liesack W (1998) Diversity and structure of the methanogenic community in anoxic rice paddy soil microcosms as examined by cultivation and direct 16S rRNA gene sequence retrieval. Appl Environ Microbiol 64:960-969.

Harris JK, Caporaso JG, Walker JJ, Spear JR, Gold NJ, Robertson CE, Hugenholtz P, Goodrich J, McDonald D, Knights D, Marshall P, Tufo H, Knight R, Pace NR (2013) Phylogenetic stratigraphy in the Guerrero Negro hypersaline microbial mat. ISME $\mathrm{J}$ 7:50-60.

Herlemann DP, Labrenz M, Jürgens K, Bertilsson S, Waniek JJ, Andersson AF (2011) Transitions in bacterial communities along the $2000 \mathrm{~km}$ salinity gradient of the Baltic Sea. ISME J 5:1571-1579.

Hugerth LW, Wefer HA, Lundin S, Jakobsson HE, Lindberg M, Rodin S, Engstrand L, Andersson AF (2014) DegePrime, a program for degenerate primer design for broadtaxonomic-range PCR in microbial ecology studies. Appl Environ Microbiol 80:51165123.

Ismail SB, Gonzalez P, Jeison D, van Lier JB (2008) Effects of high salinity wastewater on methanogenic sludge bed systems. Water Sci Technol 58:1963-1970. 
Janssen AJH, Lens PNL, Stams AJM, Plugge CM, Sorokin DY, Muyzer G, Dijkman H, van Zessen E, Luimes P, Buisman CJN (2009) Application of bacteria involved in the biological sulfur cycle for paper mill effluent purification. Sci Total Environ 407:13331343.

Lane DL (1991) 16S/23S rRNA sequencing. In: Stackebrandt E, Goodfellow M (ed) Nucleic Acid Techniques in Bacterial Systematics, John Wiley \& Sons Ltd, Chichester, United Kingdom, pp 115-148.

Lindh MV, Figueroa D, Sjöstedt J, Baltar F, Lundin D, Andersson A, Legrand C, Pinhassi J (2015) Transplant experiments uncover Baltic Sea basin-specific responses in bacterioplankton community composition and metabolic activities. Front Microbiol 6:223.

Muyzer G, Stams AJM (2008) The ecology and biotechnology of sulphate-reducing bacteria. Nat Rev Microbiol 6:441-454.

Oren A (1999) Bioenergetic aspects of halophilism. Microbiol Mol Biol Rev 63:334-348.

Otto K, Elwing H, Hermansson M (1999) Effect of ionic strength on initial interactions of Escherichia coli with surfaces, studied on-line by a novel quartz crystal microbalance technique. J Bacteriol 181:5210-5218.

Quast C, Pruesse E, Yilmaz P, Gerken J, Schweer T, Yarza P, Peplies J, Glöckner FO (2013) The SILVA ribosomal RNA gene database project: improved data processing and webbased tools. Nucl Acids Res 41:590-596.

Seth EC, Taga ME (2014) Nutrient cross-feeding in the microbial world. Front Microbiol 5:1-6.

Sobeck DC, Higgins MJ (2002) Examination of three theories for mechanisms of cationinduced bioflocculation. Water Res 36:527-538.

Sorokin DY, Rusanov II, Pimenov NV, Tourova TP, Abbas B, Muyzer G (2010) Sulfidogenesis under extremely haloalkaline conditions in soda lakes of Kulunda Steppe (Altai, Russia). FEMS Microbiol Ecol 73:278-290.

Sorokin DY, Kuenen JG, Muyzer G (2011a) The microbial sulfur cycle at extremely haloalkaline conditions of soda lakes. Front Microbiol 2:1-16.

Sorokin DY, Tourova TP, Kolganova TV, Detkova EN, Galinski EA, Muyzer G (2011b) Culturable diversity of lithotrophic haloalkaliphilic sulfate-reducing bacteria in soda lakes and the description of Desulfonatronum thioautotrophicum sp. nov., Desulfonatronum thiosulfatophilum $\mathrm{sp}$. nov., Desulfonatronovibrio thiodismutans $\mathrm{sp}$. nov., and Desulfonatronovibrio magnus sp. nov.. Extremophiles 15:391-401. 
Sousa JAB, Plugge CM, Stams AJM, Bijmans MFM (2015a) Sulfate reduction in a hydrogen fed bioreactor operated at haloalkaline conditions. Water Res 68:67-76.

Sousa JAB, Sorokin DY, Bijmans MFM, Plugge CM, Stams AJM (2015b) Ecology and application of haloalkaliphilic anaerobic microbial communities. Appl Microbiol Biotechnol 99:9331-9336.

Tarpgaard IH, Røy H, Jørgensen BB (2011) Concurrent low- and high-affinity sulfate reduction kinetics in marine sediment. Geochim Cosmochim Acta 75:2997-3010.

van Houten BHGW, Roest K, Tzeneva VA, Dijkman H, Smidt H, Stams AJM (2006) Occurrence of methanogenesis during start-up of a full-scale synthesis gas-fed reactor treating sulfate and metal-rich wastewater. Water Res 40:553-560.

van Houten RT, Oude Elferink SJWH, van Hamel SE, Hulshoff Pol LW, Lettinga G (1995) Sulphate reduction by aggregates of sulphate-reducing bacteria and homo-acetogenic bacteria in a lab-scale gas-lift reactor. Biores Technol 54:73-79.

van Houten RT, Hulshoff Pol LW, Lettinga G (1994) Biological sulphate reduction using gaslift reactors fed with hydrogen and carbon dioxide as energy and carbon source. Biotechnol Bioeng 44:586-594.

van Loosdrecht MC, Lyklema J, Norde W, Schraa G, Zehnder AJB (1987) The role of bacterial cell wall hydrophobicity in adhesion. Appl Environ Microbiol 53:1893-1897.

Weijma J, Gubbels F, Hulshoff Pol LW, Stams AJM, Lens P, Lettinga G (2002) Competition for $\mathrm{H}_{2}$ between sulfate reducers, methanogens and homoacetogens in a gas-lift reactor. Water Sci 45:75-80.

Wolin EA, Wolin MJ, Wolfe RS (1963) Formation of methane by bacterial extract. J Biol Chem 238:2882-2886.

Zhou J, Xing J (2015a) Effect of electron donors on the performance of haloalkaliphilic sulfatereducing bioreactors for flue gas treatment and microbial degradation patterns related to sulfate reduction of different electron donors. Biochem Eng J 96:14-22.

Zhou J, Zhou X, Li Y, Xing J (2015b) Bacterial communities in haloalkaliphilic sulfate-reducing bioreactors under different electron donors revealed by 16S rRNA MiSeq sequencing. J Hazard Mater 295:176-184. 


\section{Supplementary information}

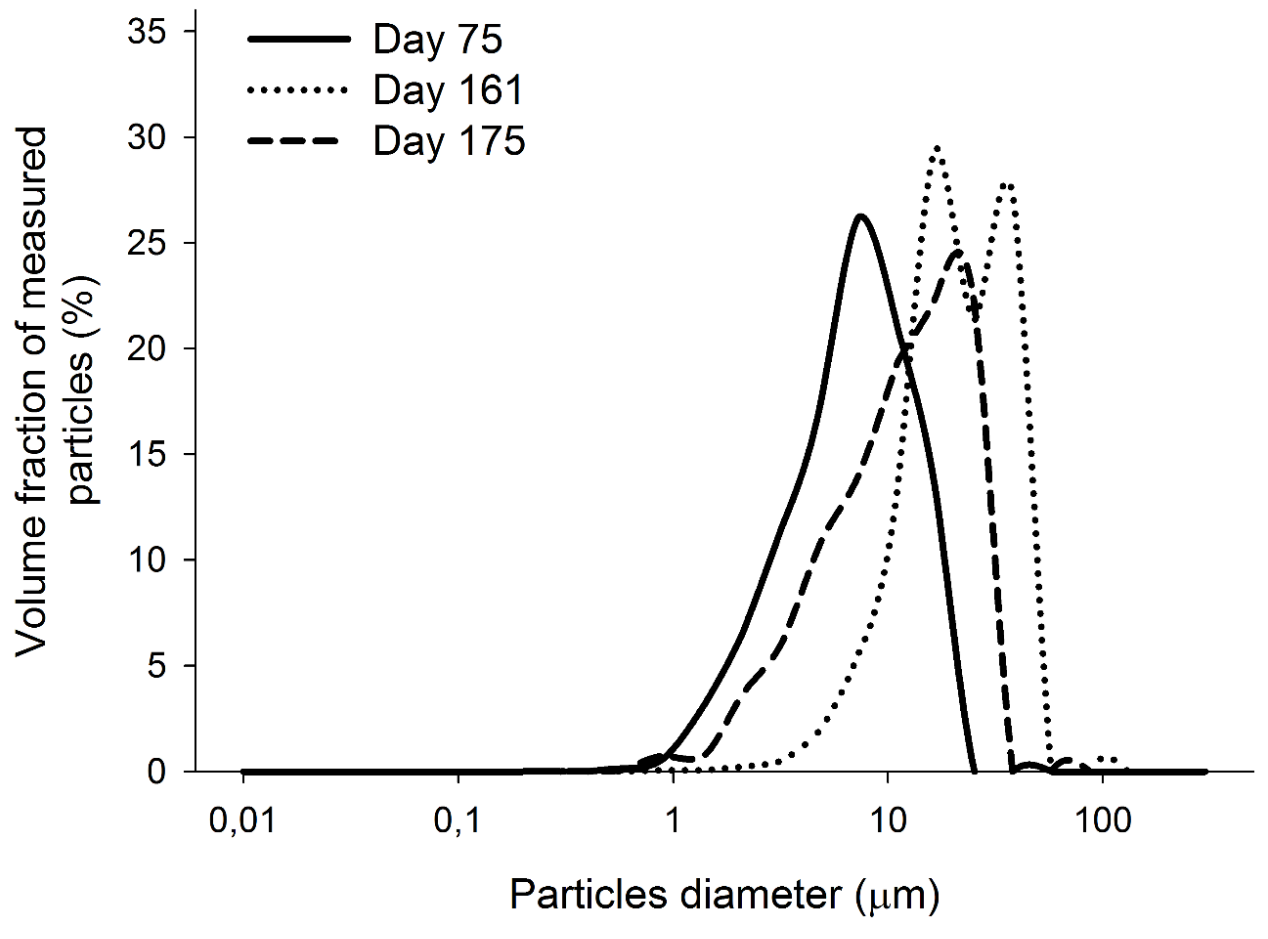

Figure S1 - Particle diameter distribution of the biomass on day 75 (Run 2), 161 and 175 (Run 5). 


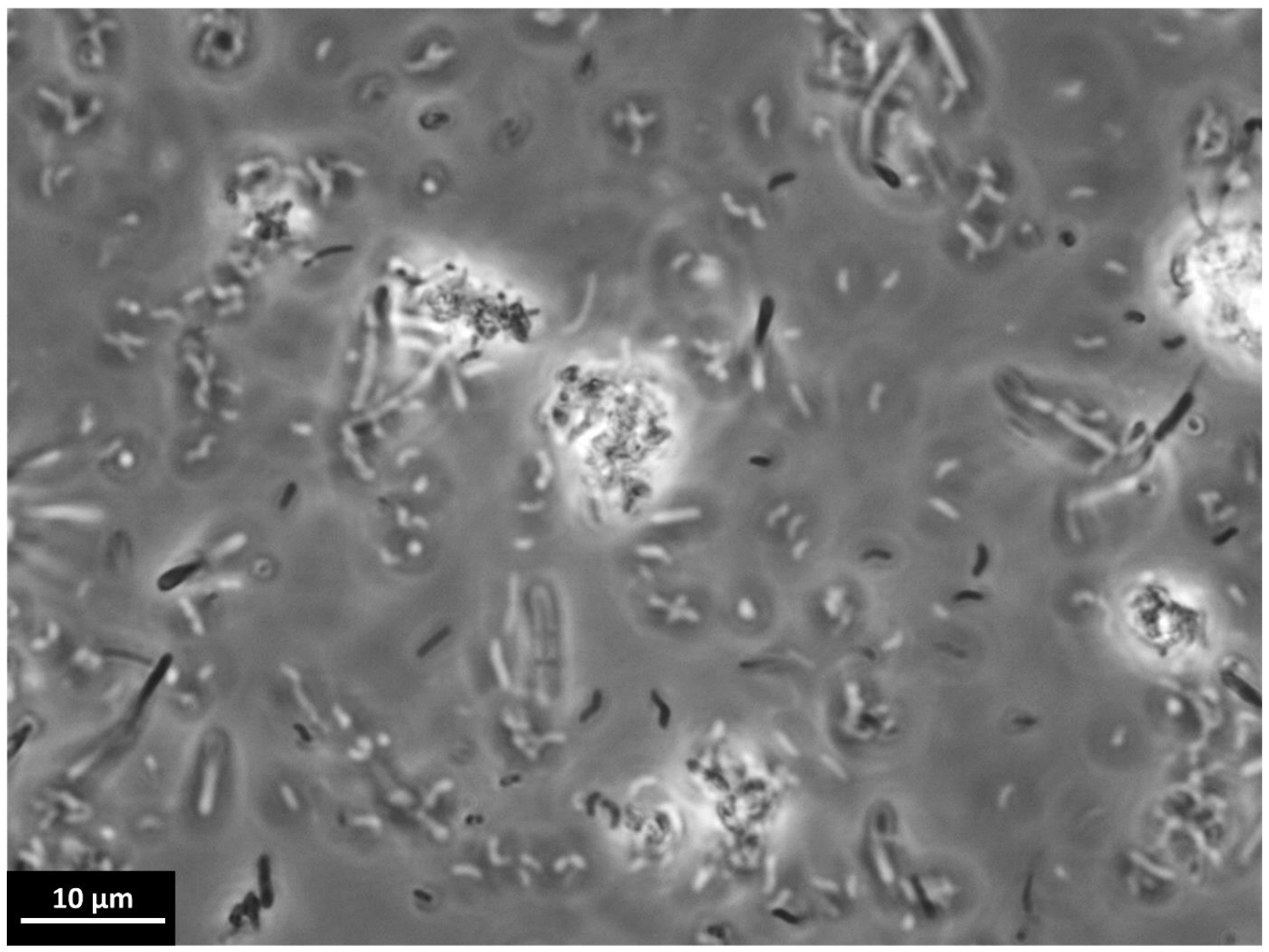

Figure $\mathbf{S 2}$ - Micrograph of small biomass aggregates observed during run 5 . The image is representative of the small aggregates observed during all run 5 . The picture was taken on day 162 using a microscope equipped with phase contrast and with 1000 fold magnification. 


\section{Chapter 6}

Syngas as electron donor for sulfate $\boldsymbol{\&}$ thiosulfate reducing haloalkaliphilic microorganisms in a gas-lift bioreactor

João A.B. Sousa, Martijn Diender, Stephan Christel, Mark Dopson, Martijn F.M. Bijmans, Alfons J.M. Stams, Caroline M. Plugge

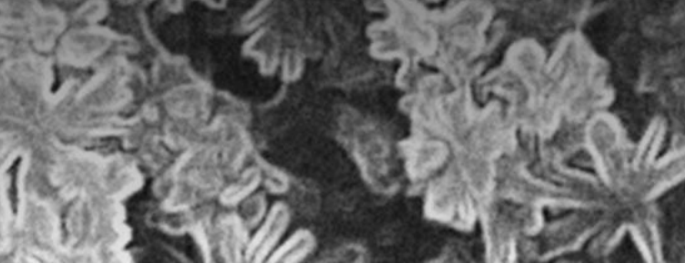




\section{Abstract}

Biodesulfurization processes are used to remove toxic and corrosive hydrogen sulfide from gas streams (e.g. natural gas, biogas, or syngas). To improve the efficiency of these processes under haloalkaline conditions, a sulfate and thiosulfate reduction step can be included. To investigate the potential to reduce the costs of the electron donor required for this reduction, the use of $\mathrm{H}_{2} / \mathrm{CO}$ mixtures (like in syngas) instead of pure $\mathrm{H}_{2}$ was tested. Initially, $\mathrm{CO}$ present in syngas inhibited hydrogen-dependent sulfate reduction. However, after 30 days the biomass had adapted to the presence of $\mathrm{CO}$ and started to consume $\mathrm{H}_{2}$ and $\mathrm{CO}$ as electron donors. Initially, acetate was produced, followed by sulfate and thiosulfate reduction, and then formate and methane production. Sulfide production rates with a mixture of sulfate and thiosulfate after adaptation were comparable with previously described rates with solely hydrogen. The addition of $\mathrm{CO}$ affected slightly the microbial community but did not change the dominance of microorganisms closely related to Tindallia in the biomass. The $\mathrm{CO}$ as electron donor led to an increase of acetate production, which became the dominant metabolism in the bioreactor. Approximately $50 \%$ of the available electron donors were converted to acetate. Acetate production promoted growth of biomass and higher biomass concentrations were reached compared to bioreactors without $\mathrm{CO}$. Also, $\mathrm{CO}$ addition resulted in the formation of small, compact microbial aggregates. This suggests that $\mathrm{CO}$ or syngas can be used to promote aggregation of microbes in biodesulfurization systems. 


\section{Introduction}

Hydrogen sulfide is a toxic and corrosive compound present in gas streams such as natural gas or biogas. In biodesulfurization systems, sulfide is removed from the gas and elemental sulfur is formed. Biodesulfurization systems that produce elemental sulfur have been studied and applied for more than 25 years (Buisman et al., 1989; Janssen et al., 2009; Roman et al., 2016a). The efficiency of converting sulfide to elemental sulfur in laboratory experiments was up to $95 \%$ and models suggest that 98\% efficiency is possible (Klok et al., 2013; Roman et al., 2016b). The remaining part of the sulfide is biologically oxidized to sulfate or chemically to thiosulfate. These compounds are soluble and accumulate in the system which causes a pH decrease. This $\mathrm{pH}$ decrease has a negative impact because high $\mathrm{pH}(>8.5)$ is required for efficient hydrogen sulfide gas absorption. To solve this problem, part of the liquid content of the system is removed, generating a bleed stream with high $\mathrm{pH}$ and high salinity that contains sulfate and thiosulfate (Janssen et al., 2009).

This bleed stream can be treated by biological reduction of sulfate and thiosulfate to sulfide in a separate bioreactor. This allows the recirculation of the bleed stream into the sulfide-oxidizing bioreactor of the biodesulfurization process. Previous studies showed that such a process is possible at high $\mathrm{pH}$ and high salinity (haloalkaline conditions) in different bioreactor types using a variety of electron donors (Sousa et al., 2015a; Zhou and Xing, 2015). Hydrogen gas $\left(\mathrm{H}_{2}\right)$ is considered a suitable electron donor for biodesulfurization systems applied for natural gas as it can be produced onsite by gas reforming of methane. However, the gas reforming process produces syngas consisting mainly of $\mathrm{H}_{2}$, carbon monoxide $(\mathrm{CO})$ and carbon dioxide $\left(\mathrm{CO}_{2}\right)$. Purification of syngas to obtain pure $\mathrm{H}_{2}$ implies higher costs due to additional posttreatment of the syngas. The application of syngas as an electron donor without removal of $\mathrm{CO}$ is thus preferred and was applied successfully under neutral $\mathrm{pH}$ and low salinity conditions (van Houten et al., 2009). On the other hand, $\mathrm{CO}$ is known to be toxic for some sulfate reducers (Parshina et al., 2010). CO mainly inhibits [Fe-Fe] and [Ni-Fe] hydrogenases involved in hydrogen metabolism (Vignais and Billoud, 2007). This blocks electron flow and inhibits $\mathrm{H}_{2}$-driven sulfate reduction and might also inhibit other hydrogen-dependent reactions in the bioreactor such as formate, acetate and methane production. Nevertheless, microorganisms capable of using $\mathrm{CO}$ as substrate exist (Diender et al., 2015; Parshina et al., 2010; Sipma et al., 2003). These 
microorganisms, which also include sulfate reducers, use $\mathrm{CO}$ via the water-gas shift reaction (eq. 1) to produce $\mathrm{H}_{2}$ that is the actual electron donor (Parshina et al., 2005a, 2005b). The effect of $\mathrm{CO}$ on sulfate-reducing biomass from bioreactors at neutral and high temperature conditions was studied, where it was possible to adapt biomass to CO (van Houten et al., 1996; Sipma et al., 2003). Additionally, it was observed that CO had an effect on the formation of granules, making them smoother (van Houten et al., 1996). This was probably caused by the development of different layers on the granule. The external layer contained acetogenic bacteria that convert $\mathrm{CO}$ while the inner layer contained sulfate-reducing bacteria. These sulfate-reducing bacteria probably used the produced acetate as an additional carbon source (Bertsch and Müller, 2015; Diender et al., 2015). Granules with a smoother shape settle better than irregular shaped aggregates, and in this way $\mathrm{CO}$ could induce the formation of better settling aggregates.

To date, the effect of $\mathrm{CO}$ on haloalkaphilic microorganisms has not been studied in pure or mixed cultures. In this study, we investigated syngas as an electron donor for a sulfate and thiosulfate reducing bioreactor operated under haloalkaline conditions. The impact of $\mathrm{CO}$ on sulfate and thiosulfate reduction as well as on formate, acetate, and methane production was investigated. In addition, biomass attachment to sand as well as microbial aggregation was studied to understand if $\mathrm{CO}$ can be used to influence the adhesion of microorganisms as observed at neutral $\mathrm{pH}$ and low salinity conditions. The feasibility of industrial application of syngas as electron donor for sulfate and thiosulfate reducing bioreactors was evaluated and the main advantages and disadvantages of the use of syngas versus pure hydrogen gas is discussed.

\section{Experimental}

\section{Bioreactor set-up}

A 4.4-L glass gas lift reactor with an internal three phase separator was used (Sousa et al., 2015a). The $\mathrm{H}_{2}, \mathrm{CO}$, and $\mathrm{CO}_{2}$ gas supply was controlled using digital mass flow controllers (F-201CV-020-AGD-22-V and F-201CV-020-AGD-22-Z, Bronkhorst, 
Ruurlo, the Netherlands). The $\mathrm{pH}$ was controlled at $\mathrm{pH} 9$ by supplying $\mathrm{CO}_{2}$ via the mass flow controller.

\section{Inoculum}

The inoculum used was a $1 / 1$ ratio mixture from a sulfate and thiosulfate reducing gaslift bioreactors fed with $\mathrm{H}_{2}$ and $\mathrm{CO}_{2}$ (Sousa et al., 2015a). For the inoculation, $100 \mathrm{ml}$ of concentrated biomass from each bioreactor was used. The biomass was concentrated by centrifuging the content of the previously operated bioreactors at the end of the experiments.

\section{Medium}

A mineral medium was used which was buffered with sodium carbonate and sodium bicarbonate at $\mathrm{pH} 9 \pm 0.05$, that contained a total of $1.5 \mathrm{M} \mathrm{Na}^{+}$. The medium composition was as follows: $\mathrm{Na}_{2} \mathrm{CO}_{3}\left(33.6 \mathrm{~g} \mathrm{l}^{-1}\right), \mathrm{NaHCO}_{3}\left(69.3 \mathrm{~g} \mathrm{l}^{-1}\right), \mathrm{KHCO}_{3}\left(1 \mathrm{~g} \mathrm{l}^{-1}\right)$, $\mathrm{K}_{2} \mathrm{HPO}_{4}\left(1 \mathrm{~g} \mathrm{l}^{-1}\right), \mathrm{NH}_{4} \mathrm{Cl}\left(0.27 \mathrm{~g} \mathrm{l}^{-1}\right), \mathrm{MgCl}_{2} .6 \mathrm{H}_{2} \mathrm{O}\left(0.1 \mathrm{~g} \mathrm{l}^{-1}\right), \mathrm{CaCl}_{2} .2 \mathrm{H}_{2} \mathrm{O}\left(0.01 \mathrm{~g} \mathrm{l}^{-1}\right)$ and $10 \mathrm{ml} \mathrm{l}^{-1}$ of vitamin solution (Wolin et al., 1963). Two trace element solutions were added (Sousa et al., 2015a). As electron acceptors, $7.1 \mathrm{~g}(25 \mathrm{mM})$ of sodium sulfate and $3.95 \mathrm{~g}(12.5 \mathrm{mM})$ of sodium thiosulfate were added.

\section{Experimental design}

After filling the bioreactor with medium, it was flushed with $\mathrm{H}_{2}$ gas overnight to lower the redox potential. The gas recirculation was set at $5 \mathrm{I} \mathrm{min}^{-1}( \pm 0.5)$. Then the $\mathrm{H}_{2}$ gas supply was set at $20 \mathrm{ml} \cdot \mathrm{min}^{-1}$, and the $\mathrm{pH}$ control (set at 9) was turned on. The inoculum was added (time 0 ) initiating the start-up phase. Hereafter, the only parameter changed was the gas composition by adding CO (Table 1). For the $60 \%$ CO spike experiment, the CO supply was increased to $60 \%$ of the gas phase on day 217 and maintained for 48 hours before being switched to $15 \%$ day 219 until the end of the experiment. 
Table 1 - Overview of operational characteristics of bioreactor runs

\begin{tabular}{lcl}
\hline & Period (d) & Mode \\
\hline Start-up & $0-6$ & Batch \\
$0 \%$ CO & $7-45$ & Continuous \\
$5 \%$ CO & $46-123$ & Continuous \\
$15 \%$ CO & $124-216$ & Continuous \\
$60 \%$ CO spike & $217-235$ & Continuous \\
\hline
\end{tabular}

*See experimental design for a detailed description

\section{Batch experiments}

Two batch experiments were performed to assess the metabolic capacity of the biomass at different stages of the bioreactor operation. All experiments were performed with the same medium composition used for the bioreactor.

To study the activity of the biomass after $\mathrm{CO}$ addition, $125 \mathrm{ml}$ of bioreactor liquid, containing biomass, from day 54 of operation was transferred to $250 \mathrm{ml}$ serum bottles. The serum bottles headspace was replaced with $\mathrm{N}_{2}$ gas. $\mathrm{CO}$ was added to make three different gas compositions: 30,55 , and $80 \% \mathrm{CO}$ (at 1 bar of total pressure). The bottles were incubated at $37^{\circ} \mathrm{C}$ and stirred at $150 \mathrm{rpm}$ for 14 days. Each $\mathrm{CO}$ composition was tested in triplicate. For each sampling time, $5 \mathrm{ml}$ of liquid content and $1 \mathrm{ml}$ of gas content were collected from the bottles.

To study the effect of formate and acetate on sulfate/thiosulfate reduction in adapted biomass in the presence of $\mathrm{CO}, 120 \mathrm{ml}$ serum bottles filled with $70 \mathrm{ml}$ fresh medium and $\mathrm{N}_{2}$ headspace were used. Three different conditions were tested: no electron donor, $25 \mathrm{mM}$ sodium formate, and with $12.5 \mathrm{mM}$ sodium acetate. $50 \mathrm{ml}$ of bioreactor liquid, containing biomass, was collected at day 90 , centrifuged $10 \mathrm{~min}$ at $10000 \mathrm{~g}$, resuspended with $10 \mathrm{ml}$ buffer ( $\mathrm{pH}$ 9, $1.5 \mathrm{M} \mathrm{Na}^{+}$) and added as inoculum. CO was added at approximately $25 \% \mathrm{CO}$ in the gas phase (1.4 bar total pressure). Each set of batch cultures was tested in triplicate. For each sampling point, $2 \mathrm{ml}$ of liquid content and 1 $\mathrm{ml}$ of gas content were collected from the bottles. 


\section{Analytical procedures}

Liquid samples for volatile fatty acids, sulfate, thiosulfate and sulfide analysis were prepared and analyzed as described previously (Sousa et al., 2015a). The $\mathrm{H}_{2}, \mathrm{CO}$, $\mathrm{CO}_{2}, \mathrm{~N}_{2}$ and $\mathrm{CH}_{4}$ in the gas phase were quantified by gas chromatography using a CP4900 microGC (Varian, Palo Alto, CA) as previously described (Sousa et al., 2015a).

To measure the biomass concentration, the sand-attached biomass was separated from the suspended biomass by settling for $30 \mathrm{~s}$ and both fractions were transferred to a new tube. One $\mathrm{ml}$ of sand was collected and the samples were washed three times with a carbonate/bicarbonate buffer with lower salinity (LS buffer; pH 9, 0.5 $\mathrm{M} \mathrm{Na}^{+}$ instead of $1.5 \mathrm{M} \mathrm{Na}^{+}$). In subsequent washing steps, sand was separated from the buffer by $30 \mathrm{~s}$ settling. Two $\mathrm{ml}$ of the suspended biomass was centrifuged (10 min, $10000 \mathrm{~g}$ ) and was washed three times with LS buffer. Finally, the total nitrogen content was determined using a cuvette test (LCK238, Hach Lange, Düsseldorf, Germany).

The particle size of the bioreactor content (including sand) was measured using laser measurement in a particle size and shape analyzer (Eyetech, Doner technologies, Or Akiva, Israel) with the Dipa 2000software (Doner technologies, Or Akiva, Israel). Each sample was analyzed in triplicate and each measurement was performed continuously for $120 \mathrm{~s}$ with stirring. Microscopy pictures were taken using a light microscope (DMI6000B, Leica, Biberach, Germany). The sand particles were not measured due to settling in the mixing chamber, being only small aggregates analyzed for particle size.

\section{Scanning electron microscopy}

Biomass samples were fixed in $2.5 \%(\mathrm{w} / \mathrm{v})$ glutaraldehyde overnight at $4^{\circ} \mathrm{C}$. The fixed samples were separated and washed following the same procedure for attached fraction and suspended fraction described above for biomass measurement. Then the samples were dehydrated in a series of ethanol solutions, $(10 \%, 25 \%, 50 \%, 75 \%, 90 \%$ and twice with 100\%) with 20 min in each step and then dried in a desiccator. The samples were coated with gold and analyzed in a JEOL JSM-6480LV Scanning Electron Microscope (JEOL Benelux, Nieuw-Vennep, The Netherlands). 


\section{DNA isolation}

Samples for DNA analysis were stored at $-80^{\circ} \mathrm{C}$. These samples were collected on days $0,46,96,123,216$ and 218 of bioreactor operation. Samples $(10 \mathrm{ml})$ from the bioreactor were separated into attached fraction and suspended fraction and washed following the same protocol as for biomass measurements. Total genomic DNA from the suspended fraction of all samples (days 0, 46, 96, 123, 216 and 218) and attached fraction of samples from day 123 was extracted. The extraction was performed using the PowerBiofilm ${ }^{\mathrm{TM}}$ DNA Isolation Kit (MoBio, Carlsbad, CA) following the manufacturer's instructions. DNA was stored at $-20^{\circ} \mathrm{C}$.

\section{Bacteria community profiling}

A fragment of the 16S rRNA gene of bacteria, including the V3-V5 regions, was amplified with primers $341 \mathrm{~F}$ and $805 \mathrm{R}$ (Herlemann et al., 2011). The PCR protocol and sequencing using the lllumina Miseq platform were performed as previously described at the Science for Life Laboratory, Sweden (www.scilifelab.se) (Hugerth et al., 2014; Lindh et al., 2015). The sequencing data were processed with the UPARSE pipeline and annotated against the SINA/SILVA database (SILVA 119) (Edgar, 2013; Quast et al., 2013). Finally, the data were analyzed using Explicet 2.10.5 (Robertson et al., 2013). Sequences were submitted to the ENA database (http://www.ebi.ac.uk/ena) under the accession number PRJEB11708.

\section{Calculations and assumptions:}

Thermodynamic calculations under actual bioreactor conditions were performed using the online tool eQuilibrator 2.0 (equilibrator.weizmann.ac.il) (Flamholz et al., 2012). The relative electron donor use calculations were based on the molar quantities indicated by the reactions described in Table 2. The assumptions used in the calculations were as follows: i. Evaporation does not cause a major loss of liquid from the bioreactor because it is a closed system. ii. The bioreactor liquid volume was assumed to be constant during the operation which meant that the liquid flow that goes into the bioreactor was equal to the liquid flow getting out of the bioreactor $\left(Q_{\text {in }}=Q_{\text {out }}\right)$. iii. Accumulation of sulfur compounds by incorporation in biomass and formation of 
sulfide precipitates was assumed to play a negligible role. This was due to the high sulfate and thiosulfate concentration in the influent compared to the low concentration of metals added to the medium. iv. Hydrogen used for biomass synthesis was assumed to play a negligible role in the bioreactor. $v$. The $N$ fraction value of 0.2 was used to calculate biomass concentration based on total $\mathrm{N}$, following the biomass molecular formula: $\mathrm{C}_{1} \mathrm{H}_{1.8} \mathrm{O}_{0.5} \mathrm{~N}_{0.2}$. vi. The attached biomass fraction was composed of the sand particles with attached microorganisms and microbial aggregates without support material.

$$
\begin{aligned}
& C_{x}=\frac{C_{T o t a l N}}{0.2} \cdot M_{x} \\
& C_{t x}=C_{x, s p}+C_{x, a} \\
& r_{v s}=\frac{Q \cdot C_{s, \text { in }}-Q \cdot C_{s, \text { out }}}{V_{r}} \\
& r_{v p}=\frac{Q \cdot C_{p, \text { out }}-Q \cdot C_{p, \text { in }}}{V_{r}}
\end{aligned}
$$

Nomenclature
$C_{x}$
Biomass concentration $\left(\mathrm{g} \mathrm{l}^{-1}\right)$
Ctx
Total biomass concentration $\left(\mathrm{g} \mathrm{l}^{-1}\right)$
$\mathrm{M}_{\mathrm{x}} \quad$ Biomass molecular weight $\left(\mathrm{g} \mathrm{mol}^{-1}\right)$
$\mathrm{V}_{\mathrm{r}} \quad$ Bioreactor volume (I)
Q Flow rate $\left(\mathrm{d}^{-1}\right)$
$\mathrm{C}_{\mathrm{S}} \quad$ Sulfate or thiosulfate concentration based on $\mathrm{S}$ molar content (mmols $\mathrm{I}^{-}$
1)
CTotalN Total nitrogen concentration $\left(\mathrm{mol} \mathrm{I}^{-1}\right)$
rvs Sulfidogenic volumetric activity $\left(\mathrm{mmols}^{-1} \mathrm{~d}^{-1}\right)$
rvp Formate, acetate or methane production volumetric activity $\left(\mathrm{mmol} \mathrm{lr}^{-1} \mathrm{~d}^{-}\right.$
1) 
Subscript:

$\begin{array}{ll}\mathrm{a} & \text { Attached biomass } \\ \mathrm{x} & \text { Biomass } \\ \text { out } & \text { Effluent } \\ \text { in } & \text { Influent } \\ \mathrm{p} & \text { Products } \\ \mathrm{r} & \text { Reactor } \\ \mathrm{s} & \text { Sulfur } \\ \mathrm{sp} & \text { Suspended biomass } \\ \mathrm{tx} & \text { Total biomass } \\ \text { TotalN } & \text { Total nitrogen }\end{array}$

\section{Results \& Discussion}

\section{Bioreactor performance}

The use of syngas as an electron donor for haloalkaliphilic sulfate and thiosulfate reducing microorganisms was possible when the $\mathrm{CO}$ present in the syngas was up to $15 \%$. However, a period of adaptation of the biomass to $\mathrm{CO}$ was required. $\mathrm{All}_{\mathrm{H}} \mathrm{H}_{2}$-driven microbial processes, including sulfate/thiosulfate reduction and formate production, were inhibited by the presence of 5\% CO (Figure 1a and 1b). This is in agreement with similar studies performed at neutral conditions where the sulfate reduction activity decreased from $140 \mathrm{mmol} \mathrm{l}^{-1} \mathrm{~d}^{-1}$ to $98 \mathrm{mmol} \mathrm{l}^{-1} \mathrm{~d}^{-1}$ with $5 \% \mathrm{CO}$ (van Houten et al., 1996). During this inhibition period (day 47 to 75 ), thiosulfate disproportionation to sulfate and sulfide was not inhibited. This can be seen by the increase of sulfate and sulfide concentrations in an approximately $1: 1$ ratio (Figure 1 ). During this period in 
which no acetate was formed, the $\mathrm{pH}$ decreased and the $\mathrm{CO}_{2}$ fraction in the gas phase increased, indicative of the water-gas shift reaction (eq. 1, Table 2, and Figure 1c).

Table 2 - Gibbs free energy under the bioreactor actual conditions $\left(\Delta G^{\prime}\right)$ for different $C O$ and $\mathrm{H}_{2}$ consuming reactions at starting and continuous operation conditions.

\begin{tabular}{|c|c|c|c|}
\hline Reaction & $\begin{array}{c}\Delta G^{\prime} \text { starting } \\
\left(\mathrm{kJ} \mathrm{mol}^{-1}\right)\end{array}$ & $\begin{array}{c}\Delta G^{\prime} \text { continuous } \\
\text { operation } \\
\left(\mathbf{k J ~ m o l}^{-1}\right)\end{array}$ & Eq. $n=$ \\
\hline $\mathrm{CO}+2 \mathrm{H}_{2} \mathrm{O} \rightarrow \mathrm{HCO}_{3}^{-}+\mathrm{H}_{2}+\mathrm{H}^{+}$ & $-22.7( \pm 10.5)$ & $-23.1( \pm 10.5)$ & 1 \\
\hline $4 \mathrm{CO}+4 \mathrm{H}_{2} \mathrm{O} \rightarrow \mathrm{C}_{2} \mathrm{H}_{3} \mathrm{O}_{2}^{-}+2 \mathrm{HCO}_{3}^{-}+3 \mathrm{H}^{+}$ & $-199.6( \pm 26.6)$ & $-182.9( \pm 26.6)$ & 2 \\
\hline $4 \mathrm{H}_{2}+2 \mathrm{HCO}_{3}{ }^{-}+\mathrm{H}^{+} \rightarrow \mathrm{C}_{2} \mathrm{H}_{3} \mathrm{O}_{2}^{-}+4 \mathrm{H}_{2} \mathrm{O}$ & $-108.9( \pm 26.9)$ & $-90.5( \pm 26.9)$ & 3 \\
\hline $4 \mathrm{CO}+\mathrm{SO}_{4}{ }^{2-}+4 \mathrm{H}_{2} \mathrm{O} \rightarrow 4 \mathrm{HCO}_{3}{ }^{-}+\mathrm{HS}^{-}+3 \mathrm{H}^{+}$ & $-240.6( \pm 34.3)$ & $-218.8( \pm 34.3)$ & 4 \\
\hline $4 \mathrm{H}_{2}+\mathrm{SO}_{4}^{2-}+\mathrm{H}^{+} \rightarrow \mathrm{HS}^{-}+4 \mathrm{H}_{2} \mathrm{O}$ & $-150.0( \pm 25.0)$ & $-126.4( \pm 25.0)$ & 5 \\
\hline $\mathrm{CO}+\mathrm{H}_{2} \mathrm{O} \rightarrow \mathrm{HCO}_{2}^{-}+\mathrm{H}^{+}$ & $-38.0( \pm 6.5)$ & $-32.3( \pm 6.5)$ & 6 \\
\hline $\mathrm{H}_{2}+\mathrm{HCO}_{3}^{-} \rightarrow \mathrm{HCO}_{2}^{-}+\mathrm{H}_{2} \mathrm{O}$ & $-15.2( \pm 8.9)$ & $-9.2( \pm 8.9)$ & 7 \\
\hline $4 \mathrm{CO}+5 \mathrm{H}_{2} \mathrm{O} \rightarrow \mathrm{CH}_{4}+3 \mathrm{HCO}_{3}^{-}+3 \mathrm{H}^{+}$ & $-215.4( \pm 30.6)$ & $-198( \pm 30.6)$ & 8 \\
\hline $4 \mathrm{H}_{2}+\mathrm{HCO}_{3}^{-}+\mathrm{H}^{+} \rightarrow \mathrm{CH}_{4}+3 \mathrm{H}_{2} \mathrm{O}$ & $-124.4( \pm 25.1)$ & $-105.6( \pm 25.1)$ & 9 \\
\hline
\end{tabular}

Conditions used for calculations: $\mathrm{pH}$ 9, 1.5 ionic strength, $825 \mathrm{mM} \mathrm{HCO}_{3}$. Starting conditions: $50 \mathrm{mM}$ sulfate, 1 $\mathrm{mM}$ sulfide, $1 \mathrm{mM}$ acetate, $1 \mathrm{mM}$ formate, $150 \mathrm{mbar} \mathrm{CO}, 850 \mathrm{mbar}_{2}, 10 \mathrm{mbar}$ methane. Continuous operation conditions (average of days 190 to 216 ): $5.7 \mathrm{mM}$ sulfate, $36.9 \mathrm{mM}$ sulfide, $37.8 \mathrm{mM}$ acetate, $4.5 \mathrm{mM}$ formate, $68 \mathrm{mbar} \mathrm{CO}, 333 \mathrm{mbar} \mathrm{H}_{2}, 575$ mbar methane. Error for each $\Delta \mathrm{G}$ ' estimation is presented in brackets because formation energy of the compounds under high $\mathrm{pH}$ and ionic strength are estimated based on models. 


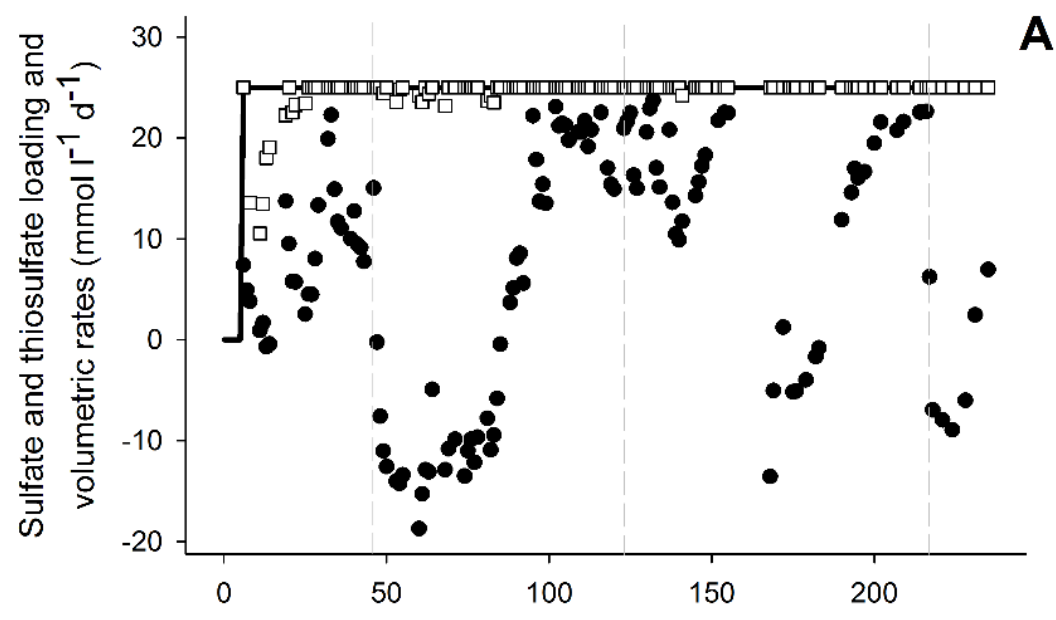

A
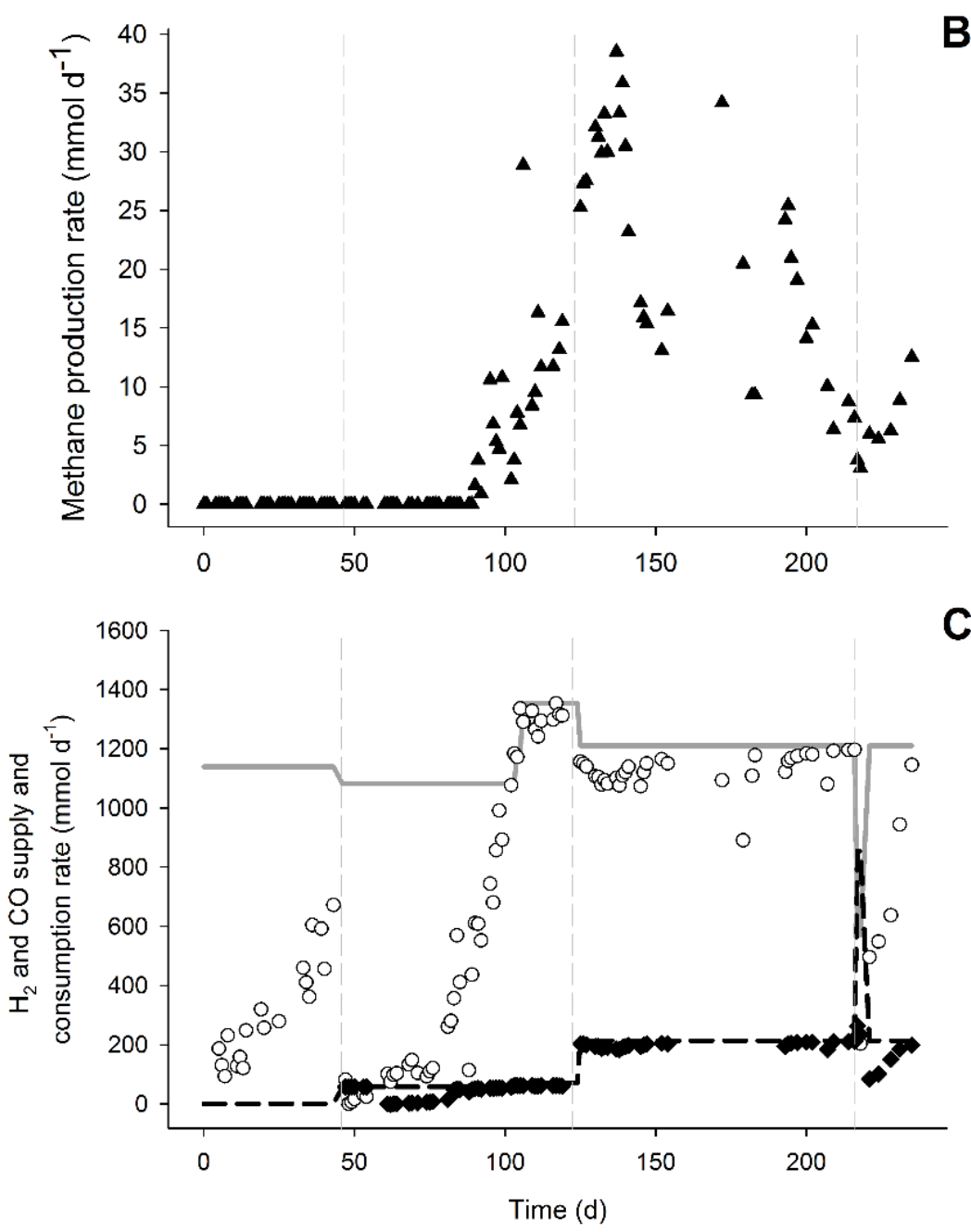

Figure 1 - Concentrations of sulfate, thiosulfate and sulfide (A), formate and acetate $(B)$ and $\mathrm{pH}$ and fractions of $\mathrm{CO}$ and $\mathrm{CO}_{2}$ in the gas phase of the bioreactor during the bioreactor experiment $(C)$. Vertical dashed lines represent the beginning of $\mathrm{CO}$ experiments: $5 \% \mathrm{CO}\left(1^{\text {st }}\right)$, $15 \%$ CO $\left(2^{\text {nd }}\right)$ and $60 \%$ CO spike $\left(3^{\text {rd }}\right)$. 
After 38 days of operation with $5 \% \mathrm{CO}$ (day 84 ), the sulfate/thiosulfate reduction activity recovered. This activity was not affected by an increase to $15 \% \mathrm{CO}$ on day 124 (Figure 1a). Thiosulfate was completely reduced and $87 \pm 3 \%$ of sulfate was reduced during the stable phase with $15 \%$ CO (day 200 to 216 ). The sulfidogenic rate was similar to that achieved in a study with only $\mathrm{H}_{2}\left(42.3 \pm 2.2 \mathrm{mmols}^{-1} \mathrm{~d}^{-1}\right)$, when applying the same sulfate/thiosulfate loading rate (Chapter 5 ). The sulfidogenic rates ( $r v s$ achieved almost matched the loading rates of sulfate and thiosulfate (Figure 2a). This indicated that sulfidogenic rates could be higher if loading of sulfate and thiosulfate was increased as described for other sulfate and thiosulfate reducing bioreactors (Table 3 ).

Table 3 - Conditions and performance of sulfate and thiosulfate reducing bioreactors operated under haloalkaline conditions

\begin{tabular}{|c|c|c|c|c|}
\hline & This study & Sand paper & Zhou et al, 2015 & Thiosulfate paper \\
\hline Reactor type & $\begin{array}{c}\text { Gas lift with } 3 \\
\text { phase separator }\end{array}$ & $\begin{array}{c}\text { Gas lift with } 3 \\
\text { phase separator }\end{array}$ & Anaerobic filter & $\begin{array}{c}\text { Gas lift with } 3 \\
\text { phase separator }\end{array}$ \\
\hline $\mathrm{e}^{-}$acceptor & $\begin{array}{l}\text { Sulfate } \\
\text { /thiosulfate }\end{array}$ & $\begin{array}{l}\text { Sulfate } \\
\text { /thiosulfate }\end{array}$ & Sulfate & Thiosulfate \\
\hline e-donor & $\mathrm{H}_{2} / \mathrm{CO}$ & $\mathrm{H}_{2}$ & Formate & $\mathrm{H}_{2}$ \\
\hline $\mathrm{pH}$ & 9 & 9 & 9.5 & 9 \\
\hline $\mathrm{Na}^{+}$conc. $(\mathrm{M})$ & 1.5 & 1.5 & 1 & 1.5 \\
\hline Temperature $\left({ }^{\circ} \mathrm{C}\right)$ & 35 & 35 & 37 & 35 \\
\hline HRT (d) & 1 & 1 & 1 & 1.7 \\
\hline $\begin{array}{l}\text { Max loading rate } \\
\left(\mathrm{mmols}^{-1} \mathrm{~d}^{-1}\right)\end{array}$ & 50 & 100 & 88.5 & 50 \\
\hline 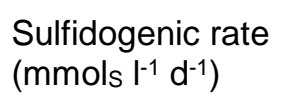 & $46.8( \pm 0.8)$ & $85.45( \pm 3)$ & $85.05( \pm 0.2)$ & $28.7( \pm 0.8)$ \\
\hline Side products & $\begin{array}{c}\text { Formate/Acetate/ } \\
\text { Methane }\end{array}$ & $\begin{array}{l}\text { Formate/Acetate } \\
\text { /Methane }\end{array}$ & Acetate & Formate \\
\hline Biomass ( $\mathrm{mg} \mathrm{l}^{-1}$ ) & $197( \pm 39)$ & $127( \pm 41)$ & N.D. & $14( \pm 2.2)$ \\
\hline
\end{tabular}

N.D. - No data availalbe 

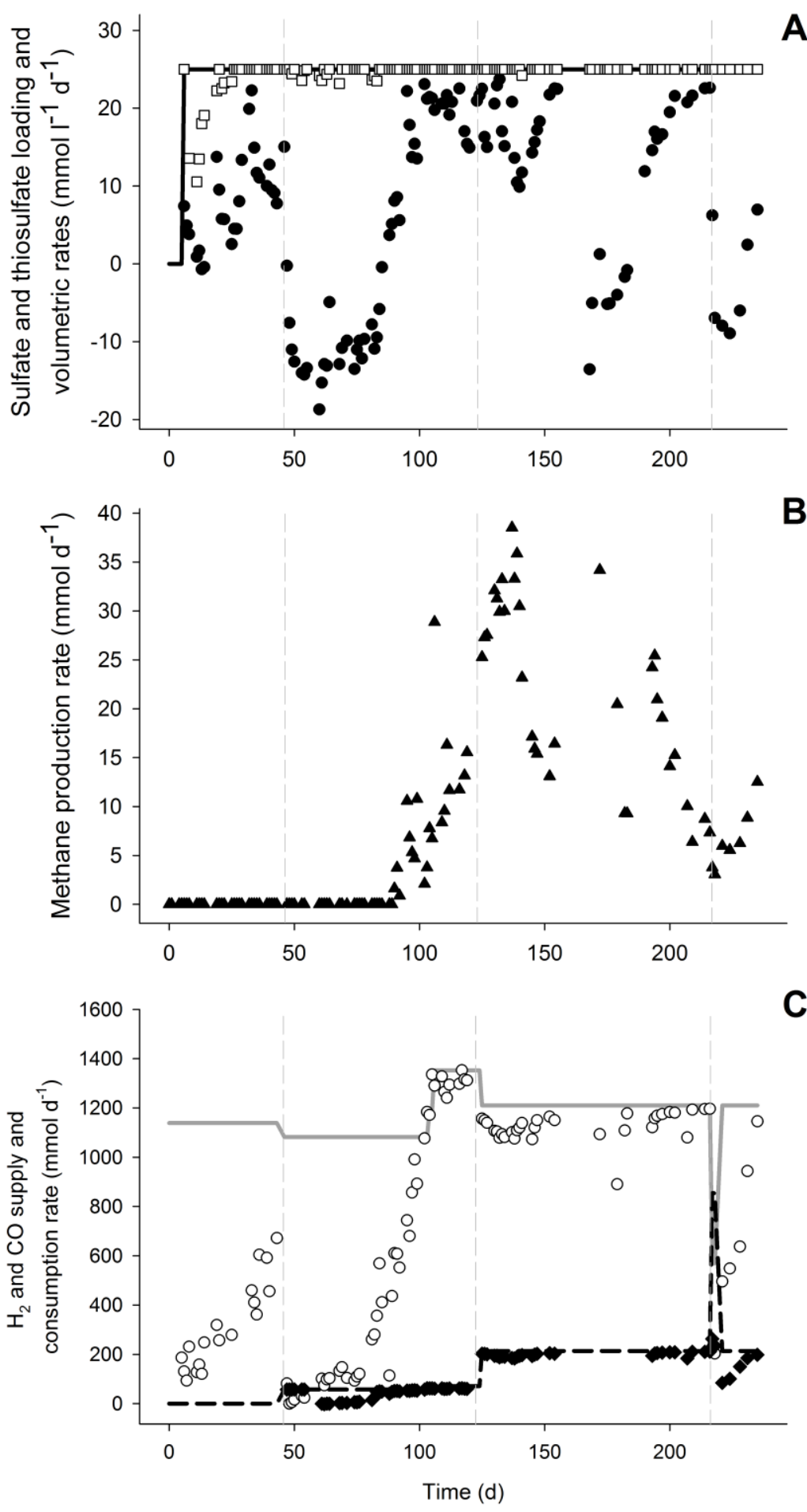

Figure 2 - Metabolic rates and electron donor consumption during the bioreactor experiment. A - Sulfate and thiosulfate loading rate (represented by the continuous line), sulfate $(\bullet)$, thiosulfate $(\square)$, and volumetric reduction rates $\left(r_{v s}\right)$. B - Total methane production rate $\left(r_{v p}\right)$. C - Supply of $\mathrm{H}_{2}$ (continuous line) and $\mathrm{CO}$ (dashed line), and consumption rate of $\mathrm{H}_{2}(\circ)$ and $\mathrm{CO}$ $(\bullet)$. Vertical dashed lines represent the start of CO addition: $5 \% \mathrm{CO}\left(1^{\text {st }}\right), 15 \% \mathrm{CO}\left(2^{\text {nd }}\right)$, and $60 \%$ CO spike $\left(3^{\text {rd }}\right)$. 
Besides sulfate and thiosulfate reduction, acetate, formate and methane were produced (Figure 1a, 1b and 2b). Acetate production started after the inhibition period on day 76, probably using hydrogen and/or $\mathrm{CO}$ as electron donors. It is not possible to distinguish if either $\mathrm{H}_{2}$ or $\mathrm{CO}$ were specifically used because $\mathrm{H}_{2}$ and $\mathrm{CO}$ were simultaneously consumed (Figure 2c). However, looking at the overall electron donor consumption $\left(\mathrm{H}_{2}+\mathrm{CO}\right)$, acetate production was the main electron donor-consuming reaction. Approximately $49 \%( \pm 5 \%)$ of the supplied electron donors in the stable phase with 15\% CO (Figure 3). This was considerably higher than reported in bioreactors fed with $\mathrm{H}_{2}$ or formate as electron donors (Chapter 5 ) (Zhou and Xing, 2015). Furthermore, high acetate concentrations might have contributed to the biomass increase compared to previous results (Table 3, Figure 4). This effect of acetate was observed when no other carbon sources were added to the media (Chapter 5).

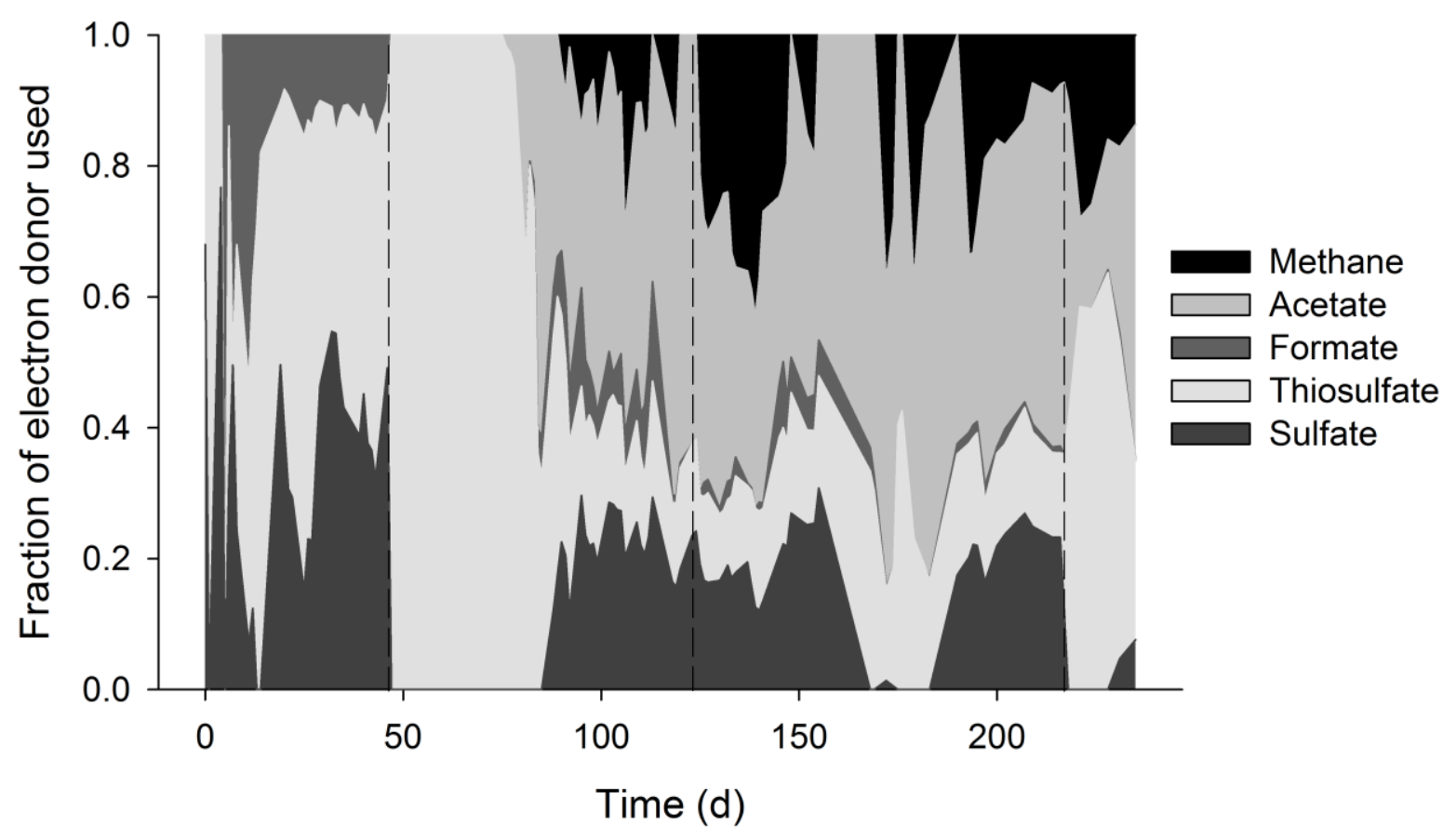

Figure 3 - Fraction of electron donor $\left(\mathrm{H}_{2}+\mathrm{CO}\right)$ used by the different metabolisms: sulfate and thiosulfate reduction and formate, acetate and methane production. For calculation, all values of electron donors and acceptors were converted to $\mathrm{mmol} / \mathrm{d}$. Vertical dashed lines represent the beginning of $\mathrm{CO}$ experiments: $5 \% \mathrm{CO}\left(1^{\text {st }}\right), 15 \% \mathrm{CO}\left(2^{\text {nd }}\right)$ and $60 \% \mathrm{CO}$ spike $\left(3^{\text {rd }}\right)$. 

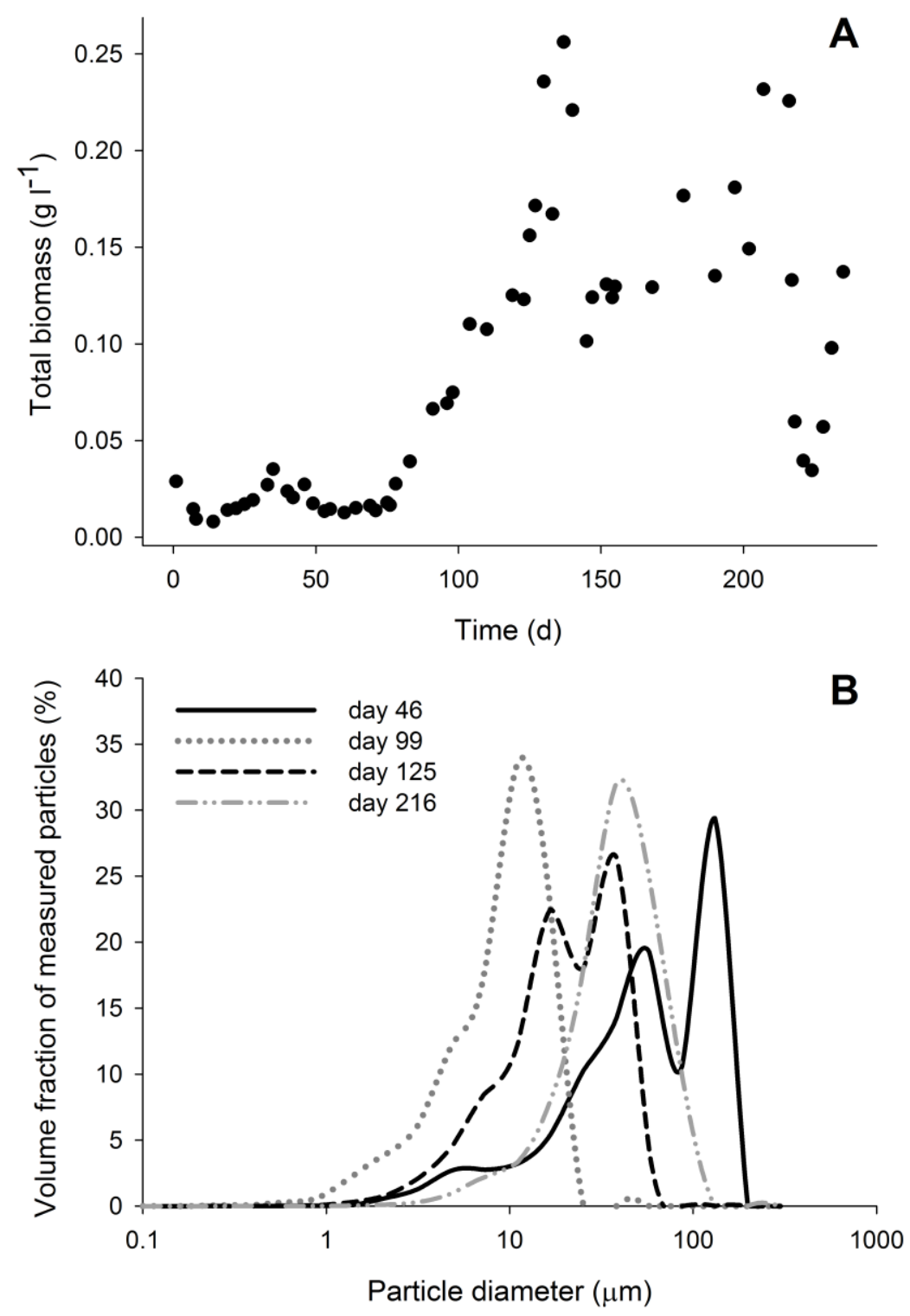

Figure 4 - Biomass in the bioreactor. A - Total biomass concentration $\left(C_{t x}\right)$ in the bioreactor during its operation. B - Particle diameter distribution of the biomass on days 46 (without CO), 99 (5\% CO), 125 (just after increase to 15\%), and 216 (stable phase with 15\% CO).

Even though high and stable sulfate and thiosulfate reduction rates with $15 \% \mathrm{CO}$ in the gas supply were achieved (Figure 1 and 2), temporary $\mathrm{CO}$ increases could still have a negative effect on the bioreactor operation. To study this, $60 \% \mathrm{CO}$ was fed to the bioreactor from day 217 until day 219 , and afterwards CO was returned to $15 \%$. The addition of $60 \% \mathrm{CO}$ led to a steep decrease in sulfate reduction, formate and acetate production, and biomass concentration (Figure 1 and 4). However, thiosulfate 
disproportionation was not affected and methane production even increased after the 60\% CO spike (Figure 1 and 2). This indicated that either methanogenesis could compete for $\mathrm{H}_{2}$ after the inhibition with the other hydrogenotrophic microorganisms or that the methanogens present were using $\mathrm{CO}$ as electron donor. Generally, methanogens poorly use $\mathrm{CO}$ and are rapidly inhibited upon exposure to $\mathrm{CO}$ (Daniels et al., 1977). However, methanogenesis with $C O$ has never been reported under haloalkaline conditions and it is thermodynamically favourable at the conditions present in the bioreactor (Table 2).

\section{Inhibition by CO}

The results indicated that $\mathrm{CO}$ affects $\mathrm{H}_{2}$-driven microbial processes in the bioreactor, such as sulfate reduction, and formate and acetate production. Due to its reductive properties $\left(E^{0}=-520 \mathrm{mV}\right)$, CO reacts with metals in the active centres of enzymes (Jeoung et al., 2014). The inhibition of hydrogenases by $\mathrm{CO}$ is well known, causing hydrogen-dependent microbial processes to be rapidly inactivated upon exposure to CO (Bertsch and Müller, 2015; Daniels et al., 1977). [Fe-Fe]-hydrogenases appear to be more sensitive to $\mathrm{CO}$ than [Ni-Fe]-hydrogenases (Adams, 1990b; De Lacey et al., 2007). Exposure of biomass to $C O$ apparently inhibited hydrogenases, resulting in low rates of $\mathrm{H}_{2}$-driven sulfate reduction, and formate and acetate production. The observation that thiosulfate disproportionation remained active supports the hydrogenase inhibition hypothesis, as thiosulfate disproportionation does not require the action of hydrogenases. Despite the inhibition of hydrogen-dependent conversions, biomass levels remained relatively constant during this phase, indicating microbial growth (Figure 4). Besides thiosulfate disproportionation and the water-gas shift reaction already described, acetate production from $\mathrm{CO}$ might also have occurred in this phase. Even though acetate was under the detection limit, its production in lower amounts might have supported the biomass growth. Slow oxidation of $\mathrm{CO}$ was observed in batch bottles incubated with biomass from the period just after $\mathrm{CO}$ was added (Figure 5). This suggests the microbial community present during this operation period had the ability to convert $\mathrm{CO}$. 


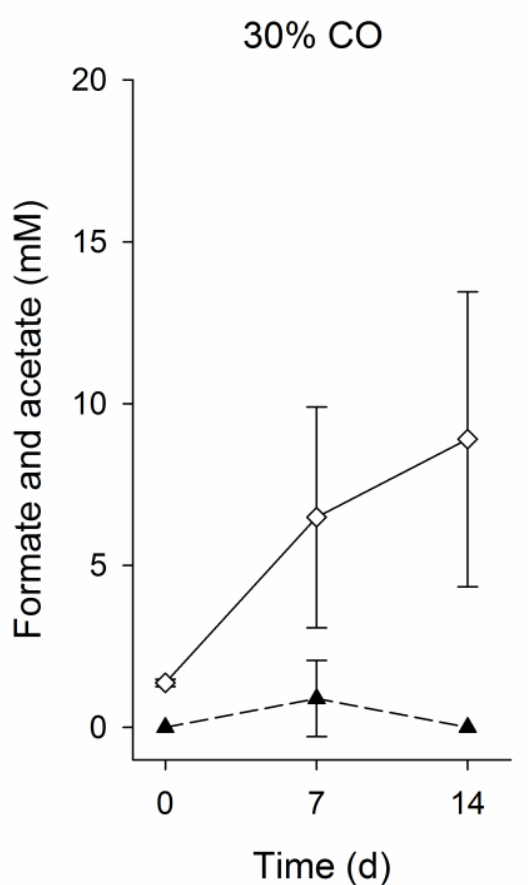

Time (d)
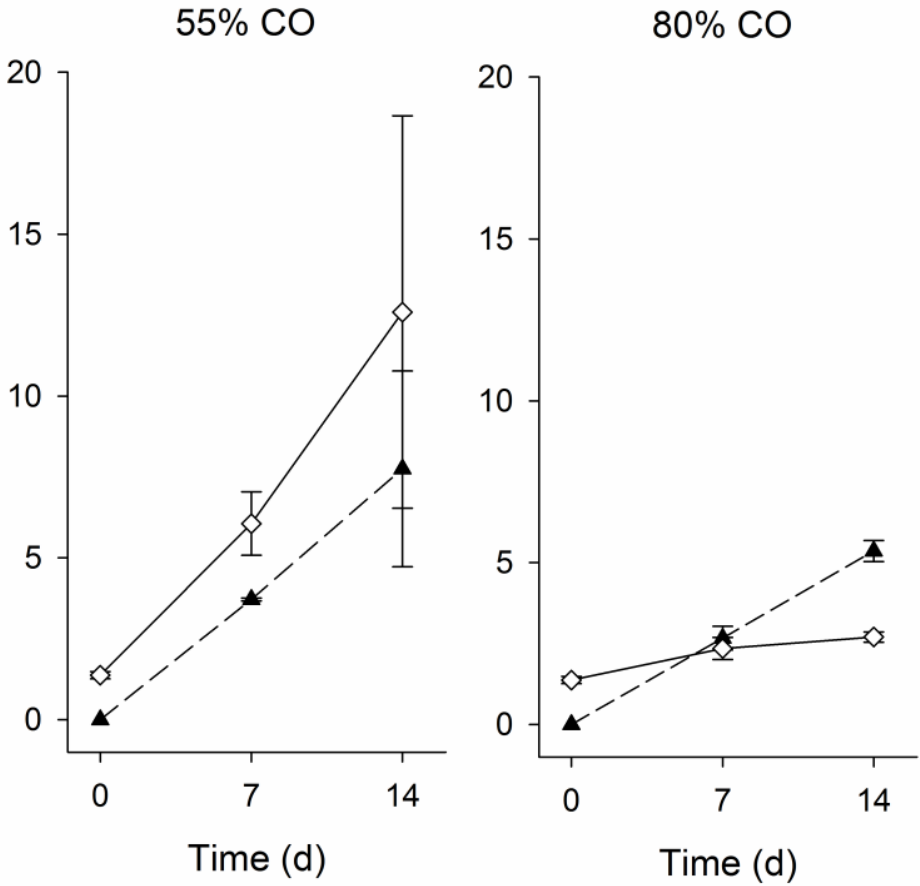

Figure 5 - Formate $(\boldsymbol{\Delta})$ and acetate $(\diamond)$ production during the batch tests with biomass from day 54 incubated with $30 \%, 55 \%$ and $80 \% \mathrm{CO}$ in the gas phase. The vertical bars indicate the standard deviation.

\section{Adaptation to CO}

After 30 days without activity of $\mathrm{H}_{2}$-driven microbial processes, at day 76 acetogenic activity was observed which correlated with removal of $\mathrm{CO}$ from the headspace (Figure 1 and 2). Several acetogens utilize $\mathrm{CO}$ as substrate, employing the Wood-Ljungdahl pathway (Bertsch and Müller, 2015). In volcanic environments that contain high levels of $\mathrm{CO}$, carboxydotrophic organisms play a role in removal of $\mathrm{CO}$, thereby creating a viable environment for non-CO-tolerant microbes (Techtmann et al., 2009). The COdriven acetogenic activity observed in the bioreactor could have created favourable conditions for hydrogenotrophic sulfate reducers and formate producers. Additionally, adaptation to $\mathrm{CO}$ by microorganisms already present in the biomass, such as via production of CO-resistant enzymes, also might have contributed to restoration of activity. Some hydrogenases have been reported to be highly resistant to $\mathrm{CO}$ like some [Ni-Fe]-hydrogenases and $\mathrm{O}_{2}$ tolerant hydrogenases (Adams, 1990a; Fox et al., 1996; Vignais and Billoud, 2007). Microorganisms capable of producing such CO-resistant hydrogenases would be able to metabolize $\mathrm{H}_{2}$ in CO-rich environments. 
The effect of different $\mathrm{CO}$ gas fractions on the activity of adapted biomass was assessed in batch experiments. Formate and acetate production from $\mathrm{CO}$ as sole electron donor occurred, but higher formate formation and lower acetate formation were observed with increasing $\mathrm{CO}$ fractions (Figure 5). Formate is produced by some bacteria and archaea which grow acetogenically on $\mathrm{CO}$, such as Clostridium ljungdahlii, Methanosarcina acetivorans, and Archaeoglobus fulgidus (Henstra et al., 2007; Köpke et al., 2010; Rother and Metcalf, 2004). However, no physiological studies are available on haloalkaliphilic CO-oxidizing acetogens. Currently, Fuchsiella alkaliacetigena is the only existing isolate representing a haloalkaliphilic hydrogenotrophic acetogen, but it is unable to grow in the presence of CO (Zhilina et al., 2012). The microbial community in the bioreactor was dominated by bacteria closely related to the Clostridiaceae family (Figure 6). By further analysis, $99 \%$ of these sequences were closely related to the Tindallia genus. These Tindallia related bacteria were previously detected as dominant bacteria in $\mathrm{H}_{2}$ fed sulfate and thiosulfate-reducing bioreactors and their role in formate production was hypothesized (Sousa et al., 2015a; Chapter 4 \& 5). Despite the low energy yield of $\mathrm{H}_{2}$-driven formate production (eq 7, Table 2), one of the Tindallia isolates was capable of $\mathrm{H}_{2}$-driven formate production coupled to growth (Sorokin et al., 2011). As Tindallia related bacteria were dominant during the whole bioreactor operation period, it was likely that they could adapt to $\mathrm{CO}$.

CO-oxidation coupled to sulfate reduction at neutral and thermophilic conditions by mixed- or pure-cultures, such as Desulfotomaculum carboxydivorans and Archaeoglobus fulgidus, is well documented (Henstra et al., 2007; van Houten et al., 1996; Parshina et al., 2005a, 2005b; Sipma et al., 2006). In the present study, sulfate reduction only started after removal of $\mathrm{CO}$, and no $\mathrm{CO}$-driven sulfate reduction occurred in batch experiments (Figure 7). This suggests that hydrogen and/or formate were the electron donors for sulfate reduction. Interestingly, incubations with $\mathrm{CO}$ and $50 \mathrm{mM}$ formate showed sulfate reduction. This indicated that formate acts as an electron donor for sulfate reduction in the presence of $\mathrm{CO}$, possibly bypassing hydrogenases. The sulfate reducers detected in both the suspended and attached biomass were related to the Desulfohalobiaceae family (Figure 6). By zooming in to genus level of Desulfohalobiaceae related sequences, all were closely related to Desulfonatronovibrio. The studied isolates belonging to this genus can use $\mathrm{H}_{2}$ or 
formate to reduce sulfate (Sorokin et al., 2012). However, to date there is no information available on the effect of $\mathrm{CO}$ on these bacteria and how formate can still be used as electron donor in the presence of $\mathrm{CO}$.

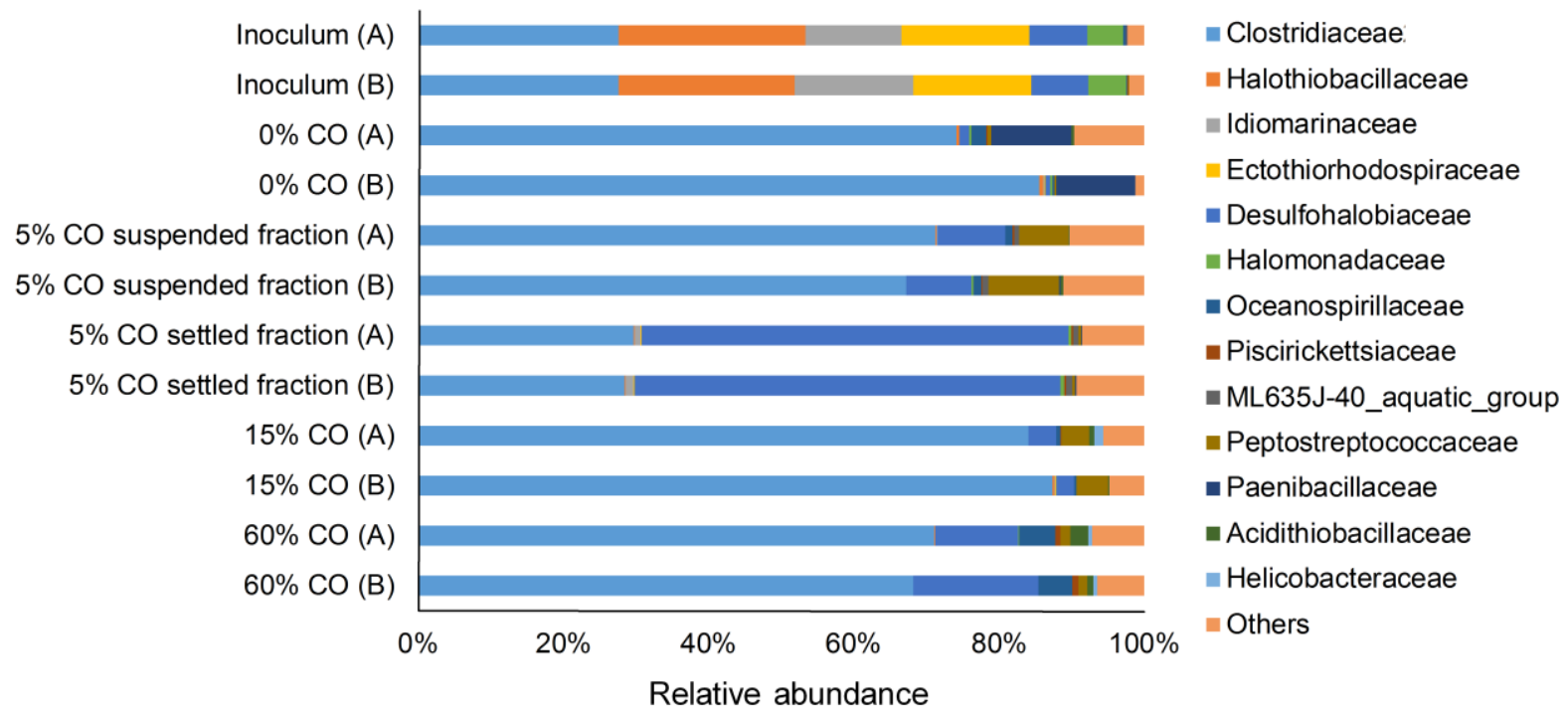

Figure 6 - Microbial 16S rRNA relative abundance on family level in the inoculum and biomass samples from the end of the runs without CO (day 46), with $5 \%$ CO (day 123), with 15\% CO (day 216) and after the spike with $60 \%$ CO (day 218). For the samples of day 123 , the suspended and settling fractions were separated and analyzed separately. A and B represent duplicates for the corresponding day. OTUs with less than $0.5 \%$ relative abundance were grouped in "others". 


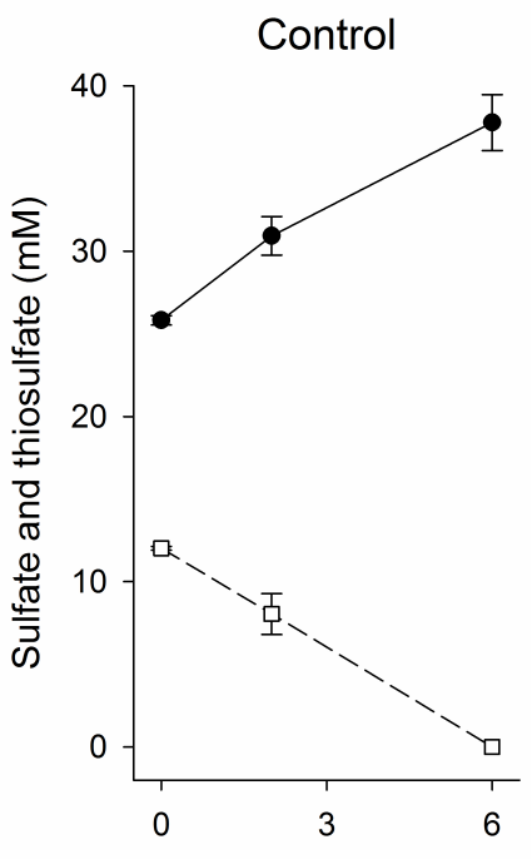

Time (d)
Formate

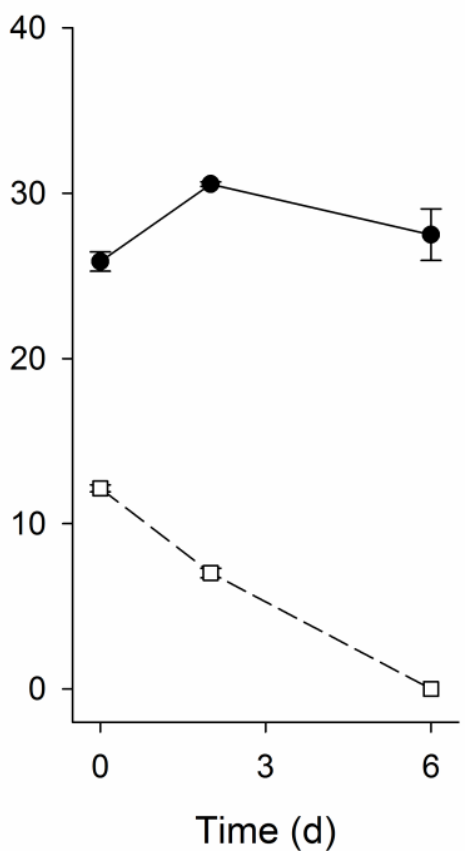

Acetate

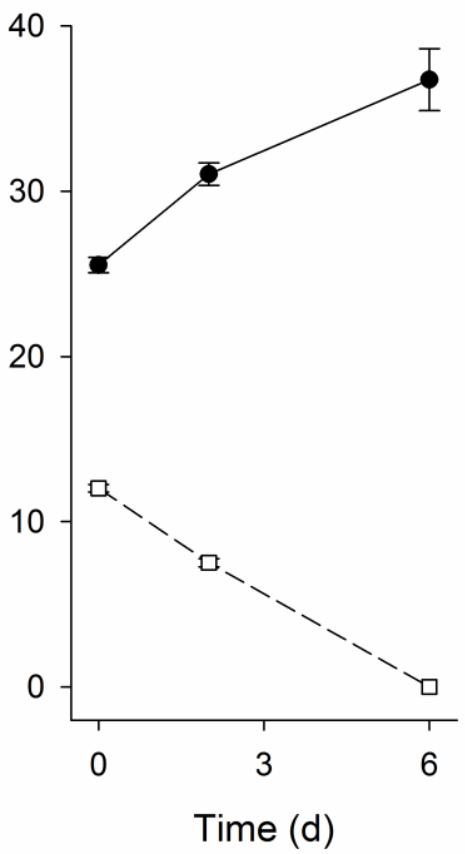

Figure 7 - Sulfate $(\bullet)$ and thiosulfate $(\square)$ conversion during the batch tests with biomass from day 90 incubated with $25 \% \mathrm{CO}$ in the gas phase. The control test was performed with regular medium, while to the formate experiment, $25 \mathrm{mM}$ formate was added, and to the acetate test, $12.5 \mathrm{mM}$ acetate was added. Vertical bars represent the standard deviation.

\section{Biomass aggregation}

The addition of $\mathrm{CO}$ to the bioreactor influenced the formation of biomass aggregates that were not attached to sand. After addition of CO, small compact biomass aggregates were observed while no biofilm formation on sand particles was observed (Figure 8). A similar effect was previously observed in bioreactors operated at neutral conditions (van Houten et al., 1996). The formation of biomass aggregates under haloalkaline conditions was previously observed in a bioreactor fed with $\mathrm{H}_{2}$, but their appearance was not as compact as observed with CO (Figure 8) (Chapter 5). The particles in the bioreactor were mainly dominated by biomass aggregates that decreased in diameter upon CO addition (Figure 4). The maximum size achieved after $\mathrm{CO}$ addition did not increase with time as can be seen by the similar particle size distribution at days 125 and 216 (Figure 4). This phenomenon might be related to the haloalkaline conditions and more specifically, the effect of $\mathrm{pH}$ on the hydrophobicity of cells surfaces or absence of soluble divalent cations for EPS stabilization (Ismail et al., 2008; Otto et al., 1999; Sousa et al., 2015b). 

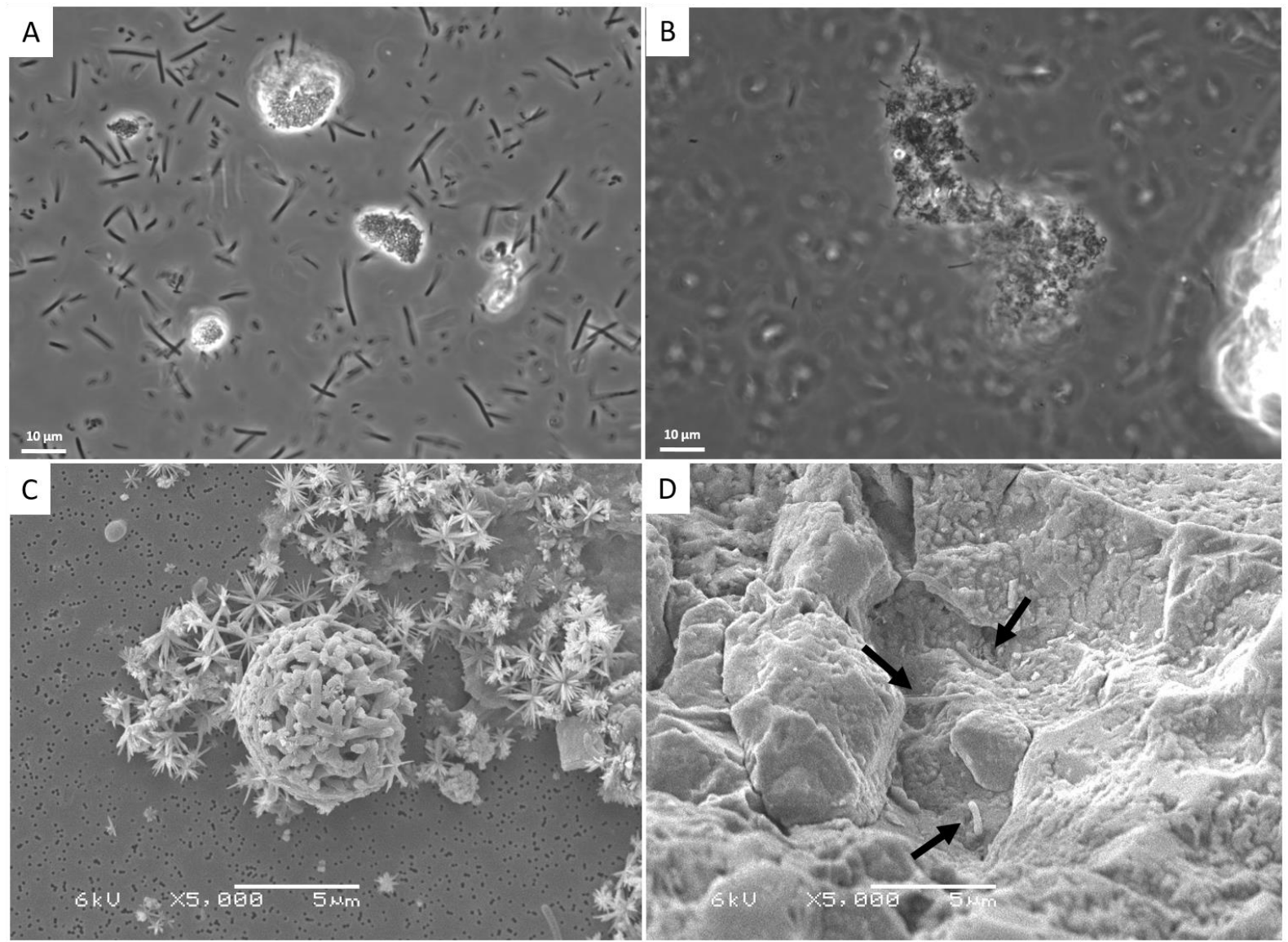

Figure 8 - Microscopic observations of the biomass from the bioreactor. A - Small compact aggregates observed on day 154 and representative for the whole period with $15 \% \mathrm{CO}$ (scale bar represents $10 \mu \mathrm{m})$. B - Small aggregates observed on a previous bioreactor operated with $\mathrm{H}_{2}$ as electron donor (Chapter 5); (scale bar represents $10 \mu \mathrm{m}$ ). C - Scanning electron micrograph of a small aggregate from a sample from day 78 (scale bar represents $5 \mu \mathrm{m}$ ). $D-$ Scanning electron micrograph of microorganisms attached to sand inside cavities on a sample from day 78 (scale bar represents $5 \mu \mathrm{m}$ and black arrows point to microorganisms).

The observed aggregates were more compact than those in a bioreactor without addition of $\mathrm{CO}$. This might be connected to a metabolic relationship between $\mathrm{CO}$ oxidizers and sulfate reducers as was observed for neutral conditions (van Houten et al., 1996). Focusing on the microbial composition of the aggregates in settled biomass on day $123, \sim 58 \%$ consisted of Desulfohalobiaceae and more specifically Desulfonatronovibrio-like bacteria (Figure 6). All studied Desulfonatronovibrio sp. isolates use acetate as carbon source for growth (Sorokin et al., 2012). Thus, aggregation of sulfate reducers together with CO-oxidizing microbes, such as acetogens, could have enhanced their growth due to acetate production. Additionally, 
the lower in situ $\mathrm{CO}$ concentrations generated by $\mathrm{CO}$ oxidizing acetogens might also have been more favourable to the sulfate reducers.

\section{Application in gas biodesulfurization}

Syngas can be used as electron donor for sulfate and thiosulfate-reducing bioreactors operated under haloalkaline conditions. However, the $\mathrm{CO}$ concentration in the syngas varies considerably depending on the feedstock used and production method, from 0 up to higher than 50\% (Guan et al., 2016; Voldsund et al., 2016). Even though inhibition effects were observed during the spike of $60 \%$ CO performed in this study, such spikes can be controlled by a proper production of syngas or pre-treatment of syngas (Voldsund et al., 2016). Thus, despite that using syngas without removing $\mathrm{CO}$ would decrease the cost of the electron donor, the capacity of biomass to withstand $\mathrm{CO}$ fractions only up to $15 \%$ might make the application of bleed stream treatment using syngas and recycling an interesting option for biodesulfurization systems (Figure 9).

Acetate production might be a drawback for the application of such bioreactor in biodesulfurization systems. For the sulfate and thiosulfate reducing bioreactor, excessive acetate production consumes additional electron donor which increases demand of electron donor. This implies the requirement of extra syngas to compensate for acetate production, which increases the costs of operation. After treatment, the sulfide and acetate rich stream from the sulfate/thiosulfate-reducing bioreactor (Figure $8, n^{\circ} 4$ ) could be recycled back into the sulfide-oxidizing bioreactor (Figure $\left.8, n^{\circ} 2\right)$ (van den Bosch, 2008). In the sulfide-oxidizing bioreactor, acetate leads to organic contamination of the system resulting in growth of unwanted microorganisms. Acetate oxidation requires extra consumption of $\mathrm{O}_{2}$, increasing aeration costs, and production of $\mathrm{CO}_{2}$, which decreases the $\mathrm{pH}$. The $\mathrm{pH}$ decrease affects the sulfide absorption process (Figure $8, n^{\circ} 1$ ) which increases the caustic required to increase $\mathrm{pH}$. 


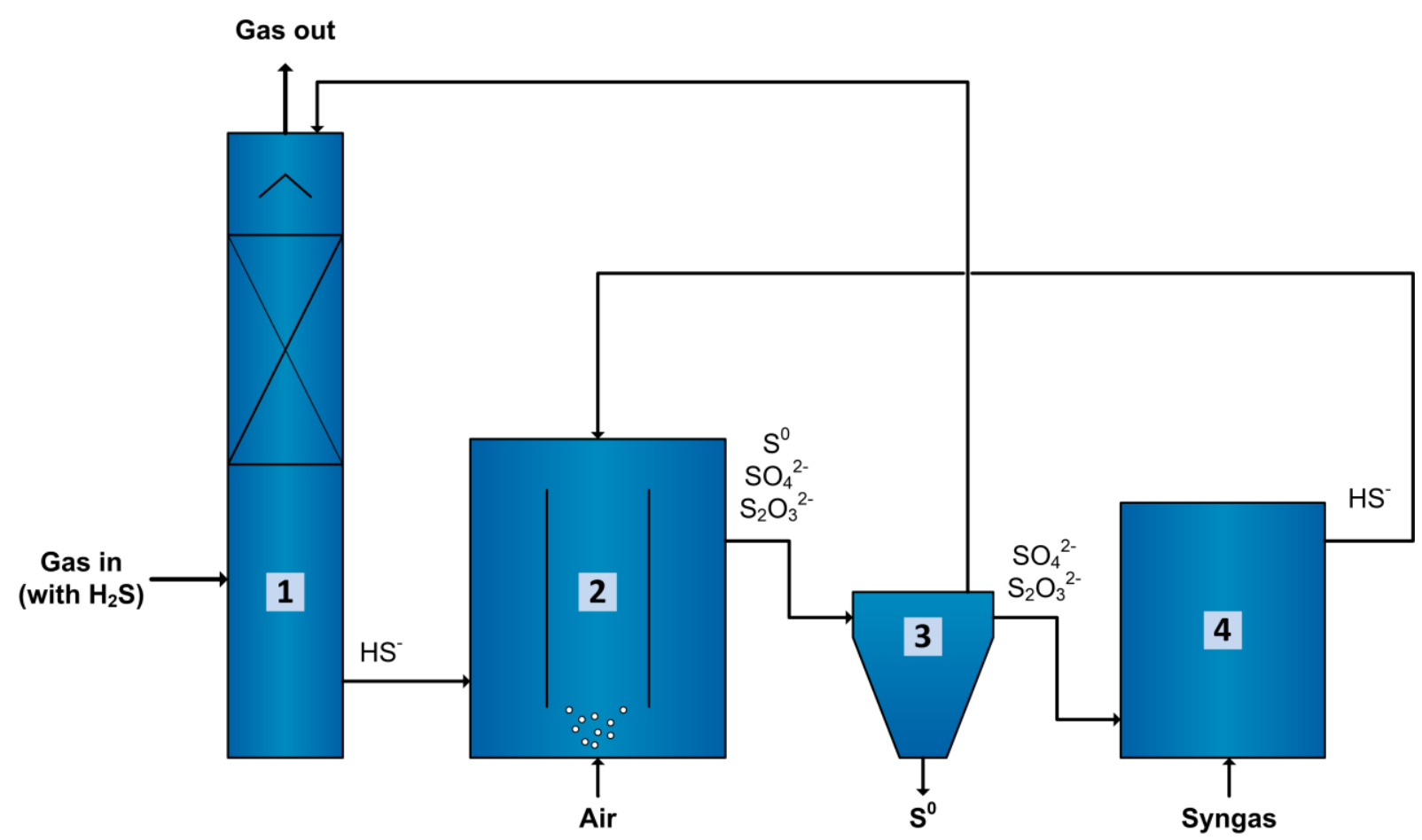

Figure 9 - Biological process for gas desulfurization using an anaerobic sulfate/thiosulfate reducing bioreactor to enable bleed stream recycling. The sulfide $\left(\mathrm{H}_{2} \mathrm{~S}\right)$ present in the gas is dissolved in an alkaline solution as HS- using a scrubber (1). This HS- rich solution goes to an aerobic bioreactor (2) where it is biologically oxidized, under controlled microaerophilic conditions, to mostly elemental sulfur $\left(\mathrm{S}^{0}\right)$ and a minor fraction to sulfate $\left(\mathrm{SO}_{4}{ }^{2-}\right)$, and chemically oxidized, via polysulfides, to thiosulfate $\left(\mathrm{S}_{2} \mathrm{O}_{3}{ }^{2-}\right)$. The $\mathrm{S}^{0}$ is separated in a settler (3) and most of the liquid is recycled to the scrubber (1). Part of the liquid from the settler (3) goes to an anaerobic bioreactor (4) where $\mathrm{SO}_{4}{ }^{2-}$ and $\mathrm{S}_{2} \mathrm{O}_{3}{ }^{2-}$ are reduced to $\mathrm{HS}^{-}$using syngas as electron donor. The HS produced is recycled back to the aerobic bioreactor (2). With time, this prevents accumulation of $\mathrm{SO}_{4}{ }^{2-}$ and $\mathrm{S}_{2} \mathrm{O}_{3}{ }^{2-}$ in the whole system, and theoretically reducing the amount of caustic required to increase the $\mathrm{pH}$ to almost zero. Additionally, it will prevent the disposal of bleed stream into the environment and maximize the $S^{0}$ production.

\section{Conclusions}

Syngas, up to $15 \%$ CO content, can be used as electron donor for a sulfate/thiosulfatereducing bioreactor operated at haloalkaline conditions. Adaptation of the biomass to $\mathrm{CO}$ is required as $\mathrm{CO}$ inhibits hydrogen-dependent microbial processes, such as sulfate reduction, formate production, and acetate production in non-adapted biomass. After adaptation, the biomass sulfate/thiosulfate reduction activity was comparable to 
reported in previous studies using other electron donors, such as $\mathrm{H}_{2}$ or formate. Acetate production was the dominant conversion in the bioreactor when $\mathrm{CO}$ was supplied. Acetate production seems to enhance growth of sulfate-reducing bacteria that require acetate as carbon source. The high acetate concentration in the treated bleed stream has consequences for the sulfide oxidation step and sulfide absorption step of the biodesulfurization process after it is recycled. 


\section{References}

Adams MWW (1990a) The metabolism of hydrogen by extremely thermophilic, sulfurdependent bacteria. FEMS Microbiol Rev 6:219-237.

Adams MWW (1990b) The structure and mechanism of iron-hydrogenases. Biochim Biophys Acta - Bioenerg 1020:115-145.

Bertsch J, Müller V (2015) CO metabolism in the acetogen Acetobacterium woodii. Appl Environ Microbiol 81:5949-5956.

Buisman C, Post R, IJspeert P, Geraats G, Lettinga G (1989) Biotechnological process for sulphide removal with sulphur reclamation. Acta Biotechnol 9:255-267.

Daniels L, Fuchs G, Thauer RK, Zeikus JG (1977) Carbon monoxide oxidation by methanogenic bacteria. J Bacteriol 132:118-126.

Diender M, Stams AJM, Sousa DZ (2015) Pathways and bioenergetics of anaerobic carbon monoxide fermentation. Front Microbiol 6:1-18.

Edgar RC (2013) UPARSE: highly accurate OTU sequences from microbial amplicon reads. Nature Methods 10:996-998.

Flamholz A, Noor E, Bar-Even A, Milo R (2012) eQuilibrator-the biochemical thermodynamics calculator. Nucleic Acids Res 40:D770-D775.

Fox JD, Kerby RL, Roberts GP, Ludden PW (1996) Characterization of the CO-induced, COtolerant hydrogenase from Rhodospirillum rubrum and the gene encoding the large subunit of the enzyme. J Bacteriol 178:1515-1524.

Guan G, Kaewpanha M, Hao X, Abudula A (2016) Catalytic steam reforming of biomass tar: Prospects and challenges. Renew Sustain Energy Rev 58:450-461.

Henstra AM, Dijkema C, Stams AJM (2007) Archaeoglobus fulgidus couples CO oxidation to sulfate reduction and acetogenesis with transient formate accumulation. Environ Microbiol 9:1836-1841.

Herlemann DP, Labrenz M, Jurgens K, Bertilsson S, Waniek JJ, Andersson AF (2011) Transitions in bacterial communities along the $2000 \mathrm{~km}$ salinity gradient of the Baltic Sea. ISME J 5:1571-1579.

Hugerth LW, Wefer HA, Lundin S, Jakobsson HE, Lindberg M, Rodin S, Engstrand L, Andersson AF (2014) DegePrime, a program for degenerate primer design for broadtaxonomic-range PCR in microbial ecology studies. Appl Environ Microbiol 80:51165123. 
Ismail SB, Gonzalez P, Jeison D, van Lier JB (2008) Effects of high salinity wastewater on methanogenic sludge bed systems. Water Sci Technol 58:1963-1970.

Janssen AJH, Lens PNL, Stams AJM, Plugge CM, Sorokin DY, Muyzer G, Dijkman H, van Zessen E, Luimes P, Buisman CJN (2009) Application of bacteria involved in the biological sulfur cycle for paper mill effluent purification. Sci Total Environ 407:13331343.

Jeoung JH, Fesseler J, Goetzl S, Dobbek H (2014) Carbon monoxide. Toxic gas and fuel for anaerobes and aerobes: Carbon monoxide dehydrogenases. In: Kroneck PMH, Sosa Torres ME (ed) Metal lons in Life Sciences, Springer, 37-69.

Klok JBM, de Graaff M, van den Bosch PLF, Boelee NC, Keesman KJ, Janssen AJH (2013) A physiologically based kinetic model for bacterial sulfide oxidation. Water Res 47:483492.

Köpke M, Held C, Hujer S, Liesegang H, Wiezer A, Wollherr A, Ehrenreich A, Liebl W, Gottschalk G, Dürre P (2010) Clostridium ljungdahlii represents a microbial production platform based on syngas. Proc Natl Acad Sci USA 107:15305-15305.

De Lacey AL, Fernández VM, Rousset M, Cammack R (2007) Activation and inactivation of hydrogenase function and the catalytic cycle: Spectroelectrochemical studies. Chem Rev 107:4304-4330.

Lindh MV, Figueroa D, Sjöstedt J, Baltar F, Lundin D, Andersson A, Legrand C, Pinhassi J (2015) Transplant experiments uncover Baltic Sea basin-specific responses in bacterioplankton community composition and metabolic activities. Front Microbiol 6:223.

Otto K, Elwing H, Hermansson M (1999) Effect of ionic strength on initial interactions of Escherichia coli with surfaces, studied on-line by a novel quartz crystal microbalance technique. J Bacteriol 181:5210-5218.

Parshina SN, Kijlstra S, Henstra AM, Sipma J, Plugge CM, Stams AJM (2005a) Carbon monoxide conversion by thermophilic sulfate-reducing bacteria in pure culture and in co-culture with Carboxydothermus hydrogenoformans. Appl Microbiol Biotechnol 68:390-396.

Parshina SN, Sipma J, Nakashimada Y, Henstra AM, Smidt H, Lysenko AM, Lens PN, Lettinga G, Stams AJM (2005b) Desulfotomaculum carboxydivorans sp. nov., a novel sulfatereducing bacterium capable of growth at 100\% CO. Int J Syst Evol Microbiol 55:21592165 . 
Parshina SN, Sipma J, Henstra AM, Stams AJM (2010) Carbon monoxide as an electron donor for the biological reduction of sulphate. Int J Microbiol 2010:1-9.

Quast C, Pruesse E, Yilmaz P, Gerken J, Schweer T, Yarza P, Peplies J, Glöckner FO (2013) The SILVA ribosomal RNA gene database project: improved data processing and webbased tools. Nucl Acids Res 41:590-596.

Robertson CE, Harris JK, Wagner BD, Granger D, Browne K, Tatem B, Feazel LM, Park K, Pace NR, Frank DN (2013) Explicet: graphical user interface software for metadatadriven management, analysis and visualization of microbiome data. Bioinformatics 29:3100-3101.

Roman P, Klok JBM, Sousa JAB, Broman E, Dopson M, van Zessen E, Bijmans MFM, Sorokin DY, Janssen AJH (2016a) Selection and application of sulfide oxidizing microorganisms able to withstand thiols in gas biodesulfurization systems. Environ Sci Technol 50:12808-12815.

Roman P, Bijmans MFM, Janssen AJH (2016b) Influence of methanethiol on biological sulphide oxidation in gas treatment system. Environ Technol 3330:1-11.

Rother M, Metcalf WW (2004) Anaerobic growth of Methanosarcina acetivorans C2A on carbon monoxide: an unusual way of life for a methanogenic archaeon. Proc Natl Acad Sci USA 101:16929-16934.

Sipma J, Lens PNL, Stams AJM, Lettinga G (2003) Carbon monoxide conversion by anaerobic bioreactor sludges. FEMS Microbiol Ecol 44:271-277.

Sipma J, Lettinga G, Stams AJM, Lens PNL (2006) Hydrogenogenic CO conversion in a moderately thermophilic $\left(55^{\circ} \mathrm{C}\right)$ sulfate-fed gas lift reactor: competition for CO-derived $\mathrm{H}_{2}$. Biotechnol Prog 22:1327-1334.

Sorokin DY, Detkova EN, Muyzer G (2011a) Sulfur-dependent respiration under extremely haloalkaline conditions in soda lake 'acetogens' and the description of Natroniella sulfidigena sp. nov. FEMS Microbiol Lett 319:88-95.

Sorokin DY, Tourova TP, Abbas B, Suhacheva MV, Muyzer G (2012) Desulfonatronovibrio halophilus sp. nov., a novel moderately halophilic sulfate-reducing bacterium from hypersaline chloride-sulfate lakes in Central Asia. Extremophiles 16:411-417.

Sousa JAB, Plugge CM, Stams AJM, Bijmans MFM (2015a) Sulfate reduction in a hydrogen fed bioreactor operated at haloalkaline conditions. Water Res 68:67-76. 
Sousa JAB, Sorokin DY, Bijmans MFM, Plugge CM, Stams AJM (2015b) Ecology and application of haloalkaliphilic anaerobic microbial communities. Appl Microbiol Biotechnol 99:9331-9337.

Techtmann SM, Colman AS, Robb FT (2009) "That which does not kill us only makes us stronger": the role of carbon monoxide in thermophilic microbial consortia. Environ Microbiol 11:1027-1037.

van den Bosch PLF (2008) Biological sulfide oxidation by natron-alkaliphilic bacteria Application in gas desulfurization. PhD thesis. Wageningen (The Netherlands): Wageningen University.

van Houten BHGW, van Doesburg W, Dijkman H, Copini C, Smidt H, Stams AJM (2009) Longterm performance and microbial community analysis of a full-scale synthesis gas fed reactor treating sulfate- and zinc-rich wastewater. Appl Microbiol Biotechnol 84:555563.

van Houten RT, van der Spoel H, van Aelst AC, Hulshoff Pol LW, Lettinga G (1996) Biological sulfate reduction using synthesis gas as energy and carbon source. Biotechnol Bioeng 50:136-144.

Vignais PM, Billoud B (2007) Occurrence, classification, and biological function of hydrogenases: an overview. Chem Rev 107:4206-4272.

Voldsund M, Jordal K, Anantharaman R (2016) Hydrogen production with $\mathrm{CO}_{2}$ capture. Int J Hydrogen Energy 41:4969-4992.

Wolin EA, Wolin MJ, Wolfe RS (1963) Formation of methane by bacterial extract. J Biol Chem 238:2882-2886.

Zhilina TN, Zavarzina DG, Panteleeva AN, Osipov GA, Kostrikina NA, Tourova TP, Zavarzin GA (2012) Fuchsiella alkaliacetigena gen. nov., sp. nov., an alkaliphilic, lithoautotrophic homoacetogen from a soda lake. Int J Syst Evol Microbiol 62:1666-1673.

Zhou J, Xing J (2015) Effect of electron donors on the performance of haloalkaliphilic sulfatereducing bioreactors for flue gas treatment and microbial degradation patterns related to sulfate reduction of different electron donors. Biochem Eng J 96:14-22. 


\section{Chapter 7}

Tindallia wetsonia strain JE1, sp. nov., isolated from a bioreactor reducing sulfate at haloalkaline conditions

João A.B. Sousa, Dimitry Y. Sorokin, Martijn Diender, Martijn F.M. Bijmans, Alfons J.M. Stams, Caroline M. Plugge

1 . 19 \& 5 a

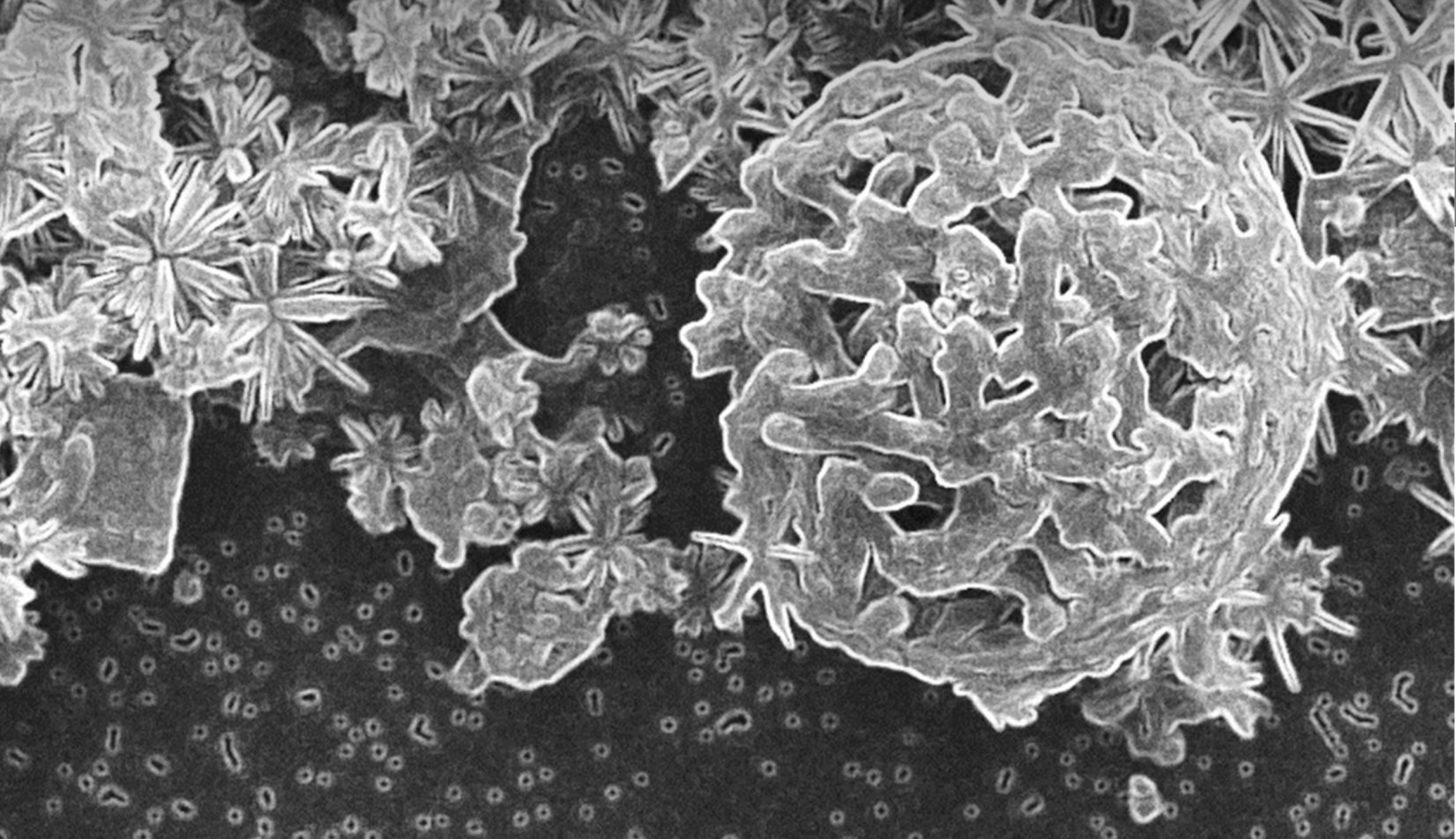




\section{Abstract}

Bacteria closely related to Tindallia sp. dominated the microbial community in sulfate and thiosulfate reducing bioreactors fed with $\mathrm{H}_{2}$ and operated at haloalkaline conditions. To understand the role of these bacteria in the bioreactors, we isolated a hydrogenotrophic bacterium (strain JE1). Strain JE1 has 98.4\% 16S rRNA gene identity with its closest relative Tindallia texcoconensis, $97.4 \%$ with $T$. californiensis, 97.1\% with T. magadiensis, and $96 \%$ with Tindallia sp. strain AHT5. In contrast to all characterized species of the genus Tindallia, strain JE1 can ferment glucose. Strain JE1 can reduce thiosulfate and elemental sulfur using $\mathrm{H}_{2}$ as electron donor. The thiosulfate reducing capacity might explain its role in the thiosulfate-fed bioreactors. In the sulfate reducing bioreactors the role of strain JE1 is not directly connected to sulfate reduction as it is not capable of sulfate reduction. Its role in sulfate reducing bioreactors seems to be limited to the production of formate from $\mathrm{H}_{2}$ and $\mathrm{HCO}_{3}$. Strain $\mathrm{JE} 1$ can grow when producing formate only in the presence of yeast extract. When comparing the 16S rRNA gene, physiological differences, glucose fermentation, reduction of thiosulfate and elemental sulfur, and production of formate from $\mathrm{H}_{2}$ and $\mathrm{HCO}_{3}{ }^{-}$to described Tindallia species, strain JE1 differed substantially and we propose strain JE1 as a new species in the genus Tindallia as Tindallia wetsonia strain JE1, sp. nov.. 


\section{Introduction}

Haloalkaline environments, characterized by high $\mathrm{pH}$ (9-11) and salinity up to saturation can be found in soda lakes that exist worldwide. The main difference of soda lakes compared to salt lakes is the dominance of sodium carbonate and bicarbonate as the main salts which provide molar concentrations of alkaline buffer that maintain the extremely high $\mathrm{pH}$ in the brines stable. The availability of divalent cations in these environments, such as $\mathrm{Ca}^{2+}$ and $\mathrm{Mg}^{2+}$, is low due to precipitation as carbonates. This creates a unique set of conditions that can be found in soda lakes as well as in manmade environments such as reactors used in gas biodesulfurization processes.

In these biodesulfurization processes, haloalkaliphilic bacteria oxidize sulfide adsorbed in an alkaline carbonate solution to elemental sulfur at oxygen-limiting conditions (Buisman et al., 1989). However, part of the sulfide is converted to thiosulfate and sulfate. To improve the sulfur production efficiency of this biodesulfurization process, sulfate and thiosulfate reduction bioreactors have been investigated (Zhou and Xing 2015, Chapter 3, 4, 5 and 6).

The microbial community of these sulfate and thiosulfate reducing bioreactors was dominated by a bacterium closely related to Tindallia species (in the class Clostridia) when $\mathrm{H}_{2}$ was used as electron donor (Chapter $3,4,5$, and 6). Three different species of Tindallia isolated from various soda lakes have been described so far: $T$. magadiensis, T. californiensis and T. texcoconensis (Alazard et al., 2007; Kevbrin et al., 1998; Pikuta et al., 2003). All these bacteria were described as amino acid fermenting, heterotrophic acetogens. Their role as possible homoacetogens was discussed, yet only hydrogenase and $\mathrm{CO}$ dehydrogenase activities from the cell extract were tested in this context. Another isolate, strain AHT5, closely related to Tindallia magadiensis, isolated from south Siberian soda lakes could use thiosulfate and elemental sulfur as electron acceptor and formate as electron donor (Sorokin et al., 2011). Additionally, Tindallia sp. AHT5 was reported to grow with $\mathrm{H}_{2}$ and $\mathrm{HCO}_{3}{ }^{-}$forming formate as the main product (Sorokin et al., 2011).

To better understand the role of Tindallia sp. in the haloalkaline bioreactors, we isolated the dominant strain in our reactor and compared its properties with the described species in the genus Tindallia and strain AHT5. 


\section{Methods}

\section{Origin of samples}

The inoculum was obtained from a sulfate-reducing bioreactor fed with $\mathrm{H}_{2}$ and operated at $\mathrm{pH} 9,1.5 \mathrm{M} \mathrm{Na}^{+}$and $35^{\circ} \mathrm{C}$ (Sousa et al., 2015). The bioreactor was characterized by formate production as a major intermediate and with the presence of bacteria closely related to Tindallia sp.

\section{Enrichment, isolation and growth conditions}

The medium used for enrichment, isolation and growth was a sodium carbonate/bicarbonate buffer with $\mathrm{pH} 9$ and $1.5 \mathrm{M} \mathrm{Na}^{+}$, except in experiments where different $\mathrm{pH}$ and salinity were tested. The medium composition was as follows: $\mathrm{Na}_{2} \mathrm{CO}_{3}$ (33.6 $\left.\mathrm{g} \mathrm{l}^{-1}\right), \mathrm{NaHCO}_{3}\left(69.3 \mathrm{~g} \mathrm{l}^{-1}\right), \mathrm{KHCO}_{3}\left(1 \mathrm{~g} \mathrm{l}^{-1}\right), \mathrm{K}_{2} \mathrm{HPO}_{4}\left(1 \mathrm{~g} \mathrm{l}^{-1}\right), \mathrm{NH}_{4} \mathrm{Cl}\left(0.27 \mathrm{~g} \mathrm{l}^{-1}\right)$, $\mathrm{MgCl}_{2} .6 \mathrm{H}_{2} \mathrm{O}\left(0.1 \mathrm{~g} \mathrm{l}^{-1}\right), \mathrm{CaCl}_{2} .2 \mathrm{H}_{2} \mathrm{O}\left(0.01 \mathrm{~g} \mathrm{l}^{-1}\right)$ and $10 \mathrm{ml} \mathrm{l}^{-1}$ of vitamin solution (Wolin et al., 1963). Two trace element solutions were added (Sousa et al., 2015).

For enrichment, $50-\mathrm{ml}$ serum bottles filled with $25 \mathrm{ml}$ of medium were closed with butylrubber stoppers and the gas phase exchanged with 1.6 bar mixture of $\mathrm{H}_{2} / \mathrm{CO}_{2}$ $(80 \% / 20 \%)$. The bottles were inoculated with $1 \mathrm{ml}$ of a biomass sample from the bioreactor operated in chapter 3 . Serial dilutions up to extinction were made. The bottles were incubated at $37^{\circ} \mathrm{C}$ while shaking $(150 \mathrm{rpm})$ for 15 days. The highest dilution with $\mathrm{H}_{2}$ consumption was used to re-inoculate new bottles, with the same medium as before but without serial dilutions. After 15 days of incubation, samples were observed under the microscope and the bottles with only one morphotype present were used for a new round of serial dilutions (as described before). The highest dilution with $\mathrm{H}_{2}$ consumption was used as inoculum for new bottles with growth medium (same composition plus $500 \mathrm{mg} \mathrm{l}^{-1}$ yeast extract) and $\mathrm{H}_{2} / \mathrm{CO}_{2}$ gas phase as before. The bottles were incubated for 7 days and the purity after growth with yeast extract was analyzed by microscopic observation and 16S rRNA gene analysis. Only pure samples with a one morphotype and a clean 16S rRNA gene sequence were used afterwards.

For comparison, Tindallia sp. AHT5, isolated previously from soda lakes (Sorokin et al., 2011) was also cultured using the same conditions. 


\section{Morphological characteristics}

For light microscopy observation, a DMI6000B optical microscope (Leica, Biberach, Germany) equipped with a DFC300FX camera (Leica, Biberach, Germany) was used. Gram staining was performed using the Gram staining kit (Sigma-Aldrich, Zwijndrecht, Netherlands). The production of spores was verified by monitoring growth during culturing after pasteurization at $80^{\circ} \mathrm{C}$ for $20 \mathrm{~min}$.

\section{Physiological characterization}

All growth experiments were performed in duplicate under sterile conditions, using 15$\mathrm{ml}$ Hungate tubes filled with the same medium used for the isolation $\left(\mathrm{pH} \mathrm{9,1.5} \mathrm{M} \mathrm{Na}^{+}\right)$. The gas phase of all tubes was exchange to $\mathrm{N}_{2} / \mathrm{CO}_{2}(80 \% / 20 \%)$ at 1.4 bar total pressure. All substrates were added from sterile anaerobic stock solutions at a concentration of $10 \mathrm{mM}$ except complex substrates that were added at $5 \mathrm{~g} \mathrm{I}^{-1}$. To support growth, $20 \mathrm{mg} \mathrm{l}^{-1}$ of yeast extract was added to the media. Growth of the cultures was measured by optical density at $600 \mathrm{~nm}$ wavelength in a spectrophotometer (UV-1280, Shimadzu, 's-Hertogenbosch, Netherlands). The pH and salinity profiles were investigated using buffers with a different proportion of sodium carbonate/ sodium bicarbonate at $37^{\circ} \mathrm{C}$, using glucose and yeast extract as substrate (Table A1). The temperature optimum and range were determined at the optimal $\mathrm{pH}$-salt conditions using glucose and yeast extract as substrate $\left(1.5 \mathrm{M} \mathrm{Na}^{+}\right.$and $\mathrm{pH} 9$ ).

\section{Analytical procedures}

Samples for organic acids analysis were filtrated through $0.4 \mu \mathrm{m}$ pore size filters and quantified using ultra-high performance liquid chromatography (Dionex ultimate 3000RS, Thermo scientific, Wilmington, MA) as described previously (Sousa et al., 2015). Samples for sulfide, sulfate and thiosulfate analysis were stabilized with zinc acetate $(0.2 \mathrm{M})$ in a 1:1 ratio immediately after sampling. Sulfide was analyzed using a cuvette test (LCK653, Hach Lange, Düsseldorf, Germany). For sulfate analysis the sample was filtrated through $0.4 \mu \mathrm{m}$ pore size filters and the concentrations were determined by ion chromatography (761 compact IC with a 762 IC interface, Metrohm, 
Herisau, Switzerland) as described previously (Sousa et al., 2015). $\mathrm{H}_{2}, \mathrm{CO}_{2}, \mathrm{~N}_{2}$ and $\mathrm{CH}_{4}$ in the gas phase were quantified by gas chromatography using a CP-4900 (Varian, Palo Alto, CA) as previously described (Sousa et al., 2015). Optical density at $600 \mathrm{~nm}$ was measured in a spectrophotometer (UV-1280, Shimadzu, 'sHertogenbosch, Netherlands).

\section{S rRNA gene sequence analysis}

Genomic DNA was extracted using the PowerBiofilm ${ }^{\mathrm{TM}}$ DNA Isolation Kit (MoBio, Carlsbad, CA) following the manufacturer's instructions. 16S rRNA genes were amplified by PCR using a Taq DNA polymerase kit (Invitrogen, Carlsbad, CA) and Bact27F and Univ1492R primers pair (Lane, 1991). The PCR program was: initial denaturation for $2 \mathrm{~min} ; 25$ cycles of $30 \mathrm{~s}$ denaturation at $95^{\circ} \mathrm{C}, 40 \mathrm{~s}$ at $52^{\circ} \mathrm{C}$ for annealing and $1.5 \mathrm{~min}$ elongation step at $72^{\circ} \mathrm{C} ; 5 \mathrm{~min}$ at $72{ }^{\circ} \mathrm{C}$ of post-elongation step. Amplified 16S rRNA samples were sent for sequencing (Baseclear BV, Leiden, the Netherlands) using the primers sets Bact27f/Univ1492r (Lane, 1991). The 16S rRNA gene sequences were analyzed and trimmed using Chromas (ver. 2.32, Technelysium) and chimera checked with DECIPHER software (ver. 2.0) (Wright et al., 2012). The similarity searches performed using the EMBL-EBI ENA sequence search program within the ENA database. (http://www.ebi.ac.uk/ena).

\section{$\underline{\text { Results }}$}

\section{Enrichment and isolation}

The strain JE1 was enriched from the bioreactor biomass (chapter 3) using $\mathrm{H}_{2}$ and $\mathrm{HCO}_{3}{ }^{-}$as substrates. These conditions were chosen as we postulated that the dominant Tindallia sp. identified in the bioreactors was involved in the production of formate from $\mathrm{H}_{2}$ and $\mathrm{HCO}_{3}{ }^{-}$. The enrichments with $\mathrm{H}_{2}$ and $\mathrm{HCO}_{3}{ }^{-}$did show formate production, but no visible increase in turbidity was observed. However, after 3 cycles of dilutions series and re-inoculation, formate was still produced, even though the cell number was low; only a few cells were observed under the microscope. Then, the 
cultures were inoculated in the same medium, but supplemented with $500 \mathrm{mg} \mathrm{l}^{-1}$ yeast extract. This resulted in good growth of the culture while still producing formate as endproduct. Under the microscope, the culture looked pure and 16S rRNA gene sequence analysis yielded a clean sequence identical to the 16S rRNA gene sequence of the Tindallia sp. found in the bioreactors (Chapters 3-6).

\section{Morphological characteristics}

Strain $\mathrm{JE} 1$ grown in liquid culture with $\mathrm{H}_{2} / \mathrm{CO}_{2}$ gas phase and $20 \mathrm{mg} \mathrm{l}^{-1}$ yeast extract was a motile, slightly curved long rod of approximately 3-10 $\mu \mathrm{m}$ length and $0.5 \mu \mathrm{m}$ diameter (Figure 1). The cells occurred mostly as single cells, but with $500 \mathrm{mg} \mathrm{l}^{-1}$ yeast extract they occur paired or as filaments, leading to the formation of flock like structures observable by naked eye. The cells stained Gram positive and endospores were not observed under experimental conditions and after pasteurization no growth was observed.

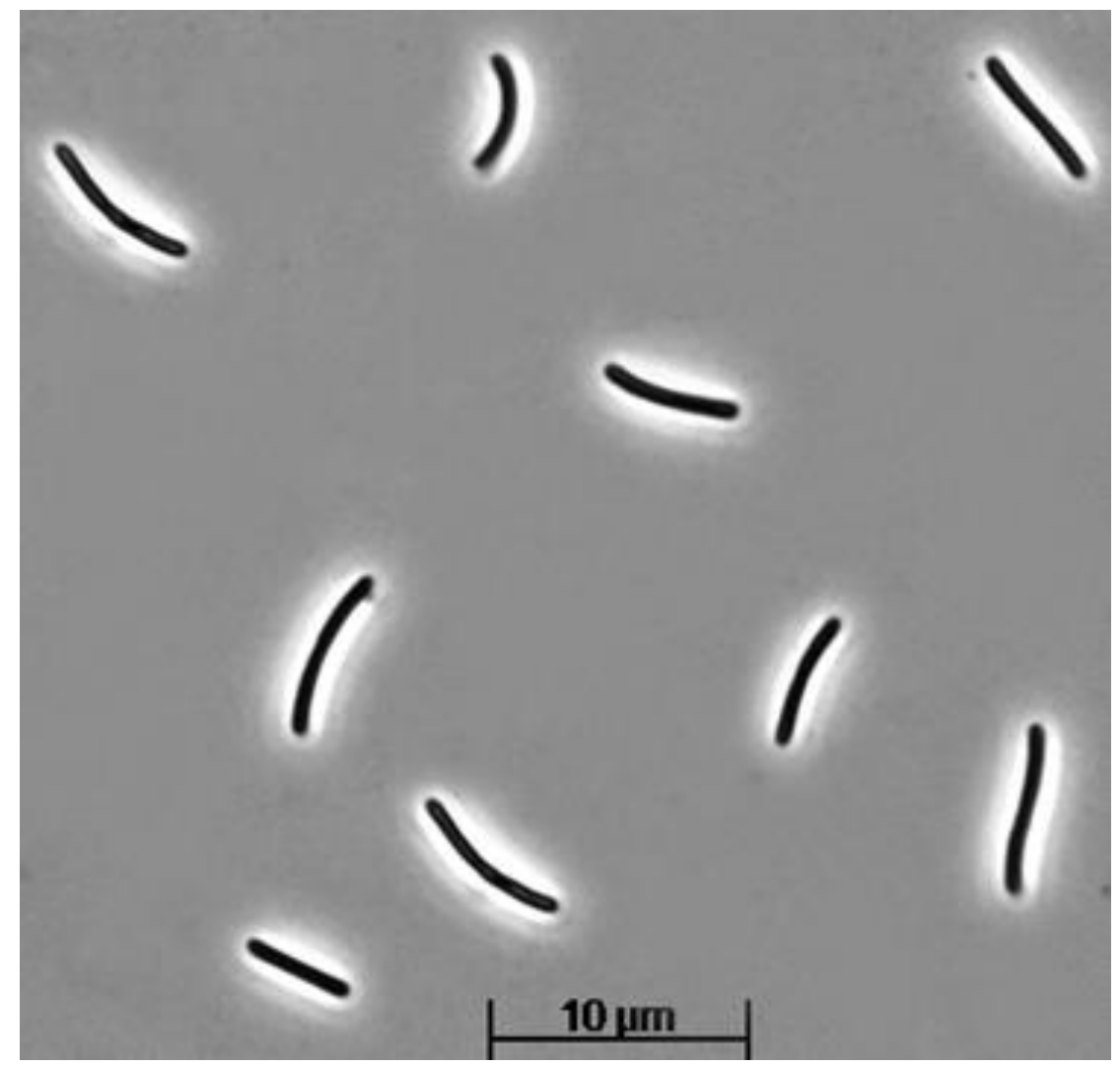

Figure 1 - Micrograph of strain JE1 cells grown for 30 days on $\mathrm{H}_{2} / \mathrm{CO}_{2}$ gas phase and yeast extract. 
Table 1 - Characteristics that differentiate strain JE1 from other Tindallia related species.

\begin{tabular}{|c|c|c|c|c|c|}
\hline & JE1 & AHT5 & $\begin{array}{c}T . \\
\text { texcoconensis }\end{array}$ & $\begin{array}{c}T . \\
\text { californiensis }\end{array}$ & $\begin{array}{c}T . \\
\text { magadiensis }\end{array}$ \\
\hline Reference & This study & 1 & 2 & 3 & 4 \\
\hline Cell length & $3-10 \mu \mathrm{m}$ & $2-6 \mu \mathrm{m}$ & $3-5 \mu \mathrm{m}$ & $1.7-3 \mu \mathrm{m}$ & $1.2-3.5 \mu \mathrm{m}$ \\
\hline Sporulation & - & n.t. & - & + & - \\
\hline $\begin{array}{l}\text { Optimum } \\
\text { temperature }\end{array}$ & $37^{\circ} \mathrm{C}$ & $37^{\circ} \mathrm{C}$ & $35^{\circ} \mathrm{C}$ & $37^{\circ} \mathrm{C}$ & $37^{\circ} \mathrm{C}$ \\
\hline Optimum pH & 9 & $9.5-10$ & 9.5 & 9.5 & 8.5 \\
\hline Optimum salinity & 1.5 & n.t. & 1.3 & 0.5 & 0.7 \\
\hline $\mathrm{O}_{2}$ tolerance & n.t. & Not tolerant & Not tolerant & Not tolerant & Not tolerant \\
\hline \multicolumn{6}{|l|}{$\begin{array}{l}\text { Fermentation } \\
\text { substrates }\end{array}$} \\
\hline Casamino acids & + & + & + & + & + \\
\hline Peptone & + & + & + & + & + \\
\hline Pyruvate & + & + & + & + & + \\
\hline Citrate & - & - & + & - & + \\
\hline Glucose & + & - & - & - & - \\
\hline Complex sugars & - & - & - & - & - \\
\hline \multicolumn{6}{|l|}{$\begin{array}{l}\text { Electron } \\
\text { acceptors }\end{array}$} \\
\hline Sulfate & - & - & - & - & n.t. \\
\hline Thiosulfate & + & + & - & n.t. & - \\
\hline Sulfur & + & + & n.t. & n.t. & n.t. \\
\hline DMSO & + & n.t. & n.t. & n.t. & + \\
\hline Iron & + & n.t. & + & n.t. & + \\
\hline Fumarate & + & + & n.t. & n.t. & n.t. \\
\hline
\end{tabular}

${ }^{a}$ based on activity of hydrogenase and CO-dehydrogenase; $(-)-$ no growth observed. $(+)$ - growth observed. (n.t) - not tested. References: 1 - Sorokin et al. 2011; 2 - Alazard et al. 2007; 3 - Pikuta et al. 2003; 4 - Kevbrin et al. 1998. 
Table 1 - Continued.

\begin{tabular}{llllll}
\hline Electron donors & & & & & \\
$\mathrm{H}_{2}$ & + & + & n.t. & n.t. & n.t. \\
Formate & + & + & n.t. & n.t. & n.t. \\
Acetate & + & + & n.t. & n.t. & n.t. \\
Lactate & + & + & n.t. & n.t. & n.t. \\
Ethanol & + & + & n.t. & n.t. & n.t. \\
Glycerol & + & + & n.t. & n.t. & n.t. \\
CO & - & n.t. & n.t. & n.t. \\
$\begin{array}{l}\text { Formate } \\
\text { production from } \\
\mathrm{H}_{2} \text { and } \mathrm{HCO}_{3}^{-}\end{array}$ & + & + & n.t. & n.t. & n.t. \\
$\begin{array}{l}\text { Homoacetogenic } \\
\text { activity }\end{array}$ & - & & & & $+^{\text {a }}$ \\
$\begin{array}{l}\text { Yeast extracted } \\
\text { required for } \\
\text { growth }\end{array}$ & & & n.t. & & + \\
\hline
\end{tabular}

a based on activity of hydrogenase and CO-dehydrogenase; $(-)-$ no growth observed. $(+)-$ growth observed. (n.t) - not tested. References: 1 - Sorokin et al. 2011; 2 - Alazard et al. 2007; 3 - Pikuta et al. 2003; 4 - Kevbrin et al. 1998.

\section{Phylogeny}

A sequence of $1403 \mathrm{bp}$ of the $16 \mathrm{~S}$ rRNA gene of strain JE1 was obtained. Comparison of the sequence with the database (ENA) revealed that it had $98.4 \%$ similarity with the 16S rRNA gene sequence of $T$. texcoconensis IMP-300, 97.4\% with the 16S rRNA gene of $T$. californiensis, $97.1 \%$ with the $16 \mathrm{~S}$ rRNA gene of $T$. magadiensis and $96 \%$ with the 16S rRNA gene of strain AHT5. The 16S rRNA gene sequence of JE1 had $100 \%$ identity with the sequences obtained from a 16 S rRNA gene clone library from the bacterial community DNA of the sulfate-reducing bioreactor that was used as inoculum (Chapter 3).

\section{Physiological characteristics}

Strain JE1 is an anaerobe that grows between 25 and $45^{\circ} \mathrm{C}$, with an optimal temperature at $37^{\circ} \mathrm{C}$ (Figure 2a). Optimal growth was observed with glucose and yeast 
extract at $\mathrm{pH} 9$ and at salinity $1.5 \mathrm{M} \mathrm{Na}^{+}$, indicating that the isolate is a haloalkaliphile (Figure $2 \mathrm{~b}$ ). At these conditions, the doubling time was $22 \mathrm{~h}$.

Strain JE1 was capable of fermentative growth with proteinaceous compounds, such as peptone, casamino acids, and yeast extract, but also with pyruvate, citrate, glycerol and glucose (Figure 3). No growth was observed with lactate, fumarate and complex polymeric sugars (cellulose and starch). Thiosulfate, sulfur, iron (III), DMSO and fumarate could be used as electron acceptors with $\mathrm{H}_{2}$, formate, acetate, lactate, citrate, ethanol and glycerol. Sulfate was not reduced. No disproportionation of sulfur compounds (sulfur, thiosulfate) was observed. Strain JE1 and strain AHT5 are capable of producing formate from $\mathrm{H}_{2}$ and bicarbonate, leading to approximately $49 \mathrm{mM}$ formate and approximately $96 \mathrm{mM}$ when yeast extract was added (Figure 4). Growth of strain $\mathrm{JE} 1$ with $\mathrm{H}_{2}$ and $\mathrm{HCO}_{3}$ was dependent on the presence of yeast extract. Under such conditions, optimal growth occurred with glucose $(10 \mathrm{mM})$ from which acetate $(6.5 \mathrm{mM})$ and succinate $(4.6 \mathrm{mM})$ together with trace amounts of formate (2.9 $\mathrm{mM})$, propionate $(0.9 \mathrm{mM})$, malate $(0.7 \mathrm{mM})$ and pyruvate $(0.4 \mathrm{mM})$ were produced (Figure 3). However, when yeast extract was not added, strain JE1 produced only traces of acetate from glucose. This indicates that some elements from yeast extract are necessary not only for growth of strain JE1, but also for production of other organic acids, such as succinate. 

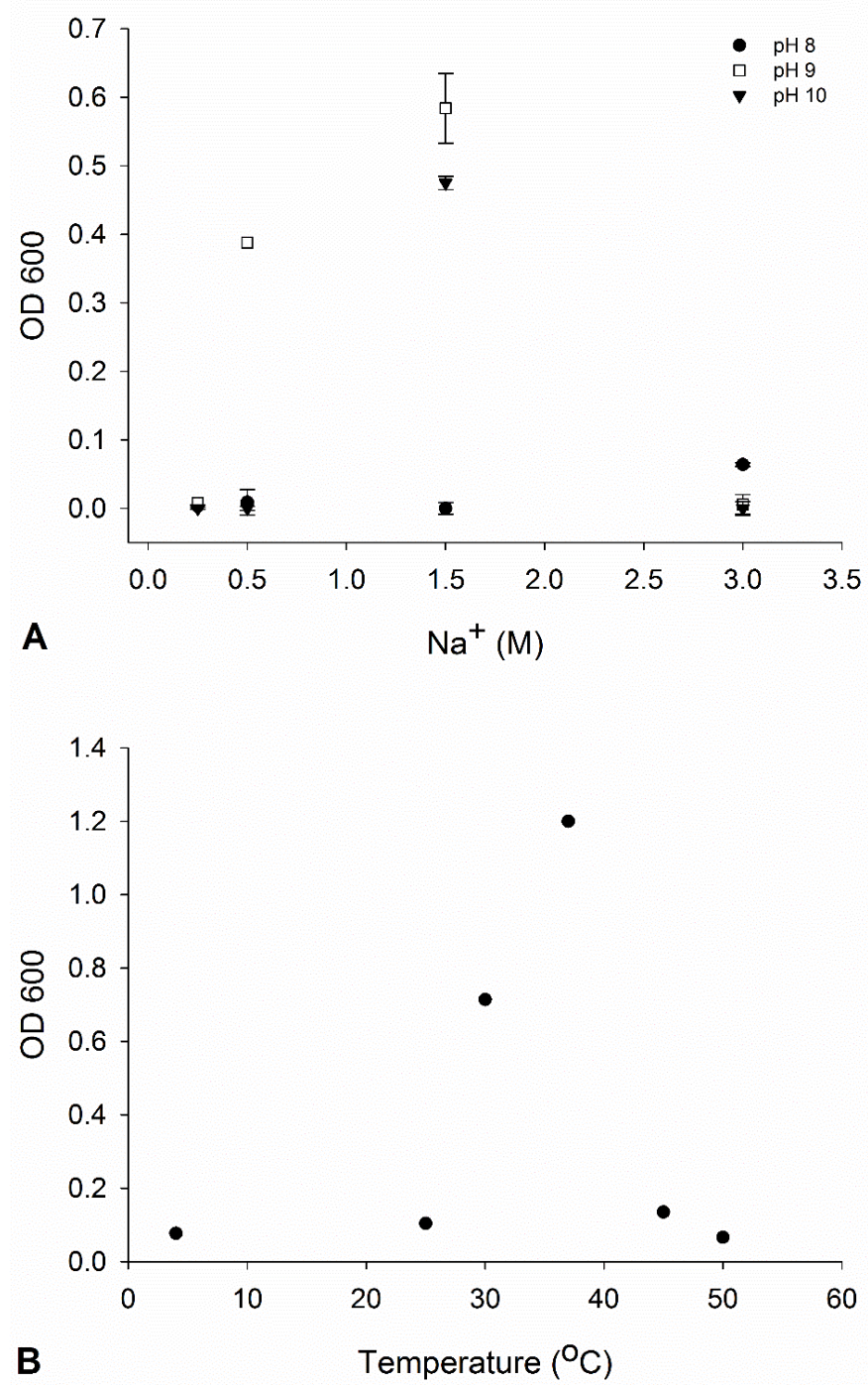

Figure 2 - Effect of $\mathrm{pH}, \mathrm{Na}^{+}$concentration and temperature on the growth of strain $\mathrm{JE} 1$ with $10 \mathrm{mM}$ glucose and yeast extract measured by optical density at $600 \mathrm{~nm}$ wavelength. A Effect of $\mathrm{pH}$ and $\mathrm{Na}^{+}$concentration at $37^{\circ} \mathrm{C}$. B - Effect of temperature at $\mathrm{pH} 9$ and $1.5 \mathrm{M} \mathrm{Na}^{+}$. 


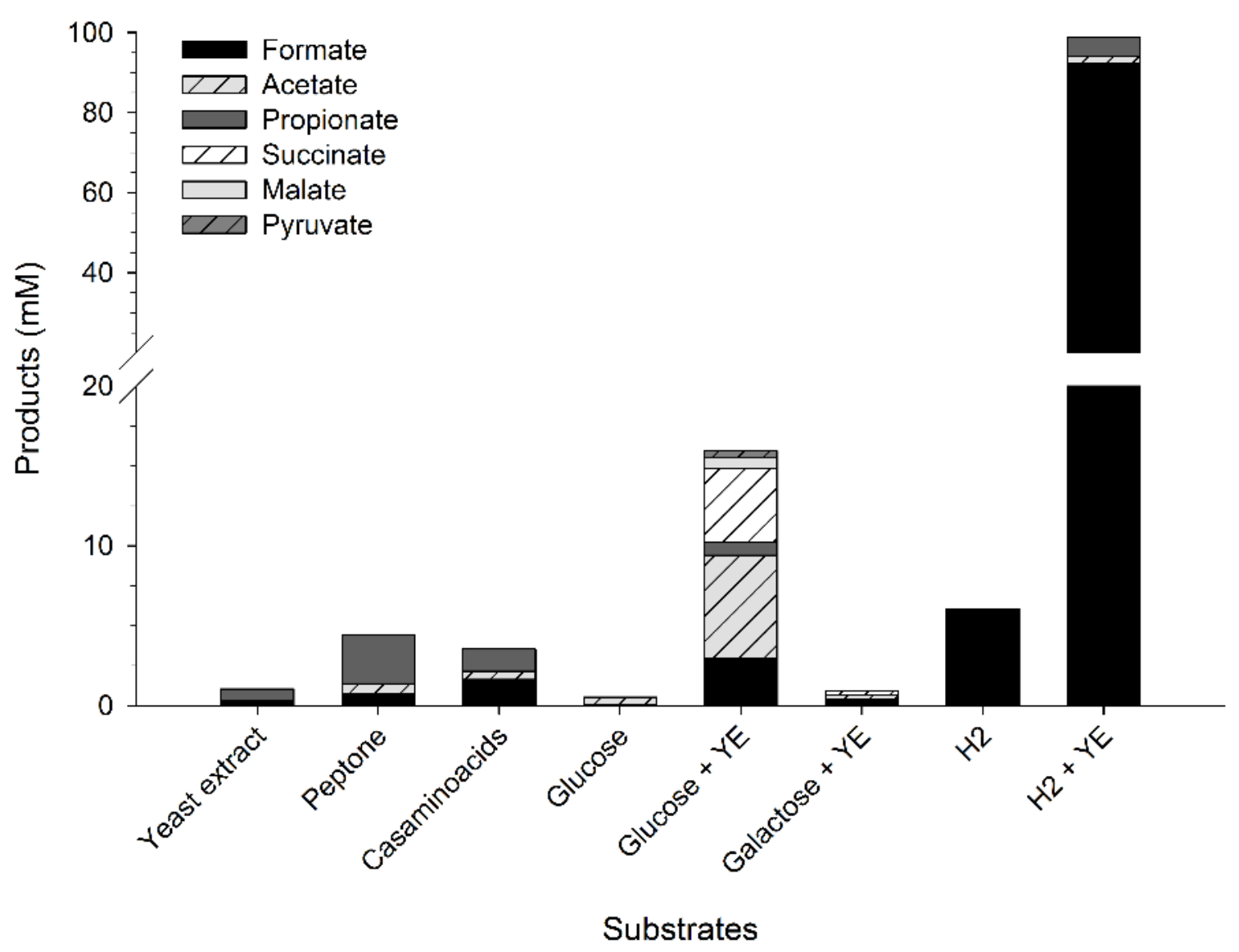

Figure 3 - Organic acids (mM) produced by strain JE1 from different substrates after 30 days of incubation. YE $-20 \mathrm{mg} / \mathrm{l}$ yeast extract.

\section{Discussion}

The physiological characterization of strain JE1 reveals that it is different from the previously characterized Tindallia species. The main difference is the fermentation of glucose that was not observed for all other isolates. The fermentation of glucose yielded succinate as a main product, which was observed in another fermentative haloalkaliphilic bacterium, Alkaliflexus imshenetskii (Zhilina et al., 2004). The production of succinate is an interesting metabolic activity for future biotechnological application (Becker et al., 2015). 


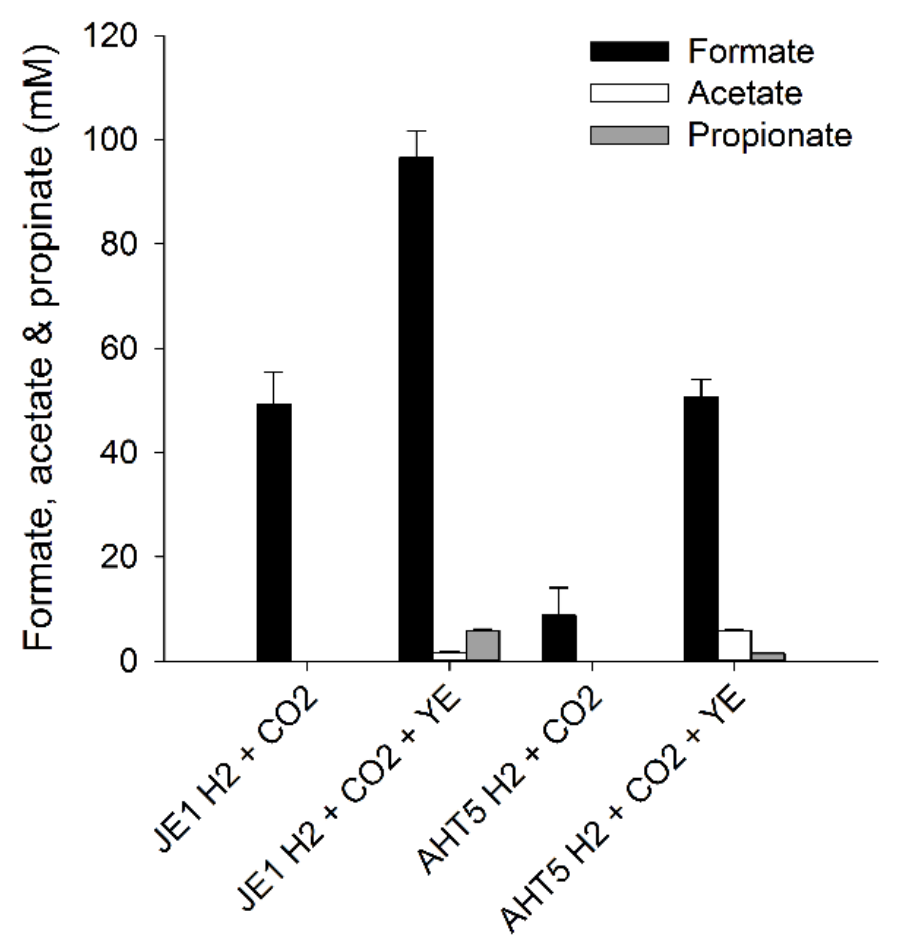

Figure 4 - Formate, acetate and propionate production by strains JE1 and AHT5 from $\mathrm{H}_{2}$ and $\mathrm{CO}_{2}$, with and without $20 \mathrm{mg} \mathrm{l}^{-1}$ of yeast extract (YE).

Strain JE1 can reduce thiosulfate and thus plays a role in thiosulfate reduction in the bioreactors. However, both strains cannot reduce sulfate which does not explain their dominance in the bioreactor fed only with sulfate, from which it was isolated (Chapter 3). We hypothesize that Tindallia sp. strain JE1 has a syntrophic relationship with sulfate-reducing bacteria, which could explain its dominance in the bioreactors (Figure 5). They likely obtain energy for growth by conversion of $\mathrm{H}_{2} / \mathrm{CO}_{2}$ to formate, while requiring organic compounds excreted by other bacteria present in the bioreactor as carbon source. In turn, formate is the preferred electron donor for the sulfate reducers. 


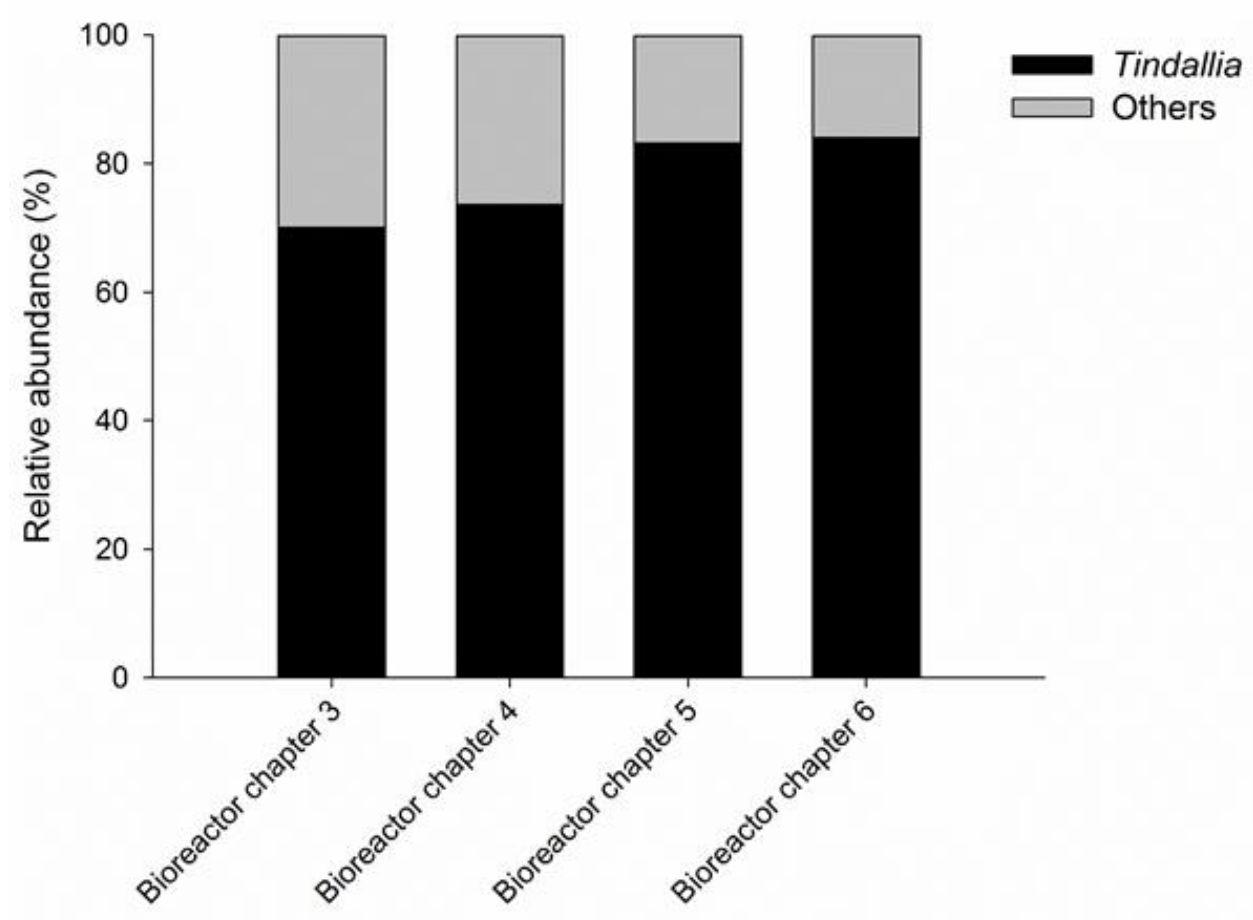

Figure 5 - Relative abundance of bacteria16S rRNA sequences closely related to Tindallia in the biomass of the bioreactors investigated in chapters 3, 4, 5 and 6. Results from chapter 3 (day 155) were obtained via 16S rRNA clone library methodology. Results from chapter 4 (day 140), chapter 5 (day 179) and chapter 6 (day 216) were obtained via 16S rRNA gene amplicon Illumina sequencing method.

Both strain AHT5 and JE1 produce formate from $\mathrm{H}_{2}$ and $\mathrm{CO}_{2}$ (Eq. 1). The high concentration of bicarbonate $\left(\mathrm{HCO}_{3}{ }^{-}\right)$together with the supply of $\mathrm{H}_{2}$ gas makes this reaction thermodynamically favourable (Chapter 5 ). The $\Delta G^{\prime}$ of formate production is $-15.6 \mathrm{~kJ} \mathrm{~mol}^{-1}$ when assuming $850 \mathrm{mM}$ of $\mathrm{HCO}_{3}{ }^{-}, 1 \mathrm{mM}$ of formate, 1 bar of $\mathrm{H}_{2}, \mathrm{pH}$ 9, $1.5 \mathrm{M}$ ionic strength and $35^{\circ} \mathrm{C}$. No other characterized bacteria, including haloalkaliphiles, besides strains AHT5 and JE1 can perform and derive energy from this reaction, although the reversed reaction (formation of $\mathrm{H}_{2}$ from formate) has been reported for other species (Lim et al., 2014; Thiele and Zeikus, 1988; Wu et al., 1993). The end products from $\mathrm{H}_{2}$-dependent $\mathrm{CO}_{2}$ reduction are usually either methane or acetate and these reactions are thermodynamically favourable (Oren, 2011). Because the energy gain per reaction is extremely low for formate production, the reason for the formate production remains unclear and requires further research. Energy conservation and growth by formate production may occur via a reversible formate 182 
dehydrogenase (FDH) that catalyses the reaction on Eq 1 (Ferry, 1990). Homoacetogens, such as Acetobacterium woodii can also produce formate instead of acetate as the product of $\mathrm{H}_{2}$-dependent $\mathrm{CO}_{2}$ reduction at non-growing conditions (Schuchmann and Müller, 2013). However, the underlying mechanism should be investigated in more detail to understand how these bacteria are capable of producing formate to such high concentrations.

$\mathrm{H}_{2}+\mathrm{HCO}_{3}^{-} \rightarrow \mathrm{HCO}_{2}^{-}+\mathrm{H}_{2} \mathrm{O}$

Another aspect that points to formate production as one of the characteristics of strain JE1 specific for the bioreactors is the fact that Tindallia related bacteria are not dominant in natural occurring soda lakes (Antony et al., 2013; Sorokin et al., 2014; Vavourakis et al., 2016). In these lakes, high concentrations of sulfate and other partly oxidized sulfur species are present and still it is not a driving force for the dominance of Tindallia related bacteria. The major difference is the lack of complex organic compounds and continuous supply of $\mathrm{H}_{2}$ in the bioreactors. The continuous $\mathrm{H}_{2}$ supply in the bioreactors could give a competitive advantage to bacteria that can use $\mathrm{H}_{2}$, as might be the case of strains JE1 and AHT5.

Strain JE1, closely related to Tindallia sp., is a key player in the bioreactors described in this thesis. Its role in the bioreactors is most probably linked to the production of formate from $\mathrm{H}_{2}$ and $\mathrm{HCO}_{3}$ - which can be subsequently used by sulfate reducers as electron donor. However, this link requires further research that is described in chapter 8.

\section{Description of Tindallia wetsonia sp. nov.}

Tindallia wetsonia [wet.so'.nia. N.L. gen., of Wetsus, from a bioreactor operated at Wetsus, European centre of excellence for sustainable water technology, located in Leeuwarden, the Netherlands]. 
Curved rods 3-10 $\mu \mathrm{m}$ in length and around $0.5 \mu \mathrm{m}$ in diameter and with motility. Stains Gram positive and no sporulation observed. Haloalkaliphilic, with optimum pH 9, optimum salinity $1.5 \mathrm{M} \mathrm{Na}^{+}$, and mesophilic with optimum temperature $37^{\circ} \mathrm{C}$.

Anaerobic organotroph capable of fermenting glucose, peptone, casamino acids and yeast extract. Main products of glucose fermentation were acetate, formate, succinate and traces of propionate, pyruvate and malate. Capable of producing formate from $\mathrm{H}_{2}$ and $\mathrm{HCO}_{3}$. Thiosulfate, elemental sulfur, DMSO, iron and fumarate are reduced with $\mathrm{H}_{2}$, formate, acetate, lactate, ethanol and glycerol as electron donors. Growth is dependent on yeast extract.

Habitat: isolated from a sulfate reducing bioreactor using $\mathrm{H}_{2}$ as electron donor and operated at $\mathrm{pH} 9$ and $1.5 \mathrm{M} \mathrm{Na}^{+}$. The bioreactor was operated at Wetsus, Leeuwarden, the Netherlands. 


\section{References}

Alazard D, Badillo C, Fardeau ML, Cayol JL, Thomas P, Roldan T, Tholozan JL, Ollivier B (2006) Tindallia texcoconensis sp. nov., a new haloalkaliphilic bacterium isolated from lake Texcoco, Mexico. Extremophiles 11:33-39.

Antony CP, Kumaresan D, Hunger S, Drake HL, Murrell JC, Shouche YS (2013) Microbiology of Lonar Lake and other soda lakes. ISME J 7:468-476.

Becker J, Lange A, Fabarius J, Wittmann C (2015) Top value platform chemicals: Bio-based production of organic acids. Curr Opin Biotechnol 36:168-175.

Buisman C, Post R, ljspeert P, Geraats G, Lettinga G (1989) Biotechnological process for sulphide removal with sulphur reclamation. Acta Biotechnol 9:255-267.

Ferry JG (1990) Formate dehydrogenase. FEMS Microbiol Rev 87:377-382.

Kevbrin VV, Zhilina TN, Rainey FA, Zavarzin GA (1998) Tindallia magadii gen. nov., sp. nov.: an alkaliphilic anaerobic ammonifier from soda lake deposits. Curr Microbiol 37:94100.

Lane DL (1991) 16S/23S rRNA sequencing. In: Stackebrandt E, Goodfellow M (ed) Nucleic Acid Techniques in Bacterial Systematics, John Wiley \& Sons Ltd, Chichester, United Kingdom, pp 115-148.

Lim JK, Mayer F, Kang SG, Müller V (2014) Energy conservation by oxidation of formate to carbon dioxide and hydrogen via a sodium ion current in a hyperthermophilic archaeon. Proc Natl Acad Sci USA 111:11497-11502.

Oren A (2011) Thermodynamic limits to microbial life at high salt concentrations. Environ Microbiol 13:1908-1923.

Pikuta EV, Hoover RB, Bej AK, Marsic D, Detkova EN, Whitman WB, Krader P (2003) Tindallia californiensis sp. nov., a new anaerobic, haloalkaliphilic, spore-forming acetogen isolated from Mono Lake in California. Extremophiles 7:327-334.

Schuchmann K, Müller V (2013) Direct and reversible hydrogenation of $\mathrm{CO}_{2}$ to formate by a bacterial carbon dioxide reductase. Science 342:1382-1385.

Sorokin DY, Detkova EN, Muyzer G (2011a) Sulfur-dependent respiration under extremely haloalkaline conditions in soda lake 'acetogens' and the description of Natroniella sulfidigena sp. nov. FEMS Microbiol Lett 319:88-95.

Sorokin DY, Berben T, Melton ED, Overmars L, Vavourakis CD, Muyzer G (2014) Microbial diversity and biogeochemical cycling in soda lakes. Extremophiles 18:791-809. 
Sousa JAB, Plugge CM, Stams AJM, Bijmans MFM (2015) Sulfate reduction in a hydrogen fed bioreactor operated at haloalkaline conditions. Water Res 68:67-76.

Thiele JH, Zeikus JG (1988) Control of interspecies electron flow during anaerobic digestion: significance of formate transfer versus hydrogen transfer during syntrophic methanogenesis in flocs. Appl Environ Microbiol 54:20-29.

Vavourakis CD, Ghai R, Rodriguez-Valera F, Sorokin DY, Tringe SG, Hugenholtz P, Muyzer $\mathrm{G}$ (2016) Metagenomic insights into the uncultured diversity and physiology of microbes in four hypersaline soda lake brines. Front Microbiol 7:1-18.

Wolin EA, Wolin MJ, Wolfe RS (1963) Formation of methane by bacterial extract. J Biol Chem 238:2882-2886.

Wright ES, Yilmaz LS, Noguera DR (2012) DECIPHER, a search-based approach to chimera identification for 16S rRNA sequences. Appl Environ Microbiol 78:717-725.

Wu W, Hickey RF, Jain MK, Zeikus JG (1993) Energetics and regulations of formate and hydrogen metabolism by Methanobacterium formicicum. Arch Microbiol 159:57-65.

Zhilina TN, Appel R, Probian C, Brossa EL, Harder J, Widdel F, Zavarzin GA (2004) Alkaliflexus imshenetskii gen. nov. sp. nov., a new alkaliphilic gliding carbohydratefermenting bacterium with propionate formation from a soda lake. Arch Microbiol 182:244-253.

Zhou J, Xing J (2015) Effect of electron donors on the performance of haloalkaliphilic sulfatereducing bioreactors for flue gas treatment and microbial degradation patterns related to sulfate reduction of different electron donors. Biochem Eng J 96:14-22. 


\section{Chapter 8}

The role of formate for sulfate reducing microorganisms in haloalkaline environments

João A.B. Sousa, Dimitry Y. Sorokin, Martijn Diender, João Sampaio, Peer H.A. Timmers, Martijn F.M. Bijmans, Alfons J.M. Stams, Caroline M. Plugge 


\section{Abstract}

In haloalkaline environments, formate is an important intermediate in the anaerobic biodegradation of organic matter. In sulfate/thiosulfate-reducing bioreactors operated at haloalkaline conditions with $\mathrm{H}_{2}$ as the only electron donor, formate intermediately accumulated up to a concentration of $150 \mathrm{mM}$. The high $\mathrm{HCO}_{3}$ concentration $(>0.5 \mathrm{M})$ under haloalkaline conditions, compared to neutral conditions, allows $\sim 100$-fold more formate formation. The formate produced from $\mathrm{H}_{2}$ and $\mathrm{HCO}_{3}^{-}$by microorganisms in these bioreactors was then used as electron donor by sulfate and thiosulfate-reducing bacteria. To better understand this metabolic interaction, co-cultures of a formate producer, Tindallia sp. strain JE1, and a sulfate reducer, Desulfonatronovibrio thiodismutans AHT10, were studied. Both species have been detected in the sulfate/thiosulfate reducing bioreactors previously studied. When hydrogen was supplied as electron donor, sulfate was reduced by D. thiodismutans AHT10 only in the presence of Tindallia sp. strain JE1, indicating a syntrophic relationship. Interspecies formate transfer occurred between the producer Tindallia and the consumer $D$. thiodismutans. The interactions were not restricted to formate transfer. Possibly, cross feeding of trace amounts of acetate or other unknown compounds produced by Tindallia sp strain JE1 plays a role as well. 


\section{Introduction}

Haloalkaline environments, such as soda lakes that can be found around the world, are characterized by their high $\mathrm{pH}$ and alkaline salt concentrations up to saturation. The prevailing salts in most soda lakes are sodium carbonate and bicarbonate which buffer the environment at high $\mathrm{pH}$ (> 8.5). In these extreme habitats, prokaryotic communities, classified as haloalkaliphiles, thrive. Under haloalkaline conditions some metabolic processes are especially important, such as the sulfur cycle. The high activity of the sulfur cycle is due to the chemical stability and lack of toxicity of several sulfur compounds, such as sulfide and polysulfides, at high $\mathrm{pH}$ compared to low $\mathrm{pH}$ conditions. These sulfur cycling prokaryotic extremophiles have also been successfully exploited in environmental biotechnology processes, such as bio- and natural gas desulfurization (van den Bosch 2008; Zhou et al. 2014; Sousa et al. 2015).

While investigating lithotrophic sulfidogenesis in soda lake native microbial communities, mixed cultures and pure cultures, formate was observed to be a significant electron donor in contrast to $\mathrm{H}_{2}$ (Sorokin et al. 2010). Some of the isolated sulfate reducers from that same study were closely related to the sulfate reducers in the biomass of the bioreactors operated in chapters 3-6. Most of these sulfate reducers in the bioreactors were closely related to Desufonatronovibrio thiodismutans sp. which can use $\mathrm{H}_{2}$ and formate as electron donors for sulfate and thiosulfate reduction (Sorokin et al. 2011b). In the bioreactors, $\mathrm{H}_{2}$ was supplied as electron donor, and formate was produced and accumulated to high concentration, up to $150 \mathrm{mM}$ (chapters 3-6). The produced formate could also be used as electron donor, and was shown to enhance sulfate reduction when supplied externally (chapter 5).

Formate production, under neutral $\mathrm{pH}$ and low salinity conditions, was described for several microorganisms (Peters et al. 1999). However, the maximum formate concentrations achieved were approximately 100 -fold lower than the concentrations reported in chapters 3-6. This is probably related to the high bicarbonate concentration in the medium which changes the thermodynamic equilibrium of the conversion of $\mathrm{H}_{2}$ and bicarbonate to formate. Under haloalkaline conditions, two isolates were shown to produce formate from $\mathrm{H}_{2}$ and bicarbonate, strains $\mathrm{AHT} 5$ and JE1, both closely related to Tindallia spp. (Sorokin et al. 2011a, Chapter 7). In chapter 4, we hypothesized that the formate production might be related to the dominance of Tindallia sp. strain JE1 in 
the bioreactors, and that the formate produced could be used for sulfate reduction. However, the dynamics of formate production and how formate affects sulfate reduction under haloalkaline conditions are still not fully understood.

In this work, the intermediate formate production from $\mathrm{H}_{2}$ and bicarbonate catalyzed by the biomass of a sulfate and thiosulfate-reducing bioreactor was investigated in more detail. To investigate the role of formate as an intermediate, co-culture experiments were performed using a haloalkaliphilic formate scavenging sulfate reducer, Desufonatronovibrio thiodismutans AHT10, and Tindallia sp. strain JE1 as formate producer. The results indicate that formate plays a key role in sulfidogenesis at haloalkaline conditions.

\section{Methods}

\section{Media}

A mineral medium with $\mathrm{pH} 9( \pm 0.05)$, buffered with sodium carbonate and sodium bicarbonate, containing a total of $1.5 \mathrm{M} \mathrm{Na}^{+}$was used. The medium composition was as follows: $\mathrm{Na}_{2} \mathrm{CO}_{3}\left(33.6 \mathrm{~g} \mathrm{l}^{-1}\right), \mathrm{NaHCO}_{3}\left(69.3 \mathrm{~g} \mathrm{l}^{-1}\right), \mathrm{KHCO}_{3}\left(1 \mathrm{~g} \mathrm{l}^{-1}\right), \mathrm{K}_{2} \mathrm{HPO}_{4}\left(1 \mathrm{~g} \mathrm{l}^{-1}\right)$, $\mathrm{NH}_{4} \mathrm{Cl}\left(0.27 \mathrm{~g} \mathrm{l}^{-1}\right), \mathrm{MgCl}_{2} .6 \mathrm{H}_{2} \mathrm{O}\left(0.1 \mathrm{~g} \mathrm{l}^{-1}\right), \mathrm{CaCl}_{2} .2 \mathrm{H}_{2} \mathrm{O}\left(0.01 \mathrm{gl}^{-1}\right)$ and $10 \mathrm{mll}^{-1}$ of vitamin solution (Wolin et al. 1963). Trace element solutions were added as described previously (Sousa et al. 2015). When sterile conditions were used, the mineral medium was autoclaved separately, without trace elements and vitamins solution. The vitamins and trace elements were sterilized using filtration and added afterwards.

\section{Mixed and pure cultures}

The mixed culture used for the batch experiments was obtained from the sulfate/thiosulfate reducing bioreactor described in chapter $5.400 \mathrm{ml}$ of the bioreactor biomass was collected during run 4 in which $50 \mathrm{mM}$ of sulfate and $25 \mathrm{mM}$ of thiosulfate were fed and $\mathrm{H}_{2}$ was supplied as electron donor. The sample was centrifuged at 5000 $\mathrm{g}$ for $10 \mathrm{~min}$ and the cells were washed twice with the same buffer as used for the 
medium. After the final washing step, $50 \mathrm{ml}$ of buffer was added and the suspension was used as inoculum for the batch experiments directly afterwards.

For the pure culture batch experiments, two pure cultures were used. A pure culture of $D$. thiodismutans AHT10 was previously isolated from soda lake (lake Bitter-1) using formate and thiosulfate as substrates (Sorokin et al. 2011b). D. thiodismutans AHT10 was grown routinely in the medium described above in batch bottles with butyl-rubber stoppers and aluminium caps using formate as electron donor (100 mM), thiosulfate as electron acceptor $(12.5 \mathrm{mM})$, acetate as carbon source $(2 \mathrm{mM})$ and $20 \mathrm{mg} \mathrm{l}^{-1}$ yeast extract. The gas phase was $80 \% \mathrm{~N}_{2}$ and $20 \% \mathrm{CO}_{2}$ (1.6 bar). D. thiodismutans AHT10 was incubated for 15 days at $37^{\circ} \mathrm{C}$ with continuous agitation at $140 \mathrm{rpm}$.

A pure culture of Tindallia sp. strain JE1 was enriched and isolated from the haloalkaline sulfate reducing bioreactor (chapter 3 ) and was described in chapter 7 . Tindallia sp. strain JE1 was routinely grown in the medium described above in $120 \mathrm{ml}$ batch bottles butyl-rubber stoppers and aluminium caps using $\mathrm{H}_{2}$ as electron donor, $\mathrm{HCO}_{3}{ }^{-}$as electron acceptor $(825 \mathrm{mM})$ and $50 \mathrm{mg} \mathrm{l}^{-1}$ yeast extract. The gas phase was $80 \% \mathrm{H}_{2}$ and $20 \% \mathrm{CO}_{2}$ (1.6 bar). Tindallia sp. strain JE1 was incubated for 15 days at $37^{\circ} \mathrm{C}$ with continuous agitation at $140 \mathrm{rpm}$.

\section{Fed-batch experiments with mixed biomass}

Fed-batch experiments with biomass from the sulfate/thiosulfate reducing bioreactor (chapter 5 ) were performed to study the $\mathrm{H}_{2}, \mathrm{HCO}_{3}{ }^{-}$and formate dynamics. Bioreactors with a total volume of 1 liter were used. Bioreactors were filled with $700 \mathrm{ml}$ mineral medium with vitamins, trace elements (as described above) and $50 \mathrm{mM}$ sodium sulfate. Prior to start, the bioreactors were flushed for 30 minutes with nitrogen or hydrogen to remove oxygen and after were inoculated with $5 \mathrm{ml}(200 \mathrm{mg}$ Total $\mathrm{N})$ of the concentrated biomass. Bioreactors were operated with a continuous $\mathrm{H}_{2}$ or $\mathrm{N}_{2}$ flow of 5

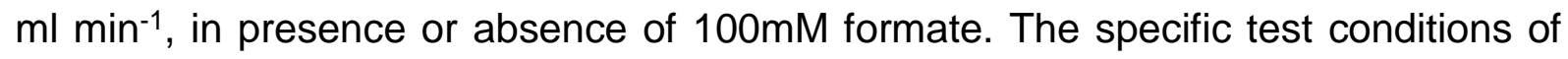
each experiment are listed in Table 1. For sampling, $5 \mathrm{ml}$ liquid and $1 \mathrm{ml}$ gas were collected using syringes. For gas sampling and analysis, a syringe with a closing valve was used.

Table 1 - Conditions of different tests of mixed biomass activity in fed-batch bioreactors 


\begin{tabular}{lccc}
\hline Test name & Inoculum & Formate added $(\mathbf{m M})$ & Gas flow \\
\hline Control & No & $100 \mathrm{mM}$ & $5 \mathrm{ml} \mathrm{min}{ }^{-1} \mathrm{H}_{2}$ \\
Formate & Yes & $100 \mathrm{mM}$ & $5 \mathrm{ml} \mathrm{min}^{-1} \mathrm{~N}_{2}$ \\
$\mathrm{H}_{2}$ & Yes & $0 \mathrm{mM}$ & $5 \mathrm{ml} \mathrm{min}^{-1} \mathrm{H}_{2}$ \\
Formate $/ \mathrm{H}_{2}$ & Yes & $100 \mathrm{mM}$ & $5 \mathrm{ml} \mathrm{min}^{-1} \mathrm{H}_{2}$ \\
\hline
\end{tabular}

\section{Batch experiments with pure and mixed pure cultures}

Batch culture experiments with pure and mixed pure cultures were performed to understand the possible interaction between a formate producing bacteria and a sulfate reducing bacteria. The cultures were grown in $120 \mathrm{ml}$ glass bottles with butylrubber stoppers and aluminium caps, using $50 \mathrm{ml}$ sterilized mineral medium with vitamins and trace elements, and $70 \mathrm{ml}$ gas volume at 1.6 bar final pressure. All bottles were incubated at $37^{\circ} \mathrm{C}$ with continuous agitation at $140 \mathrm{rpm}$. Sulfate $(25 \mathrm{mM})$ and/or formate $(100 \mathrm{mM})$ were added in specific experiments according to experimental conditions (Table 4). Sulfate was added as sodium sulfate and formate was added as sodium formate solutions from sterile anaerobic stock solutions. The gas phase applied was 1.6 bar of either $80 \% \mathrm{H}_{2}$ and $20 \% \mathrm{CO}_{2}$ or $80 \% \mathrm{~N}_{2}$ and $20 \% \mathrm{CO}_{2}$ according to the experimental conditions (Table 4). The bottles were inoculated with $1 \mathrm{ml}(2 \% \mathrm{v} / \mathrm{v})$ from the respective pure cultures and cells from the same pre-cultures were used to inoculate all experiments. In the co-culture experiments, also $1 \mathrm{ml}$ of each culture was added. Abiotic control experiments were performed for all conditions. For the time zero samples, $5 \mathrm{ml}$ liquid and $1 \mathrm{ml}$ gas were collected using syringes. Afterwards, for each sampling $2 \mathrm{ml}$ liquid and $1 \mathrm{ml}$ gas were collected. For gas collection and analysis, a syringe with a closing valve was used.

\section{Analytical procedures}

Samples for formate and acetate analysis were filtered through $0.45 \mu \mathrm{m}$ pore size filters and quantified by ion chromatography as described previously (Sousa et al. 2015). Samples for sulfide, sulfate and thiosulfate analysis were stabilized with zinc acetate $(0.2 \mathrm{M})$ in a $1: 1$ ratio $(\mathrm{v} / \mathrm{v})$ immediately after sampling. For sulfate and thiosulfate analysis the sample was filtered again through $0.4 \mu \mathrm{m}$ pore size filters and 
the concentrations were determined as described previously (Sousa et al. 2015). Gas phase composition was determined by gas chromatography as previously described (Sousa et al. 2015). Microscopy pictures were taken using a phase contrast light microscope (DMI6000B, Leica, Biberach, Germany).

\section{Thermodynamic calculations}

Thermodynamic calculations were performed using eQuilibrator online tool (Flamholz et al. 2012) and the reactant concentrations used in the calculations were based on the actual conditions in the bioreactors (chapters 3-6), pure cultures (chapter 7) and

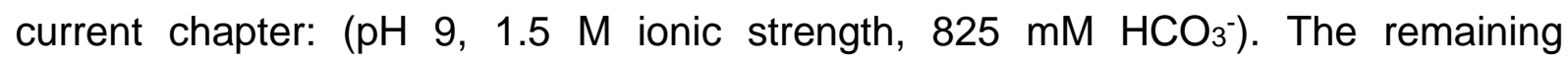
compounds concentrations were specific for each case and can be found in the results.

\section{$\underline{\text { Results \& Discussion }}$}

\section{Formate production}

Under haloalkaline conditions, formate production always occurred when $\mathrm{H}_{2}$ was supplied to bioreactors, while no organic compounds were added, excluding vitamins added (Table 2). The biomass from the bioreactor described in chapter 5 was used to test the effect of formate addition (Figure 1a). Formate was produced when $\mathrm{H}_{2}$ was supplied but also the reverse reaction occurred; when formate was supplied, $\mathrm{H}_{2}$ was produced. The formate hydrogen lyase complex, composed of a formate dehydrogenase and a hydrogenase, is capable of catalyzing both reactions depending on the equilibrium between formate and $\mathrm{H}_{2} / \mathrm{HCO}_{3}{ }^{-}$(Wu et al. 1993). In our study, this equilibrium between $\mathrm{H}_{2}$ and formate resulted in a stable formate concentration of approximately $90 \mathrm{mM}$, when both formate and $\mathrm{H}_{2}$ were added together. At the conditions in the bioreactor, mainly when the formate concentration is $90 \mathrm{mM}$, the $\Delta \mathrm{G}^{\prime}$ of both formate and $\mathrm{H}_{2}$ production reaction is similar, (Table 3). At formate concentrations of $90 \mathrm{mM}$, the $\Delta \mathrm{G}^{\prime}$ of formate production from $\mathrm{H}_{2} / \mathrm{HCO}_{3}{ }^{-}$is $-5.3( \pm 8.9)$ $\mathrm{kJ} \mathrm{mol}^{-1}$ and for $\mathrm{H}_{2}$ production from formate the $\Delta \mathrm{G}^{\prime}$ is $-6.9( \pm 8.9) \mathrm{kJ} \mathrm{mol}^{-1}$ (assuming 
$10 \mathrm{mbar} \mathrm{H}_{2}$ in the last case). For formate production, similar maximum $\Delta \mathrm{G}^{\prime}$ values can be calculated for Acetobacterium woodii, Acetobacterium carbinolicum and Methanobacterium formicicum (Table 2) (Wu et al. 1993; Peters et al. 1999). For $\mathrm{H}_{2}$ production, also similar $\Delta G^{\prime}$ values were found for Thermococcus onnurineus NA1 (Lim et al. 2014).

Table 2 - Formate accumulation and $\Delta \mathrm{G}^{\prime}$ in $\mathrm{H}_{2}$ fed bioreactors, Tindallia sp. strain JE1, Tindallia sp. strain AHT5, Acetobacterium woodii, Acetobacterium carbinolicum and Methanobacterium formicicum.

\begin{tabular}{|c|c|c|c|c|}
\hline & $\mathrm{H}_{2}$ (mbar) & Type of incubation & $\begin{array}{l}\text { Max. produced } \\
\text { formate }(\mathrm{mM})\end{array}$ & $\begin{array}{l}\Delta G^{\prime} \text { at max. formate } \\
\text { produced }\left(\mathrm{kJ} \mathrm{mol}^{-1}\right)\end{array}$ \\
\hline $\begin{array}{l}\text { Bioreactor } \\
\text { chapter } 3\end{array}$ & 1000 & Continuous & 44 & $-6.3( \pm 8.9)$ \\
\hline $\begin{array}{l}\text { Bioreactor } \\
\text { chapter } 4\end{array}$ & 1000 & Continuous & 108 & $-4.0( \pm 8.9)$ \\
\hline $\begin{array}{l}\text { Bioreactor } \\
\text { chapter } 5\end{array}$ & 1000 & Continuous & 159 & $-3.1( \pm 8.9)$ \\
\hline $\begin{array}{l}\text { Bioreactor } \\
\text { chapter } 6\end{array}$ & 1000 & Continuous & 40 & $-6.5( \pm 8.9)$ \\
\hline $\begin{array}{l}\text { Tindallia sp. } \\
\text { strain JE1 }\end{array}$ & 1280 & Batch & 96 & $-4.9( \pm 8.9)$ \\
\hline $\begin{array}{l}\text { Tindallia sp. } \\
\text { strain AHT5 }\end{array}$ & 1280 & Batch & 51 & $-6.5( \pm 8.9)$ \\
\hline A. woodii* & 500 & Batch & 1.75 & $-5.0( \pm 8.9)$ \\
\hline A. carbinolicum* & 500 & Batch & 1.5 & $-5.4( \pm 8.9)$ \\
\hline M. formicicum* ${ }^{*}$ & 470 & Batch & 1.5 & $-5.4( \pm 8.9)$ \\
\hline
\end{tabular}

* Data retrieved from (Peters et al. 1999). Calculations for bioreactors and strains JE1 and AHT 5 were performed assuming $35^{\circ} \mathrm{C}, \mathrm{pH} 9,1.5 \mathrm{M}$ ionic strength and $0.825 \mathrm{M} \mathrm{HCO}_{3}$. Calculations for $A$. woodii, A. carbinolicum and $M$. formicicum were performed assuming $25^{\circ} \mathrm{C}, \mathrm{pH} 7.2,0.05 \mathrm{M}$ ionic strength, $0.05 \mathrm{M} \mathrm{HCO}_{3}^{\text {- }}$. 


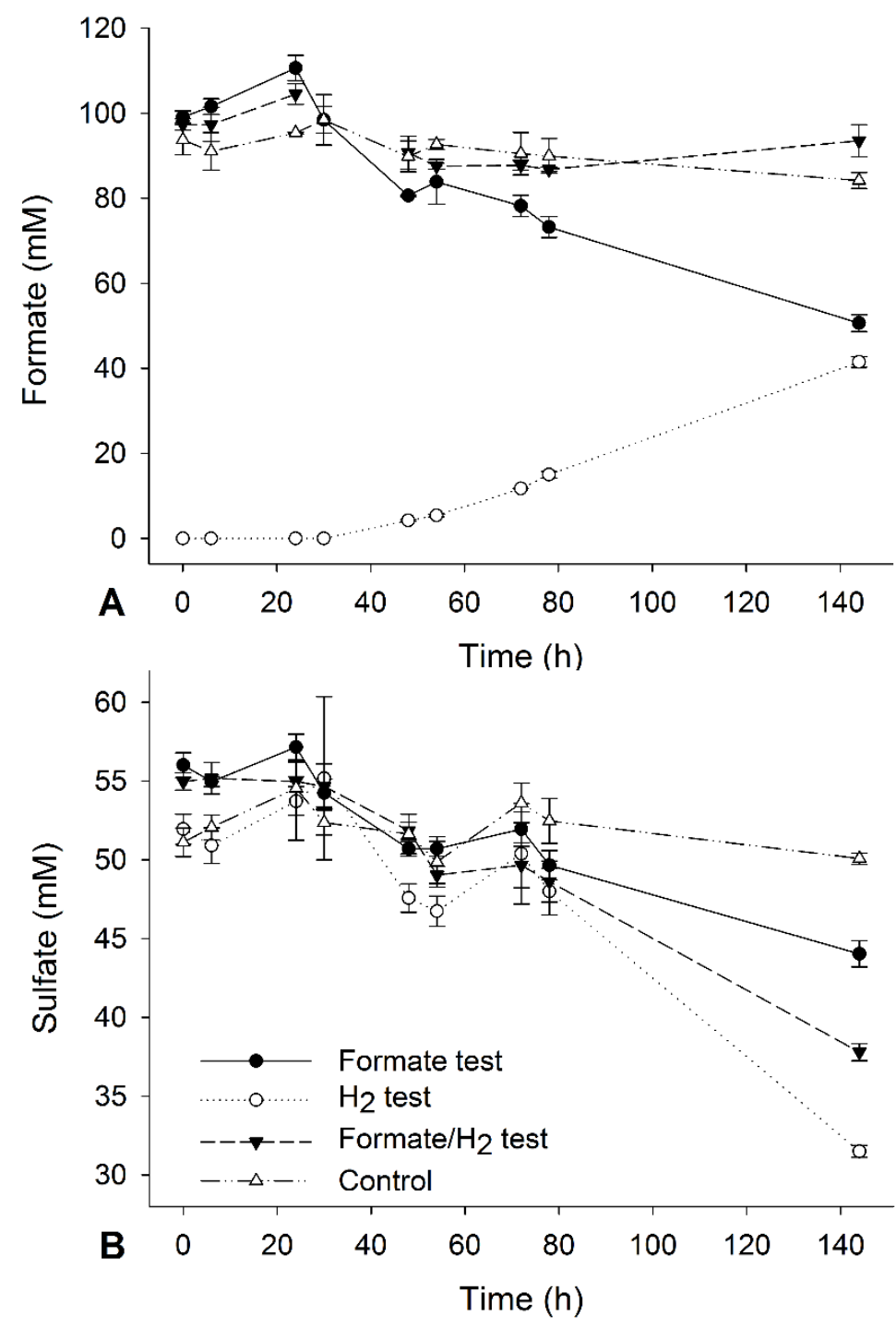

Figure 1 - Concentrations of formate $(A)$ and sulfate $(B)$ during the fed-batch experiments with mixed biomass.

The production of formate from $\mathrm{H}_{2}$ and $\mathrm{HCO}_{3}$ - by microorganisms is mainly dependent on the concentration of $\mathrm{HCO}_{3}{ }^{-}$(Thiele and Zeikus 1988; Wu et al. 1993). The major difference between formate production under neutral conditions and haloalkaline conditions is the high concentration of $\mathrm{HCO}_{3}{ }^{-}$, being $825 \mathrm{mM}$ in the bioreactors described in chapters 3-6 and even higher in soda lakes (Foti et al. 2008; Sorokin et al. 2010). The relevance of formate production at haloalkaline conditions was observed in the bioreactors described in chapters 3 to 6 , where formate was the main product of $\mathrm{H}_{2}$ conversion. In these bioreactors, the dominant microorganism, Tindallia sp. strain JE1 (described in chapter 7), was shown to produce formate from $\mathrm{H}_{2}$ and $\mathrm{HCO}_{3}{ }^{-}$up to 
high concentrations (Table 2). The only other haloalkaliphilic microorganism capable of producing formate from $\mathrm{H}_{2}$ and $\mathrm{HCO}_{3}{ }^{-}$was isolated from soda lakes sediments (Sorokin et al. 2011a).

Table 3 - Gibbs free energy $\left(\Delta G^{\prime}\right)$ for different $H_{2}$ and formate consuming reactions under the bioreactors (chapters 3-6) actual conditions.

\begin{tabular}{|c|c|c|}
\hline Reaction & $\Delta \mathbf{G}^{\prime}\left(\mathrm{kJ} \mathrm{mol}^{-1}\right)$ & Eq. $\mathrm{n}^{\circ}$ \\
\hline $\mathrm{H}_{2}+\mathrm{HCO}_{3}^{-} \rightarrow \mathrm{HCO}_{2}^{-}+\mathrm{H}_{2} \mathrm{O}$ & $-15.6( \pm 8.9)$ & 1 \\
\hline $\mathrm{HCO}_{2}^{-}+\mathrm{H}_{2} \mathrm{O} \rightarrow \mathrm{H}_{2}+\mathrm{HCO}_{3}-$ & $-12.9( \pm 8.9)$ & 2 \\
\hline $4 \mathrm{H}_{2}+2 \mathrm{HCO}_{3}{ }^{-}+\mathrm{H}^{+} \rightarrow \mathrm{H}_{2} \mathrm{C}_{3} \mathrm{O}_{2}{ }^{-}+4 \mathrm{H}_{2} \mathrm{O}$ & $-110.4( \pm 26.9)$ & 3 \\
\hline $4 \mathrm{H}_{2}+\mathrm{SO}_{4}^{2-}+\mathrm{H}^{+} \rightarrow \mathrm{HS}^{-}+4 \mathrm{H}_{2} \mathrm{O}$ & $-151.6( \pm 25.0)$ & 4 \\
\hline $4 \mathrm{HCO}_{2}{ }^{-}+\mathrm{SO}_{4}^{2-}+5 \mathrm{H}^{+} \rightarrow \mathrm{HS}^{-}+4 \mathrm{CO}_{2}+4 \mathrm{H}_{2} \mathrm{O}$ & $-134.7( \pm 26.7)$ & 5 \\
\hline $4 \mathrm{H}_{2}+\mathrm{HCO}_{3}^{-}+\mathrm{H}^{+} \rightarrow \mathrm{CH}_{4}+3 \mathrm{H}_{2} \mathrm{O}$ & $-126.0( \pm 25.1)$ & 6 \\
\hline $4 \mathrm{HCO}_{2}^{-}+\mathrm{H}^{+}+\mathrm{H}_{2} \mathrm{O} \rightarrow \mathrm{CH}_{4}+3 \mathrm{HCO}_{3}^{-}$ & $-109.1( \pm 21.5)$ & 7 \\
\hline
\end{tabular}

Conditions used for calculations: $\mathrm{pH}$ 9, 1.5 ionic strength, $825 \mathrm{mM} \mathrm{HCO}_{3}^{-}, 50 \mathrm{mM}$ sulfate, $100 \mathrm{mM}$ (substrates), $1 \mathrm{mM}$ sulfide, $1 \mathrm{mM}$ acetate, $1 \mathrm{mM}$ formate (products), $1 \mathrm{mM}$ methane, $1000 \mathrm{mbar}_{2}$. The error for each $\Delta G$ estimation is presented in brackets.

\section{Formate as electron donor}

Under haloalkaline conditions, formate seems to be one of the major electron donors for both sulfidogenesis and methanogenesis (Sorokin et al. 2010; Sorokin et al. 2015). In soda lakes, formate is mostly reported as a minor product of fermentation of more complex organic compounds while $\mathrm{H}_{2}$ is one of the major products (Zhilina et al. 1996; Pikuta et al. 2000; Zhilina et al. 2005; Pikuta et al. 2006; Pikuta et al. 2009; Begemann et al. 2012). However, there are isolates, such as Amphibacillus fermentum and Amphibacillus tropicus, that produce formate as the major product from sugar fermentation (Zhilina et al. 2001). Additionally, formate is produced from $\mathrm{H}_{2}$ and $\mathrm{HCO}_{3}{ }^{-}$ up to high concentrations by other haloalkaliphilic anaerobes (Sorokin et al. 2011a, chapter 7). Thus, formate is an abundant electron donor in haloalkaline environments. For both sulfate reduction and methanogenesis, the use of $\mathrm{H}_{2}$ as electron donor instead of formate is thermodynamically similar under haloalkaline conditions (Table 
3). Still, in soda lakes sediments, sulfate reduction has higher rates with formate than with $\mathrm{H}_{2}$ (Sorokin et al. 2010). This might be due to the low solubility of $\mathrm{H}_{2}$ but, as discussed in chapter $4, \mathrm{H}_{2}$ solubility does not fully explain the reason for the lower rates compared to formate. During operation of the bioreactors (chapters 3-6), it became clear that there is a relationship between the presence of formate and sulfate reduction. More specifically, the addition of formate increased sulfate reduction activity in the bioreactor operated in chapter 5 . In contrast to these previous results, the sulfate reduction rate in the fed-batch experiments reported here were higher when $\mathrm{H}_{2}$ was fed than when formate was fed as electron donor (Figure 1b). In this last case, the addition of formate might not have supported other processes such as acetate production as occurred in the sulfate/thiosulfate reducing bioreactor fed with $\mathrm{H}_{2}$ (chapter 5). Also, Tindallia sp. strain JE1, the dominant species in that bioreactor, can produce small amounts of acetate when yeast extract was present (chapter 7). This indicates that the biomass used in the fed-batch experiments had the potential for production of small amounts of acetate from hydrogen and bicarbonate. Thus, in the fed-batch experiments fed with $\mathrm{H}_{2}$, acetate production might have occurred even though acetate accumulation was not observed. This could be due to the rapid consumption of acetate as $\mathrm{C}$ source for microbial growth, keeping acetate under the detection limit, which could explain the higher sulfate reduction rates observed with $\mathrm{H}_{2}$.

Overall, the results from the bioreactors (chapters 3-6) and the fed-batch experiments point to a relation between formate producers, also capable of acetate production, and sulfate reducers.

\section{Interspecies formate transfer}

To investigate the relationship between formate production and sulfate reduction, several batch tests using two microorganisms were used. Tindallia sp. strain JE1 was used as formate producer and D. thiodismutans AHT10 as sulfate reducer (Chapter 7; Sorokin et al. 2008). Both strains were selected because they were closely related to the bacteria identified in the bioreactors (chapters 3-6). Their capacity for formate production and sulfate reduction was investigated in pure and co-cultures (Table 4). Tindallia sp. strain JE1 produced formate from $\mathrm{H}_{2}$ and $\mathrm{HCO}_{3}{ }^{-}$and did not reduce sulfate (as described in chapter 7). D. thiodismutans AHT10 did not produce formate and did 
not reduce sulfate with either $\mathrm{H}_{2}$ or formate as electron donors. Curiously, only when in co-culture and with $\mathrm{H}_{2}$ available, sulfate reduction occured using the formate produced (Table 4, Figure 2). This indicates that sulfate reduction by $D$. thiodismutans AHT10 only occurs in the presence of Tindallia sp. strain JE1.

Table 4 - Formte production and sulfate reduction by Tindallia sp strain JE1, Desulfonatronovibrio thiodismutans AHT10 and a co-culture of both.

\begin{tabular}{|c|c|c|c|c|}
\hline Inoculum & e- donor & e- acceptor & $\begin{array}{c}\text { Formate } \\
\text { produced (mM) }\end{array}$ & $\begin{array}{c}\begin{array}{c}\text { Sulfide } \\
\text { produced } \\
(\mathrm{mM})\end{array} \\
\end{array}$ \\
\hline \multirow[t]{8}{*}{ Tindallia sp. strain JE1 } & None & $\mathrm{HCO}_{3}{ }^{2-}$ & - & - \\
\hline & $\mathrm{H}_{2}$ & $\mathrm{HCO}_{3}{ }^{2-}$ & $92.8 \pm 16$ & - \\
\hline & Formate & $\mathrm{HCO}_{3}{ }^{2-}$ & - & - \\
\hline & $\mathrm{H}_{2}+$ Formate & $\mathrm{HCO}_{3}{ }^{2-}$ & - & - \\
\hline & None & $\mathrm{HCO}_{3}{ }^{2-}+$ Sulfate & - & - \\
\hline & $\mathrm{H}_{2}$ & $\mathrm{HCO}_{3}{ }^{2-}+$ Sulfate & $56.4 \pm 28$ & - \\
\hline & Formate & $\mathrm{HCO}_{3}{ }^{2-}+$ Sulfate & - & - \\
\hline & $\mathrm{H}_{2}+$ Formate & $\mathrm{HCO}_{3}{ }^{2-}+$ Sulfate & - & - \\
\hline \multirow[t]{8}{*}{ D. thiodismutans $\mathrm{AHT} 10$} & None & $\mathrm{HCO}_{3}^{2-}$ & - & - \\
\hline & $\mathrm{H}_{2}$ & $\mathrm{HCO}_{3}^{2-}$ & - & - \\
\hline & Formate & $\mathrm{HCO}_{3}{ }^{2-}$ & - & - \\
\hline & $\mathrm{H}_{2}+$ Formate & $\mathrm{HCO}_{3}{ }^{2-}$ & - & - \\
\hline & None & $\mathrm{HCO}_{3}{ }^{2-}+$ Sulfate & - & - \\
\hline & $\mathrm{H}_{2}$ & $\mathrm{HCO}_{3}{ }^{2-}+$ Sulfate & - & - \\
\hline & Formate & $\mathrm{HCO}_{3}{ }^{2-}+$ Sulfate & - & - \\
\hline & $\mathrm{H}_{2}+$ Formate & $\mathrm{HCO}_{3}{ }^{2-}+$ Sulfate & - & - \\
\hline \multirow{2}{*}{$\begin{array}{l}\text { Tindallia sp. strain JE1 }+ \\
\text { D. thiodismutans AHT10 }\end{array}$} & $\mathrm{H}_{2}$ & $\mathrm{HCO}_{3}^{2-}+$ Sulfate & $96.4 \pm 7$ & $11.7 \pm 1.5$ \\
\hline & None & $\mathrm{HCO}_{3}^{2-}+$ Sulfate & - & - \\
\hline
\end{tabular}

(-) Formate or sulfide under the detection limit. Experiments were performed with mineral medium. No additional reactions using $\mathrm{H}_{2}$ or formate were detected, such as methanogenesis or homoacetogenesis. Tindallia sp. strain $\mathrm{JE} 1+D$. thiodismutans $\mathrm{AHT} 10$ with $\mathrm{H}_{2}$ and sulfate was the only condition yielding growth. 

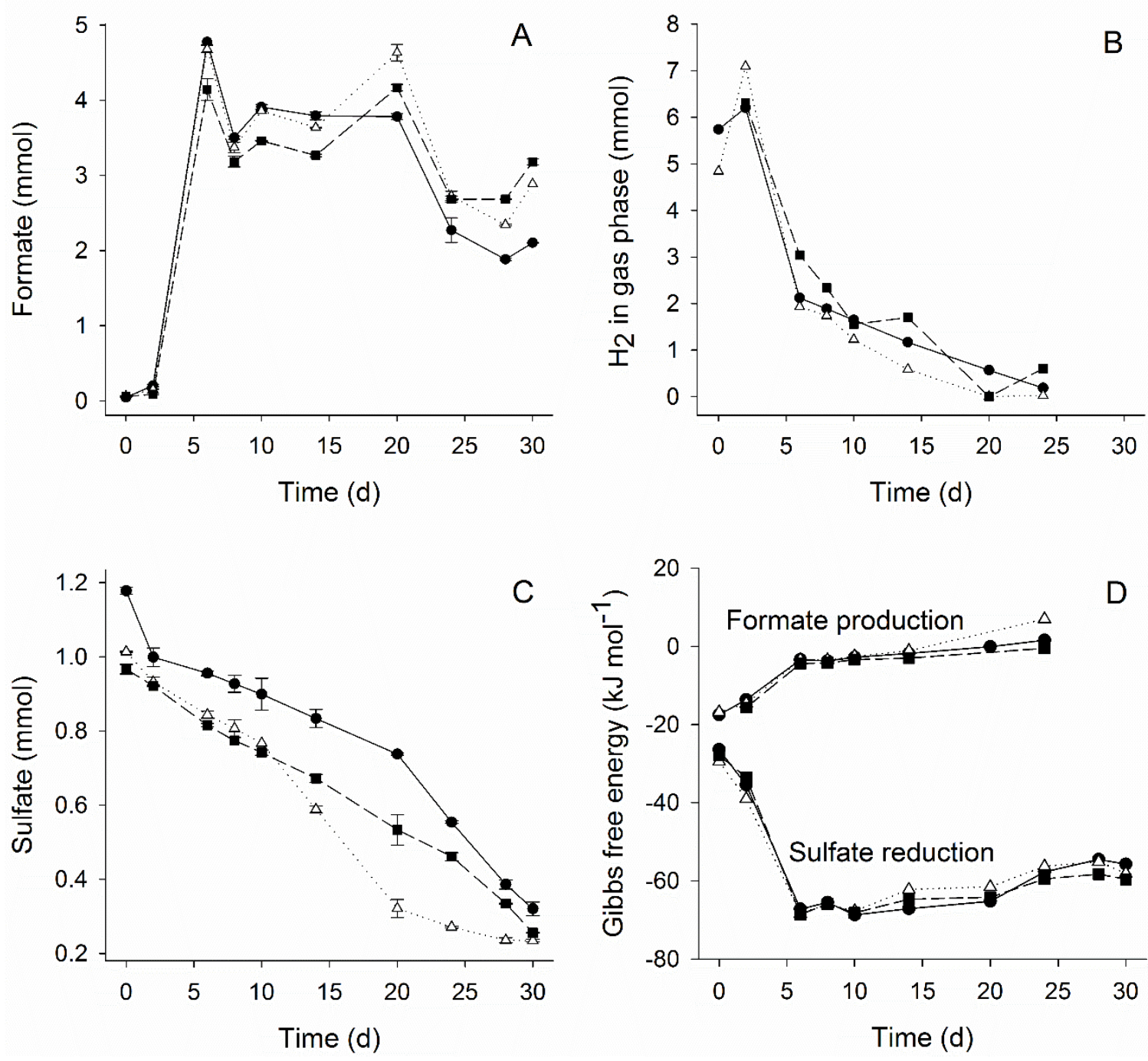

Figure 2 - Formate, $\mathrm{H}_{2}$ and sulfate in the batch bottles with the co-culture of Tindallia sp. strain JE1 and $D$. thiodismutans AHT10. $(\bullet)$ - replicate $1 ;(\Delta)$ - replicate $2 ;(\boldsymbol{\bullet})$ - replicate 3 . A Formate in the liquid. $\mathrm{B}-\mathrm{H}_{2}$ in the gas phase. $\mathrm{C}-$ Sulfate in the liquid. $\mathrm{D}-$ Actual Gibbs freeenergy changes of formate production and sulfate reduction.

The observation that $D$. thiodismutans AHT10 could not reduce sulfate using supplied formate, contrary to when there is produced formate and presence of Tindallia sp. strain JE1, indicates that there is a missing piece to this process. Additionally, in bottles with the co-culture and $\mathrm{H}_{2}$ present the turbidity increased significantly, indicating growth of the co-culture, while no turbidity increase was observed in all other bottles. The observed growth might also be connected to the increase of the sulfate reduction activity (Figure 2). The occurrence of growth and sulfate reduction in only these bottles could be explained in two different ways. One is the production of trace amounts of 
acetate from $\mathrm{H}_{2} / \mathrm{HCO}_{3}{ }^{-}$as carbon source and the other is the production of an additional organic compound that might be required by one of the organisms for growth. For the culture of $D$. thiodismutans AHT10 used as inoculum, yeast extract and acetate were added to promote growth, which did not happen without.

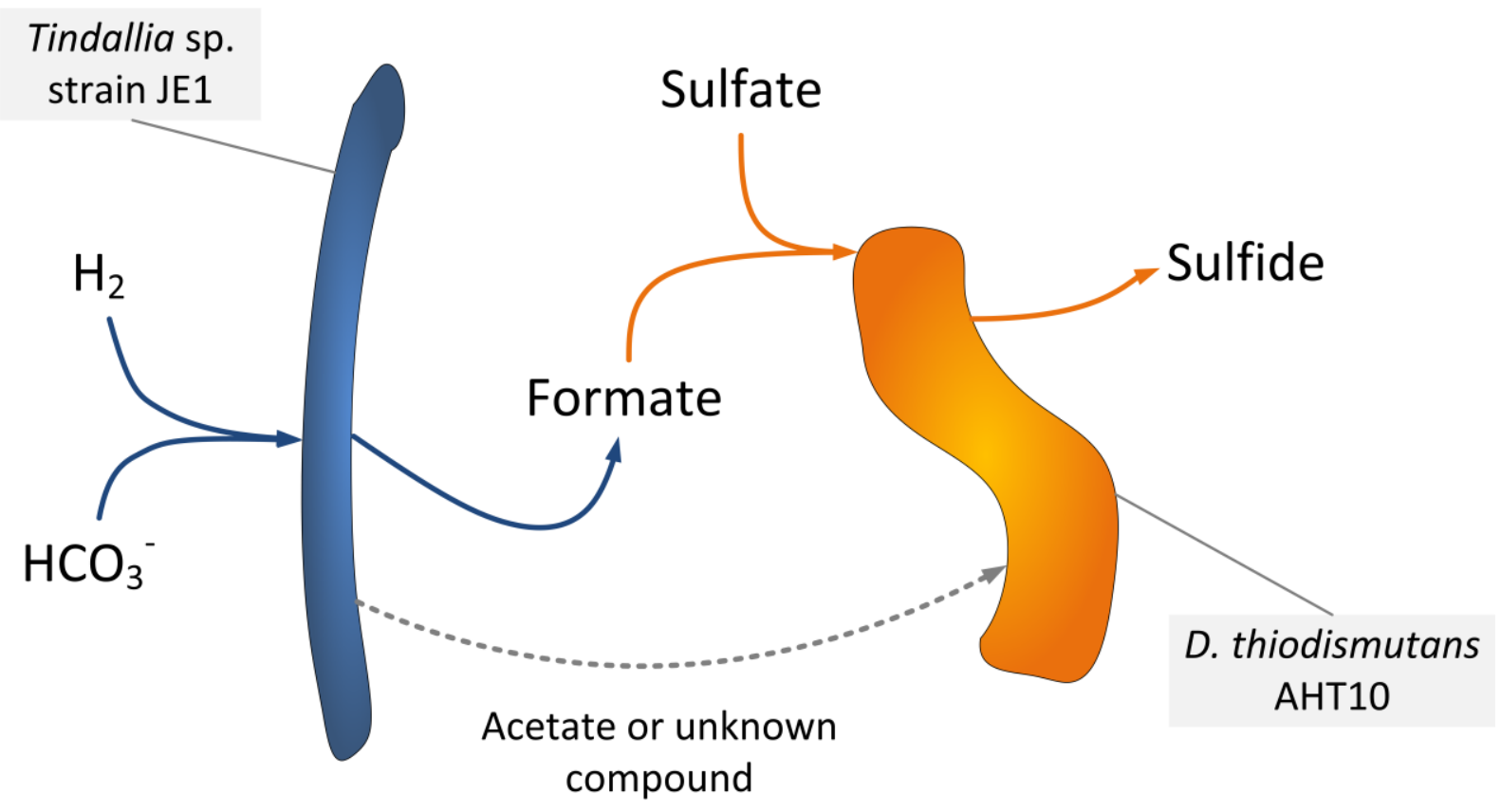

Figure 3 - Scheme with the syntrophic interaction between Tindallia sp. strain JE1 and $D$. thiodismutans AHT10. The dotted line represents our hypothesized reaction that was not experimentally confirmed in the present study.

Tindallia sp. strain JE1 produced trace amounts of acetate when yeast extract was present, but it was never detected when yeast extract was absent (Chapter 7). In the co-culture, strain JE1 might obtain trace amounts of acetate, for example via starving biomass. This acetate could be used by $D$. thiodismutans AHT10 as carbon source for growth. We did not measure acetate, but it may have been produced in amounts below the detection limit of our equipment. $D$. thiodismutans AHT10 is dependent on acetate as carbon source when using $\mathrm{H}_{2}$ or formate as electron donor for sulfate reduction (Sorokin et al. 2011b). The other possibility is that $D$. thiodismutans AHT10 might be dependent not only on the formate produced, but also on an additional unknown compound produced by Tindallia sp. strain JE1. Some microorganisms can depend on trace compounds, such as vitamins or amino acids, excreted by other microorganisms 
in complex communities (Seth and Taga 2014). To understand the metabolic relationship between these two microorganisms, further research is still required to evaluate if acetate or another compound is the missing piece in this syntrophic relation (Figure 3).

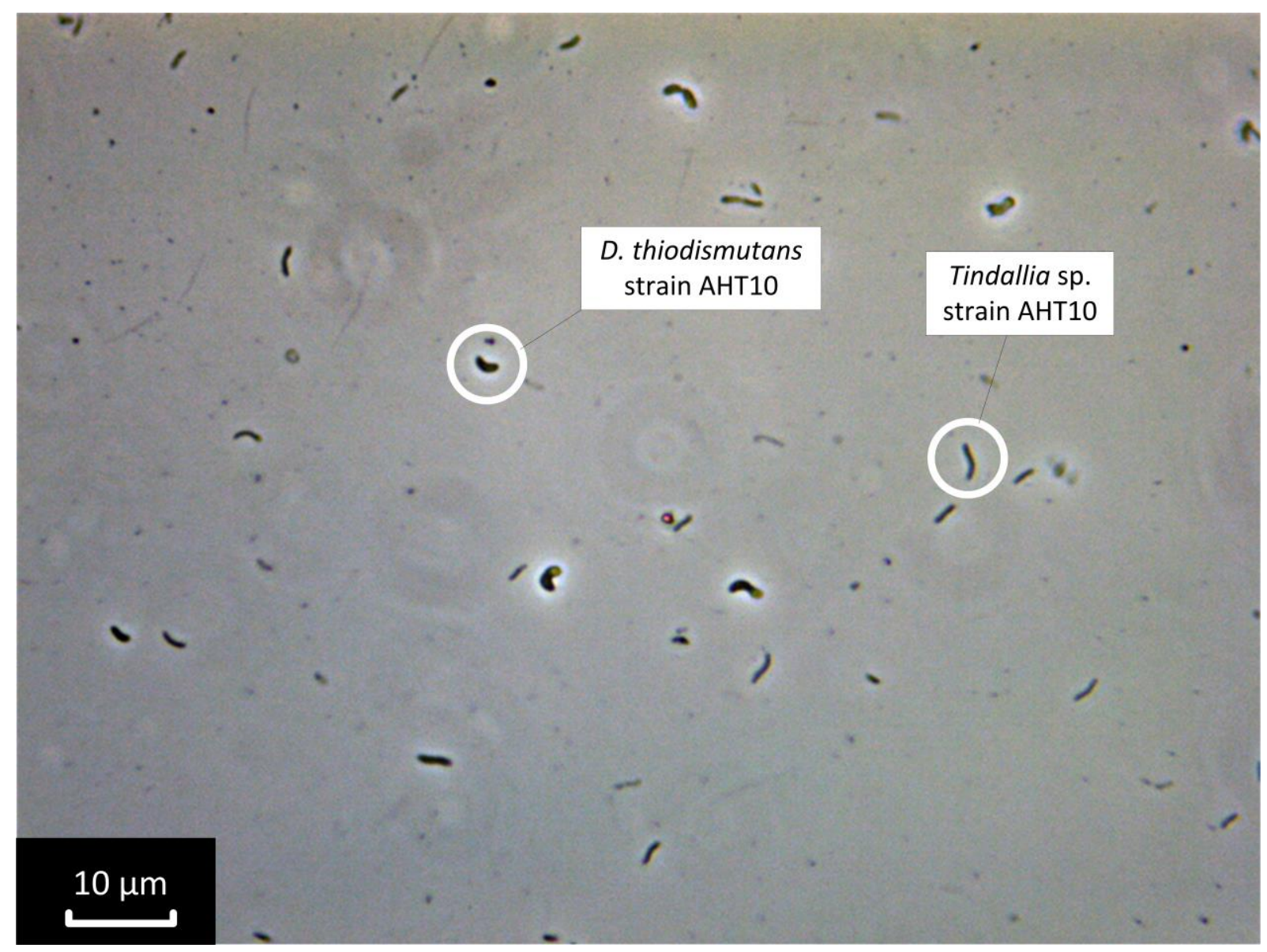

Figure 4 - Phase contrast micrograph of a co-culture of Tindallia sp. strain JE1 and $D$. thiodismutans AHT10 grown with $\mathrm{H}_{2}$ and sulfate after 30 days of incubation $\mathrm{Bar}=10 \mu \mathrm{m}$

Though D. thiodismutans AHT10 and Tindallia sp strain JE1 are dependent on each other, both bacteria grew suspended and did not attach to each other (Figure 4). Even though there might be an advantage to attach to each other, syntrophic microorganisms do not always do this (Stams and Plugge 2009). Growth without aggregation in the current study shows that the nature of their metabolic relationship may be rather complex involving multiple compounds such as formate and acetate as well as other trace compounds. 


\section{Conclusions}

Formate plays a key role in haloalkaline environments where it accumulated up to high concentrations when formed from $\mathrm{H}_{2}$ and bicarbonate. This is due to the high concentrations of $\mathrm{HCO}_{3}{ }^{-}$that make the reaction thermodynamically favorable. Two haloalkaliphilic microorganisms capable of formate production from $\mathrm{H}_{2}$ and $\mathrm{HCO}_{3}$ - were previously isolated: Tindallia sp. strain JE1 and Tindallia sp. strain AHT5. The formate produced by Tindallia sp. strain JE1 was used as electron donor for sulfate reduction by $D$. thiodismutans AHT10 in a coculture. Growth of both species was only observed in co-culture, indicating a possible syntrophic relationship. However, formate transfer was not the only metabolic interaction taking place. Since $D$. thiodismutans AHT10 could not grow in pure culture when supplied with sulfate and formate or hydrogen, trace amounts of acetate or other unknown compounds might be a key link in this syntrophic relationship. This requires further research. 


\section{References}

Begemann MB, Mormile MR, Sitton OC, Wall JD, Elias DA (2012) A streamlined strategy for biohydrogen production with Halanaerobium hydrogeniformans, an alkaliphilic bacterium. Front Microbiol 3:1-12.

Flamholz A, Noor E, Bar-Even A, Milo R (2012) eQuilibrator--the biochemical thermodynamics calculator. Nucleic Acids Res 40:D770-D775.

Foti MJ, Sorokin DY, Zacharova EE, Pimenov NV, Kuenen JG, Muyzer G (2008) Bacterial diversity and activity along a salinity gradient in soda lakes of the Kulunda Steppe (Altai, Russia). Extremophiles 12:133-145.

Lim JK, Mayer F, Kang SG, Müller V (2014) Energy conservation by oxidation of formate to carbon dioxide and hydrogen via a sodium ion current in a hyperthermophilic archaeon. Proc Natl Acad Sci U S A 111:11497-11502.

Peters V, Janssen PH, Conrad R (1999) Transient Production of Formate During Chemolithotrophic Growth of Anaerobic Microorganisms on Hydrogen. Curr Microbiol 38:285-289.

Pikuta E, Lysenko A, Chuvilskaya N, Mendrock U, Hippe H, Suzina N, Nikitin D, Osipov G, Laurinavichius K (2000) Anoxybacillus pushchinensis gen. nov., sp. nov., a novel anaerobic, alkaliphilic, moderately thermophilic bacterium from manure, and description of Anoxybacillus flavithermus comb. nov. Int J Syst Evol Microbiol 50:2109-2117.

Pikuta EV, Itoh T, Krader P, Tang J, Whitman WB, Hoover RB (2006) Anaerovirgula multivorans gen. nov., sp. nov., a novel spore-forming, alkaliphilic anaerobe isolated from Owens Lake, California, USA. Int J Syst Evol Microbiol 56:2623-2629.

Pikuta EV, Hoover RB, Bej AK, Marsic D, Whitman WB, Krader P (2009) Spirochaeta dissipatitropha sp. nov., an alkaliphilic, obligately anaerobic bacterium, and emended description of the genus Spirochaeta Ehrenberg 1835. Int J Syst Evol Microbiol 59:1798-1804.

Seth EC, Taga ME (2014) Nutrient cross-feeding in the microbial world. Front Microbiol 5:1-6.

Sorokin DY, Tourova TP, Henstra AM, Stams AJM, Galinski EA, Muyzer G (2008) Sulfidogenesis under extremely haloalkaline conditions by Desulfonatronospira thiodismutans gen. nov., sp. nov., and Desulfonatronospira delicata sp. nov. - a novel lineage of Deltaproteobacteria from hypersaline soda lakes. Microbiology 154:14441453. 
Sorokin DY, Rusanov II, Pimenov NV, Tourova TP, Abbas B, Muyzer G (2010) Sulfidogenesis under extremely haloalkaline conditions in soda lakes of Kulunda Steppe (Altai, Russia). FEMS Microbiol Ecol 73:278-290.

Sorokin DY, Detkova EN, Muyzer G (2011a) Sulfur-dependent respiration under extremely haloalkaline conditions in soda lake "acetogens" and the description of Natroniella sulfidigena sp. nov. FEMS Microbiol Lett 319:88-95.

Sorokin DY, Tourova TP, Kolganova TV, Detkova EN, Galinski EA, Muyzer G (2011b) Culturable diversity of lithotrophic haloalkaliphilic sulfate-reducing bacteria in soda lakes and the description of Desulfonatronum thioautotrophicum sp. nov., Desulfonatronum thiosulfatophilum sp. nov., Desulfonatronovibrio thiodismutans sp. nov., and Desulfonatronovibrio magnus sp. nov.. Extremophiles 15:391-401.

Sorokin DY, Abbas B, Geleijnse M, Pimenov NV., Sukhacheva MV., van Loosdrecht MCM (2015) Methanogenesis at extremely haloalkaline conditions in the soda lakes of Kulunda Steppe (Altai, Russia). FEMS Microbiol Ecol 91, fiv016.

Sousa JAB, Plugge CM, Stams AJM, Bijmans MFM (2015) Sulfate reduction in a hydrogen fed bioreactor operated at haloalkaline conditions. Water Res 68:67-76.

Stams AJM, Plugge CM (2009) Electron transfer in syntrophic communities of anaerobic bacteria and archaea. Nat Rev Microbiol 7:568-577.

Thiele JH, Zeikus JG (1988) Control of interspecies electron flow during anaerobic digestion: significance of formate transfer versus hydrogen transfer during syntrophic methanogenesis in flocs. Appl Environ Microbiol 54:20-29.

van den Bosch PLF (2008) Biological sulfide oxidation by natron-alkaliphilic bacteria Application in gas desulfurization. Wageningen University.

Wolin EA, Wolin MJ, Wolfe RS (1963) Formation of methane by bacterial extracts. J Biol Chem 238:2882-2886.

Wu W, Hickey RF, Jain MK, Zeikus JG (1993) Energetics and regulations of formate and hydrogen metabolism by Methanobacterium formicicum. Arch Microbiol 159:57-65.

Zhilina TN, Zavarzin GA, Rainey F, Kevbrin VV, Kostrikina NA, Lysenko AM (1996) Spirochaeta alkalica sp. nov., Spirochaeta africana sp. nov., and Spirochaeta asiatica sp. nov., alkaliphilic anaerobes from the Continental Soda Lakes in Central Asia and the East African Rift. Int J Syst Bacteriol 46:305-312.

Zhilina TN, Garnova ES, Turova TP, Kostrikina NA, Zavarzin GA (2001) Amphibacillus 
fermentum sp. nov., Amphibacillus tropicus sp. nov.--new alkaliphilic, facultatively anaerobic, saccharolytic Bacilli from Lake Magadi. Mikrobiologiia 70:825-837.

Zhilina TN, Kevbrin VV., Tourova TP, Lysenko AM, Kostrikina NA, Zavarzin GA (2005) Clostridium alkalicellum sp. nov., an obligately alkaliphilic cellulolytic bacterium from a soda lake in the Baikal region. Microbiology 74:557-566.

Zhou JM, Song ZY, Yan DJ, Liu YL, Yang MH, Cao HB, Xing JM (2014) Performance of a haloalkaliphilic bioreactor and bacterial community shifts under different $\mathrm{COD} / \mathrm{SO}_{4}{ }^{2-}$ ratios and hydraulic retention times. J Hazard Mater 274:53-62. 


\title{
Chapter 9
}

\section{General discussion and outlook}

\author{
João AB Sousa
}

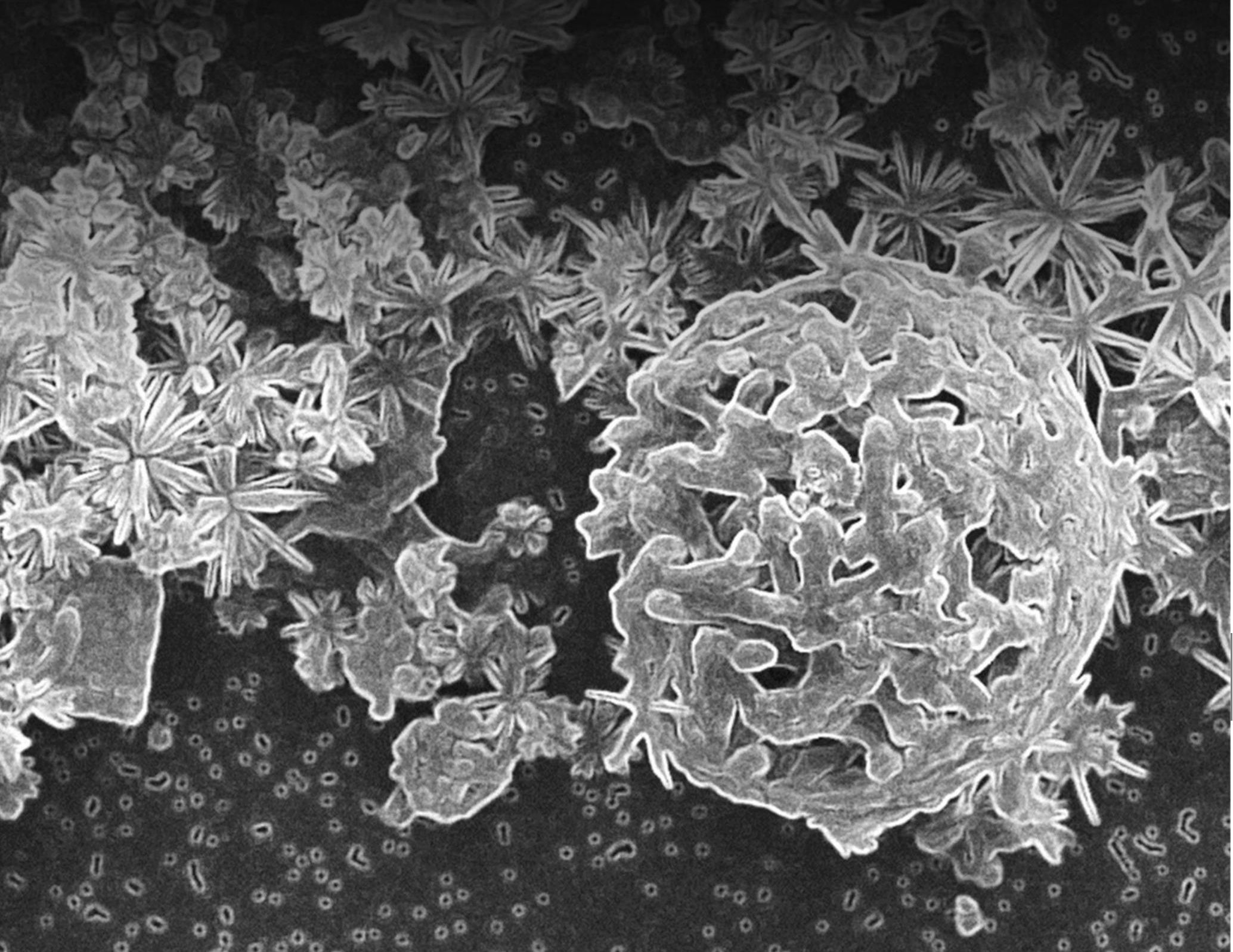


Sulfidogenic bioreactors have been investigated and applied in different industries at mesophilic and neutral pH conditions, but also more extreme conditions such as acidic $\mathrm{pH}$ and high temperature (van Houten et al. 1996; Sipma et al. 2006; Bijmans et al. 2008b; Muyzer and Stams 2008). The work in this thesis complements this knowledge by investigating the application of sulfidogenic bioreactors at haloalkaline conditions, high $\mathrm{pH}(>8.5)$ and high salinity $\left(>0.5 \mathrm{M} \mathrm{Na}^{+}\right)$. These are the conditions used in biodesulfurization processes, where sulfidogenic bioreactors could be used to treat sulfate and thiosulfate-rich waste streams. Along the research described in this thesis, new challenges and opportunities for application, and new microbial syntrophic relationships were discovered. In this chapter the results are discussed concerning two main topics: i) Application of sulfidogenic bioreactors under haloalkaline conditions, ii) Formate and formate producers in haloalkaline environments and their biotechnological potential.

\section{Application of sulfidogenic bioreactors under haloalkaline conditions}

We showed that application of sulfidogenic bioreactors at haloalkaline conditions is possible using different bioreactor designs and conditions of operation (Chapters 3-6). Previous research focused on liquid electron donors for sulfate reduction at haloalkaline conditions which allowed the choice of an anaerobic filter filled with sediments (Zhou and Xing 2015). In this thesis, gaseous electron donors, $\mathrm{H}_{2}$ and syngas, were investigated, which have the advantage of being produced locally from natural gas using gas reforming technology (Pei et al. 2014). The choice of gaseous electron donors led us to choose a gas lift bioreactor to promote a good gas-liquid contact to allow optimal diffusion of $\mathrm{H}_{2}$ in the liquid and prevent gradients, as shown for other conditions (van Houten et al. 1996; Bijmans et al. 2008a). Research with both liquid or gaseous electron donors showed similar maximum sulfidogenic volumetric rates (Zhou and Xing 2015; Chapters 3-6). In view of these results the choice for the best bioreactor system and electron donor will depend on electron donor availability and price, side reactions with each electron donor and biomass retention requirements. 


\section{$\mathrm{H}_{2}$ or syngas as electron donor}

This thesis focused on the use of gaseous electron donors, mainly $\mathrm{H}_{2}$ and syngas $\left(\mathrm{H}_{2}\right.$ $+\mathrm{CO}$ ). When using $\mathrm{H}_{2}$ as electron donor, sulfate and thiosulfate were both reduced, most probably by bacteria closely related to Desulfonatronovibrio spp. and Desulfonatronospira spp (Chapters 3-6). The characterized species from these genera are known to reduce sulfate and thiosulfate using $\mathrm{H}_{2}$ and formate (Sorokin et al. 2008; Sorokin et al. 2011b). Desulfonatronovibrio thiodismutans and Desulfonatronospira thiodismutans, can also disproportionate thiosulfate without using an electron donor, which was also observed in the bioreactors (Chapters 4-6). Most Desulfonatronovibrio spp. previously characterized are dependent on acetate as carbon source for growth (Sorokin et al. 2012). Because no organic compounds were added to the medium, this was considered as one of the reasons for the low biomass yield and lack of biomass retention in the bioreactors in chapters 3 and 4 . In $\mathrm{H}_{2}$-fed sulfate-reducing bioreactors operated at neutral $\mathrm{pH}$ and low salinity conditions, sulfate reducers were dependent on acetate produced by homoacetogens (van Houten et al. 2009). In chapters 3 and 4 , acetate production was never observed; only formate production was observed. In chapter 5 , the addition of sand as biomass carrier material to the bioreactor led to other microbial conversion as well. Besides sulfate/thiosulfate reduction and formate production, also acetate and methane were produced from $\mathrm{H}_{2}$ and $\mathrm{HCO}_{3}{ }^{-}$. This increase of acetate production was associated with an increase of biomass growth, thus resulting in a higher biomass concentration in the bioreactor. This observation indicates that acetate is an essential carbon source for obtaining high biomass concentrations in the sulfidogenic bioreactors fed with $\mathrm{H}_{2}$ under haloalkaline conditions.

As stated before, by using $\mathrm{H}_{2}$ as electron donor we achieved sulfidogenic rates similar to other studies using different liquid electron donors. A cheaper source of $\mathrm{H}_{2}$ is syngas produced via gas reforming process (Pei et al. 2014). The drawback of using syngas without purification, is the presence of $\mathrm{CO}$. $\mathrm{CO}$ is a known inhibitor of hydrogenases, which consequently inhibits $\mathrm{H}_{2}$ fuelled biotransformations (Vignais and Billoud 2007; Parshina et al. 2010). This inhibition effect of $\mathrm{CO}$ occurred in the experiments described in chapter 6 . But, after an adaptation period, the biomass recovered, being able to use $\mathrm{H}_{2}$ and also $\mathrm{CO}$ after this period. This activity was still affected by a further shock of higher $\mathrm{CO}$ concentrations ( $60 \%$ of the gas phase), but the biomass recovered 
afterwards when $\mathrm{CO}$ concentrations were reduced back to $15 \%$. The results indicate that when biomass is exposed to $\mathrm{CO}$ for longer periods, it can adapt to $\mathrm{CO}$. Interestingly, there was a slight change in the microbial population that adapted to $\mathrm{CO}$, but the dominant microorganisms remained the same. Especially a bacterium closely related to Tindallia spp. remained the same. This bacterium was enriched, isolated and characterized in chapter 7, where it was shown to produce formate from $\mathrm{H}_{2}$ and $\mathrm{HCO}_{3}{ }^{-}$ and to reduce thiosulfate. Both reactions were inhibited at the start of the $\mathrm{CO}$ addition but recovered after approximately 30 days (chapter 6 ). This indicated a possible adaptation at the metabolic level, probably by changing the type of hydrogenases, or by reducing the $\mathrm{CO}$ via the water-gas shift reaction.

Overall the results showed that adaptation to $\mathrm{CO}$ is possible and that syngas can be considered as a feasible cheaper alternative source for pure $\mathrm{H}_{2}$ as electron donor for sulfidogenesis at haloalkaline conditions. However, further research using syngas with high fractions of $\mathrm{CO}(>15 \%)$ for longer periods should be done to clearly understand the limits of using syngas. Also, research efforts should focus on how the microbial community adapts to the presence of $\mathrm{CO}$.

\section{The challenge of microbial aggregation}

In chapters 3 and 4 , the absence of microbial attachment and aggregation in the bioreactors was discussed. Even though the bioreactors were equipped with an internal settler to retain settling particles, no microbial aggregates were found during the bioreactors operation, which contrasts with previous research at neutral conditions (van Houten et al. 1995). The only microbial attachment observed was on the glass walls of the bioreactors, possibly favoured by the reduced shear forces near the bioreactor walls. The possible reasons for the lack of microbial aggregation were discussed in chapter 3 . The possible causes include the lack of soluble divalent cations (Ismail et al. 2010), differences in cell surface hydrophobicity (Otto 2008) and reduced microbial interactions due to the absence of organic substrates (Chapters 3 and 5).

In chapter 5 , sand was added as a biomass support material because sand has the same molecular composition as the glass where biofilm was formed. The attachment of biomass to the sand was weak, limiting the presence of attached microorganism to cracks in the sand particles where they were protected from shear forces. However, 
the addition of sand sustained acetate production which caused an increase in biomass. After acetate accumulated in the bioreactor, formation of small microbial flocks was observed. However, the size of the flocks did not increase over time, pointing again to a weak aggregation of the biomass. The presence of small aggregates indicated that the weak aggregation is caused by factors affecting their stability, such as lack of or reduced EPS production, and not initial attraction factors, such as cells surface charge or hydrophobicity.

The addition of $\mathrm{CO}$ to the gas phase in chapter 6 led to the formation of different types of aggregates. Even though they were similar in size compared to the ones obtained in chapter 5 , they had a more granular and compact structure. This indicated that $\mathrm{CO}$ influenced the spatial behaviour of microorganisms in aggregates, possibly due to toxicity effects of $\mathrm{CO}$ or metabolic interactions, as previously reported (van Houten et al. 1995). Thus, CO could be used to influence the type of aggregation in bioreactors operated under haloalkaline conditions.

Besides microbial self-aggregation or attachment to carrier materials, other technologies can be used to enable control of the biomass retention in bioreactors:

- Membrane bioreactors allow the control of biomass retention even if microbes are present only as free-swimming. Sulfate reducing bioreactors were already studied at neutral, acidic and high temperature conditions (Vallero et al. 2005; Bijmans et al. 2008b; Suarez-Zuluaga et al. 2015).

- Encapsulation of biomass in gel-based granules can be used to control biomass retention but also select for microbes with high activity by pre-culturing them in the granules (Trögl et al. 2012).

- Bioelectrochemical cells with $\mathrm{H}_{2}$ production at the cathode can also be used for sulfate reduction, which was already shown for neutral conditions (Sharma et al. 2013). Microorganisms might attach to or associate with the cathode since that is the location where $\mathrm{H}_{2}$ is produced, thus increasing the biomass retention in the process.

All these processes can be further investigated for haloalkaline conditions as alternative methods for improving biomass retention, and consequently, sulfide production volumetric rates. 


\section{Sulfide toxicity}

In both research lines, using liquid or gaseous electron donors, it became clear that the lower sulfide toxicity at alkaline $\mathrm{pH}$ for sulfidogenic microorganisms represents an advantage (Zhou and Xing 2015; Sousa et al. 2015). This allows the operation of sulfidogenic bioreactors under haloalkaline conditions at very high sulfate loading rates compared to sulfidogenic bioreactors operated at lower $\mathrm{pH}$ values $(<9)$. The lower sulfide toxicity is related to the speciation of sulfide at high $\mathrm{pH}$, where $\mathrm{HS}^{-}$is the dominant species. It is generally assumed that HS- is not toxic and only the $\mathrm{H}_{2} \mathrm{~S}$ species is toxic because it can freely diffuse across cell membranes. We performed preliminary experiments with mixed cultures incubated at different $\mathrm{pH}$ values with $\mathrm{H}_{2}$ and sulfate (0.5 M) (Figure 1, suppl. info. SI1). Sulfate reduction activity ceased at similar values for $\mathrm{H}_{2} \mathrm{~S}$ concentration, while the total sulfide (all sulfide species) concentrations differed considerably. In view of these results, the operation of these bioreactors at higher $\mathrm{pH}$ values might even allow higher sulfate loading rates than investigated in this thesis, above $100 \mathrm{mM} \mathrm{d}^{-1}$. This should be further investigated, especially considering that the high $\mathrm{pH}$, above 10, will also have a negative effect on the activity of sulfate reducing microbes (Sorokin et al. 2011b). The balance between the high pH effect and sulfide toxicity will result in an optimum $\mathrm{pH}$ for operation of sulfidogenic bioreactors. Such research should also include efforts to define the sulfide toxicity mechanism at alkaline conditions. The main toxicity mechanism described in literature is related to the capacity of $\mathrm{H}_{2} \mathrm{~S}$ to freely cross cell membranes, affecting the $\mathrm{pH}$ homeostasis in the cell by dissociating into $\mathrm{HS}^{-}$and $\mathrm{H}^{+}$(Ghose and Wiken 1955; Bijmans et al. 2008a). However, as described before (Chapter 1), alkaliphiles have structural and physiological mechanisms of keeping the intracellular $\mathrm{pH}$ lower than the extracellular environment. Thus, the described effect of $\mathrm{H}_{2} \mathrm{~S}$ crossing the cell membranes, dissociating and producing $\mathrm{H}^{+}$which decreases intracellular $\mathrm{pH}$ does not seem to apply for alkaliphiles. To clarify this, further research could focus on understanding the effect of toxic concentrations of sulfide on the intracellular $\mathrm{pH}$ and clarify if this is or not the toxicity mechanism. Another possible effect of higher intracellular sulfide concentrations hypothesized is the reaction of $\mathrm{HS}^{-}$with metal containing compounds in the cell, possibly disturbing its function (Madigan et al. 2012). A deeper look into the transcriptome and proteome of sulfidogenic microorganisms at toxic sulfide concentrations could provide clues on this alternative toxicity mechanism. 

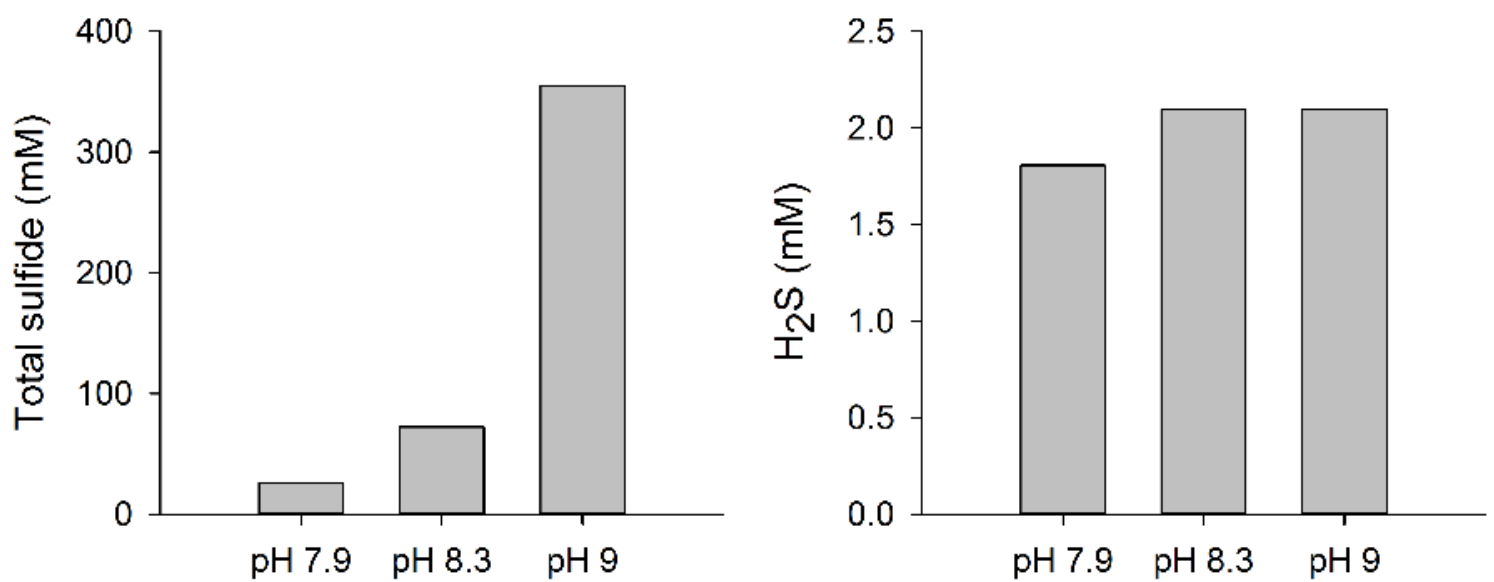

Figure 1 - Maximum total sulfide (including all sulfide species) and $\mathrm{H}_{2} \mathrm{~S}$ concentrations in the liquid reached in sulfidogenic mixed cultures at different $\mathrm{pH}$ values (suppl. info. SI1). Salinity was always set at $1.5 \mathrm{M} \mathrm{Na}^{+}$. The tests at $\mathrm{pH} 7.9$ and 8.3 were performed in 2 I reactors operated in batch mode mixed with a magnetic stirrer and with a continuous $\mathrm{H}_{2}$ supply of $5 \mathrm{ml}$ $\mathrm{min}^{-1}$. The test at $\mathrm{pH} 9$, described also in chapter 3 , was performed in a 4.4 I gas lift reactor operated in batch mode and with a continuous $\mathrm{H}_{2}$ supply of $5 \mathrm{ml} \mathrm{min}^{-1}$. All reactors were fed with $0.5 \mathrm{M}$ of sodium sulfate.

\section{Application of sulfidogenesis in biodesulfurization processes}

One of the major applications of sulfidogenesis at haloalkaline conditions is treating the bleed stream from biodesulfurization processes, such as the Thiopaq ${ }^{\circledR}$ process (Figure 2a). In this process the sulfide is absorbed in an alkaline solution, which is sent to a microaerophilic bioreactor. In this bioreactor, the redox conditions are kept low (< -350) to favour the oxidations of sulfide to $S^{0}$ instead of to sulfate. As explained in chapter 1 , the difficulties in redox control during the microaerophilic oxidation of sulfide leads to the unwanted production and accumulation of sulfate and thiosulfate in the process. This accumulation of sulfate and thiosulfate leads to a decrease in $\mathrm{pH}$. To maintain the $\mathrm{pH}$ (above 8.5) part of the process liquid must discharged, which is called the bleed stream. This implies the addition of new caustic solution to the biodesulfurization process which increases the operational expenses (OPEX) of the biodesulfurization process. Additionally, the thiosulfate in the bleed stream can be oxidized, and thus contributes to the chemical oxygen demand (COD) of the disposed bleed stream, implying extra discharge costs. 


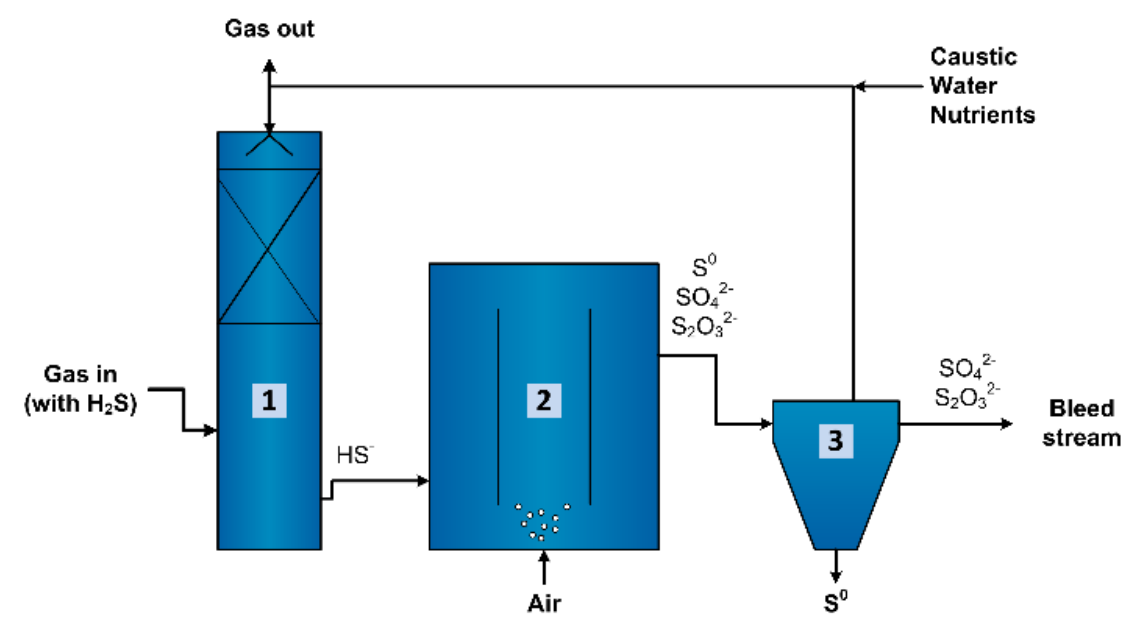

NBT

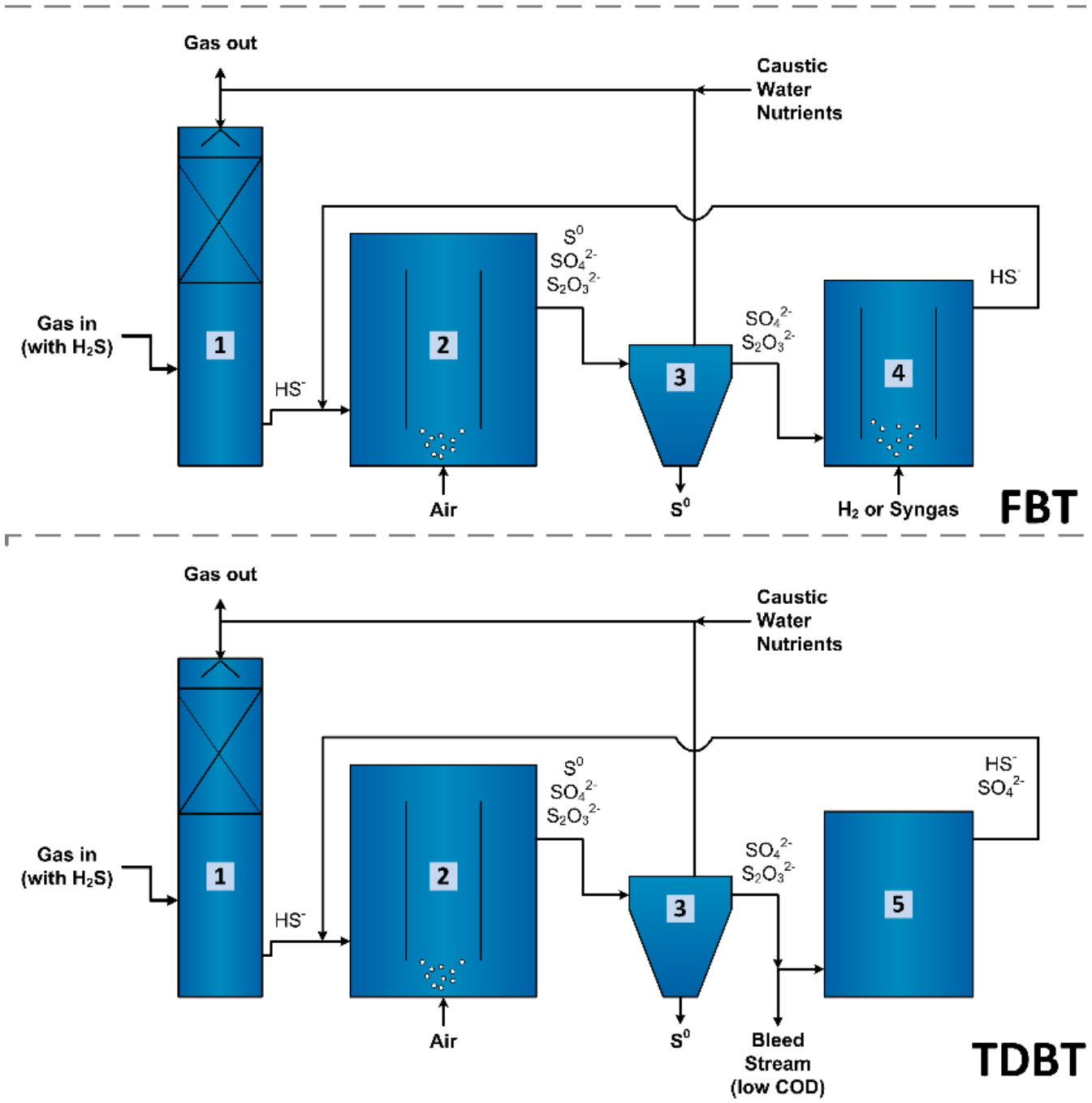

Figure 2 - Process scheme of 3 different configurations for biodesulfurization processes. NBT - No bleed stream treatment; FBT - With full bleed stream treatment (reduction of sulfate and thiosulfate, addition of electron donor); TDBT - With thiosulfate removal from the bleed stream via disproportionation, no addition of electron donor; 1 - Scrubber. 2 - Sulfide oxidation microaerophilic bioreactor; 3 - Settler for sulfur separation; 4 - Sulfate/thiosulfate reducing bioreactor; 5 - Thiosulfate disproportionating bioreactor. 
The addition of a sulfidogenic bioreactor allows the reduction of sulfate and thiosulfate to sulfide while regenerating the caustic solution (Figure $2 b$ ). This solution can be recycled into the microaerophilic reactor where sulfide is again oxidized. However, this process involves the addition of an electron donor leading to extra OPEX. The economic feasibility of applying a sulfidogenic reactor depends for a large part on the availability and price of the electron donor, and the $S^{0}$ selectivity of the sulfide oxidation process. The $\mathrm{S}^{0}$ selectivity in the sulfide oxidation bioreactors can be between $90 \%$ and $95 \%$ and models predict that $98 \%$ could be achieved (Klok et al. 2013; Roman et al. 2016). To evaluate this, a simplified economic calculation for the sulfidogenic bioreactor application on biodesulfurization processes was performed (Supplementary information SI2 and SI3). For OPEX, only costs of the caustic consumption, bleed stream discharge and electron donor consumption were used, which usually represent the main costs. As can be seen in Figure 3, the OPEX of a biodesulfurization process with bleed stream treatment (FBT) is lower than without (NBT) for all scenarios with different $S^{0}$ selectivity. Within the FBT options, the OPEX is directly related to the electron donor price. Syngas production by gas reforming provides higher savings, but similar to $\mathrm{H}_{2}$ purified from syngas. However, the capital expenses (CAPEX) are higher when using a gaseous electron donor, such as $\mathrm{H}_{2}$ or syngas, compared to the use of a liquid electron donor, such as formate, which increases the investement payback period (Figure 4). This is mainly due to the compressors required to recirculate $\mathrm{H}_{2}$ or syngas to promote a good gas diffusion. However, the investement payback period of the CAPEX of FBT, using savings in OPEX by using bleed stream treatment, is still slightly lower for $\mathrm{H}_{2}$ and syngas produced by gas reforming compared to formate. CAPEX costs related to the gas reformer were not included in the calculation but could increase the CAPEX payback time of FBT using $\mathrm{H}_{2}$ or syngas from gas reforming.

Overall, the investment in bleed stream treatment can be recovered, being the payback time shorter for bigger size biodesulfurization plants and longer for plants with high $\mathrm{S}^{0}$ selectivity in their sulfide oxidation bioreactors (Figure 4). Achieving higher $\mathrm{S}^{0}$ selectivity in the sulfide oxidation bioreactor, approximately $98 \%$, can be an effective strategy to decrease the OPEX (Klok et al. 2013). 


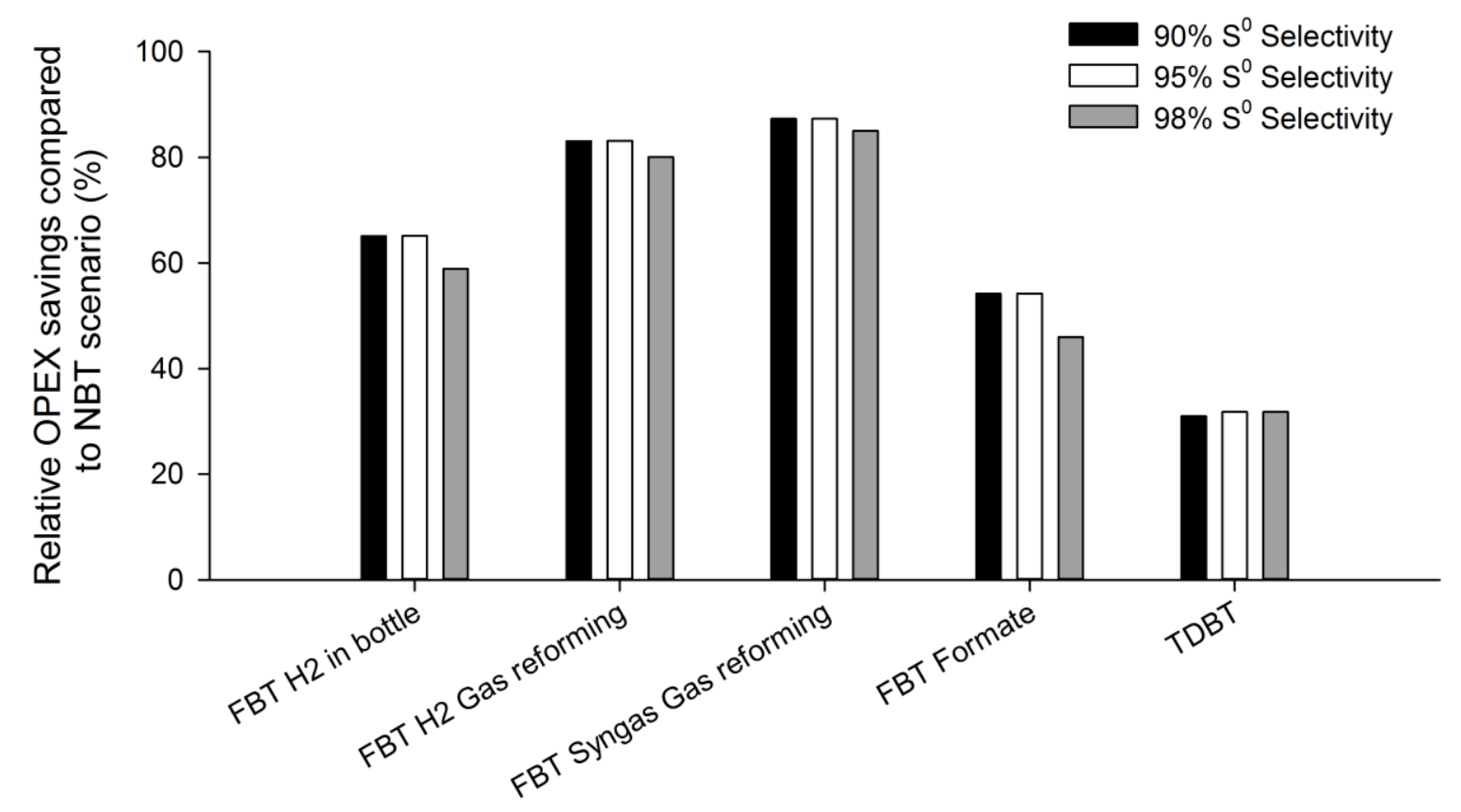

Figure 3 - Relative operational costs (OPEX) savings compared to the NBT scenario. Different reactor configurations were evaluated: without bleed stream treatment (NBT), with full bleed stream treatment by sulfate and thiosulfate reduction (FBT) and with partial bleed stream treatment by thiosulfate disproportionation (TDBT). For the FBT, the OPEX was calculated with cryogenic liquid $\mathrm{H}_{2}, \mathrm{H}_{2}$ from gas reforming, syngas from gas reforming and formate as electron donors. For each option, the OPEX was calculated for three different $\mathrm{S}^{0}$ selectivity (\% is based on the mol of $\mathrm{HS}^{-}$supplied): $90 \% \mathrm{~S}^{0}$ with $5 \%$ sulfate and $5 \%$ thiosulfate production; $95 \% \mathrm{~S}^{0}$ selectivity with $2.5 \%$ sulfate and $2.5 \%$ thiosulfate production; $98 \% \mathrm{~S}^{0}$ selectivity with $2 \%$ thiosulfate production. The values were calculated based on a biodesulfurization plant treating 1 ton $_{\text {s }}$ day $^{-1}$. The calculations and values used are described in supplementary information SI2 and SI3. 


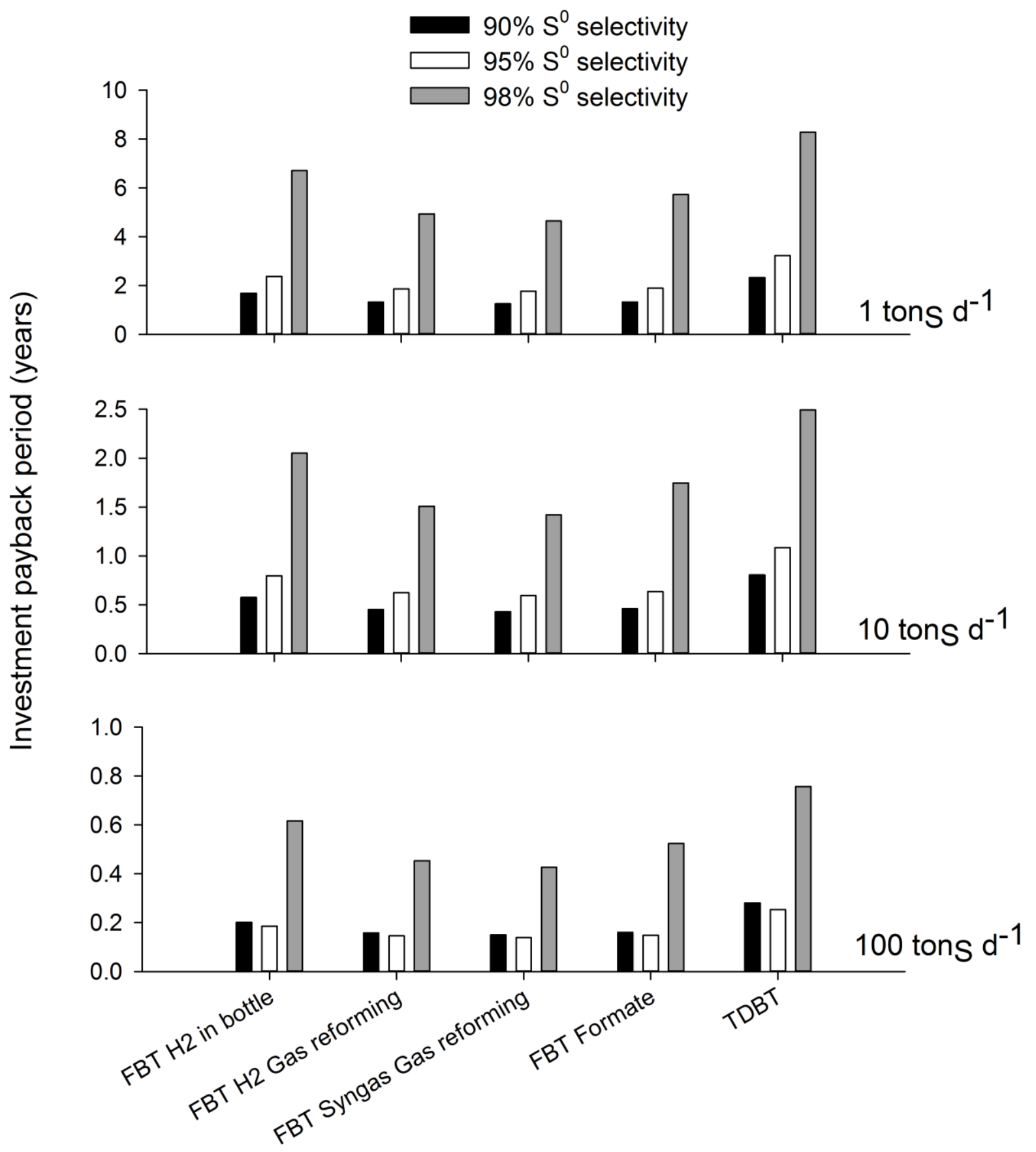

Figure 4 - Investement payback period in years of the different reactor configurations in different scenarios of $\mathrm{S}^{0}$ selectivity and biodesulfurization plant size based on the $\mathrm{S}$ load.

When thiosulfate disproportionation was observed in the bioreactor (chapter 4), another process configuration was designed, using a thiosulfate disproportionating bioreactor (TDBT). When including a reactor that exclusively performs thiosulfate disproportionation there is no need for an electron donor. In addition, the thiosulfate is 
converted and reduces the COD of the bleed stream to low values (Figure 2c). This would not be a cost saving step in caustic, but could lead to a cost saving in bleed stream discharge. The TDBT process reduces the OPEX of the biodesulfurization process when compared to the NBT in all $\mathrm{S}^{0}$ selectivity scenarios evaluated but is always higher than the FBT options (Figure 3). This is also applicable for the payback time of CAPEX, which is always longer than the FBT options, rendering this option less attractive from an economic perspective (Figure 4).

\section{The missing pieces}

Besides the topics investigated in this thesis, additional factors might dictate the success or failure of sulfidogenic bioreactors application at haloalkaline conditions. These factors include mainly: i) effect of $\mathrm{S}^{0}$ as competing electron acceptor for sulfate and thiosulfate reduction; ii) effect of organic $S$ compounds; iii) lack of oxygen tolerance of sulfidogenic microorganisms.

\section{Effect of $\mathrm{S}^{0}$ as competing electron acceptor}

$\mathrm{S}^{0}$ that does not settle properly is present in the bleed stream entering the sulfidogenic bioreactor, where it will be reduced to sulfide (van den Bosch 2008). First, $S^{0}$ reacts abiotically with sulfide present in the sulfidogenic bioreactor, yielding polysulfides, which are stable at haloalkaline conditions. The polysulfides are soluble and can be easily reduced by sulfur-reducing microorganisms, producing sulfide. Haloalkaliphilic sulfur-reducing microorganisms have been previously isolated from both soda lakes and microaerophilic and anaerobic bioreactors (Itoh et al. 2005; Sorokin et al. 2007; Sorokin and Muyzer 2010; Sorokin et al. 2011a; Sorokin et al. 2013; Chapter 7). In soda lakes sediments from Kulunda steppe in Russia, $\mathrm{S}^{0}$ reduction activity is higher than sulfate or thiosulfate reduction activity. Thus, $S^{0}$ can interfere with sulfate and thiosulfate reduction mainly by competing for the same electron donor, increasing the amount of electron donor required. This was observed in tests performed by us where $\mathrm{S}^{0}$ was added to a bioreactor as $5 \%$ and $10 \%$ (in mol) of the total $\mathrm{S}$ supplied. All sulfur was reduced to sulfide, being trace amounts of polysulfides, mainly $S_{4}^{-}$, detected as intermediates. However, more research is required to understand the different kinetics of $\mathrm{S}^{0}$-reducing microorganisms compared to sulfate-reducing microorganisms. This 
would allow developing strategies to prevent $\mathrm{S}^{0}$ reduction when it is not required, as in biodesulfurization processes.

\section{Effect of organic S compounds}

Besides inorganic $S$ compounds, organic $S$ compounds can be found in natural environments and bioreactors, such as dimethyl sulfide (DMS), dimethyl disulfide (DMDS) or methanethiol (MT). These compounds can be converted by methylotrophic methanogens (Lomans et al. 2002a), and to a lesser extent by sulfate reducers (Lomans et al. 2002b).The removal of organic $S$ compounds could be considered in processes where organic $S$ compounds are toxic, as is the case for the sulfideoxidizing bacteria in biodesulfurization processes (Roman et al. 2015; Roman et al. 2016). The removal of MT and DMDS in anaerobic bioreactors was studied in the past, where it was mainly converted by methanogens, and more efficiently when a cosubstrate was added, such as methanol (van Leerdam et al. 2008). However, in the sulfidogenic bioreactors operated in this study, the dominant methanogens identified are hydrogenotrophic and not methylotrophic, which could represent a challenge to the degradation of MT or DMDS. We performed some preliminary research in fed-batch bioreactors studying the effect of DMDS on sulfidogenic biomass with and without $\mathrm{H}_{2}$ in the gas phase. DMDS was abiotically converted to MT which was used by both methanogens and sulfate reducers. The presence of $\mathrm{H}_{2}$ as co-substrate had a positive effect, allowing operation of the bioreactor under higher DMDS concentrations, $2.5 \mathrm{mM}$ with $\mathrm{H}_{2}$ compared to $0.5 \mathrm{mM}$ without. More research is required to understand why MT and DMDS degradation can be performed at higher concentrations when co-substrates are used, such as $\mathrm{H}_{2}$.

\section{$\underline{\text { Oxygen tolerance of sulfidogenic microorganisms }}$}

In biodesulfurization processes, such as the ones discussed above, the microorganisms from the sulfidogenic bioreactor recycle through the sulfide oxidation bioreactor. In this bioreactor, operated under microaerophilic conditions, the anaerobic sulfidogenic microorganisms will be exposed to oxygen $\left(\mathrm{O}_{2}\right)$. All haloalkaliphilic sulfate 
and sulfur reducers isolated so far are obligate anaerobes. The $\mathrm{O}_{2}$ presence is lethal to sulfidogenic microorganisms due to: i) reactive oxygen species (ROS) production, for example by reacting with HS- (Cypionka et al. 1985); ii) inactivation of enzymes, such as hydrogenases (Lubitz et al. 2014); ii) destabilizing the intracellular redox potential (Dolla et al. 2006). However, sulfur reducers have been isolated from a microaerophilic bioreactor operated for almost 20 years continuously (Sorokin et al. 2013), meaning that the sulfur reducers were able survive at low $\mathrm{O}_{2}$ conditions. Some neutrophilic sulfate reducing bacteria, such as Desulfovibrio spp., have mechanisms to handle reactive oxygen species formed in the presence of $\mathrm{O}_{2}$ (Dolla et al. 2006; Zhou et al. 2011). In the case of the FBT or TDBT biodesulfurization processes (Figure 2), sulfidogenic microorganisms are also exposed to low $\mathrm{O}_{2}$ conditions. The sulfidogenic microorganisms might cope with oxygen and ROS by producing reactive oxygen species scavengers or by aggregating, as shown for neutral conditions (Dolla et al. 2006; van den Brand et al. 2015). However, none of these $\mathrm{O}_{2}$ tolerance processes were studied for haloalkaliphilic sulfidogenic microorganisms. More research is needed to understand if and how haloalkaliphilic sulfidogenic microorganisms can resist $\mathrm{O}_{2}$ during their passage through the microaerophilic bioreactor of biodesulfurization processes.

\section{Formate and formate producers in haloalkaline environments and their biotechnological potential}

\section{Formate production under haloalkaline conditions}

During all experiments with sulfidogenic bioreactors fed with $\mathrm{H}_{2}$ or syngas, formate was produced and accumulated in the medium (Chapters 3-6). Under haloalkaline conditions, formate can be produced during fermentation of organic compounds, as performed by Amphibacillus spp. (Zhilina et al. 2001), or via $\mathrm{H}_{2}$ and $\mathrm{HCO}_{3}$, as performed by Tindallia spp. strains AHT5 and JE1 (Sorokin et al. 2011a; Chapter 7). Formate production from $\mathrm{H}_{2}$ and $\mathrm{HCO}_{3}{ }^{-}$is thermodynamically favorable because of the high concentration of $\mathrm{HCO}_{3}{ }^{-}$present in haloalkaline environments (Chapter 8). 
Consequently, formate can accumulate up to higher concentrations when compared with formate formation at neutral conditions with lower $\mathrm{HCO}_{3}{ }^{-}$concentrations. This indicates that formate dependent metabolisms might be more active in haloalkaline environments.

In the bioreactors studied in chapters 3-6, the production of formate as one of the main products led us to hypothesize that the dominant bacterium in the microbial community, related to Tindallia spp., were responsible for it (Chapter 4). To validate this hypothesis, we isolated that dominant bacterium, Tindallia sp. strain JE1, which could produce formate from $\mathrm{H}_{2}$ and $\mathrm{HCO}_{3}{ }^{-}$, up to $96 \mathrm{mM}$ of formate (Chapter 7). Growth of this species was dependent on the presence of yeast extract, like the other Tindallia spp. described in literature (Chapter 7). This indicated that Tindallia sp. strain JE1 required an additional carbon source and/or a trace element that we did not add the defined media. Such carbon source and/or trace element could have been present in the bioreactors in chapters 3-6, originating from dead biomass, allowing Tindallia sp. to grow and become the dominant microorganism. Tindallia sp. strain JE1 was also able to reduce thiosulfate and $\mathrm{S}^{0}$ using $\mathrm{H}_{2}$, but not sulfate. This cannot explain its dominance in the bioreactor fed only with sulfate, indicating that another competitive advantage might have been important in the bioreactors.

\section{Formate as interspecies electron carrier}

In view of the previously describe results, we hypothesised that the sulfate reducers present in the bioreactors were dependent on the formate produced by Tindallia sp. strain JE1. The dependence of sulfate reducers on the formate produced by Tindallia sp. strain JE1 might have allowed the dominance of Tindallia sp. strain JE1 in the bioreactors. In chapter 8 , this syntrophic relationship was studied in co-cultures with Tindallia sp. strain JE1 (formate producer) and Desulfonatronovibrio thiodismutans AHT10 (sulfate reducer). Besides formate production, another unknown factor played a role in the syntrophic relationship. This factor could be the dependence of $D$. thiodismutans $\mathrm{AHT} 10$ on acetate or another unknown trace compound produced by Tindallia sp. strain JE1. Also, Tindallia sp. strain JE1 was shown to require yeast extract to grow (Chapter 7). In the co-culture without yeast extract, it might get similar 
compounds from the $D$. thiodismutans $\mathrm{AHT} 10$ as present in yeast extract which allows it to grow.

In soda lakes in the Kulunda steppe in Russia, sulfate reduction activity of sediments was always higher with formate than with $\mathrm{H}_{2}$ gas (Sorokin et al. 2010). This indicates that formate is a preferred electron donor in soda lakes, as in the bioreactors (chapters 3-6). The cause for this preference might be related to the uptake mechanisms involved in utilization of $\mathrm{H}_{2}$ and formate. In the syntrophic relationship, formate producers might have higher affinity mechanisms for $\mathrm{H}_{2}$ uptake compared to the sulfate reducers. The sulfate reducers dependent on formate, might have higher affinity for sulfate uptake or higher sulfate reduction rates than the sulfate reducers that use $\mathrm{H}_{2}$ directly. This would generate an advantage if the two microorganisms cooperate. This should be further researched together with the hypothesized effect of acetate and/or trace element production by the formate producer.

\section{Application of formate production}

Formate production at haloalkaline conditions can also be applied as a technology on its own. Formate can be used in wide range of applications, from $\mathrm{CO}_{2}$ capture and $\mathrm{H}_{2}$ storage (Schuchmann and Müller 2013; Blanchet et al. 2015; Singh et al. 2015) to production of various chemicals and production of proteins for feedstock (Liu et al. 2015; Yishai et al. 2016). The best studied process for formate production is the electrochemical route that uses specific metal, molecular or enzymatic catalysts to produce formate from $\mathrm{H}_{2}$ and $\mathrm{CO}_{2}$ (Taheri and Berben 2016). One of these enzymatic catalysts used was a formate dehydrogenase from Syntrophobacter fumaroxidans which was successfully coated on an electrode and produced formate from $\mathrm{CO}_{2}$ (Reda et al. 2008). Several microorganisms have the capacity of producing formate from $\mathrm{H}_{2}$ and $\mathrm{CO}_{2}$, mostly as an intermediate for electron transfer (Peters et al. 1999). However, the formate production halts at formate concentrations below $2 \mathrm{mM}$ at neutral $\mathrm{pH}$ and low salinity conditions. Recombinant Escherichia coli cells with formate dehydrogenase genes from Pyrococcus furiosus could produce formate up to $44 \mathrm{mM}$ (Alissandratos et al. 2014). In this last study, a higher salinity was used, $0.25 \mathrm{M} \mathrm{HCO}_{3}{ }^{-}$ instead of $0.05 \mathrm{M} \mathrm{HCO}_{3}{ }^{-}$by Peters et al. (1999). High $\mathrm{HCO}_{3}{ }^{-}$concentrations change the thermodynamic equilibrium of $\mathrm{H}_{2}$ /formate in favour of formate production. This is 
confirmed by our observation at high $\mathrm{HCO}_{3}{ }^{-}$concentrations, $0.825 \mathrm{M}$ (Chapter 8), where formate was accumulated up to $90 \mathrm{mM}$, but it even reached about $160 \mathrm{mM}$ (Chapter 5). Formate production at haloalkaline conditions allows the accumulation of higher formate concentrations, which is an advantage for transport and downstream applications.

Future research is required to understand formate production from $\mathrm{H}_{2}$ and $\mathrm{HCO}_{3}{ }^{-}$at haloalkaline conditions. We still need answers to why the formate producing microbes, such as Tindallia spp, produce formate and not acetate, which is energetically more favourable. Information on formate dehydrogenase used by formate producing Tindallia spp. could shed light on this subject. This information could allow the application of bioreactors with mixed biomass where conditions are steered to the specific production of formate. 


\section{References}

Alissandratos A, Kim H-K, Easton CJ (2014) Formate production through carbon dioxide hydrogenation with recombinant whole cell biocatalysts. Bioresour Technol 164:7-11.

Bijmans MFM, Dopson M, Ennin F, Lens PNL, Buisman CJN (2008a) Effect of sulfide removal on sulfate reduction at $\mathrm{pH} 5$ in a hydrogen fed gas-lift bioreactor. J Microbiol Biotechnol 18:1809-1818.

Bijmans MFM, Peeters TWT, Lens PNL, Buisman CJN (2008b) High rate sulfate reduction at $\mathrm{pH} 6$ in a $\mathrm{pH}$-auxostat submerged membrane bioreactor fed with formate. Water Res 42:2439-2448.

Blanchet EM, Duquenne F, Rafrafi Y, Etcheverry L, Erable B, Bergel A (2015) Importance of the hydrogen route in up-scaling electrosynthesis for microbial $\mathrm{CO}_{2}$ reduction. Energy Environ Sci 3731-3744.

Madigan MT, Martinko JM, Stahl DA, Clark DP (2012) Brock biology of microorganisms. $13^{\text {th }}$ edn. Benjamin Cummings, San Francisco, CA, pp 386-487.

Cypionka H, Widdel F, Pfennig N (1985) Survival of sulfate-reducing bacteria after oxygen stress, and growth in sulfate-free oxygen-sulfide gradients. FEMS Microbiol Lett 31:3945.

Dutch Association of Cost Engineers (2011) Prijzenboekje. $28^{\text {th }}$ edn. Aart Freriks, Doetinchem, Netherlands, pp 15-200.

Dolla A, Fournier M, Dermoun Z (2006) Oxygen defense in sulfate-reducing bacteria. J Biotechnol 126:87-100.

Ghose TK, Wiken T (1955) Inhibition of bacterial sulphate-reduction in presence of short chain fatty acids. Physiol Plant 8:116-135.

Ismail SB, de La Parra CJ, Temmink H, van Lier JB (2010) Extracellular polymeric substances (EPS) in upflow anaerobic sludge blanket (UASB) reactors operated under high salinity conditions. Water Res 44:1909-1917.

Itoh T, Yamaguchi T, Zhou P, Takashina T (2005) Natronolimnobius baerhuensis gen. nov., sp. nov. and Natronolimnobius innermongolicus sp. nov., novel haloalkaliphilic archaea isolated from soda lakes in Inner Mongolia, China. Extremophiles 9:111-116.

Klok JBM, de Graaff M, van den Bosch PLF, Boelee NC, Keesman KJ, Janssen AJH (2013) A physiologically based kinetic model for bacterial sulfide oxidation. Water Res 47:483492. 
Liu X, Li S, Liu Y, Cao Y (2015) Formic acid: A versatile renewable reagent for green and sustainable chemical synthesis. Chinese J Catal 36:1461-1475.

Lomans BP, Pol A, Op den Camp HJM (2002a) Microbial cycling of volatile organic sulfur compounds in anoxic environments. Water Sci Technol 45:55-60.

Lomans BP, van der Drift C, Pol A, Op den Camp HJM (2002b) Microbial cycling of volatile organic sulfur compounds. Cell Mol Life Sci 59:575-588.

Lubitz W, Ogata H, Rüdiger O, Reijerse E (2014) Hydrogenases. Chem Rev 114:4081-148.

Muyzer G, Stams AJM (2008) The ecology and biotechnology of sulphate-reducing bacteria. Nat Rev Microbiol 6:441-454.

Otto K (2008) Biophysical approaches to study the dynamic process of bacterial adhesion. Res Microbiol 159:415-422.

Parshina SN, Sipma J, Henstra AM, Stams AJM (2010) Carbon monoxide as an electron donor for the biological reduction of sulphate. Int J Microbiol 2010:319527.

Pei P, Korom SF, Ling K, Nasah J (2014) Cost comparison of syngas production from natural gas conversion and underground coal gasification. Mitig Adapt Strateg Glob Chang 115.

Peters V, Janssen PH, Conrad R (1999) Transient production of formate during chemolithotrophic growth of anaerobic microorganisms on hydrogen. Curr Microbiol 38:285-289.

Reda T, Plugge CM, Abram NJ, Hirst J (2008) Reversible interconversion of carbon dioxide and formate by an electroactive enzyme. Proc Natl Acad Sci U S A 105:10654-10658.

Roman P, Veltman R, Bijmans MFM, Keesman KJ, Janssen AJH (2015) Effect of methanethiol concentration on sulfur production in biological desulfurization systems under haloalkaline conditions. Environ Sci Technol 49:9212-9221.

Roman P, Bijmans MFM, Janssen AJH (2016) Influence of methanethiol on biological sulphide oxidation in gas treatment system. Environ Technol 3330:1-11.

Schuchmann K, Müller V (2013) Direct and reversible hydrogenation of $\mathrm{CO}_{2}$ to formate by a bacterial carbon dioxide reductase. Science 342:1382-1385.

Sharma M, Jain P, Varanasi JL, Lal B, Rodríguez J, Lema JM, Sarma PM (2013) Enhanced performance of sulfate reducing bacteria based biocathode using stainless steel mesh on activated carbon fabric electrode. Bioresour Technol 150C:172-180. 
Singh AK, Singh S, Kumar A (2015) Hydrogen energy future with formic acid: a renewable chemical hydrogen storage system. Catal Sci Technol 6:12-40.

Sipma J, Lettinga G, Stams AJM, Lens PNL (2006) Hydrogenogenic CO conversion in a moderately thermophilic $\left(55^{\circ} \mathrm{C}\right)$ sulfate-fed gas lift reactor: competition for $\mathrm{CO}$-derived $\mathrm{H}_{2}$. Biotechnol Prog 22:1327-1334.

Sorokin DY, Foti M, Tindall BJ, Muyzer G (2007) Desulfurispirillum alkaliphilum gen. nov. sp. nov., a novel obligately anaerobic sulfur- and dissimilatory nitrate-reducing bacterium from a full-scale sulfide-removing bioreactor. Extremophiles 11:363-70.

Sorokin DY, Tourova TP, Henstra AM, Stams AJM, Galinski EA, Muyzer G (2008) Sulfidogenesis under extremely haloalkaline conditions by Desulfonatronospira thiodismutans gen. nov., sp. nov., and Desulfonatronospira delicata sp. nov. - a novel lineage of Deltaproteobacteria from hypersaline soda lakes. Microbiology 154:14441453.

Sorokin DY, Muyzer G (2010a) Desulfurispira natronophila gen. nov. sp. nov.: an obligately anaerobic dissimilatory sulfur-reducing bacterium from soda lakes. Extremophiles 14:349-55.

Sorokin DY, Rusanov II, Pimenov N V, Tourova TP, Abbas B, Muyzer G (2010b) Sulfidogenesis under extremely haloalkaline conditions in soda lakes of Kulunda Steppe (Altai, Russia). FEMS Microbiol Ecol 73:278-290.

Sorokin DY, Detkova EN, Muyzer G (2011a) Sulfur-dependent respiration under extremely haloalkaline conditions in soda lake "acetogens" and the description of Natroniella sulfidigena sp. nov. FEMS Microbiol Lett 319:88-95.

Sorokin DY, Tourova TP, Kolganova T V, Detkova EN, Galinski EA, Muyzer G (2011b) Culturable diversity of lithotrophic haloalkaliphilic sulfate-reducing bacteria in soda lakes and the description of Desulfonatronum thioautotrophicum sp. nov., Desulfonatronum thiosulfatophilum sp. nov., Desulfonatronovibrio thiodismutans sp. nov., and Desulfonatronovibrio magnus sp. nov.. Extremophiles 15:391-401.

Sorokin DY, Tourova TP, Abbas B, Suhacheva M V, Muyzer G (2012) Desulfonatronovibrio halophilus sp. nov., a novel moderately halophilic sulfate-reducing bacterium from hypersaline chloride-sulfate lakes in Central Asia. Extremophiles 16:411-417.

Sorokin DY, Tourova TP, Muyzer G (2013) Isolation and characterization of two novel alkalitolerant sulfidogens from a Thiopaq bioreactor, Desulfonatronum alkalitolerans $\mathrm{sp}$. nov., and Sulfurospirillum alkalitolerans sp. nov. Extremophiles 17:535-543. 
Sousa JAB, Plugge CM, Stams AJM, Bijmans MFM (2015) Sulfate reduction in a hydrogen fed bioreactor operated at haloalkaline conditions. Water Res 68:67-76.

Suarez-Zuluaga DA, Timmers PHA, Plugge CM, Stams AJM, Buisman CJN, Weijma J (2015) Thiosulphate conversion in a methane and acetate fed membrane bioreactor. Environ Sci Pollut Res. 23:2467-2478.

Taheri A, Berben LA (2016) Making $\mathrm{C}-\mathrm{H}$ bonds with $\mathrm{CO}_{2}$ : production of formate by molecular electrocatalysts. Chem Commun Chem Commun 52:1768-1777.

Trögl J, Krhůtková $O$, Pilařová V, Dáňová $P$, Holíček R, Kohlová $M$, Hejda $S$, Smrčka J, Boušková A, Křiklavová L (2012) Removal of nitrates from high-salinity wastewaters from desulphurization process with denitrifying bacteria encapsulated in Lentikats Biocatalyst. Int J Environ Sci Technol 9:425-432.

Vallero MVG, Lettinga G, Lens PNL (2005) High rate sulfate reduction in a submerged anaerobic membrane bioreactor (SAMBaR) at high salinity. J Memb Sci 253:217-232.

van den Bosch PLF (2008) Biological sulfide oxidation by natron-alkaliphilic bacteria Application in gas desulfurization. Wageningen University

van den Brand TPH, Roest K, Chen GH, Brdjanovic D, van Loosdrecht MCM (2015) Occurrence and activity of sulphate reducing bacteria in aerobic activated sludge systems. World J Microbiol Biotechnol 31:507-516.

van Houten BHGW, van Doesburg W, Dijkman H, Copini C, Smidt H, Stams AJM (2009) Longterm performance and microbial community analysis of a full-scale synthesis gas fed reactor treating sulfate- and zinc-rich wastewater. Appl Microbiol Biotechnol 84:555563.

van Houten RT, Elferink SJWH, van Hamel SE, Hulshoff Pol LW, Lettinga G (1995) Sulphate reduction by aggregates of sulphate-reducing bacteria and homo-acetogenic bacteria in a lab-scale gas-lift reactor. Bioresour Technol 54:73-79.

van Houten RT, van der Spoel H, van Aelst AC, Hulshoff Pol LW, Lettinga G (1996) Biological sulfate reduction using synthesis gas as energy and carbon source. Biotechnol Bioeng $50: 136-144$.

van Leerdam RC, Bonilla-Salinas M, de Bok FAM, Bruning $H$, Lens PNL, Stams AJM, Janssen AJH (2008) Anaerobic methanethiol degradation and methanogenic community analysis in an alkaline $(\mathrm{pH} 10)$ biological process for liquefied petroleum gas desulfurization. Biotechnol Bioeng 101:691-701. 
Vignais PM, Billoud B (2007) Occurrence, classification, and biological function of hydrogenases: an overview. Chem Rev 107:4206-72.

Yishai O, Lindner SN, Gonzalez de la Cruz J, Tenenboim H, Bar-Even A (2016) The formate bio-economy. Curr Opin Chem Biol 35:1-9.

Zhilina TN, Garnova ES, Turova TP, Kostrikina NA, Zavarzin GA (2001) Amphibacillus fermentum sp. nov., Amphibacillus tropicus sp. nov. new alkaliphilic, facultatively anaerobic, saccharolytic Bacilli from Lake Magadi. Mikrobiologiia 70:825-837.

Zhou J, He Q, Hemme CL, Mukhopadhyay A, Hillesland K, Zhou A, He Z, van Nostrand JD, Hazen TC, Stahl DA, Wall JD, Arkin AP (2011) How sulphate-reducing microorganisms cope with stress: lessons from systems biology. Nat Rev Microbiol 9:452-466.

Zhou J, Xing J (2015) Effect of electron donors on the performance of haloalkaliphilic sulfatereducing bioreactors for flue gas treatment and microbial degradation patterns related to sulfate reduction of different electron donors. Biochem Eng J 96:14-22. 


\section{Supplementary information}

The materials and methods for the sulfide toxicity experiments and economic calculations of the biodesulfurization processes are described in this section.

\section{SI1 - Sulfide toxicity experiments}

Two fed-batch 2 I glass anaerobic bioreactors with mixing were used. The bioreactors were filled with $1.5 \mathrm{I}$ of mineral medium and the $\mathrm{pH}$ was adjusted by the addition of sodium bicarbonate to 8.5 in one and 8 in the other. Sodium sulfate $(0.55 \mathrm{M})$ was added to the medium in excess to prevent substrate limitation. The gas phase added was $80 \% \mathrm{H}_{2}$ and $20 \% \mathrm{CO}_{2}$ at 1.6 bar and, to prevent major $\mathrm{O}_{2}$ leaks and $\mathrm{H}_{2}$ limitation, it was replaced when the pressure in the bioreactor was under 1 bar.

In each sampling, $10 \mathrm{ml}$ of liquid and $3 \mathrm{ml}$ of gas were collected. Sulfate, thiosulfate, sulfide, formate and acetate were analysed in the liquid as previously described (Sousa et al. 2015). Pressure in the headspace of the bioreactors and $\mathrm{H}_{2}, \mathrm{CO}_{2}, \mathrm{CH}_{4}, \mathrm{H}_{2} \mathrm{~S}, \mathrm{O}_{2}$ and $\mathrm{N}_{2}$ fractions in the gas were analysed as previously described (Sousa et al. 2015). The $\mathrm{pH}$ of the bioreactors was measured in the first and final sample, where a decrease in $\mathrm{pH}$ was observed: from 8.5 to 8.3 and from 8 to 7.9 . The final $\mathrm{pH}$ values were used to calculate the fractions of $\mathrm{H}_{2} \mathrm{~S}$ and $\mathrm{HS}^{-}$from the total sulfide measurements.

\section{SI2 - Model of steady state conditions}

A simplified model of the biodesulfurization process was modelled to achieve the caustic consumption and bleed stream disposal requirements. This was performed for different configurations:

- Biodesulfurization process - Without bleed stream treatment (NBT); with sulfate and thiosulfate reduction of the bleed stream (FBT); with only disproportionation of thiosulfate (TDBT).

- $\mathrm{S}^{0}$ selectivity in the sulfide oxidation bioreactor $-90 \% \mathrm{~S}^{0}$ production with $5 \%$ sulfate and $5 \%$ thiosulfate; $95 \% \mathrm{~S}^{0}$ production with $2.5 \%$ sulfate and $2.5 \%$ thiosulfate; $98 \% \mathrm{~S}^{0}$ production with $2 \%$ thiosulfate. 
- Plant size - Load of 1 tons $\mathrm{d}^{-1}$ (50 $\mathrm{m}^{3}$ liquid volume), 10 tons $\mathrm{d}^{-1}\left(500 \mathrm{~m}^{3}\right.$ liquid volume) and 100 tons $\mathrm{d}^{-1}$ (5000 $\mathrm{m}^{3}$ liquid volume).

Each calculation cycle equals to 1 day of the specific $S$ load (1, 10 or 100 tons) to the process. In the first cycle, the S load (as HS) to the sulfide oxidation bioreactor is only the $S$ load from the influent, but in the following calculation cycles, the $S$ load from the recycle is added to the $\mathrm{S}$ load of the influent. In the sulfide oxidation bioreactor, the $\mathrm{S}^{0}$ selectivity was used to calculate the amount of $S^{0}$, sulfate and thiosulfate leaving the bioreactor. In the settler, it was assumed that $98 \%$ of the $\mathrm{S}^{0}$ settles and is separated from the rest (personal communication by Paques BV, Balk, Netherlands). In the FBT model, $\mathrm{S}^{0}$ and thiosulfate are fully converted to sulfide while sulfate is $90 \%$ converted to sulfide. This is based in observations from chapters 3-6. In the TDBT model, $\mathrm{S}^{0}$ and thiosulfate are fully disproportionated to sulfate and sulfide while sulfate is not removed. In the models NBT and TDBT, a bleed stream is formed, while in the FBT model, no bleed stream is produced. The calculation was performed for 150 cycles to assure that steady conditions were achieved (Figure S1). The values of cycle 150, at steady state, were used for the caustic consumption, bleed stream production and electron donor consumption calculations. 


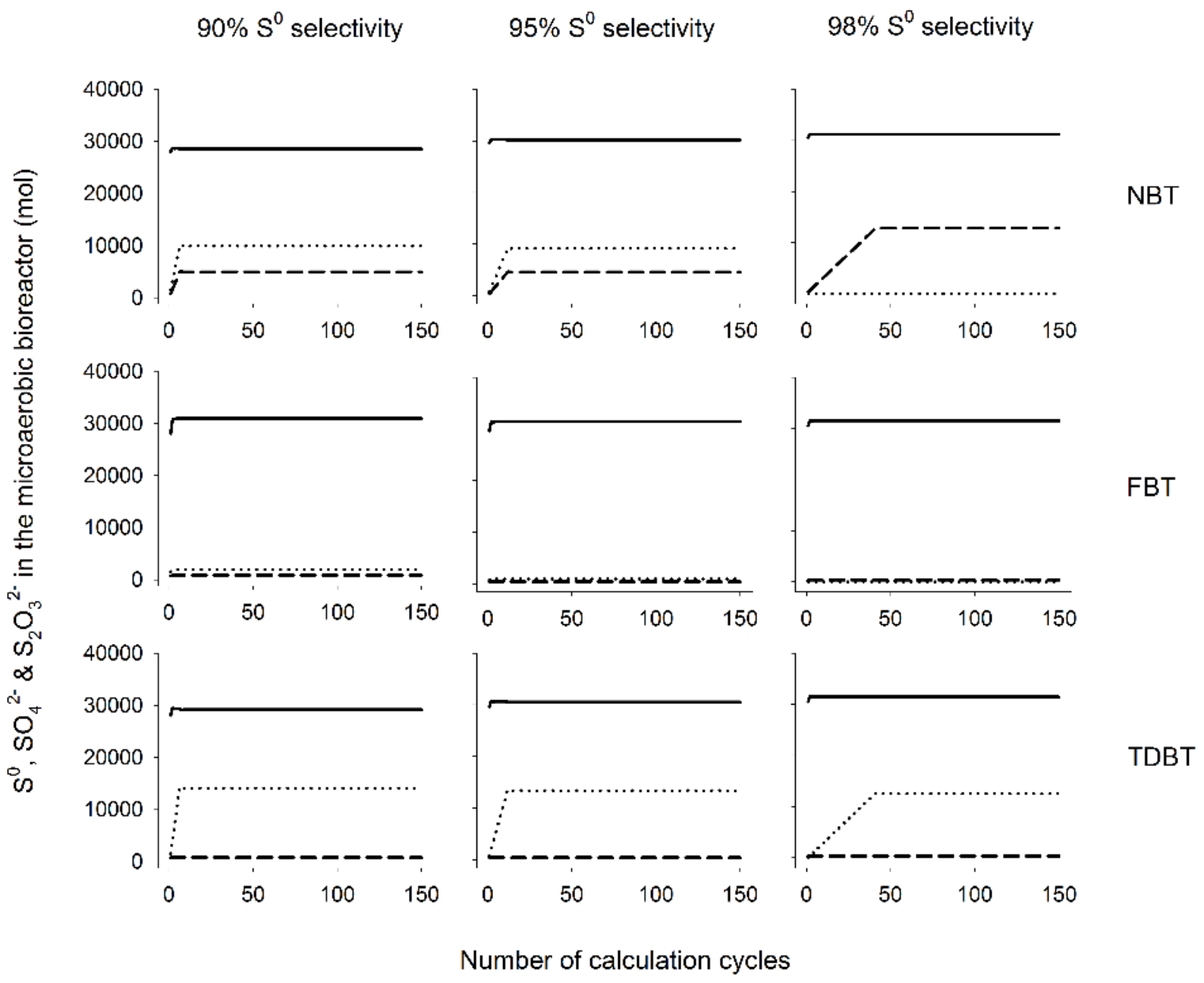

Figure S1 - Models of 150 calculation cycles for NBT, FBT and TDBT for a load of 1 ton day $^{-}$ ${ }^{1}$ with $90 \%, 95 \%$ and $98 \% \mathrm{~S}^{0}$ slectivity.

The caustic solution used in the process has $1.5 \mathrm{M} \mathrm{Na}^{+}$and this concentration must be kept preferably above $1 \mathrm{M}$. This means that the maximum sulfate or thiosulfate concentration that the process can handle is $0.25 \mathrm{M}$ of $\mathrm{S}$, which will mean a loss of 0.5 $\mathrm{M}$ of $\mathrm{Na}^{+}$to sodium sulfate or sodium thiosulfate formation. Thus, the bleed stream production was calculated based on the amount of sulfate and thiosulfate that needed to be removed to keep their combined concentration below $0.25 \mathrm{M}$ of S. Based on the amount of bleed stream produced, the volume (Eq. 1) and mass (Eq. 2) of new caustic solution required was calculated.

\footnotetext{
$\mathrm{v}_{\text {bleed stream }}=\mathrm{v}_{\text {new caustic solution }}$

$\mathrm{m}_{\text {caustic }}=\mathrm{v}_{\text {new caustic solution }} \times[$ caustic solution $] \times \mathrm{Mw}_{\mathrm{NaOH}}$
} Eq. 1 
In the case of FBT scenarios, the electron donor consumption per day was calculated based on the stoichiometry of sulfate, thiosulfate and $\mathrm{S}^{0}$ reduction using $\mathrm{H}_{2}$ or Formate (Eq. 3). Based on the worst-case scenario of the results of chapter $5,50 \%$ of the electron donor added was assumed to be used for other reactions, such as formate, acetate or methane production. For this reason, the supply of electron per day was multiplied by a factor 2 (Eq. 3).

$\mathrm{mol}_{\mathrm{e}-\text { donor }}=\left(\left(\left[\mathrm{mol}_{\mathrm{SO}_{4}^{2-}}\right] \times 4\right)+\left(\left[\mathrm{mol}_{\mathrm{S}_{2} \mathrm{O}_{3}^{2-}}\right] \times 4\right)+\left(\left[\mathrm{mol}_{S^{0}}\right] \times 2\right)\right) \times 2$

Eq. 3

\section{SI3 - OPEX and CAPEX calculations}

In this chapter, we presented a simplified version of the OPEX which includes only major operational costs: caustic consumption, bleed stream disposal and electron donor consumption. OPEX values were calculated based on the values calculated as described above and the prices in Table S1.

Table S1 - Market prices of caustic, bleed stream disposal and electron donors.

\begin{tabular}{lcc}
\hline & Price & Source \\
\hline Caustic $20 \%(w / v)$ solution & $250 €$ per $\mathrm{m}^{3}$ & Alibaba.com \\
Bleed stream disposal & $36 €$ per $\mathrm{m}^{3}$ & Paques B.V. \\
Cryogenic liquid $\mathrm{H}_{2}$ & $7 €$ per $\mathrm{Kg}$ & Energieonderzoek Centrum Nederland \\
$\mathrm{H}_{2}$ gas from gas reforming & $3.4 €$ per Kg & Eurostat \\
Syngas from gas reforming & $2.55 €$ per Kg & Based on Pei et al. (2014) and Eurostat \\
Sodium formate & $0.44 €$ per Kg & Alibaba.com
\end{tabular}


For the CAPEX calculations, the bioreactor volume was estimated on the maximum volumetric rates obtained from chapter $5,0.085 \mathrm{~mol} \mathrm{l}^{-1} \mathrm{~d}^{-1}$. The bioreactor volumes were used to estimate total CAPEX based on estimated cost values of the bioreactors, pumps and compressors (Dutch Association of Cost Engineers, 2011). The total CAPEX and CAPEX payback period were calculated as follows:

$\begin{array}{lc}\text { CAPEX }_{\mathrm{FBT}}=€_{\text {Bioreactor }}+€_{\mathrm{Pumps}}+€_{\text {Compressor }} & \text { Eq. } 4 \\ \text { CAPEX }_{\mathrm{TDBT}}=€_{\text {Bioreactor }}+€_{\mathrm{Pumps}} & \text { Eq. } 5 \\ \mathrm{CAPEX} \text { payback period }=\frac{\mathrm{CAPEX}}{\left(\mathrm{OPEX}_{\mathrm{NBT}}-\mathrm{OPEX}_{\mathrm{FBT}}\right)} & \text { Eq. } 6\end{array}$ 


\title{
Appendices
}

\author{
Summary \\ Co-author affiliations
}

List of publications

Acknowledgements

About the author 


\section{Summary}

Haloalkaline environments are characterized by their high salinity $(>0.5 \mathrm{M} \mathrm{Na}+)$ and buffered high $\mathrm{pH}$ (> 8.5). In these environments, the sulfur cycle is especially interesting due to the chemical stability of some $S$ compounds, like sulfide and polysulfides. Sulfide, at high $\mathrm{pH}$, is present in the deprotonated form, $\mathrm{HS}^{-}$, which is not volatile and accumulates in the liquid up to high concentrations. Sulfide is produced by sulfidogenic microorganisms, for instance sulfate or sulfur reducers. These microorganisms can reduce sulfate, thiosulfate, sulfite, $S^{0}$ and polysulfides to sulfide with a suitable electron donor, such as $\mathrm{H}_{2}$, organic acids or alcohols. Sulfidogenesis for biotechnological application under haloalkaline conditions, has been explored only for the use of liquid electron donors, for example ethanol or formate. However, $\mathrm{H}_{2}$ or syngas are interesting electron donors since they can be produced on-site by natural gas reforming. This has not been investigated for haloalkaline conditions.

In this thesis, we investigated sulfate-reducing bioreactors (Chapter 3) and thiosulfatereducing bioreactors (Chapter 4) fed with $\mathrm{H}_{2}$ as electron donor. Sulfate was reduced to sulfide, while thiosulfate was either reduced to sulfide or disproportionated to sulfide and sulfate, and sulfate was then reduced to sulfide. Sulfidogenic rates in these bioreactors were lower compared to previous studies, mainly due to the low biomass concentration in the bioreactors. The low biomass was caused by a lack of microbial aggregation, even though an internal settler was used in the bioreactors to promote aggregates selection. Due to this absence of aggregation, sand was added to a sulfate/thiosulfate reducing bioreactor as a biomass carrier material, but microorganisms attached only weakly to sand particles (Chapter 5). They colonized small cracks in the sand particles. However, in this bioreactor small microbial aggregates, without using sand as support, became visible when biomass concentrations started to increase. This increase in biomass concentration was linked to the acetate production from $\mathrm{H}_{2}$ and $\mathrm{HCO}_{3}{ }^{-}$, which might have supported microbial growth as an extra organic carbon source.

Besides $\mathrm{H}_{2}$, syngas is also a promising electron donor, but $\mathrm{CO}$ present in syngas is a known inhibitor of hydrogenases. The biomass used in this study adapted to addition of CO up to $15 \%$ CO of the gas fed to the bioreactor (Chapter 6 ). Thus, syngas can be used as electron donor for sulfate and thiosulfate reduction under haloalkaline 
conditions considering that an adaptation period is included. Other effects associated with the $\mathrm{CO}$ addition were the formation of more granular shaped small microbial aggregates and an increased acetate production compared to bioreactors fed only with $\mathrm{H}_{2}$.

Overall, considering the limitations due to lack of aggregation, the biotechnological application of sulfidogenesis under haloalkaline conditions using $\mathrm{H}_{2}$ or syngas is possible. For biodesulfurization processes, operated at haloalkaline conditions, the use of these sulfidogenic bioreactors could lead to savings in caustic consumption and disposal of COD and S-rich wastewater (Chapter 9).

In all bioreactors, formate production from $\mathrm{H}_{2}$ and $\mathrm{HCO}_{3}{ }^{-}$was observed together with the dominance of a bacterium closely related to Tindallia spp. in the microbial community. By isolating this bacterium, Tindallia sp. strain JE1, we could show its involvement in formate production (Chapter 7). Formate production from $\mathrm{H}_{2}$ and $\mathrm{HCO}_{3}{ }^{-}$ is thermodynamically not favourable at neutral conditions, but becomes feasible under haloalkaline conditions, due to the high $\mathrm{HCO}_{3}$ concentrations. To explain its dominance in the microbial community of all bioreactor we hypothesized that sulfate reducers were dependent on formate produced by Tindallia sp. strain JE1 as electron donor for sulfate reduction (Chapter 8). The experiments performed in chapter $\mathbf{8}$ show this syntrophic relationship between Tindallia sp. strain JE1 and Desulfonatronovibrio thiodismutans AHT10, a sulfate reducer closely related to the sulfate reducers present in the bioreactors. These experiments revealed that $D$. thiodismutans AHT10 was also dependent on an additional compound produced by Tindallia sp. strain JE1, which could be acetate and an unknown compound, such vitamins or amino acids. 


\section{Co-author affiliations}

\section{Caroline M Plugge, Alfons JM Stams, Martijn Diender, Peer HA Timmers}

Laboratory of Microbiology, Wageningen University, Stippeneng 4, 6708 WE Wageningen, The Netherlands

\section{Caroline M Plugge, Martijn FM Bijmans, Andrea Bolgár, Peer HA Timmers, João}

\section{Sampaio}

Wetsus, European Centre of excellence for sustainable water technology, Oostergoweg 9, 8911 MA Leeuwarden, The Netherlands

\section{Alfons JM Stams, João Sampaio}

CEB-Centre of Biological Engineering, University of Minho, Campus de Gualtar, 4710-057, Braga, Portugal

\section{Dimitry Y Sorokin}

Winogradsky Institute of Microbiology, Research Centre of Biotechnology, Russian Academy of Sciences, Moscow, Russia

\section{Dimitry Y Sorokin}

Department of Biotechnology, Delft University of Technology, Van der Maasweg 9, $2629 \mathrm{HZ}$ Delft, The Netherlands

\section{Stephan Christel, Mark Dopson}

Centre for Ecology and Evolution in Microbial Model Systems (EEMiS), Linnaeus University, SE-391 82 Kalmar, Sweden

\section{Peer HA Timmers}

Soehngen Institute of Anaerobic Microbiology, Heyendaalseweg 135, 6525 AJ Nijmegen, The Netherlands 


\section{Acknowledgements}

I would like to thank all the management of Wetsus for making Wetsus the amazing place it is! The international and multidisciplinary environment and the cooperation between partners make it a unique place to do great research, relevant to the real world of water technology. I will always see Wetsus as a place of inspiration!

I want to thank all my colleagues from Wetsus for the wonderful time I lived during my time there. Their motivation, creativity, ambition and above all, fun spirit were always contagious! I am very glad I had the opportunity to work with all of you in such an amazing environment.

I would like to thank Paqell for starting and funding my project at Wetsus in such a unique technology! The enthusiasm of the Sulfur team in the research results and numerous discussions contributed substantially for this work.

Thank you Wetsus technical staff! You were essential parts in my research project. You were always open to troubleshoot and to help in whatever was needed which lead to boost in quality of the work performed.

To my colleagues at Paques B.V. thank you for all the discussions and supportive spirit during the last months of my PhD.

Special thank you to all my students: Eszter Szabo, Raul Mastan, Salomé Duarte, Ágnes Jánoska, Andrea Bolgár, Martijn Diender, Luísa Ferreira and João Sampaio. Working with you was awesome and you are all big contributors to the work presented in this thesis!

Thank you, friends from office Hw 1.06! From the beginning, we all had the ambition to do great things and push us and Wetsus to higher levels! By doing this I had a lot of fun during all my time with you guys. We were a great team!

A special thank you to Pedro Silva, my oldie looking Portuguese friend from Wetsus. Not only our time together was amazing but you supported me during very rough moments during this period. Something that will never be forgotten! 
A big thank you to Pawel Roman, my research colleague and friend within the Sulfur theme! Thank you for the countless discussions and support in all phases of my PhD. It was great working as a team with you in the good and bad days!

Thank you, Bruna Oliveira, for sharing the courage to take the step into this adventure of leaving Portugal to come to the Netherlands.

Before reaching my $\mathrm{PhD}$, a lot of people were incredibly important for my development: Professora Maria Olga Lage, Professor Vitor Vasconcelos and Nuno Gomes. You not only motivated me but also inspired me!

To my promotor, Fons Stams, thank you for believing that young guy showing up for a meeting in Braga! And along the way, your wisdom was always inspiring.

To my co-promotor, Caroline Plugge, you were always supportive in all moments and I could feel that you would fight by my side in the many battles along the way. Of course, you also pushed hard for me to go further. But as we discussed several times, I really appreciate that you did it! Thank you for everything Caroline!

To my always happy co-promotor, Martijn Bijmans, thank you for all the great discussions and fun times we had. Your commitment to making everything possible for me at Wetsus was amazing.

To my family, you are all an inspiration source for me! All different but always together no matter what. Even though I was far away, your support from $2000 \mathrm{~km}$ away was incredible! We are an amazing family!

To Lisette, I cannot thank you enough for all your dedication during the hard time of the final phase of my PhD! Your everyday enthusiasm and life spirit always kept me happy and moving on. Still does!

To my Parents, I am forever grateful to you for everything I am today! You always supported me in every decision I took and always believed that by following my passion I would be happy. You always motivated my enthusiasm for the living world and by this, you made all possible! Adoro-vos Mamã e Papá! 


\section{About the author}

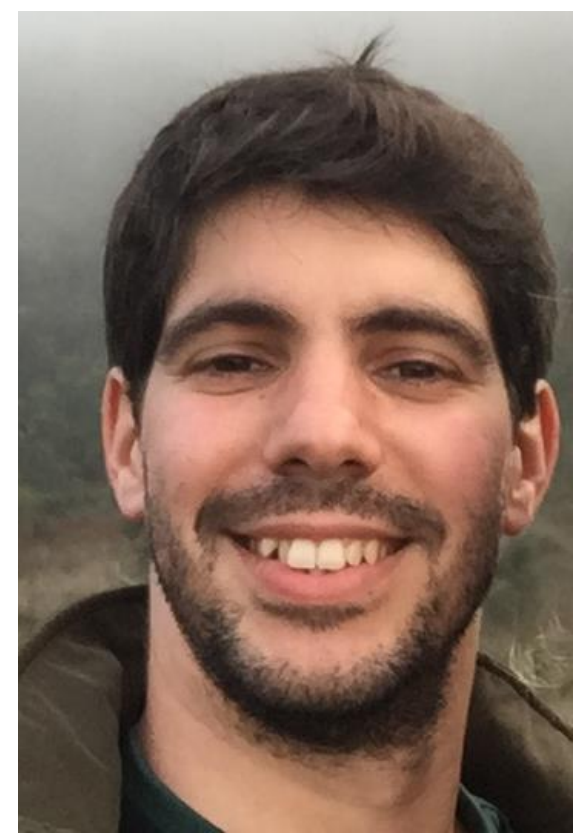

João Alexandre Bastos Sousa was born on the $5^{\text {th }}$ of March of 1985 in Oliveira de Azeméis, a small town from the district of Aveiro in Portugal. In 2004 he started his Biology bachelor in Faculdade de Ciências from Porto University in Portugal. During this time, he worked as a volunteer intern in CIIMAR, Interdisciplinary Center of Marine and Environmental Research. In this work, he was responsible for organizing the laboratory cyanobacteria culture collection. In 2008 he started his MSc studies in Environmental Contamination and Toxicology in Faculdade de Ciências and Instituto de Ciências Biomédicas Abel Salazar from

Porto University. Along with his MSc studies, he started a project with the Laboratório de Ecofisiologia Microbiana (LEMUP) and Bluemater S.A., where he was responsible for organizing a small team to develop and study biotrickling filters using planctomycetes. This collaboration between LEMUP and Bluemater S.A. lead to his MSc thesis work, entitled: Landfill leachate treatment: a new photobioreactor technology. The thesis involved planning, assembling, operating and investigating a landfill leachate treatment pilot plant in a landfill in Porto, LIPOR I. He continued to support this project after the end of his MSc thesis, until end of 2011. In 2010, João got a research scholarship in a project in the Environmental Department of Aveiro University about polyhydroxyalkanoates (PHA) production via industrial wastewater treatment, POLIBIO. In the beginning of 2012, he started his work as a PhD student of the Laboratory of Microbiology from Wageningen University. However, he was located at Wetsus, European Center of Excellence for Water Technology Research, in Leeuwarden in the Netherlands, where he performed the work presented in this thesis. In the third year of his PhD, he started working part-time as a Process Specialist at Paques B.V. There, he is currently working full-time on PHA production from industrial wastewater. 


\section{List of publications}

Sousa JAB, Plugge CM, Stams AJM, Bijmans MFM (2015) Sulfate reduction in a hydrogen fed bioreactor operated at haloalkaline conditions. Water Res 68:67-76.

Sousa JAB, Sorokin DY, Bijmans MFM, Plugge CM, Stams AJM (2015) Ecology and application of haloalkaliphilic anaerobic microbial communities. Appl Microbiol Biotechnol 99:9331-9336.

Sousa JAB, Bijmans MFM, Stams AJM, Plugge CM (2017) Thiosulfate conversion to sulfide by a haloalkaliphilic microbial community in a bioreactor fed with $\mathrm{H}_{2}$ gas. Environ Sci Technol. 51:914-923.

Roman P, Klok JBM, Sousa JAB, Broman E, Dopson M, van Zessen E, Bijmans MFM, Sorokin DY, Janssen AJH (2016) Selection and application of sulfide oxidizing microorganisms able to withstand thiols in gas biodesulfurization systems. Environ Sci Technol acs.est.6b04222. 


\section{SENSE}

Netherlands Research School for the

Socio-Economic and Natural Sciences of the Environment

\section{I P L O M A}

For specialised PhD training

The Netherlands Research School for the Socio-Economic and Natural Sciences of the Environment (SENSE) declares that

\section{João Alexandre Bastos Sousa}

born on 5 March 1985 in Oliveira de Azeméis, Portugal

has successfully fulfilled all requirements of the

Educational Programme of SENSE.

Leeuwarden, 21 April 2017

the Chairman of the SENSE board

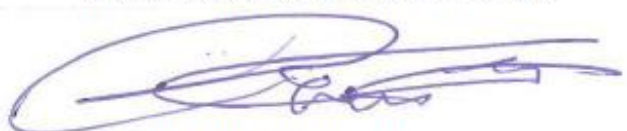

Prof. dr. Huub Rijnaarts the SENSE Director of Education

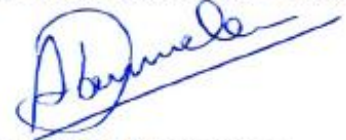

Dr. Ad van Dommelen

The SENSE Research School has been accredited by the Royal Netherlands Academy of Arts and Sciences (KNAW)

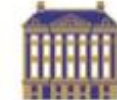

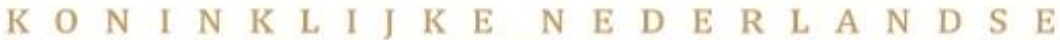

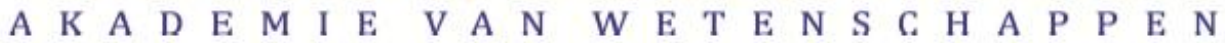




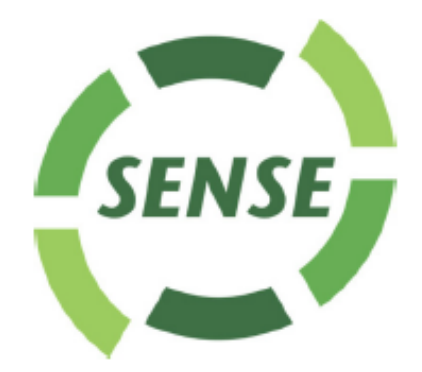

The SENSE Research School declares that Mr João Bastos Sousa has successfully fulfilled all requirements of the Educational PhD Programme of SENSE with a work load of $37.8 \mathrm{EC}$, including the following activities:

\section{SENSE PhD Courses}

- Environmental research in context (2012)

- Research in context activity: 'Co-organising exchange meeting for WETSUS and WUR Laboratory of Microbiology groups' (2013)

\section{Other PhD and Advanced MSc Courses}

Advanced course on environmental biotechnology, Delft University of Technology (2012)

- Techniques for writing and presenting a scientific paper, Wageningen University (2013)

- ARB/SILVA basic training in software for sequence data, Wageningen University (2013)

- MatLab course, Wetsus, Leeuwarden (2013)

- Lasers and optics in fluid research, Wetsus, centre of excellence for sustainable water technology, Leeuwarden (2014)

- Atomic Force Microscopy Workshop, Wetsus, Leeuwarden(2014)

\section{Management and Didactic Skills Training}

- PhD representative at Wetsus (2012-2014)

- Organising meeting between the Microbial Physiology Group of the Laboratory of Microbiology, Wageningen University, and Wetsus, Leeuwarden (2013)

- Co-organising and managing several courses and workshop (2013-2015)

\section{Oral Presentations}

- Sulfate and thiosulfate reduction in $\mathrm{H} 2$-fed bioreactors operated at haloalkaline conditions. International conference on extremophiles, 7-12 September 2014, Saint Petersburg, Russia

- Bleed stream reduction by biological conversion of (thio)sulfate to sulfide. Internal Wetsus Congress (SENSE meeting), 29 November 2012, Leeuwarden, the Netherlands

\section{SENSE Coordinator PhD Education}

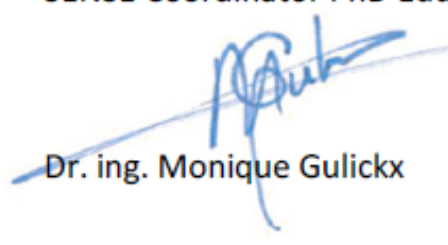


This work was performed within the cooperation framework of Wetsus, European Centre of Excellence for Sustainable Water Technology (www.wetsus.nl). Wetsus is co-funded by the Netherlands' Ministry of Economic Affairs and Ministry of Infrastructure and the Environment, the European Union's Regional Development Fund, the Province of Fryslân, and the Northern Netherlands Provinces. The authors thank the participants of the research theme "Sulfur" and Paqell for fruitful discussions and financial support.

Cover design: João Sousa

Cover photo: Anne Hennig

Printed by Gildeprint - Enschede (Netherlands) 